



\section{WILDLIFE CONSERVATION SOCIETY: 20 AÑOS DE TRABAJO CON PUEBLOS INDÍGENAS Y COMUNIDADES LOCALES PARA LA CONSERVACIÓN DE LA VIDA SILVESTRE EN LA AMAZONÍA ANDINA}

Zulema Lehm

Especialista en Temas Sociales

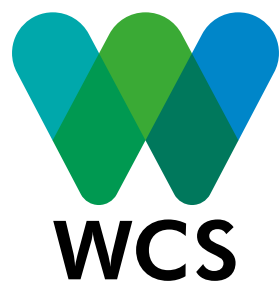




\title{
Wildlife Conservation Society (WCS)
}

\section{Coordinación general y redacción técnica \\ ZULEMA LEHM ARDAYA}

\author{
Editores \\ Wildlife Conservation Society \\ Minka - Compartiendo conocimiento en Andes Amazonia Orinoquia
}

Cuidado de edición

FIORELLA ARENAS, IRINA MELGAR

Primera Edición

OCTUBRE de 2019

Este documento fue revisado y recibió valiosos comentarios y sugerencias de Mariana Varese, Directora Paisajes Amazónicos de WCS; Robert Wallace, Director del Programa de Conservación Gran Paisaje Madidi-Tambopata de WCS; Lilian Painter, Directora de WCS Bolivia;

Mariana Montoya, Directora de WCS Perú; y Paulina Dalgo, Técnica Social de WCS Ecuador.

\section{Agradecimientos}

La presente sistematización recoge las diversas experiencias de WCS en Bolivia, Ecuador y Perú trabajando con pueblos indígenas y poblaciones locales para la conservación de la vida silvestre en la Amazonia Andina durante los últimos 20 años y que han sido posibles gracias al apoyo de Gordon and Betty Moore Foundation, U.S. Agency for International Development (USAID), The Overbrook Foundation, The U.S. Fish \& Wildlife Service, Global Environmental Facility (GEF), The Blue Moon Fund, MacArthur Foundation, Danish International Development Agency (DANIDA), Agencia Suiza para Desarrollo y Cooperación (COSUDE), HELVETAS Swiss Intercooperation.

Su publicación ha sido posible gracias al apoyo de Gordon and Betty Moore Foundation

Cita sugerida:

Lehm, Z. 2019. Wildlife Conservation Society: 20 años de trabajo con pueblos indígenas y comunidades locales para la conservación de la vida silvestre en la Amazonía Andina. Wildlife Conservation Society 


\section{CONTENIDO}

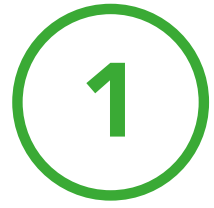

\section{ENFOQUES METODOLÓGICOS INTERPRETATIVOS PARA COMPRENDER LAS EXPERIENCIAS DE TRABAJO DE WCS CON POBLACIONES INDÍGENAS Y COMUNIDADES LOCALES}

El péndulo en los debates sobre conservación y población local

Conservación "para", "con" o "por" la población loca

Gobernanza para la conservación a nivel de paisaje

Sistemas de organización territorial multinivel o sistemas anidados

Gobernanza desde "abajo" y desde "arriba"

Legitimidad de los sistemas de gobernanza y de las reglas para el uso y acceso a los recursos naturales

Reglas, regímenes y sistemas de acceso común

La naturaleza tradicional y racional de las reglas de acceso y uso de los recursos naturales

Desarrollo de las capacidades locales para implementar las acciones

Esferas económicas: entre la reciprocidad y el mercado

Dinámica de la inserción mercantil de los pueblos

indígenas en la Amazonía

Sistemas anidados, multinivel e iniciativas

económicas basadas en el manejo de los recursos

naturales, orientadas a la "esfera del mercado"

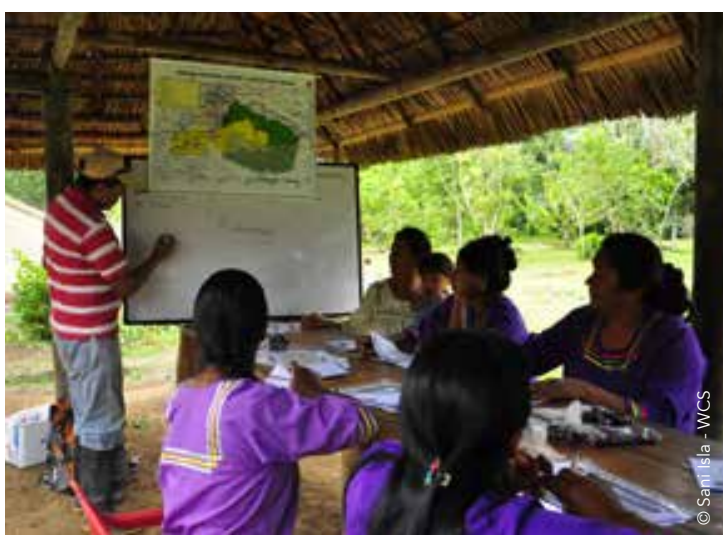

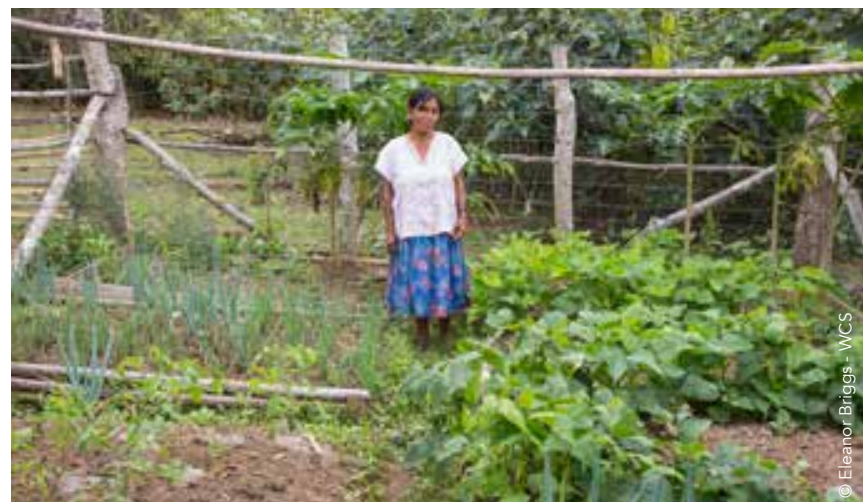

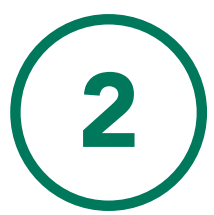

Pag. 29

\section{ESTUDIOS DE CASO}

BOLIVIA: Paisaje Madidi y la gestión territorial indígena de 30 los pueblos indígenas Tacana y Leco de Apolo.

Organización: sistemas multinivel y redes horizontales y verticales

Las demandas y titulación de territorios indígenas

Planificación para la Gestión Territorial Indígena

Procesos de zonificación y la articulación entre territorios 38 indígenas y áreas protegidas: los corredores de vida silvestre y la conectividad entre ecosistemas y unidades de gestión a nivel paisaje

Construcción de redes sociales verticales y horizontales de tipo "puente": gestión compartida en áreas sobrepuestas entre territorios indígenas y áreas protegidas

Regulación para el acceso y uso de los recursos naturales

Articulación de cadenas productivas con base en el manejo de los recursos naturales y de las redes sociales verticales

El caso tacana y las esferas económicas de la reciprocidad y el mercado

Los esfuerzos de capacitación y asistencia técnica

PERÚ: Área de Conservación Regional Comunal Tamshiyacu 69 Tahuayo. La conservación por las comunidades ribereñas.

El enfoque económico para el uso sostenible de los recursos 71 naturales sobre la base de la fauna silvestre.

Breve historia sobre el uso de los recursos en la región. 
Creación de la Reserva Comunal Tamshiyacu -

Tahuayo y la construcción de redes sociales.

La población ribereña y el uso de los recursos naturales

La conservación de la ACRCTT basada en

el manejo de los recursos naturales por las comunidades

Regulación para el acceso y uso de los recursos naturales

Conclusiones

ECUADOR: El Paisaje Yasuní, la gestión

integrada de territorios indígenas y el manejo

de recursos por las comunidades kichwas y

waorani

El enfoque de la gestión integrada de las tierras

comunitarias y territorios ancestrales

Tendiendo "puentes" entre las comunidades

indígenas y el Estado para la conservación

Manejo de recursos naturales y experiencias de

turismo comunitario

Conclusiones

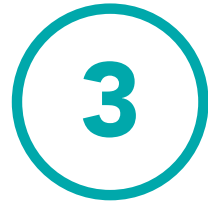

\section{ESTUDIO COMPARATIVO Y LECCIONES APRENDIDAS}

Una ruta crítica para la gestión territorial indígena

Titulación y/o reconocimiento legal de tierras comunitarias,

territorios indígenas o ancestrales

Planificación territorial

Mapeo, zonificación y ordenamiento del uso de la tierra

Autorregulación para el acceso y uso de los recursos naturales 158

Manejo de recursos naturales

Apoyo a los sistemas de control y vigilancia de los recursos

naturales en áreas comunales, territorios indígenas y su

relación con las áreas naturales protegidas

Fortalecimiento de capacidades administrativas y búsqueda de fuentes de financiamiento sostenible

La investigación y el monitoreo para la toma de decisiones de las comunidades y las organizaciones indígenas

Experiencias y reflexión en torno a los marcos teóricos y éticos para el trabajo de conservación "por" las poblaciones locales

La construcción de redes sociales tipo "vínculo": el

fortalecimiento de las organizaciones indígenas, comunitarias

y de las mujeres indígenas

La construcción de relaciones sociales de tipo "puente" entre

las comunidades, los pueblos indígenas y el Estado

Las construcciones teóricas y conceptuales relativas a la gobernanza y al manejo de los recursos naturales por las comunidades locales y pueblos indígenas

Los paradigmas de conservación "para", "con" y "por" las poblaciones locales en los programas de WCS en la Cuenca Amazónica

Una aproximación al trabajo de conservación con comunidades locales y pueblos indígenas con arreglo a principios y valores

\begin{tabular}{lc}
\hline Riesgos, dificultades y desafíos & 178 \\
\hline Lecciones aprendidas: & 182 \\
\hline
\end{tabular}




\section{ÍNDICE DE TABLAS}

Tabla 1: Representación de la combinación de las relaciones horizontales/verticales y tipo vínculo/puente

Tabla 2: Elementos de conflicto entre las esferas de la reciprocidad y del mercado en relación a la economía de los pueblos indígenas de la Amazonía

Tabla 3: Fortaleza y debilidades en la cadena productiva de las artesanías de chambira de la AMWAE

\section{ÍNDICE DE MAPAS}

Mapa 1: Gran Paisaje Madidi - Tambopata

Mapa 2: Gran Paisaje Madidi, áreas protegidas, territorios indígenas, propiedades privadas y concesiones forestales

Mapa 3: Área de Conservación Regional 70 Comunal Tamshiyacu Tahuayo

Mapa 4: Zonificación de la Reserva Comunal Tamshiyacu Tahuayo (1991)

Mapa 5: Acceso y uso de los recursos naturales por las comunidades de la región del Tamshiyacu y Tahuayo

Mapa 6: Paisaje Yasuní - Llanganates

Mapa 7: Ubicación del Parque Nacional

Yasuní respecto de las comunidades kichwas y zonificación

\section{ÍNDICE DE GRÁFICOS}

Gráfico 1: Representación de sistemas anidados multinivel 16

Gráfico 2: Representación de las redes verticales y horizontales

Gráfico 3 : Representación de esferas de las reciprocidad y mercado articuladas

Gráfico 4: Articulación de niveles organizativos a través de

distribución de beneficios y rendición de cuentas

Gráfico 5: Reglamentación tacana. Sujetos y gradación en la aplicación de las sanciones

Gráfico 6: Articulación de niveles organizativos a través de la distribución de beneficios y rendición de cuentas

Gráfico 7: Número de asociaciones productivas según año de creación en la TCO Tacana I y TCO Leco de Apolo

Gráfico 8: Distribución de las asociaciones según actividad o recurso utilizado $(n=27)$

Gráfico 9: Número de eventos de capacitación y asistencia técnica según territorio indígena (2000 - 2015)

Gráfico 10: Número de eventos de capacitación según tema y territorio indígena

Gráfico 11: TCO Tacana I: Número de eventos de capacitación y asistencia técnica según tema y año

Gráfico 12: TCO Lecos de Apolo: número de eventos de capacitación y asistencia técnica según tema y año

Gráfico 13: Número de participantes en eventos según sexo (2000 - 2015)

Gráfico 14: Representación del sistema de autoridades comunales por un grupo de mujeres de la comunidad

Gráfico 15: Representación del sistema de autoridades comunales por un grupo de hombres de la comunidad

Gráfico 16: Representación de la cadena productiva de las 


as experiencias de trabajo de Wildlife Conservation Society (WCS) en la región amazónica con poblaciones locales en proyectos de conservación se remontan a la década de 1980. Estas experiencias han sido sistematizadas en los países bajo diferentes enfoques y metodologías. Aquí, se propone sistematizar comparativamente el trabajo de WCS en la Amazonía Andina, específicamente en tres áreas: la porción boliviana del Gran Paisaje Madidi-Tambopata (de ahora en adelante Paisaje Madidi) en el noroeste de Bolivia; la porción de tierras bajas del Gran Paisaje Llanganates-Yasuní (de ahora en adelante Paisaje Yasuní) en el oriente de Ecuador; y la porción del Gran Paisaje Yavarí-Samiria que se sitúa en el Area de Conservación Regional Comunal TamshiyacuTahuayo (ACRCTT) y zonas aledañas (de ahora en adelante Tamshiyacu-Tahuayo) en el noreste de Perú.

Algunos principios comunes han guiado el trabajo de conservación de WCS con las poblaciones locales. Los más destacados son respeto, flexibilidad, compromiso de largo plazo y acompañamiento con investigación científica. Tomando en cuenta estos principios comunes, las experiencias de cada país se han desarrollado de una manera diversa y adaptada a las condiciones particulares geográficas, ambientales, económicas, sociales y políticas. En todos los casos, los programas país de WCS han construido sus estrategias combinando la experiencia en el terreno con el análisis crítico.

En este contexto, se propone un marco conceptual para interpretar las acciones de WCS en los últimos treinta años en los diferentes países de la Cuenca Amazónica. El tema central se refiere al trabajo de WCS para la conservación en general y de la vida silvestre en particular con las poblaciones locales y pueblos indígenas de la Amazonía.

3

Dos grandes ámbitos destacan en este quehacer de WCS: el trabajo con comunidades locales y poblaciones indígenas para fortalecer sus sistemas de gobernanza, y el apoyo para el manejo sostenible de los recursos naturales por las comunidades, agrupaciones y asociaciones locales.

El marco interpretativo que nos proponemos desarrollar está basado en los debates sobre la importancia de considerar la inclusión de la población local en las políticas y acciones de la conservación y se refiere por un lado, a las estrategias relacionadas con sistemas anidados de gobernanza multinivel para comprender los procesos de fortalecimiento de la gobernanza y por otro, los sistemas económicos de las comunidades locales de la Amazonía como articulaciones de esferas económicas relativas a la reciprocidad y el mercado derivadas de la antropología económica.

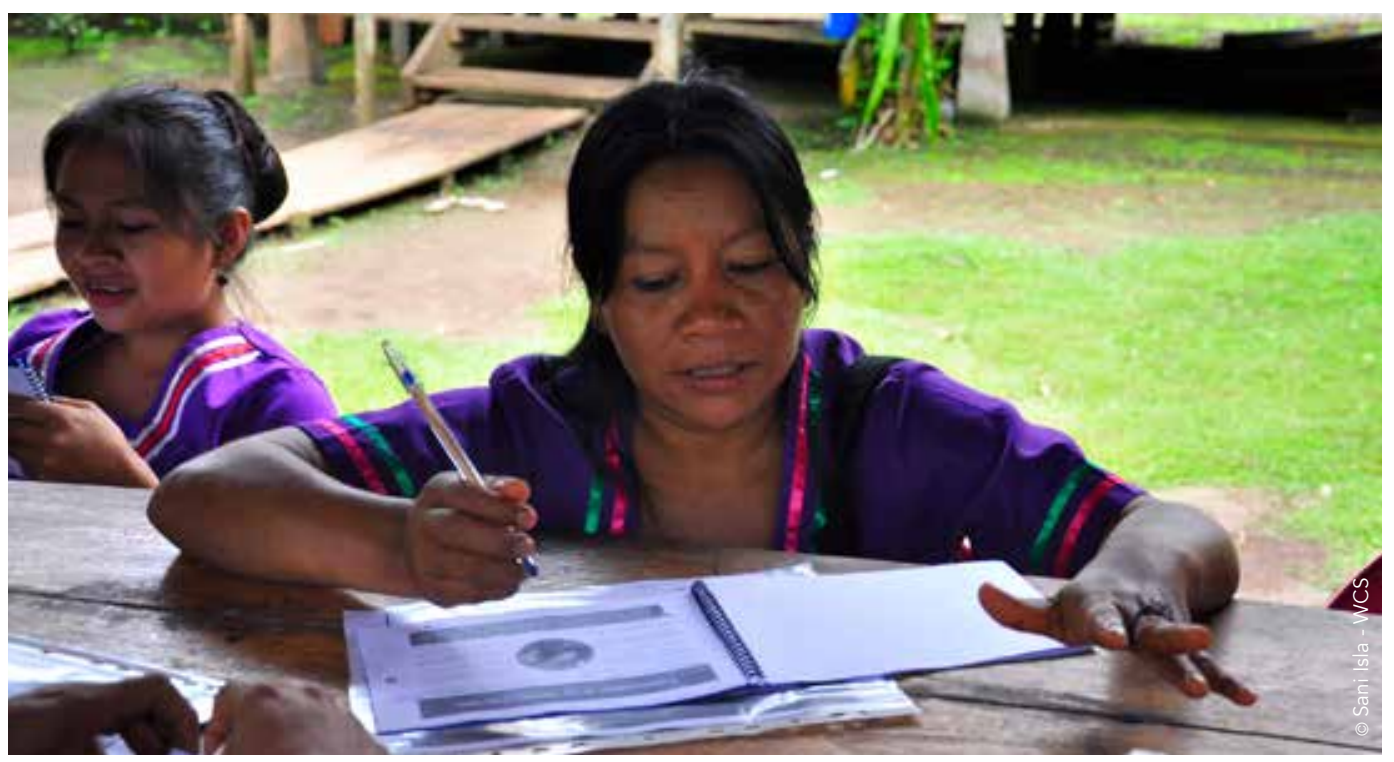




\section{EL PÉNDULO EN LOS DEBATES SOBRE CONSERVACIÓN Y POBLACIÓN LOCAL}

El trillado debate sobre conservación y desarrollo se remonta a principios del siglo XX. Alude a la tensión recurrente en el pensamiento, la política y la práctica de la conservación entre el desarrollo económico y la sustentabilidad ambiental. Un intento de conciliación de esta tensión es la propuesta que se expresa en la noción del "desarrollo sostenible", generalizada a partir de la segunda Conferencia de Naciones Unidas sobre Medio Ambiente y Desarrollo de 1992 (Bodmer, 1993; Brian, 2004).

El debate sobre si el desarrollo sostenible es posible continúa y se relaciona estrechamente con la problemática de la población local. En el mundo, muchas áreas de alta biodiversidad coinciden con asentamientos humanos cuyos habitantes son altamente dependientes de los recursos naturales. En 1995, se consideraba que más de un billón de personas estaban viviendo en 25 sitios de concentración de alta biodiversidad (biodiversity hotspots), constituyendo aproximadamente el $20 \%$ de la población mundial. La tasa de crecimiento poblacional en estas áreas aumentó en 1,8\% anual, más alta que la tasa de crecimiento global de 1,3\% así como de los países en desarrollo de 1,6\%. En tres zonas de alta diversidad silvestre en el mundo, entre ellas la Alta Amazonía y el escudo Guyanés (la cuenca del río Congo y las islas de Nueva Guinea y Melanesia), vivían 75 millones de personas con una tasa de crecimiento anual de 3,1\%, el doble de la tasa de crecimiento global (Cincotta, Wisnewski, \& Engelman, 2000; Camacho-Benavides, Porter-Bolland, Ruiz-Mallén, \& McCandless, 2013).

Esquemáticamente pueden considerarse en un extremo las tendencias convencionales que sostienen que la conservación solo puede ser efectiva si las áreas de alta prioridad para la conservación están deshabitadas, se protegen de las actividades humanas, y por tanto se prescinde de la población local para la toma de decisiones (Oats, 2000; Terbogh, 1999). En el otro extremo se encontrarían quienes sustentan que la conservación solo es posible si la gente local está involucrada en ella (Berkes, Folke, \& Colding, 2000; Maffi \& Woodly, 2010; Camacho-Benavides, Porter-Bolland, Ruiz-Mallén, \& McCandless, 2013). Desde la década de 1980, se han documentado experiencias a las que se ha denominado "conservación de base comunitaria", enfoque que tiene muchos detractores así como adeptos (Hutton, Adams, \& Murombedzi, 2005). En esta última línea, se ha propuesto un nuevo paradigma: "Biocultural Diversity" para referir a la articulación entre la diversidad lingüística, cultural y biológica (Maffi \& Woodly, 2010; Camacho-Benavides, Porter-Bolland, Ruiz-Mallén, \& McCandless, 2013).

El debate se ha visto reforzado con las mediciones de efectividad en diferentes unidades de conservación. En muchos aspectos, los parques son efectivos para la conservación de la biodiversidad, sin embargo, en un $40 \%$ tienen algunas condiciones comparables con las de su entorno (Bruner, Gullison, Rice, \& Da Fonseca, 2001; Hutton, Adams, \& Murombedzi, 2005). Los métodos convencionales de medición de la efectividad de la protección en áreas protegidas habrían sobreestimado en dos tercios la deforestación evitada (Kwaw S., Ferraro, Pfaff, Sanchez-Azofeifa, \& Robalino, 2008). Un estudio más reciente muestra que las tasas anuales de deforestación son menores en las comunidades que manejan bosques que en los bosques protegidos (Porter-Bolland, y otros, 2011, págs. 1, 5-6). A partir de esta constatación, se sugiere que una estrategia de conservación de los bosques debería abarcar una visión regional con diferentes tipos de uso de la tierra en la cual, las necesidades sociales y económicas de los habitantes locales, así como los derechos a la tierra y las capacidades locales son reconocidas (Porter-Bolland, y otros, 2011).

En relación con este debate, la Amazonía ha sido y es un espacio rico en experiencias. De hecho, desde su conquista y colonización hasta los Estados Republicanos y aún en la actualidad, se ha cernido sobre ella uno de los grandes mitos: el del gran vacío amazónico, entre otros relacionados, como El Dorado o el Gran Paititi, en referencia a 
una región de tesoros incalculables o el país de las Amazonas, al cual la región debe su nombre (Levillier, 1976).

Las evidencias arqueológicas e históricas indican más bien una región densamente poblada en el periodo precolombino, que contrasta con el mito del gran vacío amazónico y que parece más bien tener base en las dramáticas caídas demográficas del periodo de la conquista (Denevan, 1980 b). Incluso, hay quienes proponen que el conjunto de los ecosistemas amazónicos tendrían un origen antrópico, en una relación constante de transformación de la naturaleza y viceversa, para dar lugar a los sistemas adaptativos de las poblaciones nativas (Balée \& Erickson, 2006), cuyo legado es la Amazonía conservada, albergue de la mayor biodiversidad del mundo.

La historia de la Amazonía está marcada por la "expansión de los frentes de la civilización" (Ribeiro, 1977), por auges basados en la extracción de los recursos naturales (quina, gomas elásticas, fauna silvestre, madera, minerales, hidrocarburos), su conexión con los mercados nacionales e internacionales y devastadoras relaciones con la población nativa. Estos procesos estuvieron acompañados de inmigraciones de poblaciones de diferente tipo que también han devenido en grupos locales. Cada grupo ostenta diversos intereses, generándose también una gran variedad de conflictos locales. La resistencia indígena, por su parte, se ha manifestado bajo diferentes modalidades, generando en las últimas décadas, importantes movimientos sociales, logrando gravitar en las políticas nacionales e internacionales, particularmente en relación a la defensa de sus territorios.

En la actualidad, en la Amazonía habitan 33 millones de personas, que incluyen 385 pueblos indígenas - con cerca de 1,4 millones de personas ocupando 2244 territorios indígenas, además de los que viven en las ciudades y un número desconocido que vive en aislamiento voluntario de la sociedad moderna - y miles de comunidades tradicionales (caboclos, afrodescendientes o campesinos de distinto origen), que dependen de la biodiversidad de la Amazonía para su sustento (RAISG, 2015).

De tal suerte, en la Amazonía, es difícil sino imposible pensar la conservación al margen de la población local, pues es una población que mayormente depende de los recursos naturales de la región. Al mismo tiempo, la comparación de la deforestación entre 2000 y 2013, entre áreas protegidas y territorios indígenas en toda la Amazonía, muestra que en las primeras fue de 1,1\% en tanto que en los segundos fue de $0,8 \%$, menor que en las áreas protegidas. Ambas unidades contrastan con una pérdida de bosque de $3 \%$ en el mismo periodo de tiempo para el conjunto de la Amazonía. Con valores de deforestación acumulados de 2,1\% para las áreas protegidas, 2,3\% para los territorios indígenas y 13,3\% para el conjunto de la región (RAISG, 2015).

\section{CONSERVACIÓN "PARA", "CON" O "POR" LA POBLACIÓN LOCAL}

Ya en 2004, en un contexto de ascenso de los paradigmas relacionados con el libre mercado, los incentivos a los privados y valores como la eficiencia y eficacia, etc., y con base en las experiencias de conservación en Sudáfrica, Brian (2004) y otros plantearon las preguntas de conservación: ¿para quién, para qué y por quién? En general, se trataba de un llamado de retorno al paradigma original de los parques "para la gente". Constatando que las ofertas de los parques hacia la sociedad eran muy generales y difusas y en el caso de países en transición como Sudáfrica no se adecuaban a las necesidades de la población local, la pregunta sobre el "qué" apuntaba a sustentar la necesidad de la generación de beneficios económicos, o más bien la necesidad de que las áreas protegidas demostrasen el valor agregado, en términos económicos, que su presencia trae a este tipo de sociedades. 
de las ofertas de los parques nacionales, tales como turismo u otros usos supuestamente benéficos para las poblaciones locales, en Sudáfrica eran mejor manejados por propietarios privados, sean individuales o comunitarios. Además, las áreas manejadas por estos propietarios de las tierras estaban siendo capaces de demostrar no solo rentabilidad económica sino también al menos igual estado de conservación que las áreas protegidas centralmente manejadas por los Estados (Brian, 2004).

Al igual que en otras regiones del mundo, en la Amazonía se puede percibir el desarrollo de al menos tres maneras de poner en práctica la relación entre conservación y la población local, a las que se puede considerar una suerte de paradigmas de conservación con la población local. Como tales solo se pueden distinguir analíticamente, ya que en la realidad se combinan unos con otros de diversas maneras.

El primero hace referencia a la conservación "para" la gente que tiene dos connotaciones. Por un lado, considera a la población local como objeto pasivo, receptora de los beneficios de la conservación. Sin embargo, al mismo tiempo, reconoce la importancia de los ecosistemas bien conservados para el bienestar de la población.

Un segundo paradigma hace referencia a la conservación "con" la gente, es decir, con participación de la gente. En este se inscriben, por ejemplo, las acciones de consulta y algunos Comités de Gestión (según las atribuciones que les definen las legislaciones nacionales). Considera a la población como sujetos de algunas acciones de la conservación, pero no como decisores fundamentales.

El tercer paradigma hace referencia a la conservación "por" la gente. Considera a la población local como agente decisivo para la conservación. Supone que la sostenibilidad de la conservación en el largo plazo solo es posible si la población local organizada se hace cargo, establece sus propios mecanismos de autorregulación (Bodmer, 1993, pág. 6) y gobernanza. Constituye un modelo que parte de reconocer, por un lado, que los conocimientos y prácticas de la población local son fundamentales para la conservación y, por otro, las limitaciones de los Estados nacionales para controlar la aplicación de las leyes en las áreas rurales. Con tal finalidad, en el marco de esta propuesta, se desarrollan actividades orientadas al fortalecimiento de las capacidades de la población local.

En cualquiera de estos modelos de la relación entre conservación y la población local, es necesario tomar en cuenta la participación de los Estados, de las Organizaciones No Gubernamentales y de la comunidad científica orientada a la conservación (Bodmer, 1993). Según sea el tipo de relación entre la conservación y la población local, uno u otro de estos actores serán más o menos importantes. Los tres modelos requieren acciones concurrentes, pero las orientaciones de estas serán diferentes según el tipo de relación. Al mismo tiempo, es necesario considerar el carácter histórico de estas relaciones entre conservación y la población local, pues a lo largo del tiempo se transforman unas formas en otras, se combinan, avanzan o retroceden en uno u otro sentido.

Ninguna de estas ideas o paradigmas ignora las amenazas que se ciernen sobre los ecosistemas amazónicos. Se asume que las amenazas más importantes son agricultura y ganadería extensivas en gran escala, minería, exploración y explotación hidrocarburífera, construcción de gran infraestructura, etc. Al mismo tiempo, estas son amenazas no solo sobre los ecosistemas, sino también sobre las poblaciones locales y sus medios de vida.

De hecho, la historia de las relaciones entre conservación y población local está plagada de conflictos y son estos los que en gran medida exigen que los enfoques, políticas y prácticas de conservación tomen en cuenta las necesidades e intereses de las poblaciones locales, así como sus horizontes auto-determinativos.

Con la finalidad de administrar o resolver los conflictos, se han desarrollado tecnologías instrumentales basadas en la clasificación y el ordenamiento del uso de las tierras, buscando 
"combinar los usos dentro de una escala de distribución, que va desde áreas de uso intensivo hasta zonas completamente protegidas" (Bodmer, 1993). Así como enfoques de base económica orientados a promover diferentes tipos de incentivos o compensaciones para la población local buscando reducir, orientar y manejar los recursos naturales hacia usos más sostenibles, incluyendo acciones de fortalecimiento de las capacidades locales (Bodmer, 1993; UICN, 2014, pág. 21).

Enfoques más complejos señalan la importancia de considerar simultáneamente los impactos sociales de la conservación, los resultados ecológicos, la legitimidad de la gobernanza de la conservación y la aceptabilidad de las propuestas de manejo, con la finalidad de mejorar tanto las políticas como las prácticas de la conservación (Bennet, 2016).

En general, tanto los tipos de relación como las estrategias más operativas tienen como objetivo la producción de soportes sociales que aseguren la conservación efectiva de los ecosistemas y las especies.

El enfoque de "conservación a nivel de paisaje" implica considerar espacios de conservación más amplios que las solas áreas protegidas. Puede definirse como la articulación de diferentes unidades de gestión e incluye tanto áreas protegidas en sus diferentes categorías como tierras privadas sean estas individuales o colectivas, aledañas o próximas a las áreas protegidas. Entre las unidades de gestión de carácter comunal o colectivo, se incluyen los territorios indígenas y las tierras de comunidades campesinas y/o ribereñas. Cada unidad de gestión tiene sus propios actores o grupos de gobernanza principales y secundarios. La conservación a nivel de paisaje involucra el desafío de la construcción de redes sociales y de gobernanza a distintos niveles y entre unidades de gestión diferentes. Por tanto, los "paisajes de conservación" constituyen escenarios privilegiados de experimentación donde la gama de combinaciones de modelos y paradigmas de conservación en relación a la población local es más amplia, generosa y necesaria.

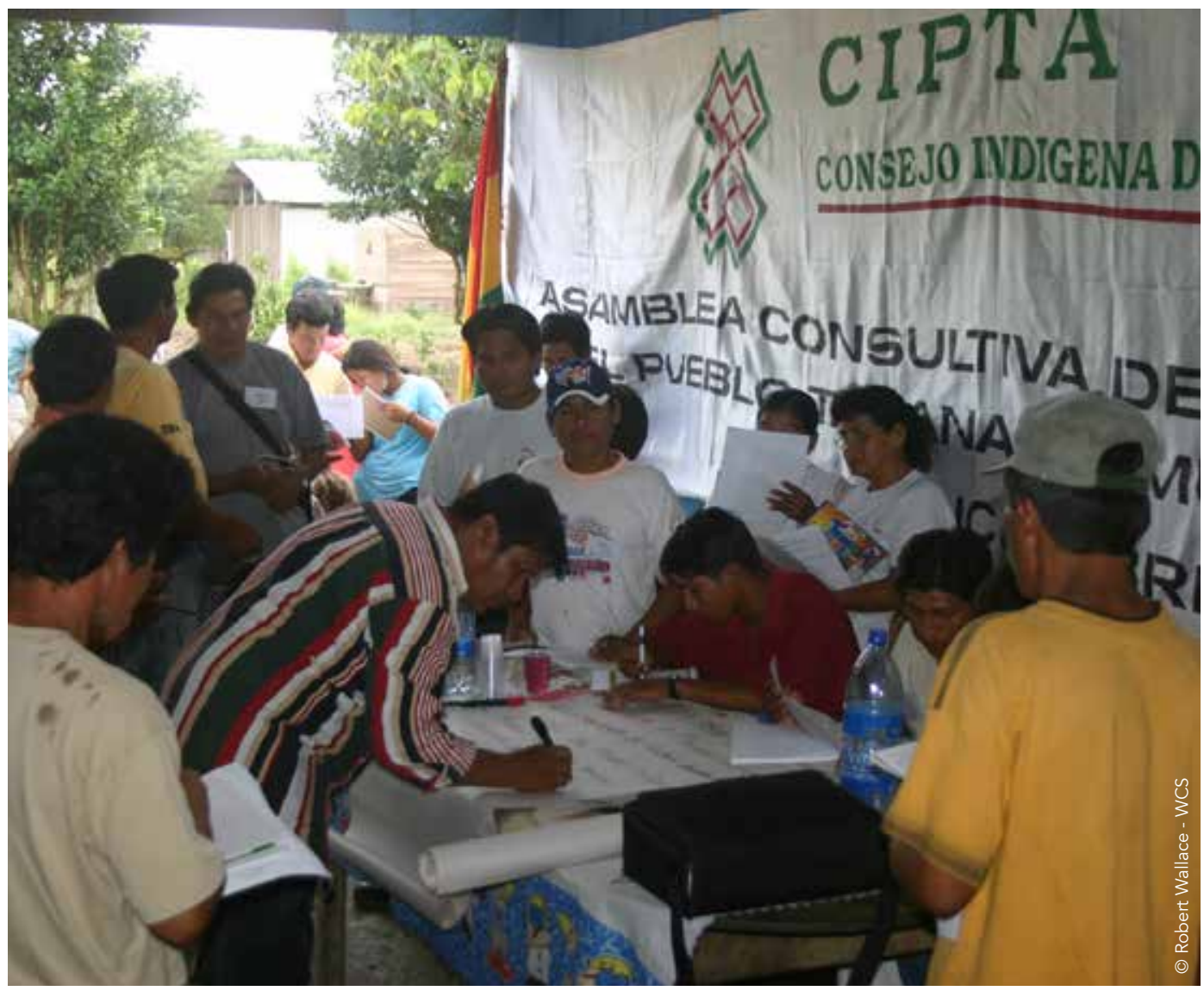




\section{GOBERNANZA PARA LA CONSERVACIÓN A NIVEL DE PAISAJE}

Una orientación fundamental de WCS en la Amazonía se basa en la idea fuerza de construir y trabajar en: "Paisajes de oportunidad basados en la gobernanza de la biodiversidad y los recursos naturales para la conservación efectiva" (Wallace, 2008).

A partir de lo anterior, preliminarmente pero de manera amplia, se puede definir la gobernanza como: "La habilidad de un grupo de tomar decisiones, implementar acciones y reforzar reglas que aseguren la sostenibilidad de los recursos naturales bajo su control" (Wilkie \& Cowles, 2014)'. Donde un grupo puede ser una instancia de gobierno estatal, una instancia de gobierno comunitario local o un grupo de usuarios y usuarias que tienen ciertos niveles de control o dominio sobre los recursos naturales.

Si lo anterior es válido para cualquier grupo de gobernanza, sea como grupo individual o una asociación de grupos de gobernanza, la gobernanza para la conservación a nivel de paisaje exige poner atención en las redes que los grupos de gobernanza generan articulando una o varias unidades de gestión y configurando un "paisaje de oportunidades" para "la conservación efectiva".

\section{SISTEMAS DE ORGANIZACIÓN TERRITORIAL MULTINIVEL O SISTEMAS ANIDADOS}

Desde la década de 1980 y especialmente en función del desarrollo sostenible, se hicieron evidentes las preocupaciones por comprender que para lograr mayor efectividad y mejores impactos de las políticas era necesario poner en evidencia y fortalecer los sistemas de organización local, comprendiéndolos como la articulación de redes horizontales y/o verticales.

En este quehacer, Uphoff (1986; 2003), llegó a distinguir hasta 10 niveles institucionales u organizacionales, que van desde las personas individuales en el nivel local hasta la esfera internacional, en los cuales pueden generarse o tomarse decisiones que afectan de una manera u otra la sostenibilidad del desarrollo. Sin embargo, de acuerdo con él, son tres los niveles que tienen una importancia decisiva: 1) las localidades, que refieren a un conjunto de comunidades; 2) las comunidades, aldeas o poblados y 3) los grupos de usuarios o usuarias de los recursos naturales.

La característica común de estos tres niveles, que los hacen tan fundamentales en la toma de decisiones respecto del desarrollo sostenible, es la prevalencia de relaciones interpersonales cara a cara, las que son más intensas en las comunidades o en los grupos de usuarios o usuarias que en las localidades. En el mismo sentido que el capital social, son redes basadas en la confianza, capaces de movilizar recursos sobre una base auto-dirigida y auto-sostenible. Las instituciones u organizaciones externas, incluso estatales, favorecen o desfavorecen esos núcleos donde en última instancia se determinan las decisiones más significativas.

1 Otras definiciones, como por ejemplo del Programa de Naciones Unidas, por gobernanza hace referencia a: "el ejercicio de la autoridad económica, política y administrativa para manejar los asuntos de un país en todos sus niveles" (Hyden \& Court, 2002). En este caso, el concepto refiere a un enfoque de gobernanza centrado en los Estados nacionales, expresa un enfoque de gobernanza de "arriba" hacia "abajo". Otros definen la gobernanza como "las estructuras, instituciones y procesos que determinan quién toma las decisiones, cómo se toman estas decisiones y cómo estas acciones son tomadas para resolver problemas sociales y ambientales" (Bennet, 2016). En este último caso, la definición es más abierta en el sentido de que la gobernanza puede ser ejercida no solo por el Estado sino por cualquier estructura orgánica y remite centralmente al concepto de legitimidad o a los procesos mediante los cuales se legitiman las decisiones y las acciones. En nuestro caso, hemos adoptado una definición más operativa, ya que permite enmarcar mejor el trabajo que WCS realiza en términos del fortalecimiento de la gobernanza para la conservación y el manejo sostenible de los recursos naturales, sea con instancias estatales de diferentes niveles o con las poblaciones locales, en el caso del presente documento se refiere a las comunidades locales y pueblos indígenas. 
Respecto de la gobernanza en relación a la biodiversidad y los recursos naturales, la importancia privilegiada de las comunidades o grupos de usuarios o usuarias, del mismo modo que la razón por la que priman en términos de capital social es por el contacto estrecho con los recursos naturales, la tienen por su proximidad a las áreas donde se distribuyen los recursos naturales. Es decir, en términos de gobernanza, es determinante su proximidad en relación a los recursos naturales que se encuentran bajo su dominio ${ }^{2}$.

Según Uphoff, el nivel de los individuos y el de los hogares quedarían sujetos a las determinaciones de los grupos, comunidades o localidades (Uphoff, 2003). Sin embargo, nuestra experiencia indica que los hogares y los individuos constituidos por mujeres y hombres, reservan para sí importantes cuotas de poder en la toma de decisiones sobre recursos naturales específicos, haciendo que estos niveles sean igualmente importantes de considerar. Este sistema anidado multinivel para la conservación y el manejo de los recursos naturales, puede quedar esquemáticamente representando de la siguiente manera:

\section{GRÁFICO 1: \\ REPRESENTACIÓN DE SISTEMAS ANIDADOS MULTINIVEL}

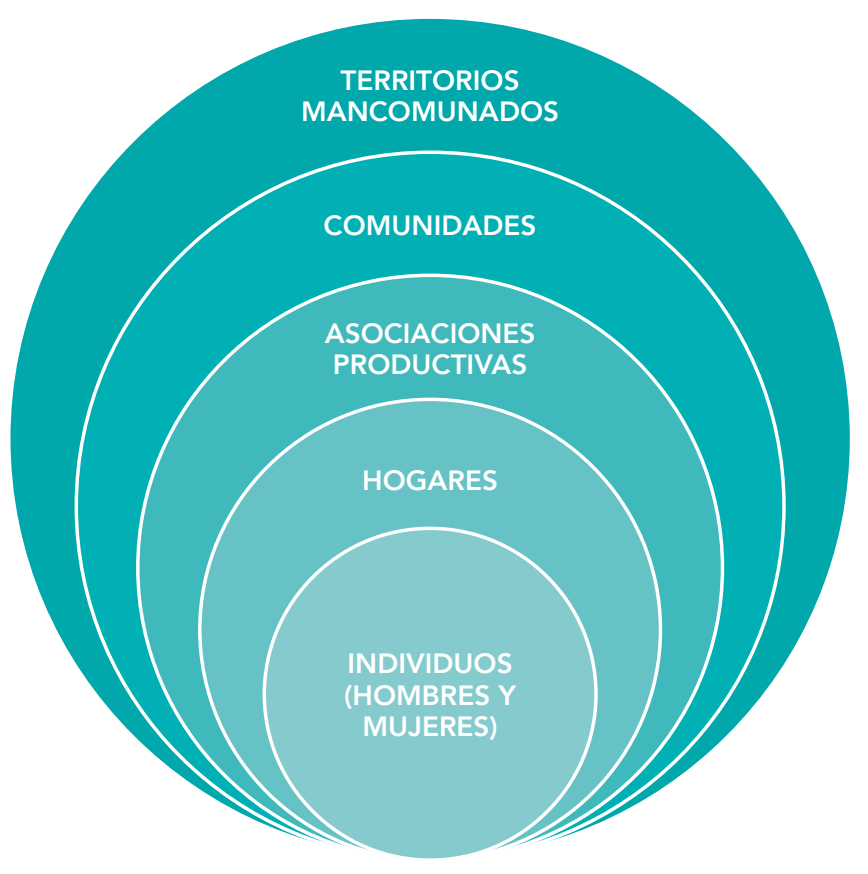

Entonces, esta propuesta de enfoque para interpretar el trabajo de WCS en diferentes países de la Cuenca Amazónica, está basado en el análisis de redes sociales como sistemas de articulación de actores sociales o grupos de gobernanza que configuran "paisajes de oportunidad", como fue definido por Wallace (2008).

En este contexto, es necesario distinguir los procesos de articulación de redes verticales y horizontales. Las redes horizontales refieren a las relaciones entre grupos de gobernanza dentro de un mismo nivel o escala. Las redes verticales refieren a diferentes niveles o escalas de los grupos de gobernanza, que van desde las personas (individuos sean mujeres u hombres), los hogares, los grupos de usuarios y usuarias, las comunidades y las mancomunidades $\mathrm{u}$ organizaciones territoriales. 


\section{GRÁFICO 2: \\ REPRESENTACIÓN DE LAS REDES VERTICALES Y HORIZONTALES}

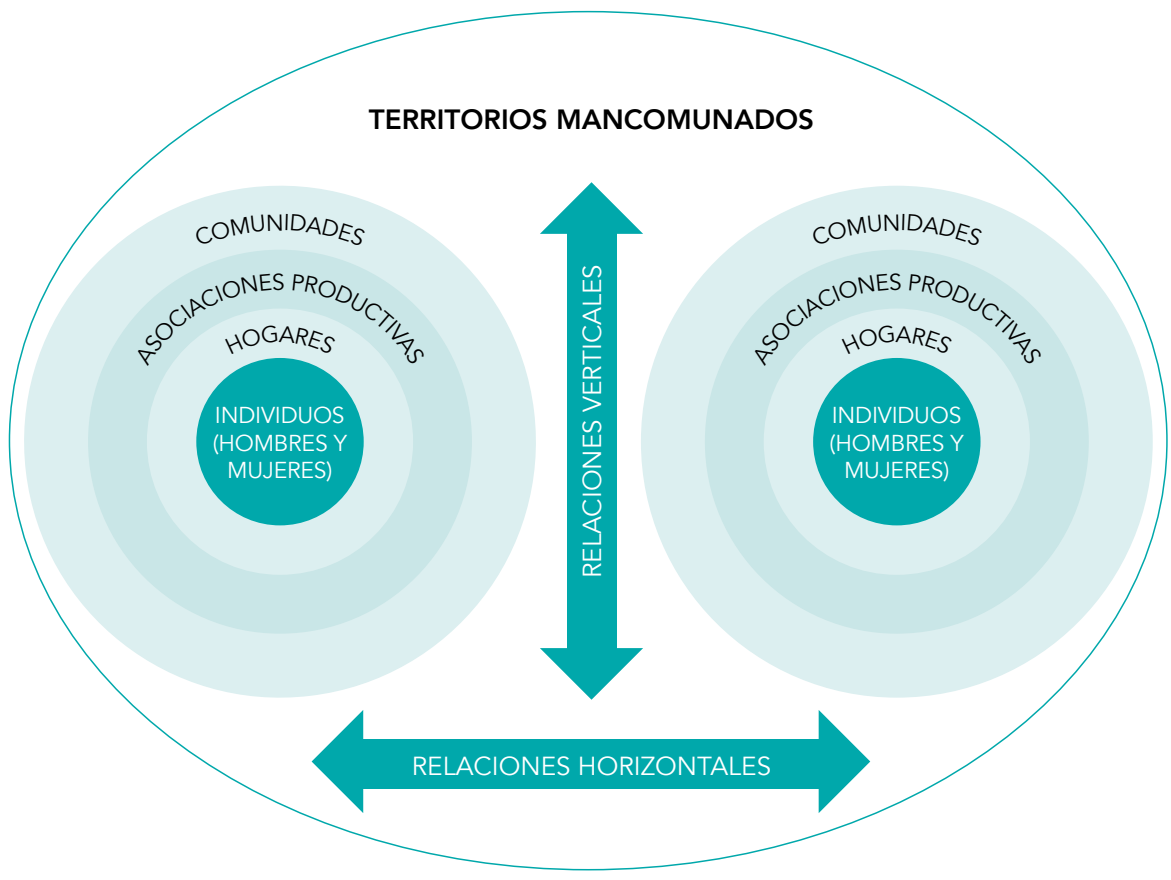

En ambos casos, estas redes sociales (horizontales y verticales) son expresiones del capital social ${ }^{3}$, el cual se define como la posesión de redes sociales basadas en normas de reciprocidad, colaboración mutua y confianza, susceptibles de ser movilizadas en función de ciertos fines (Putnam \& Feldstein, 2003, pág. 2). Es en el contexto del capital social que se distinguen las relaciones de tipo "vínculo" entre unidades socialmente parecidas, por ejemplo, entre comunidades de un mismo grupo étnico, y las relaciones de tipo "puente", entre unidades sociales diferentes (Putnam, 2000; Putnam \& Feldstein, 2003). Mientras las relaciones tipo "vínculo" ayudan a resolver los problemas locales, las relaciones de tipo "puente" son esenciales para una mejor democracia, pero estas últimas son más difíciles de construir (Putnam \& Feldstein, 2003, pág. 2)4.

La combinación de los conceptos de "redes horizontales" y "verticales" con las relaciones de tipo "vínculo" o de tipo "puente", permite construir teóricamente cuatro categorías analíticas, útiles para orientar las acciones de conservación: relaciones "horizontales" tipo "vínculo", relaciones "horizontales" tipo "puente", relaciones "verticales" tipo "vínculo" y relaciones "verticales" tipo "puente".

3 Capital social como "posesión efectiva de una red de relaciones de parentesco (o de otras) susceptibles de ser movilizadas o, por lo menos, manifestadas" (Bourdieu, 2007, pág. 59) y como referencia a "redes sociales, normas de reciprocidad asistencia mutua y confianza" (Putnam \& Feldstein, 2003, pág. 2).

4 Una aproximación a las redes verticales de organización social puede encontrarse en un documento relativo al pueblo indígena Tacana del Paisaje Madidi - Tambopata. En los años 1980, Wentzel, basándose en Uphoff (1986), intentó comprender a las comunidades locales indígenas tacanas y colonas tomando en cuenta, por un lado, su situación económica y social y su historia organizativa y por otro, sustentando que el desarrollo de redes sociales verticales permitiría a estas comunidades tener representación de sus intereses en el nivel nacional para resolver los problemas locales que enfrentaban (Wentzel, 1989, págs. 332, 350).

Wentzel esperaba que, atendiendo a una condición común de pobreza, se tejieran "puentes" horizontales y verticales entre las comunidades indígenas tacanas -originarias de la Amazonía- y las comunidades campesinas colonizadoras provenientes de los Andes. Como se vio en otro trabajo (Lehm, 2012), el tiempo demostró que fue más factible que se tejieran articulaciones horizontales y verticales tipo "vínculo" entre organizaciones comunales y supra - comunales correspondientes a los pueblos indígenas de las tierras bajas que articulaciones horizontales y verticales tipo "puente" entre indígenas amazónicos y comunidades colonizadoras o campesinas de los Andes.

Aquí, puede entenderse que las disputas por la tenencia de la tierra, diferencias en la identidad étnica y cultural, formas de uso de los recursos naturales y orientaciones al mercado diferentes y, como consecuencia, estilos de vida distintos, constituyen elementos estructurales que dificultan el tejido de relaciones tipo "puente" entre las comunidades indígenas de las tierras bajas y las campesinas colonizadoras. 
TABLA 1:

REPRESENTACIÓN DE LA COMBINACIÓN DE LAS RELACIONES HORIZONTALES/VERTICALES Y TIPO VÍNCULO/PUENTE

\begin{tabular}{l|l|l|l|l} 
NIVEL & "RELACIONES TIPO VÍNCULO" & "RELACIONES TIPO PUENTE" \\
\hline Horizontal & $\begin{array}{l}\text { Ejemplo: entre comunidades del } \\
\text { mismo pueblo indígena. }\end{array}$ & $\begin{array}{l}\text { Ejemplo: entre comunidades de } \\
\text { diferentes pueblos indígenas. }\end{array}$ \\
\hline Vertical & $\begin{array}{l}\text { Ejemplo: entre la comunidad y } \\
\text { su propia entidad representativa } \\
\text { del territorio (del mismo pueblo } \\
\text { indígena). }\end{array}$ & $\begin{array}{l}\text { Ejemplo: entre comunidades de } \\
\text { diferentes pueblos indígenas y } \\
\text { sus correspondientes entidades } \\
\text { representativas del territorio. }\end{array}$ \\
\hline
\end{tabular}

También pueden entenderse las relaciones entre las organizaciones indígenas y el Estado como una relación de tipo "puente", y sus relaciones "horizontales" o "verticales" según los niveles de las organizaciones indígenas y del Estado según sus correspondientes niveles de organización. Este tipo de relación y la forma cómo fueron construidas para relacionar las áreas protegidas y los territorios indígenas, serán demostradas a través de los diferentes estudios de caso de esta sistematización.

\section{GOBERNANZA DESDE "ABAJO" Y DESDE "ARRIBA"}

3

En las últimas décadas, en América Latina en general y en la Amazonía en particular se observa un proceso de reafirmación de identidades étnicas o indígenas, se trata de "una reactivación de identidades ancestrales junto a estrategias de recuperación de territorios, costumbres y formas de gobierno comunitario" (Torres Carrillo, 2014, pág. 5). De hecho, las comunidades locales tienen sistemas de gobernanza que son el resultado de procesos y experiencias de larga data en relación a diversos campos de la vida social y económica, entre ellos, el que se refiere al acceso y uso de las tierras y los recursos naturales. Muchos problemas de la vida comunitaria son resueltos por estos sistemas "tradicionales", cumpliendo en muchos casos funciones gubernativas en los niveles locales de sus jurisdicciones ${ }^{5}$.

Con frecuencia, los sistemas y prácticas gubernativas comunitarias colisionan con sistemas de gobernanza construidos desde "arriba" hacia "abajo" basados en visiones que restringen las funciones gubernativas al quehacer del Estado. En la práctica, la gobernanza de los recursos naturales es el resultado de la articulación de procesos que se gestan, desarrollan y se negocian en diferentes niveles que van desde el local hasta el nacional y viceversa. En este contexto, la gobernanza se relaciona con las redes sociales antes mencionadas. El capital social se transforma ya no solo en un factor que permite la solución de problemas a nivel local sino en una fuente de legitimidad, es decir, de la capacidad de tomar decisiones, implementar acciones y establecer o fortalecer reglas.

5 De manera notable, las comunidades indígenas tanto de los Andes como de la Amazonía son herederas de un conjunto de prácticas gubernativas y administrativas que fueron reforzadas por los regímenes coloniales y republicanos con diversos fines como: la administración de los conflictos internos e incluso la sanción de actos considerados lesivos al bien común, la constante reafirmación y mantenimiento de los límites comunitarios, la regulación y organización de trabajos o actividades colectivas y festivas e incluso, la organización de los servicios al Estado y la recaudación de los tributos. En su estudio clásico sobre Estado boliviano y ayllu andino: tierra y tributo en el Norte de Potosí, Platt demostró cómo el sistema tributario reforzó los sistemas de gobierno interno de los ayllus en el Norte de Potosí (Platt, 1982). 


\section{LEGITIMIDAD DE LOS SISTEMAS DE GOBERNANZA Y DE LAS REGLAS PARA EL USO Y ACCESO A LOS RECURSOS NATURALES}

La legitimidad de las decisiones, acciones o reglas en cualquiera de los niveles es central para el funcionamiento del sistema y el desarrollo de "círculos virtuosos" que redunden en la sostenibilidad del manejo de los recursos naturales; por el contrario, la ausencia de legitimidad puede generar "círculos viciosos" (Uphoff, 2003).

La toma de decisiones, la implementación de acciones o el establecimiento de reglas en los diferentes niveles de la gobernanza pueden reforzar la conservación y el manejo sostenible de los recursos naturales o por el contrario desfavorecerlos. Teórica e idealmente, es necesaria la sincronización entre las decisiones, acciones y reglas que se generan en los niveles de las personas individuales, los hogares, las comunidades, las entidades supracomunales (por ejemplo, territorios indígenas) y las diferentes instancias estatales en sus niveles sub-nacionales y nacionales. Sin embargo, en la práctica, la toma de decisiones, implementación de acciones o establecimiento de reglas se convierten en espacios de negociación en los que entran en juego las relaciones de poder. El ejercicio del poder está relacionado con la articulación de las redes horizontales y verticales, sea tipo "vínculo" o tipo "puente" entre las comunidades, con la legitimidad o la fuerza coercitiva del Estado. Personas individuales, hogares, grupos de usuarios o usuarias y comunidades locales fuertemente articuladas en redes horizontales o verticales podrán tener mayor poder para hacer prevalecer sus reglas o propuestas de políticas que si están débilmente articuladas.

En América Latina, las comunidades y sus organizaciones se caracterizan por sus importantes grados de autonomía que frecuentemente entran en colisión con el Estado, aunque no siempre las decisiones, de unas y otro, estén necesariamente orientadas a la conservación y el manejo sostenible de los recursos naturales. Sin embargo, puede constatarse que la fuerza en el ejercicio del poder en la toma de decisiones, cuando se refiere a los recursos naturales, en gran medida depende de la mayor o menor proximidad de los actores a las áreas donde se distribuyen estos recursos. De ahí la importancia de asegurar la vocación y orientación de las entidades locales hacia la conservación.

Por su parte, las reglas pueden originarse tanto en los grupos de usuarios y/o usuarias, en las comunidades, como en los niveles supra-comunales. De hecho, las comunidades o grupos de usuarios y usuarias generan constantemente normas o acuerdos para regular tanto las relaciones entre sus miembros como con los recursos que aprovechan, sin que en muchos casos exista intervención estatal. Del mismo modo, muchas comunidades o grupos de usuarios y/o usuarias adoptan las normas estatales y las adecúan en su aplicación.

Una norma (ley, reglamento, procedimiento administrativo, etc.) puede ser legal, si es emitida por el Estado, pero puede no ser legítima entre las personas o grupos usuarios de los recursos naturales en el nivel local. En este caso, dicha norma no podrá aplicarse plenamente o su aplicación demandaría costos extraordinarios por parte del Estado hasta hacer imposible su permanencia en el tiempo. En cambio, si la norma fuera legítima, hacerla cumplir no debería generar costos excesivos para el Estado.

Puede entenderse por legitimidad la adhesión, el cumplimiento, el reconocimiento y la valoración de las personas partícipes a un determinado orden o conjunto de reglas sean estas legales, tradicionales o aún de origen religioso (Weber, 1977, pág. 194).

Debido a que, en el plano local, WCS trabaja fundamentalmente con comunidades locales y pueblos indígenas en la construcción o el reforzamiento de las reglas para asegurar la conservación y el manejo sostenible de los recursos naturales, este trabajo se relaciona por un lado con los debates sobre los sistemas de acceso común y por otro lado con la discusión sobre la naturaleza de las reglas y su viabilidad. 


\section{REGLAS, REGÍMENES Y SISTEMAS DE ACCESO COMÚN}

Desde la década de los sesenta se vienen debatiendo las ventajas y desventajas de los sistemas de acceso común a los recursos naturales. En 1968, el biólogo Garrett Hardin propuso la teoría que se denominó "la tragedia de los comunes". Para su demostración, el autor utilizó el ejemplo teórico de un campo de pastoreo en el cual los dueños de los rebaños buscan, instintivamente, incrementar constantemente sus beneficios individuales, generando una tendencia a la sobreexplotación del recurso, situación en la que todos terminan perdiendo (Hardin, 1968). Esta interpretación conducía a sobrevalorar la propiedad privada individual o la propiedad estatal, en la búsqueda de establecer con claridad las responsabilidades individuales y en detrimento de los sistemas de acceso común, donde los sujetos que ostentan los deberes y derechos se tornan difusos.

Las críticas a esta propuesta se basan en estudios sobre experiencias concretas que demostraron que el régimen común fue interpretado por Hardin como un sistema abierto y desregulado (Berkes F. , 1986; Berkes \& et.al, 1989; Messerschmidt, 1993; McKean \& Ostrom, 1994) donde la propiedad común se asemejaba a una ausencia de propiedad, en términos de la imposibilidad del dominio o el control. Es decir, se desconocía el hecho de que, en muchos casos, los comunitarios (o miembros de un sistema de acceso común) toman acuerdos para regular el aprovechamiento de los recursos naturales reduciendo el riesgo de la sobreexplotación y potenciando el control social. Esto se debe en gran medida a que los comunitarios interactúan repetidamente en el tiempo (en el largo plazo) para usar el recurso común, toman decisiones sobre su uso y terminan normándolo. La repetición de la interacción o la negociación sobre el acceso y uso de los recursos naturales es clave para asegurar la sostenibilidad de los sistemas de acceso común.

3

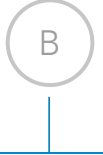

INICIO

ÍNDICE FINAL

Los autores también coinciden en que los sistemas de acceso común no están blindados a las posibilidades de la sobreexplotación sino que, para ser eficaces, deberían cumplir ciertas condiciones, entre ellas: a) los límites del recurso deben ser claros; b) los criterios para decidir quién podrá formar parte del grupo de usuarios también deben ser claros; c) los usuarios deben tener derecho a modificar sus normas de utilización a lo largo del tiempo; d) las reglas de uso deben corresponder a la capacidad de carga del sistema, ser conservadoras desde el punto de vista del medio ambiente, y prever un margen de error y e) las normas de uso deben ser claras y de fácil aplicación (McKean \& Ostrom, 1994).

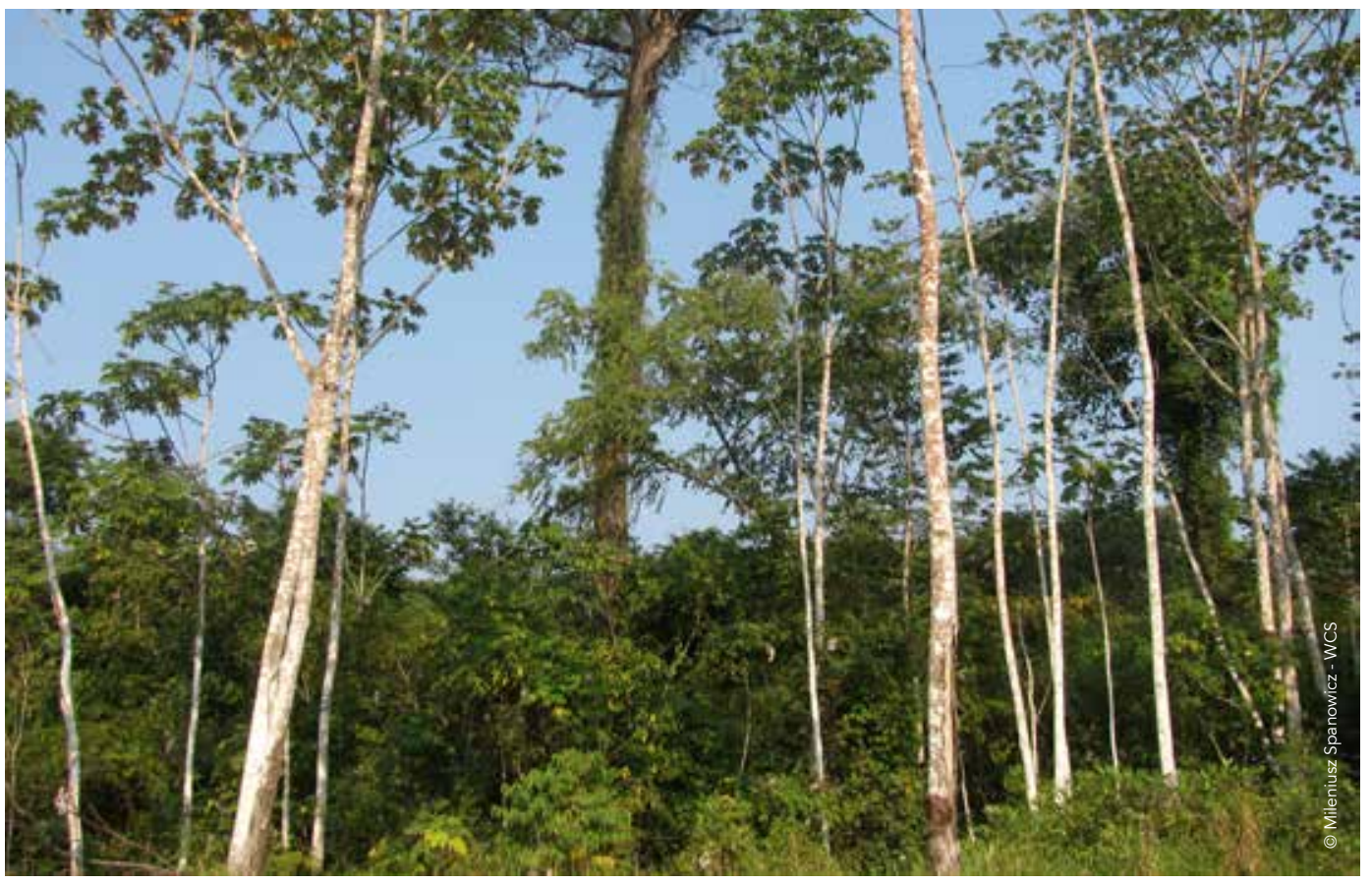




\section{LA NATURALEZA TRADICIONAL Y RACIONAL DE LAS REGLAS DE ACCESO Y USO DE LOS RECURSOS NATURALES}

Como se sabe, Weber clasificó la "acción social" en tipos ideales distinguiendo: la acción racional con arreglo a fines, la racional con arreglo a valores, la afectiva y la tradicional (Weber, 1977, pág. 20). Extendiendo esta clasificación a un orden normativo, puede atribuirse esta misma tipología a la naturaleza de las reglas en general y a las reglas de acceso y uso de los recursos naturales en particular. Las reglas "racionales con arreglo a fines" son la expresión más clara del derecho positivo moderno, cuyas características principales son: 1) su externalidad, 2) el alineamiento racional de los medios en función de los fines y 3 ) donde un cuadro administrativo aplica coactivamente una sanción cuando la regla no es cumplida.

En el otro extremo, una regla basada en la "tradición" puede entenderse, como el resultado de la repetición por razón de que "siempre fue asi" y en este último caso, frecuentemente, pero no siempre, se presenta como parte de un sistema religioso que implica que la sanción no es aplicada por un cuadro administrativo de manera coactiva, sino por unas deidades omnipresentes.

De hecho, entre las poblaciones locales en general y entre los pueblos indígenas amazónicos en particular, han regido y aún lo hacen, reglas de un tipo o naturaleza relacionado con la "tradición" y la "religión". Por ejemplo, en el caso de los tacanas, las fuentes etnográficas, especialmente de los años 1950, describen una sociedad altamente regulada con base en un sistema de creencias y religiosidad: las personas debían observar infinidad de tabúes alimenticios según su sexo y edad, reglas para todas las actividades humanas y para su relación con la naturaleza, de esta manera se regulaba la "natural" tendencia a la extralimitación en las prácticas de cacería, pesca, recolección y otras. La contravención a estas reglas implicaba diversos tipos de castigos impuestos por las deidades: los amos de los animales, de las plantas, de las aguas, etc. Estos castigos se expresaban a través de enfermedades o aún de la muerte. En este contexto, la intermediación de los chamanes o sacerdotes rituales era fundamental tanto para interpretar la razón del mal como para curar, pero no eran ellos quienes castigaban sino las deidades (Hissink, K.; Hahn, A., [19521954] 2000). De estas descripciones, se percibe que las reglas correspondían a un orden tradicional y religioso, marcadas por la costumbre, transmitidas a cada individuo a través de la cultura (Lehm, 2010).

Dada la naturaleza de estas reglas, no es menor la importancia de su contraste con las reglas de un orden racional y positivo como las que en la actualidad vienen adoptando las comunidades y pueblos indígenas, sea con la finalidad de hacer un uso más sostenible de los recursos naturales o de protegerlos frente a las invasiones de terceros a sus tierras. La externalidad de estas reglas se expresa por un lado en su carácter positivo, es decir, son reglas escritas en reglamentos o en "libros de actas" $y$, por otro lado, en el hecho de que la capacidad de sancionar el incumplimiento a las reglas o acuerdos establecidos para el uso y el acceso a los recursos naturales está referida, generalmente, a las autoridades seculares de la comunidad o a las autoridades estatales competentes. Aunque en muchos casos, el contenido de las reglas recoge en gran medida las prácticas comunales tradicionales, la forma de su expresión y la designación de la autoridad para hacer cumplir las reglas provienen de una naturaleza distinta. Estos últimos son elementos nuevos que contrastan con la tradición, de ahí parece emanar la dificultad frecuentemente observable de la ausencia de sanción o castigo a las personas de la comunidad que infringen la norma.

De hecho, en este contraste, ya se constató la fragilidad de las reglas correspondientes a un orden racional con arreglo a fines frente a las reglas que corresponden al orden tradicional marcadas por la costumbre o la religión (Weber, 1977, págs. 25 - 26). Sin embargo, también se puede observar la fragilidad de las reglas tradicionales cuando las poblaciones locales se insertan en el mercado o cuando sus espacios son invadidos por 
agentes económicamente más agresivos y la pérdida de los recursos naturales termina empobreciendo especialmente a aquellos más tradicionales.

\section{DESARROLLO DE LAS CAPACIDADES LOCALES PARA IMPLEMENTAR LAS ACCIONES}

La posibilidad de implementar acciones que aseguren la conservación y el uso sostenible, y el ejercicio del poder para balancear a los grupos de gobernanza en los escenarios de negociación, está estrechamente relacionada con las capacidades en términos de conocimientos y habilidades, con los recursos a disposición para su implementación y el desarrollo institucional (Wilkie \& Cowles, 2014). De hecho, en gran medida, los esfuerzos de WCS en el trabajo con los pueblos indígenas y las poblaciones locales en la Amazonía se han orientado a la superación de déficits que pudieran existir en relación a este atributo de la gobernanza. Sin embargo, aquí debe considerarse que las poblaciones locales y pueblos indígenas, mujeres y hombres, tienen sus propios sistemas de conocimientos acumulados en relación a los recursos y su medio, de tal manera que lo que se produce es un intercambio de conocimientos.

\section{ESFERAS ECONÓMICAS: ENTRE LA RECIPROCIDAD Y EL MERCADO}

Como se mencionó, otro campo importante de trabajo de WCS con las comunidades tradicionales y pueblos indígenas de la Amazonía es la promoción de iniciativas para el manejo sostenible de los recursos naturales. En algunos casos, estas iniciativas están más orientadas al mercado y en otros al fortalecimiento de los medios de vida. Las acciones de WCS en este campo requieren ser comprendidas en el contexto de la dinámica histórica de inserción de las poblaciones locales, particularmente de los pueblos indígenas de la Amazonía en la economía mercantil y la problemática que plantea el proceso de articulación entre sistemas más tradicionales de uso y acceso a los recursos naturales con las dinámicas del mercado. Con la finalidad de proponer un marco interpretativo de las acciones de WCS, aquí apelamos a la idea de "esferas económicas de la reciprocidad y el mercado".

Las contribuciones de la "Teoría del don" de Malinowsky y de Mauss, así como de sus seguidores como Sahlins y otros, constituyen la base para las descripciones de los sistemas de intercambio en las denominadas "sociedades primitivas", ponen al descubierto el funcionamiento de la "esfera de la reciprocidad": definida esencialmente por el principio "de la obligación de dar, de la obligación de recibir y de la obligación de retribuir", en estos intercambios no solo ingresan bienes materiales, es más, los bienes intercambiados contienen no solo una calidad material sino también, frecuentemente, espiritual, e incluyen en el intercambio otros valores como el poder y el prestigio (Firth, 1974, pág. 17).

El concepto de las "esferas económicas de la reciprocidad y del mercado" es una construcción teórica que pertenece a la antropología económica. Su origen nos remite al debate entre antropólogos sociales, al constatar la necesidad de interpretar a las sociedades tradicionales como entidades económicas. Hasta entonces, la antropología social puso más énfasis en descubrir la racionalidad de las relaciones sociales en los intercambios pero no tanto la racionalidad económica del intercambio con base en las observaciones sobre las poblaciones tradicionales y pueblos indígenas desde el siglo XVIII, con más énfasis en el XIX $X^{6}$. No es sino hasta la década de los sesenta que la antropología logra articular una disciplina denominada "antropología económica" para diferenciarla de la "economía primitiva" (Firth, 1974).

6 La constatación de que el intercambio en las sociedades primitivas tenía más razones sociales que económicas, habría llevado a los antropólogos a ver solo las determinaciones sociales en el intercambio y no tanto así razones económicas. 
De otro lado, esta antropología económica y su propuesta de las "esferas económicas de la reciprocidad y el mercado" busca superar las visiones de la economía cuyo objeto de estudio, al privilegiar la institucionalidad empresarial típica de occidente, orientada a la maximización de la utilidad, deja de lado la interpretación de otro tipo de economías, como las de las comunidades tradicionales e indígenas, por considerarlas "pre-económicas", "no económicas", "ineficientes" y por tanto, sus sujetos condenados a vivir en los "márgenes de la economía".

La formulación del concepto de "esferas económicas" para referirse a las "esferas de la reciprocidad y del mercado" de manera articulada, intenta dejar atrás las limitaciones antes mencionadas y se propone como medio teórico para comprender a las "sociedades primitivas" desde el punto de vista de la antropología económica moderna (Frankenberg, 1974, pág. 57).

La propuesta de articulación de ambas esferas puede representarse en un diagrama, en el que además de coexistir cada una de ellas, se interrelacionan de alguna manera.

\section{GRÁFICO 3:}

\section{REPRESENTACIÓN DE ESFERAS DE LAS RECIPROCIDAD Y MERCADO} ARTICULADAS

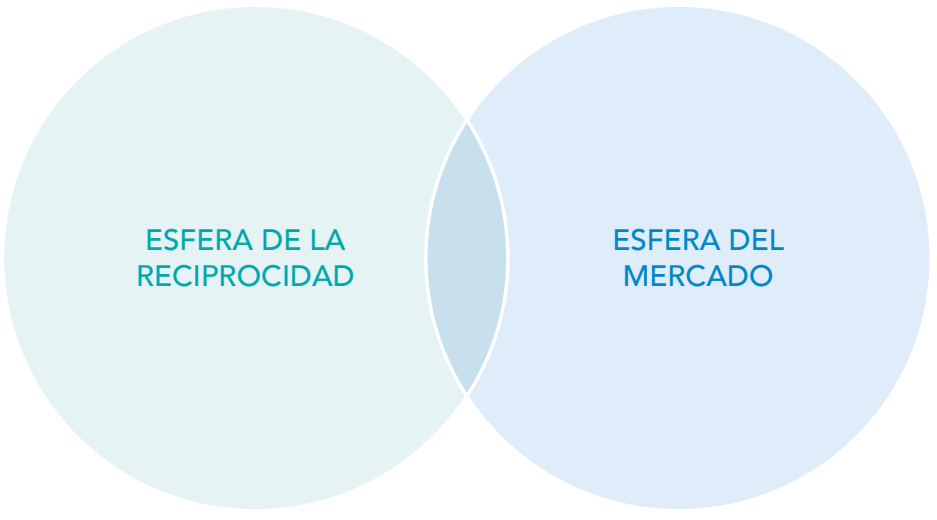




\section{DINÁMICA DE LA INSERCIÓN MERCANTIL DE LOS PUEBLOS INDÍGENAS EN LA AMAZONÍA}

Durante la colonización a través de misiones o los auges extractivistas del siglo XIX y principios del XX, la relación de los pueblos indígenas con el mercado estuvo mediada sea por misioneros, "patrones" o "enganchadores" (COICA - OXFAM AMERICA, 1996). Esta situación empezó a cambiar drásticamente a partir de los años sesenta con la apertura de carreteras, la expansión de otros "frentes económicos" (Ribeiro, 1977), el arribo creciente de colonizadores, la explotación de la fauna silvestre, la madera y los hidrocarburos. Estos procesos implicaron la relación directa de las familias y comunidades indígenas con el mercado. En principio, a través de la venta de la mano de obra y el intercambio monetario de productos. Progresivamente, un nuevo fenómeno se hace visible especialmente desde fines de los ochenta: el surgimiento y el desarrollo de iniciativas productivas basadas en el manejo de recursos naturales por los mismos comunarios y comunarias o pobladores locales.

Los cambios en los sistemas de uso y acceso a los recursos y en las relaciones sociales de los pueblos indígenas así como de comunidades tradicionales (por ejemplo comunidades ribereñas ${ }^{7}$ ) trajeron la atención sobre los impactos de la inserción mercantil en los sistemas tradicionales de organización social y económica caracterizados por el uso altamente diverso de los recursos naturales, la producción con fines de subsistencia y la sujeción de las relaciones sociales a los sistemas de intercambio recíproco basados en el parentesco. En contraste, como resultado de las demandas del mercado, surgieron tendencias orientadas a la simplificación de los sistemas productivos: la especialización en unos pocos productos; el disciplinamiento de la fuerza de trabajo, la necesidad de cuadros y sistemas administrativos, relaciones impersonales, orientación hacia la obtención de utilidades, etc.

3

B

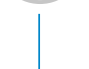

INICIO

ÍNDICE FINAL

A cada esfera de la reciprocidad y del mercado, le corresponde además condiciones y sistemas de valores diferentes y su encuentro implica una confusión ideológica y cultural que en el peor de los casos conduce a inviabilizar el desarrollo de ambas esferas, dejando a las personas, sus hogares y comunidades sumidas en la "pobreza absoluta": sin la base de sus recursos naturales y con las redes sociales tradicionales completamente desarticuladas (COICA - OXFAM AMERICA, 1996). Una aproximación a estas condiciones y sistemas de valores correspondientes a cada una de las esferas fue recogida en la siguiente tabla.

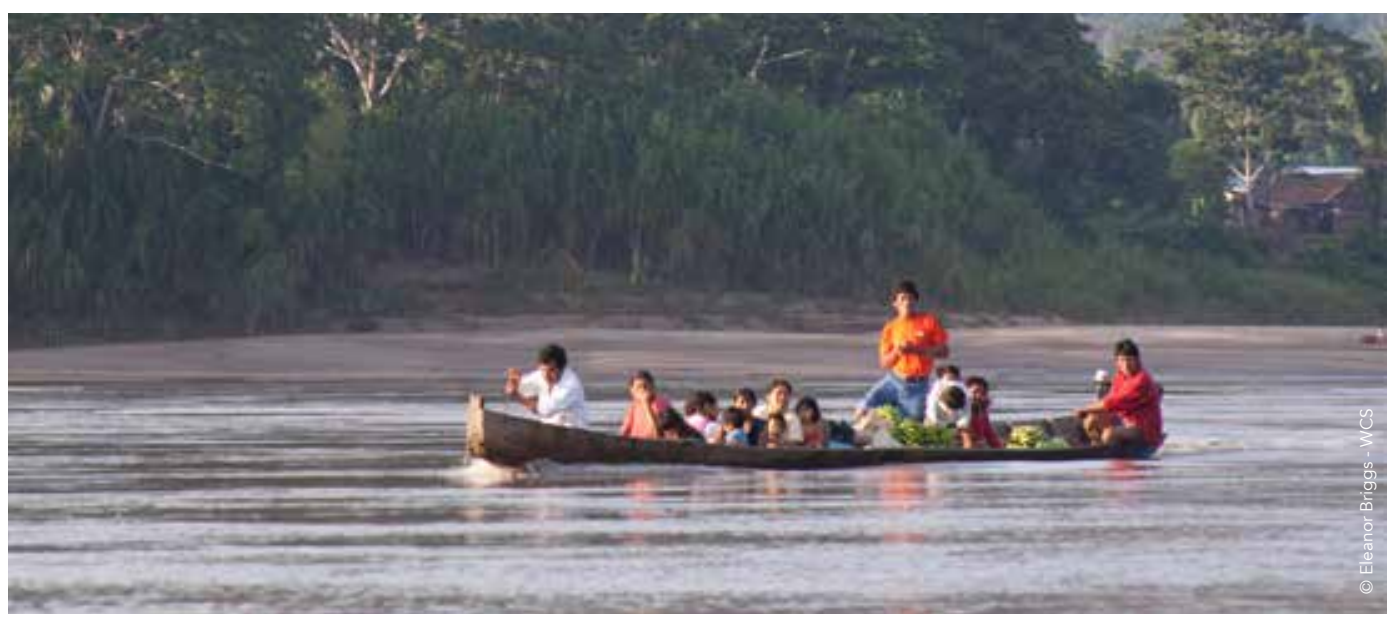

7 Muchas de las cuales, como resultado de la desintegración provocada por el auge gomero, son conglomerados de individuos o grupos familiares cuyos orígenes étnicos se encuentran en los pueblos indígenas amazónicos pero que al haber sido entremezclados unos con otros, ya no se identifican con ningún grupo étnico en particular. Sin embargo, especialmente sus prácticas en relación al uso de los recursos naturales, muestran adaptaciones tecnológicas de larga data a los ecosistemas y características ecológicas del medio. Un ejemplo de tales asentamientos son las comunidades ribereñas que habitan el Tamshiyacu - Tahuayo, importante área de trabajo de WCS en Perú (Chirif, 2012). 
TABLA 2:

ELEMENTOS DE CONFLICTO ENTRE LAS ESFERAS DE LA RECIPROCIDAD Y DEL MERCADO EN RELACIÓN A LA ECONOMÍA DE LOS PUEBLOS INDÍGENAS DE LA AMAZONÍA

CONDICIONES DE LA ESFERA DE LA RECIPROCIDAD

Sistemas locales altamente autónomos vinculados por intercambios materiales y simbólicos.

Sistemas de acceso a los recursos: flexibles, concéntricos de mayor a menor exclusión.

Decisiones económicas familiares reguladas por controles sociales con arreglo a valores.

Obligación moral de redistribuir los excedentes entre los miembros de la sociedad.

Diversidad productiva para satisfacer necesidades internas y mantenimiento de la biodiversidad.

Divisiones del trabajo basadas en las diferencias de género y generación.

Relación directa de los instrumentos de trabajo con lo(a)s trabajadores.

Las personas tienen autonomía para decidir la distribución de su tiempo, y las actividades festivas, comunitarias y de la producción tienen una misma importancia en esta distribución del tiempo.
CONDICIONES DE LA ESFERA DEL MERCADO

Sistemas crecientemente dependientes (precios, inversiones e información a distintos niveles).

Sistemas de acceso a los recursos: rígidos y dominantemente excluyentes.

Decisiones económicas familiares frecuentemente ignoradas y sujetas a estructuras institucionales legales.

Excedentes orientados a la acumulación del capital.

Especialización productiva para satisfacer las necesidades del mercado y pérdida de biodiversidad.

División técnica y diferenciación social.

Instrumentos de trabajo y equipos que requieren mecanismos de control impersonales (administrativos).

Es la demanda de productos la que gobierna la distribución del tiempo, y el trabajo productivo se sobrevalora en desmedro de las demás actividades.

Fuente: (Lehm, 2002, pág. 38)

Frente a lo anterior, destacan por un lado las visiones que vislumbran un destino inexorable de asimilación de las "economías indígenas" a la economía de mercado con los efectos negativos antes mencionados. En el otro extremo, se encuentran las visiones más pragmáticas en el sentido de señalar que lo que queda es hacer que las unidades económicas, percibidas como completamente asimiladas o en tendencia inevitable de subsumirse en el mercado, sean económicamente eficientes en el sentido de los valores que exige el mercado. Sin embargo, muchas iniciativas orientadas a este fin tropiezan sistemáticamente con resistencias que emanan de las condiciones y valores de los sistemas tradicionales basados en la reciprocidad y el parentesco.

En realidad, con las dinámicas enunciadas en curso, es improbable que en la Amazonía existan (excepción hecha de los grupos en aislamiento voluntario) personas, hogares o comunidades exclusivamente basadas en la economía de la reciprocidad o exclusivamente basadas en la economía de mercado. Resulta más adecuado considerar los sistemas económicos a diferentes escalas y constituidos tanto por la "esfera de la reciprocidad" como "por la esfera del mercado". Es decir, como sistemas en los que ambas "esferas" convergen y se "interpenetran" (Firth, 1974, pág. 28) y donde elementos de una y otra están en relación de competencia o de complementariedad. 


\section{SISTEMAS ANIDADOS, MULTINIVEL E INICIATIVAS ECONÓMICAS BASADAS EN EL MANEJO DE LOS RECURSOS NATURALES, ORIENTADAS A LA "ESFERA DEL MERCADO"}

El desarrollo de asociaciones productivas basadas en los recursos naturales puede ser analizado considerándolas de manera aislada, como entidades independientes. Sin embargo, esta visión pierde de vista el hecho de que los recursos naturales en los que basan su accionar, por lo general, son bienes de dominio común y esta condición, más temprano que tarde, determina los límites y las posibilidades de su desarrollo como entidades completamente autónomas.

Mientras unas corrientes plantean que la sujeción de las asociaciones productivas a las redes de solidaridad y confianza limita su desarrollo como entidades económicas eficientes, otras corrientes plantean que más bien el desarrollo del capital social aparejado con el desarrollo del capital económico consigue que estas asociaciones sean más sostenibles en el tiempo. El hecho de que los recursos naturales en los que basan las acciones de manejo, producción y comercialización sean de dominio común, reforzado esto por las legislaciones nacionales latinoamericanas, define la preferencia de comprenderlas en sus relaciones multidimensionales.

En este campo, más o menos desde los años 2000, WCS ha desarrollado una propuesta que presenta a estas asociaciones articuladas con los niveles comunales y territoriales (entidades de mancomunidades) a través del flujo de los beneficios económicos que generan, y que al mismo tiempo busca establecer un sistema de pesos y contrapesos que orienten a todo el sistema de organización multinivel hacia una forma de administración con vocación de transparencia y rendiciones de cuentas recíprocas. Este sistema puede representarse gráficamente de la siguiente manera: DE BENEFICIOS Y RENDICIÓN DE CUENTAS

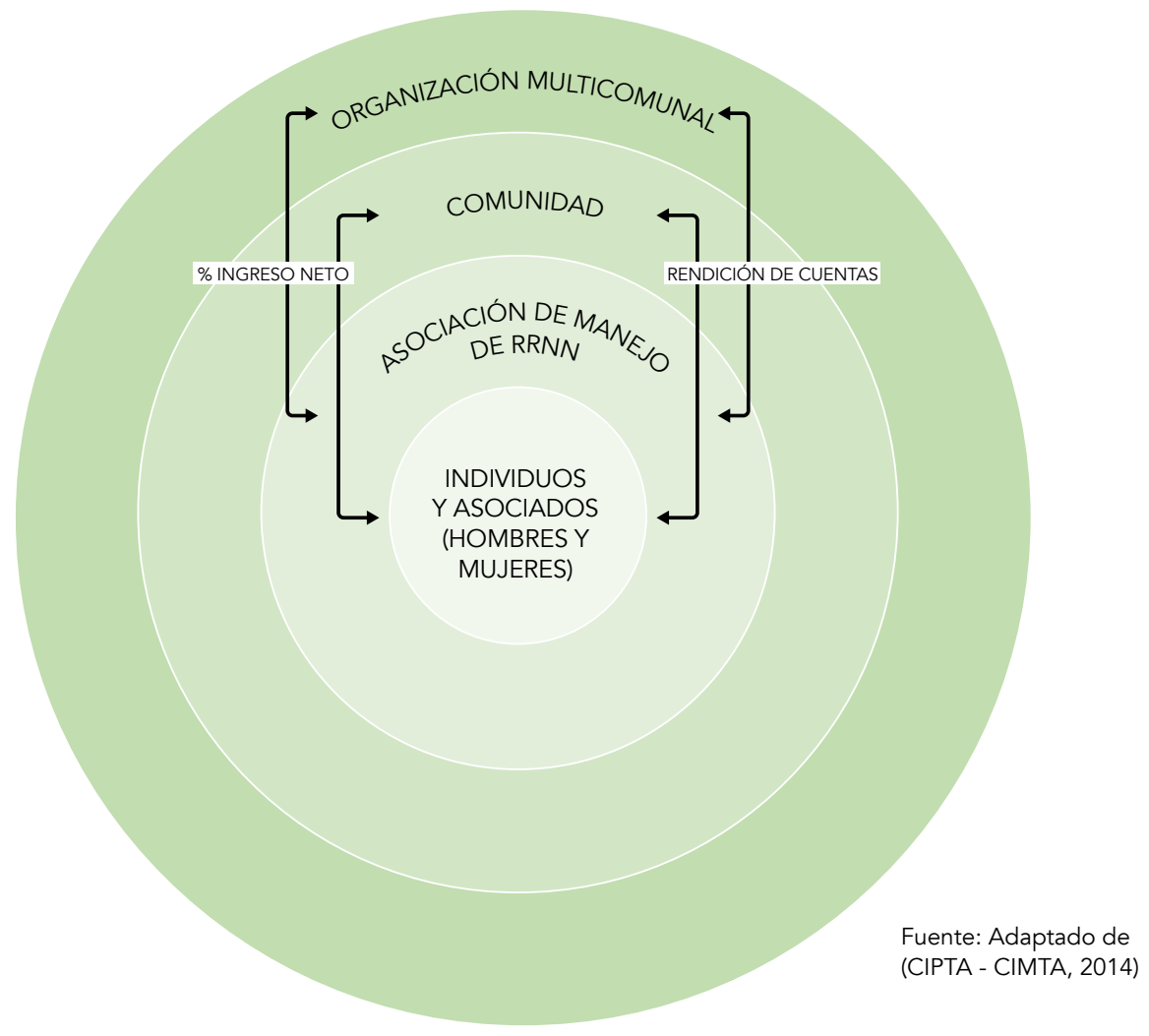


Recientemente, el Centro de Investigaciones Forestales (CIFOR) ha puesto énfasis en sus investigaciones sobre los sistemas anidados multinivel de carácter local, en relación a las decisiones sobre el uso de la tierra y los mecanismos de Reducción de Emisiones por Deforestación y Degradación + (REDD+). Estas investigaciones ponen en relieve la ausencia de estos sistemas anidados multinivel en el diseño e implementación de los esquemas de distribución de beneficios, lo que incidiría negativamente en la legitimidad de la toma de decisiones de mecanismos de REDD+ (Kowler, Gonzales Tovar, Ravikumar, \& Larson, 2015).

Aceptando que las redes multinivel constituyen sistemas de gobernanza orientados a tomar decisiones, implementar acciones y construir o reforzar reglas que aseguren la sostenibilidad de los recursos naturales bajo su control, y considerando la investigación de CIFOR y nuestra propia experiencia, entre los insumos que fluyen al interior de los sistemas multinivel, deben mencionarse: los beneficios monetarios y no monetarios, la capacitación y la asistencia técnica, la información y, finalmente, pero no menos importantes, las consultas.

En síntesis, para comprender el trabajo de WCS en el campo del fortalecimiento de la gobernanza con un enfoque basado en la población local, es necesario distinguir las redes verticales y horizontales. Las primeras refieren a diferentes niveles o escalas que van desde las personas (individuos sean mujeres $u$ hombres), los hogares, los grupos de usuarios y usuarias, las comunidades y las mancomunidades. Las segundas, refieren a las relaciones entre unidades dentro de un mismo nivel. En ambos casos (redes verticales y horizontales), éstas pueden ser de tipo "vínculo" cuando se realizan entre unidades semejantes o de tipo "puente" cuando se relacionan entre unidades social o culturalmente heterogéneas. Estas redes sociales, también denominadas capital social, permiten canalizar planteamientos y resolver problemas locales.

En aras de su efectividad, la conservación requiere el fortalecimiento de la gobernanza desde "abajo", esto implica el reconocimiento de que las poblaciones locales y particularmente los pueblos indígenas resuelven problemas de diversos órdenes cumpliendo funciones gubernativas en el nivel de sus jurisdicciones. En el contexto latinoamericano, esta tradición es notable tanto en las comunidades de los Andes como de la Amazonía. Estos sistemas locales de gobernanza frecuentemente colisionan con las políticas, reglas y acciones (gobernanza) que se buscan establecer desde "arriba". La gobernanza para la conservación y el manejo de los recursos naturales también puede ser entendida como un espacio de disputas y negociaciones donde la legitimidad cumple un papel fundamental.

Para interpretar el apoyo de WCS a las comunidades o grupos de usuarios y usuarias en la formulación y reforzamiento de reglas para asegurar el uso sostenible de los recursos naturales, es importante considerar tanto los regímenes de acceso común y los requisitos que, a través de varios estudios, se han establecido en la búsqueda de asegurar la sostenibilidad, así como la naturaleza de las reglas, sean estas de orden formal, racional con arreglo a fines o tradicional basadas en la costumbre y la religión.

La formación de capacidades para la gobernanza es un ámbito en el que WCS ha concentrado esfuerzos. Preguntas significativas para esta sistematización comparativa del trabajo de WCS en la Amazonía durante algunas décadas son: ¿a cuánta población se ha alcanzado en estos procesos de asistencia y capacitación?, ¿de qué tipo de comunidades se está hablando (indígenas, ribereñas, campesinas) ?, ¿de qué género o grupo de edad?, ¿sobre qué temas han versado las capacitaciones?

En cuanto al apoyo de WCS a emprendimientos basados en el manejo de los recursos naturales, aquí se busca comprenderlos en su relación tanto con la esfera de la reciprocidad (obligación de distribución y redistribución recíproca) como con la esfera del mercado (la producción para la venta). Asimismo, es necesario considerar la articulación de los 
emprendimientos en su relación con los sistemas anidados y multinivel de la gobernanza, así como con el capital social, considerando que los recursos que utilizan corresponden mayormente a regímenes de acceso común.

Las fuentes de información para esta sistematización se refieren a la experiencia personal de trabajo con pueblos indígenas, entrevistas individuales y colectivas al personal directivo y técnico de los diferentes programas de cada país, visitas a algunas comunidades, proyectos, informes y publicaciones, así como al sistema de bases de datos del Programa Andes - Amazonía - Orinoquia, denominado Amazon Measures. 


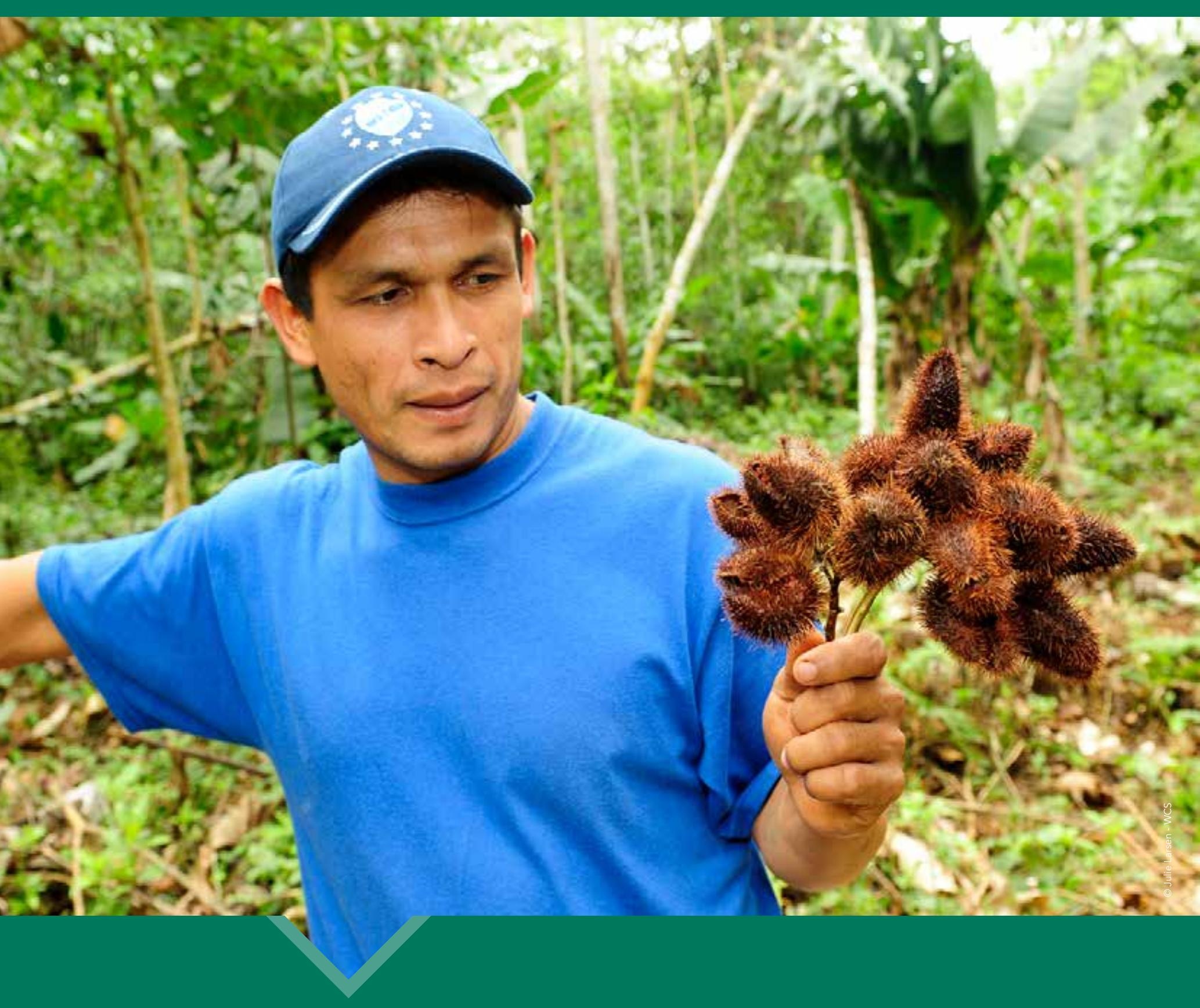

2

ESTUDIOS DE CASO 


\section{BOLIVIA:}

\section{PAISAJE MADIDI Y LA GESTIÓN TERRITORIAL INDÍGENA DE LOS PUEBLOS INDÍGENAS TACANA Y LECO DE APOLO}

El "Gran Paisaje Madidi - Tambopata" se extiende entre Bolivia y Perú sobre una superficie de 10978000 ha, de las cuales 8201000 ha se encuentran en Bolivia, en el norte del departamento de La Paz y oeste del Beni. Desde el punto de vista de WCS, se denomina "Paisaje Madidi" a la porción boliviana del Gran Paisaje Madidi-Tambopata. Comprende un conjunto de ecosistemas y hábitats distribuidos en una gradiente altitudinal que va de los 6000 m s.n.m. hasta los 200 m s.n.m., es una de las regiones más biodiversas del mundo, tanto su superficie como características ecológicas son adecuadas para la conservación de siete especies de vida silvestre: vicuña, cóndor y oso, en los Andes; jaguar, londra y borochi, en la Amazonía; y paraba militar en los bosques del piedemonte. Por sus características, se las denomina "especies paisaje". La conservación de los hábitats que requieren estas especies y la conectividad entre los mismos, asegurarían en gran medida la conservación de estas especies silvestres y de todas las demás que comparten el mismo espacio (Wallace, Gómez, \& Coppolillo, 2001, pág. 8).

El denominado "Paisaje Madidi", tiene como referencia al Parque Nacional y Área Natural de Manejo Integrado Madidi, pero abarca cuatro áreas protegidas adicionales: Área Natural de Manejo Integrado Apolobamba, Territorio Indígena y Reserva de la Biósfera Pilón Lajas (de carácter nacional), el Área Protegida Municipal Ixiamas y el Área Protegida Municipal Pampas del Yacuma (como su nombre indica, las últimas corresponden al nivel municipal). También son parte de este gran paisaje 10 territorios indígenas: Marka CololoCopacabana- Antaquilla, Lecos de Apolo, Lecos de Larecaja, Mosetenes, Pilón Lajas (sobrepuesta completamente con la Reserva de la Biósfera), San José de Uchupiamonas, Tacana I, Tacana II y Tacana III así como el Territorio Indígena Araona; más de 8927 propiedades privadas individuales: pequeñas, medianas y estancias ganaderas, así como más de 10 concesiones forestales.

En el paisaje pueden distinguirse diversas unidades de gestión para la conservación: las áreas protegidas, los municipios y los territorios indígenas. Esta diversidad está representada por diferentes actores sociales. Un diagnóstico realizado en 2002 daba cuenta de la existencia de 22 entidades estatales de diferentes niveles, 61 organizaciones de la sociedad civil (en su sentido amplio) y más de 200 comunidades indígenas y campesinas, como actores sociales solo en jurisdicciones relacionadas con el PNANMI Madidi (Lehm, Salas, Salinas, Gómez, \& Lara, 2002).

A partir del año 2000, WCS realizó diversas acciones dando apoyo a las unidades de gestión priorizando las áreas protegidas, territorios indígenas y municipios.

Si bien WCS ha trabajado y trabaja en otros territorios indígenas o Tierras Comunitarias de Origen como Tacana II, Tierra Comunitaria de Origen y Reserva de la Biósfera Pilón Lajas, Lecos de Larecaja, Marka Antaquilla Cololo y San José de Uchipiamonas, esta sistematización se concentrará en el trabajo realizado por WCS en los territorios indígenas: 
Tacana I y Lecos de Apolo. Sin perder de vista el enfoque de conservación a nivel de paisaje, se hará referencia a las relaciones entre estos territorios indígenas y las otras unidades de gestión o actores sociales.

Como el lector podrá percatarse, la descripción del estudio de caso sobre el Paisaje Madidi en Bolivia tiene un carácter más general que contrasta con el detalle de los casos del Paisaje Yasuní en Ecuador y el área de Tamshiyacu-Tahuayo en Perú. Se debe a la mayor densidad de la información existente para este caso, así como al hecho de que las experiencias de gestión territorial indígena y manejo de recursos por las comunidades, especialmente en relación a la TCO Tacana I, han sido sistematizadas de manera detallada y publicadas recientemente. Véase (Painter, Siles, Reinaga, \& Wallace, 2013) (Lehm, 2016 a; 2016 b; 2016 c; 2016 d) (Lehm, Lara, \& Solares, 2017).

MAPA 1: GRAN PAISAJE MADIDI - TAMBOPATA

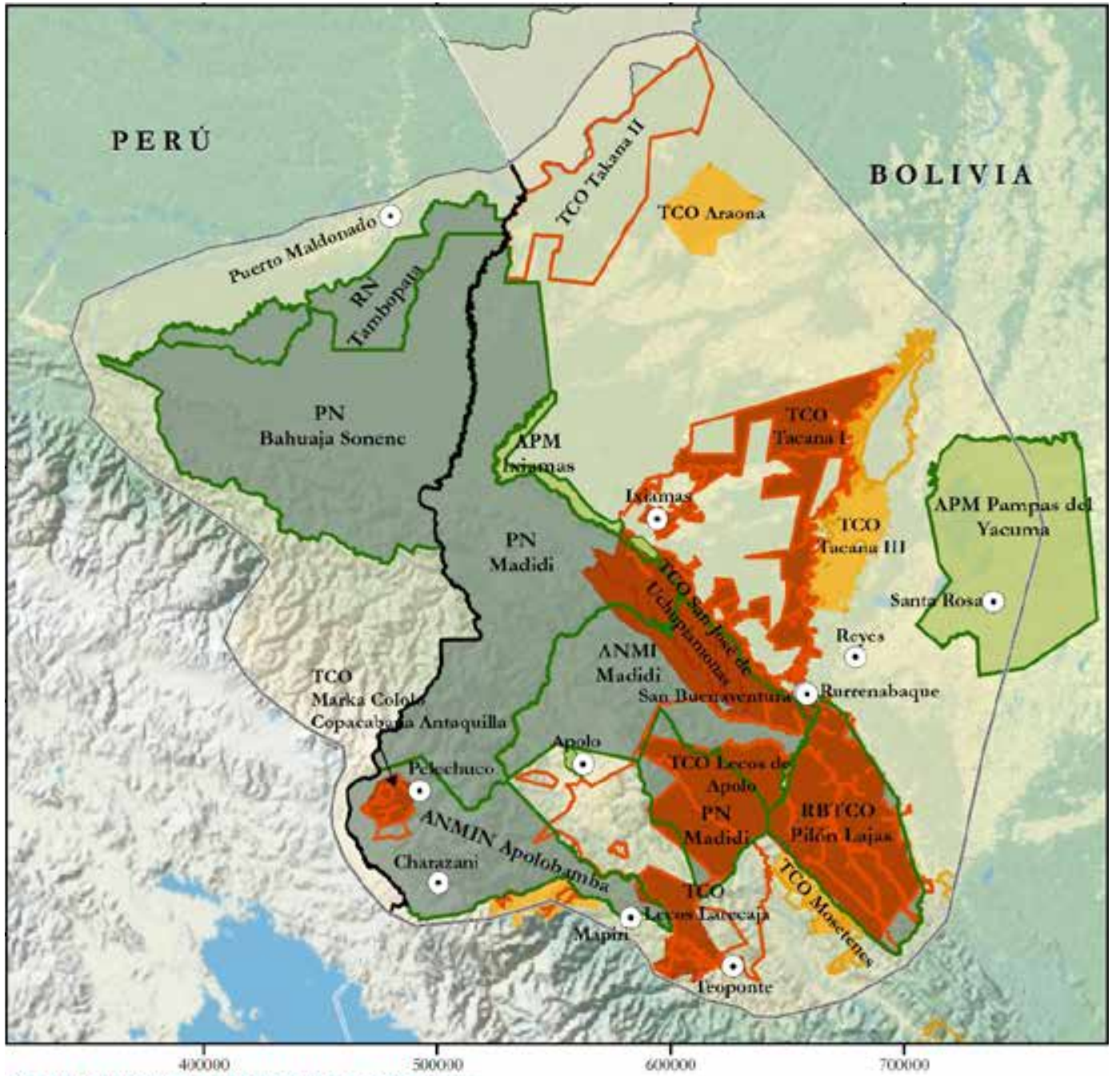

GRAN PAISAJE MADIDI-TAMBOPATA:

ÁREAS PROTEGIDAS Y TERRITORIOS INDÍGENAS

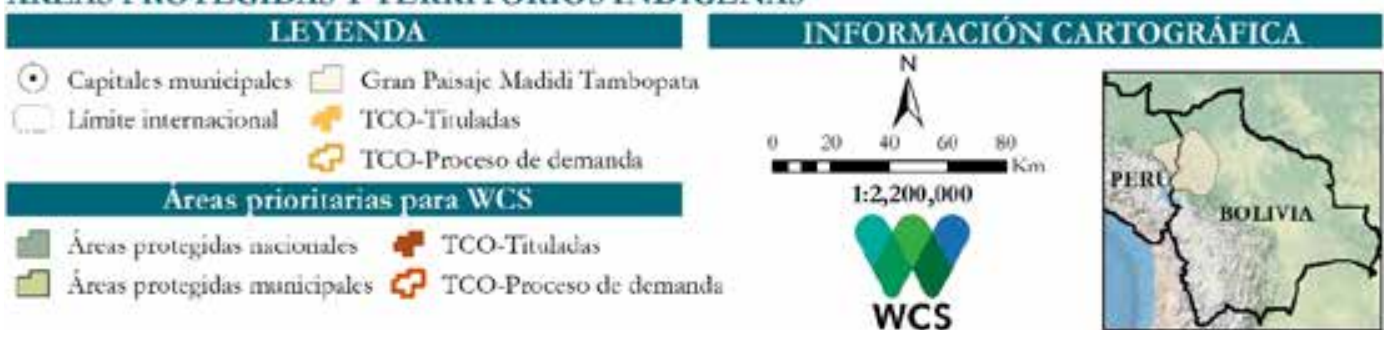


MAPA 2: GRAN PAISAJE MADIDI, ÁREAS PROTEGIDAS, TERRITORIOS INDÍGENAS, PROPIEDADES PRIVADAS Y CONCESIONES FORESTALES

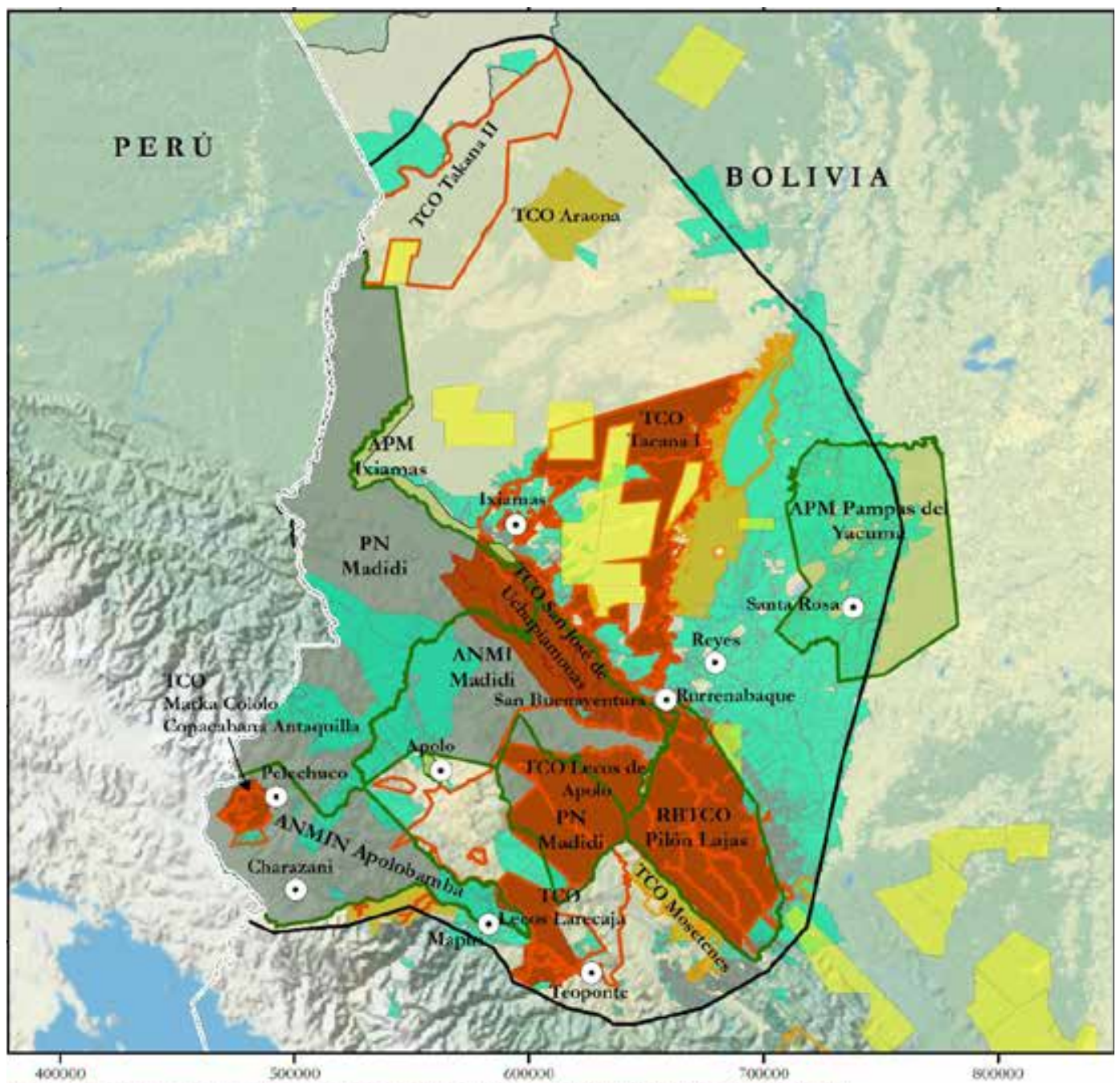

PAISAJE MADIDI: ÁREAS PROTEGIDAS, TERRITORIOS INDIGENAS, PROPIEDADES INDIVIDUALES Y CONCESIONES FORESTALES

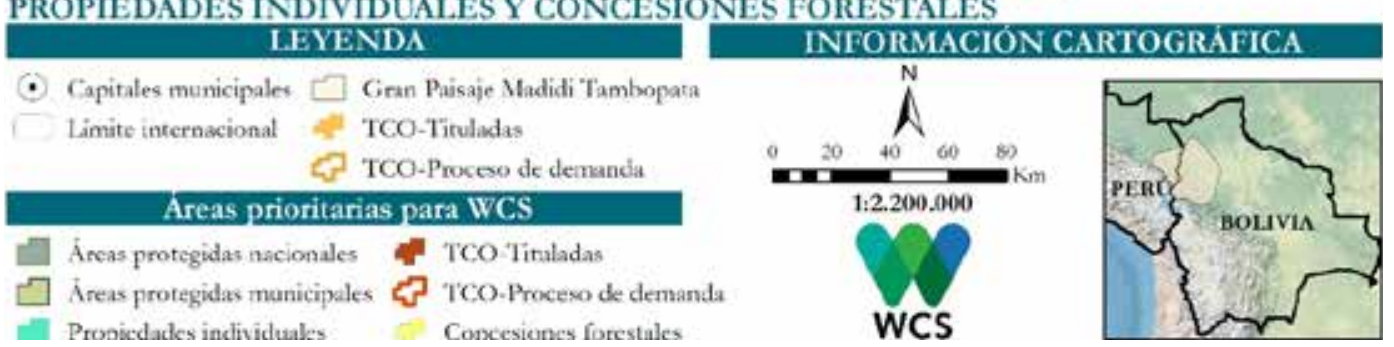


Por un lado, el Consejo Indígena del Pueblo Tacana (CIPTA) y por el otro, el Consejo Indígena del Pueblo Leco de Apolo (CIPLA) surgieron como organizaciones en 1993 y 1997 respectivamente (CIPTA - WCS, 2002; CIPLA, 2002). Este proceso organizativo se realizó en el contexto de emergencia de las organizaciones étnicas de la Amazonía en la década de 1960 con la Federación Shuar en Ecuador, el Congreso de Comunidades Amuesha y el Consejo Aguaruna - Huambisa en Perú. Posteriormente, a partir de los 1970, daría origen a las organizaciones de carácter étnico en cada uno de los nueve países de la Cuenca Amazónica y finalmente a la Coordinadora Indígena de la Cuenca Amazónica (COICA) (Smith, 1984; Chirif, 2015, págs. 14,15,252).

En relación con el pueblo indígena Tacana, en 1989, el sistema de organización mostraba comunidades con su propio sistema de autoridades, heredadas de periodos misionales del siglo XVIII. Aunque ya existía la Central Indígena del Oriente Boliviano (CIDOB), las comunidades tacanas no se habían articulado en un sentido vertical. Al mismo tiempo y al influjo de políticas estatales orientadas a la ocupación de la Amazonía o del Oriente de Bolivia, en lo que fuera el territorio ancestral del Pueblo Tacana, se incrementaba la población colonizadora proveniente de los Andes con sus propios sistemas de organización basados en sindicatos. De alguna manera, estas comunidades sí se articulaban verticalmente, aunque débilmente a través de subcentrales, centrales, federaciones y confederaciones, haciéndose parte de una importante organización nacional: la Central Obrera Boliviana (Wentzel, 1989, págs. 332, 350).

En términos de estructura organizativa, el surgimiento de CIPTA y CIPLA y posteriormente de la Central de Pueblos Indígenas de La Paz (CPILAP) significaba el surgimiento de eslabones orgánicos que aseguraron la articulación vertical de las comunidades indígenas con estructuras de segundo, tercer y cuarto nivel. En términos cualitativos este proceso de articulación se inició con reuniones entre representantes de las comunidades y el movimiento de algunos líderes que visitaron algunas comunidades hasta conformar un núcleo que dio origen a las estructuras anteriormente referidas. La construcción de redes verticales se inició con el reforzamiento de las redes horizontales entre comunidades.

Sin embargo, lo que aquí parece un proceso simple estuvo preñado de dificultades. En el caso del pueblo indígena Tacana pero más en el del pueblo Leco, el menosprecio por lo indígena había determinado que muchos rasgos de la cultura y sobretodo de la identidad se oscurecieran, se difuminaran, se ocultaran premeditadamente para evitar el estigma de ser considerados indígenas, que para el caso de las tierras bajas de Bolivia y en particular de la región oriental de los Andes, implicaba ser considerados "chunchos" o "salvajes". En el caso tacana, aproximadamente desde los años 1930, se establecieron algunas escuelas en la región en las que se castigaba a los niños por hablar su propio idioma.

En Bolivia, a partir de las reformas nacionalistas de los años 1950 se buscó desterrar del lenguaje y la práctica oficial el uso del término indio o indígena y se decretó que todos los pobladores del área rural eran campesinos. Con la dictación de la Reforma Agraria en 1953, se dispuso la disolución de los grandes latifundios y la dotación de la tierra a las comunidades y productores rurales en la calidad de campesinos. Si bien lo anterior se produjo centralmente en la región andina del país, esto implicó la sobrevaloración de la agricultura y la pecuaria como actividades económicas típicas de estas poblaciones campesinas. En esa condición se diseñó el sistema de dotación de las tierras, atendiendo en alguna medida a las particularidades regionales diferenciando a los Andes del Trópico, pero manteniendo a la agricultura como el atributo fundamental para la asignación de las tierras.

En este contexto, las poblaciones indígenas amazónicas, cuyos sistemas económicos se basan en el acceso y uso diverso de tierras y recursos naturales, quedaron excluidas o sus derechos recortados. A pesar de ello, con la finalidad de acceder al menos a una parte 
de la tierra, en muchos casos se asimilaron como campesinos y obtuvieron porciones de tierra estrictamente para su actividad agrícola, entre tanto, otras actividades como la caza, pesca y aprovechamiento de diversos recursos forestales se realizaban fuera de los predios que les habían reconocido en un contexto en el que todavía existía tierra disponible. Esto duró hasta que las políticas estatales promovieron la colonización del oriente con la finalidad de llenar un espacio, la Amazonía, a la que se había considerado como un espacio vacío.

La articulación de las comunidades para generar sistemas orgánicos de mayor escala implicó dificultosos y en alguna medida dolorosos procesos de re-identificación como indígenas y al mismo tiempo, en el marco de esta categoría, como unidades culturales específicas. Si en el caso de los tacanas, este proceso fue difícil, en el caso de los lecos fue peor. La población indígena leca se encontraba dividida en dos grandes facciones: los lecos de Larecaja y los lecos de Apolo, más en este segundo caso que en el primero, la población se había fundido casi completamente con población quechua y se encontraba articulada a los movimientos campesinos a través de las organizaciones sindicales. El tratar de diferenciarse en organizaciones que denotaran otra especificidad desató crecientes conflictos sociales.

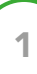

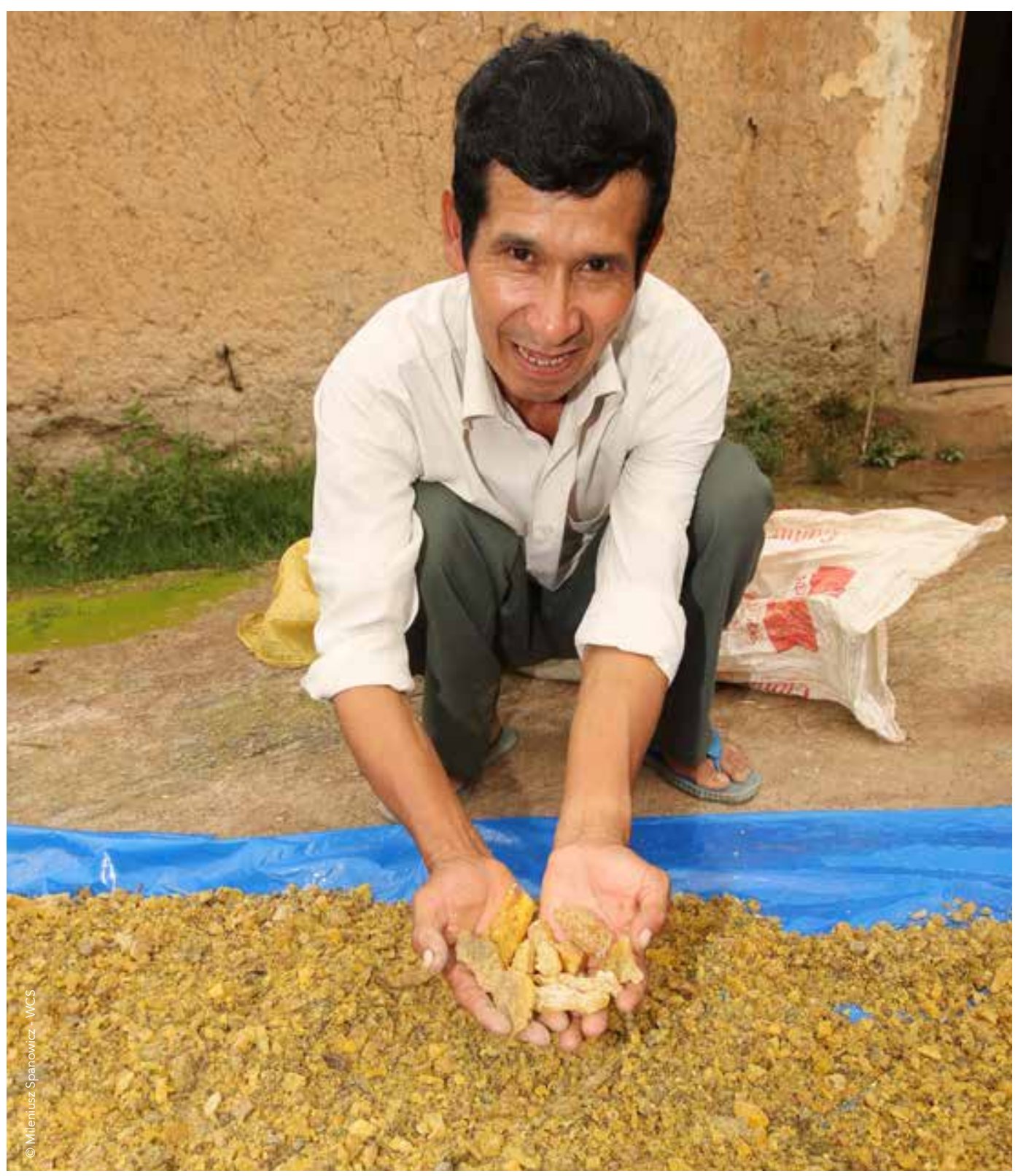




\section{LAS DEMANDAS Y TITULACIÓN DE TERRITORIOS INDÍGENAS}

En 1990, las organizaciones indígenas de las tierras bajas de Bolivia, protagonizaron un movimiento reivindicativo a través de una caminata que se conoció como la "Marcha Indígena por el Territorio y la Dignidad". Aunque no constituía la primera acción del movimiento indígena de las tierras bajas en procura del reconocimiento de sus tierras, éste se caracterizó por haber sido "amplificado" por los medios de comunicación. En este movimiento participaron algunos representantes tacanas, claramente identificados e identificables. Entre sus demandas exigían la reversión de concesiones forestales y expulsión de dragas mineras, en el primer caso debido a que se encontraban "devastando el bosque irracionalmente" y en el segundo "por estar contaminando irreversiblemente las aguas y destruyendo la vida acuática de la zona". Esta aparición en el escenario nacional destaca por sus reivindicaciones en favor de su integridad territorial y la protección del medioambiente.

Al influjo de este movimiento social en ascenso, en 1996, se promulgó una nueva ley agraria, mediante la cual se reconocía los territorios indígenas en su calidad de Tierras Comunitarias de Origen (TCO), las mismas que para llegar a ser tituladas deberían basarse en demandas planteadas por organizaciones representativas de los pueblos indígenas, pasar por un proceso de saneamiento de las tierras, lo que implicaba la identificación del dominio real y legal de las propiedades de terceros y finalmente, como consecuencia de lo anterior, sobrevendría la titulación.

El Consejo Indígena del Pueblo Tacana (CIPTA) y la Central Indígena del Pueblo Leco de Apolo (CIPLA) presentaron sus respectivas demandas en 1997. El primero lo haría sobre una superficie de 769892 ha y la segunda sobre 654136 ha (CIPTA - WCS, 2002; CIPLA, 2010). Sin embargo, el engorroso proceso de saneamiento determinaría que hasta el año 2000 estos procesos avanzaran muy lentamente.

Es, en estas circunstancias, que WCS inicia más intensamente acciones en la región. Entre ellas, el apoyo al Servicio Nacional de Áreas Protegidas (SERNAP) para la conservación del PNANMI - Madidi. Bajo el enfoque de conservación a través de los "paisajes vivientes", WCS establece que la conservación del área protegida y las especies de vida silvestre podría ser viable solo si se involucraban también las áreas de su entorno. Los territorios indígenas, dada su extensión, constituían una oportunidad. Sin embargo, para hacer esto posible era necesario apoyar a las organizaciones indígenas para que sus demandas territoriales sean reconocidas y tituladas por el Estado, y se requería una base sólida para asegurar las acciones en vistas a hacer posible la conservación.

Pronto se vería que la articulación de una alianza entre una entidad orientada a la conservación como WCS y las organizaciones indígenas no era tarea fácil. Las organizaciones tenían sus propias agendas. Como se vio, en el caso tacana, por un lado, demandaban que actores extractivistas como madereros y mineros abandonasen su región y denunciaron los daños ambientales que estaban provocando. Por otro lado, sostenían claramente la necesidad de desarrollo para sus comunidades, tanto en términos de alternativas económicas como en relación al acceso a los servicios básicos. Adicionalmente, malas experiencias de relacionamiento con alguna ONG que trabajaba en la zona, determinaron que vieran con desconfianza a cualquier institución no gubernamental. La reivindicación más profundamente sentida era la del reconocimiento de sus territorios por el Estado boliviano.

WCS planteó la posibilidad de apoyarles en la elaboración de un plan de manejo de la fauna silvestre, la contraparte indígena argumentaba que para cuidar la fauna silvestre y otros recursos requerían la seguridad jurídica sobre su territorio. Finalmente, se forjaron acuerdos formales sobre esas bases. 
La titulación de los territorios indígenas supuso un conjunto de acciones relacionadas con la asistencia legal, capacitación y movilización para acompañar y asegurar una participación adecuada de las organizaciones indígenas durante el largo proceso de saneamiento y titulación a cargo de la entidad encargada de los procesos agrarios: el Servicio Nacional de Reforma Agraria (INRA), en un contexto de intensos conflictos sociales.

Por un lado, el proceso de saneamiento, requirió el fortalecimiento de las relaciones entre comunidades y de estas con sus líderes territoriales, es decir, de las redes sociales horizontales y verticales de tipo vínculo, entre niveles que compartían cierta homogeneidad étnica y cultura, profundizándose el proceso de auto-identificación como indígenas sean tacanas o lecos, cada uno por su lado. El reforzamiento de las identidades tacana y leca se forjó en los conflictos que tuvieron que enfrentar con colonizadores, otros campesinos, gobiernos municipales y aún una que otra ONG adversa a las demandas territoriales indígenas, así como con los propios funcionarios del INRA y las empresas que habían contratado para el saneamiento de las tierras indígenas.

Por otro lado, los procesos de saneamiento y titulación de las TCOs generaron sólidos vínculos "tipo puente" entre las organizaciones indígenas y la entidad de conservación. Esta relación se forjó en las vertiginosas corrientes de la conflictividad social en la que tanto las organizaciones indígenas como WCS se vieron lanzadas teniendo que lidiar con poderosos sectores políticos y sociales.

En el caso tacana, hasta 2008 se alcanzó titular 389304 ha a favor de las veinte comunidades tacanas representadas por CIPTA. De acuerdo a un Estudio de Necesidades Espaciales realizado por la instancia estatal competente, deberían titularse 405665 ha (CIPTA - CIMTA, 2014). En el caso del pueblo Leco de Apolo, hasta 2007 se tituló una superficie de 238162 ha, faltando 190088 ha por titularse a favor de 17 comunidades representadas por CIPLA (CIPLA, 2009). En el conjunto del "Paisaje Madidi", WCS ayudó a diferentes organizaciones indígenas en la titulación de más de 700000 ha (WCS, 2017).

\section{PLANIFICACIÓN PARA LA GESTIÓN TERRITORIAL INDÍGENA}

Entre 2000 y 2001, CIPTA y WCS encararon la elaboración de una Estrategia de Desarrollo Sostenible con Base en el Manejo de los Recursos Naturales constituyó la primera acción para establecer la Gestión Territorial Indígena por el pueblo Tacana en su territorio. Se realizó simultáneamente al apoyo para la titulación de la TCO Tacana I.

El propósito de WCS fue proporcionar a la organización indígena de un instrumento que le permitiera identificar objetivos, lineamientos y acciones sobre la base del relevamiento de demandas y propuestas que provenían desde las comunidades. Para ello, colaboró con CIPTA en desarrollar una metodología que permitiera recoger la información y las prioridades en cada una de las 20 comunidades representadas por él.

Una vez más, esta fase de la planificación permitió fortalecer aún más las redes verticales de la organización, relacionando a las dirigencias del CIPTA con sus comunidades. Se conformó un equipo técnico mixto entre dirigentes y personal técnico de WCS. El equipo estuvo a cargo de una especialista social con su contraparte de la dirigencia indígena $y_{\text {, }}$ asimismo, cada uno de los cuatro especialistas técnicos (en agronomía, biología, ingeniería

8 La Gestión Territorial Indígena puede comprenderse como un proceso antiguo y nuevo de apropiación social, económica y cultural del territorio. Desde sus ancestros, a través de diferentes prácticas de distinto orden, los Pueblos Indígenas han ejercido su territorialidad, sin embargo, dadas las condiciones de invasión de sus territorios e inserción mercantil se hizo necesario el desarrollo de renovadas formas de apropiación y gobernanza sobre los territorios a las que se ha denominado Gestión Territorial Indígena. Para Bolivia, este proceso es descrito y conceptualizado en: (CIDOB, 2008; Muiba Núñez, Loayza Cossio, Durán Laura, \& Gonzales Buitrago, 2011; Lehm, 2015). 
forestal y antropología) contó con su contraparte indígena. Este equipo recorrió todas y cada una de las comunidades de la TCO Tacana I facilitando talleres y aplicando un conjunto de herramientas participativas que fueron previamente diseñadas. Al finalizar el recorrido por las comunidades, un proceso de compatibilización de la información y las demandas comunales permitió la producción del documento de planificación a nivel de toda la TCO y se desarrollaron varios talleres entre representantes de las comunidades con la finalidad de validar el producto final.

En el caso del pueblo Leco, el proceso de elaboración del Plan de Vida se desarrolló entre 2007 y 2009 (CIPLA, 2010). En este caso, el equipo técnico profesional estuvo conformado por personal técnico de la Confederación Indígena del Oriente de Bolivia (CIDOB). El proceso tuvo una duración mayor que en el caso tacana. Siguió el mismo procedimiento de elaborar Diagnósticos Rurales Participativos a nivel de cada comunidad para finalmente, agregando y compatibilizando la información dar lugar a un instrumento de planificación a nivel de toda la TCO Leco de Apolo. Este proceso, también contribuyó a la construcción y fortalecimiento de las redes horizontales entre comunidades, además, al haber involucrado a la CIDOB, la red vertical se ampliaba ya no solo al nivel local y departamental sino al nivel nacional.

El proceso de planificación para hacer efectiva la gestión territorial no se agotó en la formulación de la Estrategia de Desarrollo Sostenible con Base en el Manejo de los Recursos Naturales o del Plan de Vida del Pueblo Leco, sino que, para lograr desarrollar una cultura de planificación entre las organizaciones indígenas, WCS proveyó los recursos técnicos y financieros para capacitar y asistir a las organizaciones indígenas en los procesos de planificación más operativa sea anual o incluso mensual, la elaboración de los informes de gestión, el monitoreo, la evaluación y la sistematización de las experiencias. La reiteración de estas actividades durante varios años consecutivos buscó y encontró la forma de desarrollar habilidades y crear hábitos de planificación y rendición de cuentas de las dirigencias a las bases comunitarias.

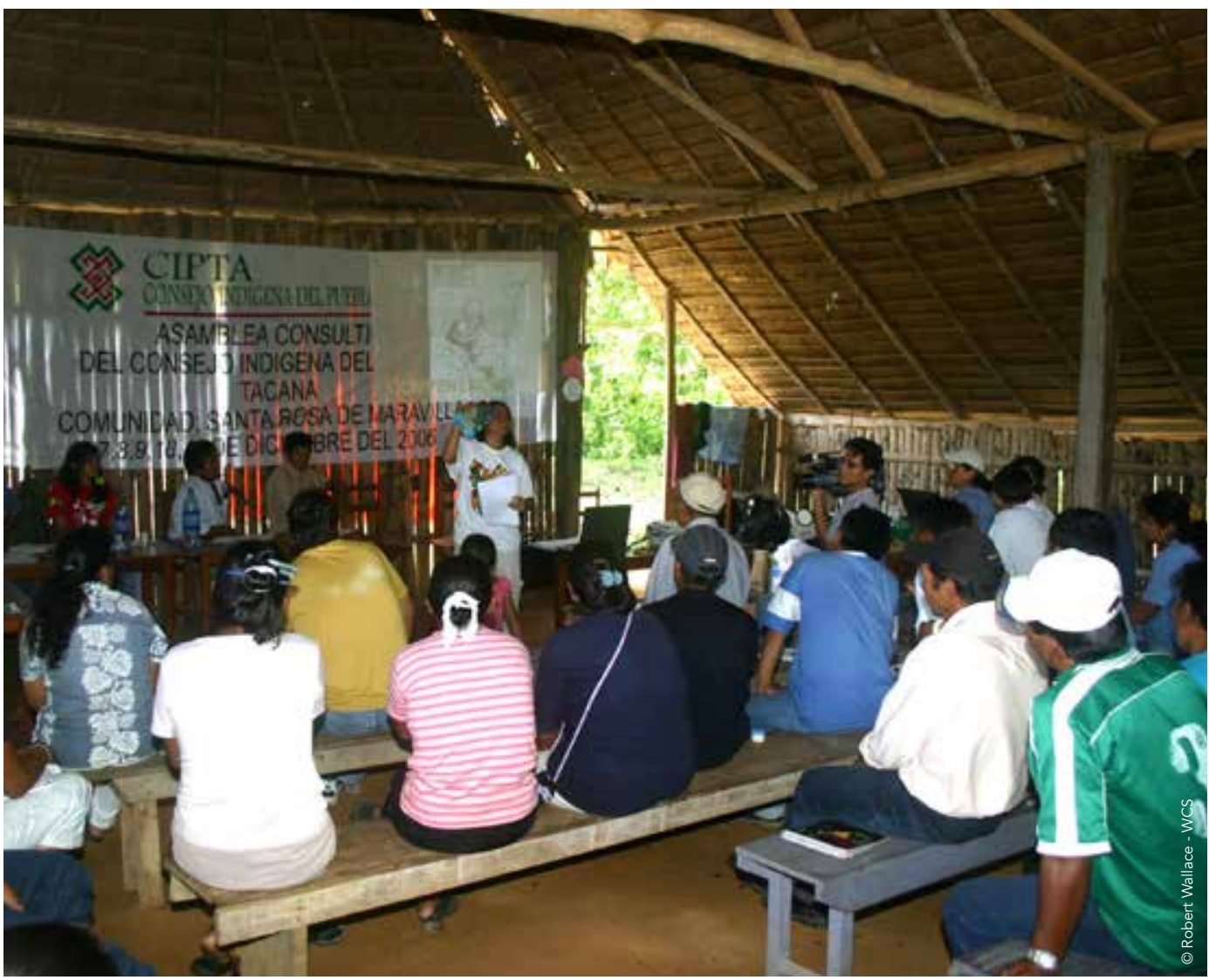




\section{PROCESOS DE ZONIFICACIÓN Y LA ARTICULACIÓN ENTRE TERRITORIOS INDÍGENAS Y ÁREAS PROTEGIDAS: LOS CORREDORES DE VIDA SILVESTRE Y LA CONECTIVIDAD ENTRE ECOSISTEMAS Y UNIDADES DE GESTIÓN A NIVEL PAISAJE}

La tensión entre el desarrollo, anhelado por las organizaciones y comunidades indígenas, y la conservación podía ser resuelta a través de procesos de zonificación de los territorios indígenas. A esta premisa apostó WCS en su trabajo con las organizaciones y comunidades tacanas y lecas. El proceso de elaboración de la Estrategia de Desarrollo con Base en el Manejo de los Recursos Naturales implicó el ordenamiento del espacio para asegurar que las acciones contenidas en la Estrategia tuvieran una definición clara acerca de donde deberían desarrollarse asegurando su sostenibilidad.

De esta manera, tanto en el caso de los tacanas como de los lecos, las metodologías para la elaboración de los Diagnósticos Rurales Participativos que darían lugar a la Estrategia y al Plan de Vida a nivel territorial, incorporaron técnicas relacionadas con el mapeo y transectos participativos logrando identificar, con mucho detalle, las diferentes áreas de uso de los recursos en cada una de las comunidades, asimismo, las expectativas de usos que en ese momento las comunidades no realizaban, pero esperaban realizar, tales como el turismo.

Debido a que los límites entre varias comunidades no eran definitivamente claros, como resultado de la flexibilidad de los sistemas tradicionales de acceso y uso de los recursos naturales, el desafío sobrevendría al tratar de compatibilizar los usos en áreas sobrepuestas entre comunidades donde algunas proponían un uso y otras, otro. Sobre la base de una tabla de priorización por pares, técnica participativa de los DRP, WCS diseñó una matriz a la que se denominó de compatibilidad de usos. Consistía en comparar sistemáticamente cada tipo de uso, señalando si eran completamente compatibles, compatibles con manejo o no compatibles. Esta matriz, aplicada con anterioridad a la definición de los usos en el espacio, se convertiría en un instrumento de negociación y administración de conflictos entre comunidades, facilitando la zonificación a nivel del territorio mancomunado.

Una vez más, la zonificación demandaba reuniones y talleres entre comunidades y entre estas y sus dirigentes, convirtiéndose en otro vehículo que haría posible el fortalecimiento de las redes sociales horizontales y verticales. Este tipo de redes construidas progresivamente eran de tipo vínculo, es decir, entre unidades socio-culturales relativamente homogéneas. Entre 2001 y 2002, WCS realizó investigaciones relacionadas con las "especies paisaje" del Gran Paisaje Madidi específicamente relacionadas con la suficiencia en términos de extensión, calidad y diversidad de hábitats para los troperos (Tayassu pecari) y jaguares (Pantera onca), mostrando que probablemente el PNANMI Madidi, a pesar de su gran extensión, no sería suficiente para conservar poblaciones viables de estas especies. Al principio, se logró identificar dos corredores de conexión entre el PNANMI Madidi y la TCO Tacana I (Gómez, Espinoza, \& Wallace, 2002). Posteriormente, fueron identificados 28 corredores relacionados con la TCO Tacana I, seis de los cuales fueron críticos para la conexión entre la TCO y el PNANMI - Madidi.

Simultáneamente, a fines de sustentar la superficie necesaria para la titulación de la TCO Tacana I, se relevó información sobre el consumo de la carne de fauna silvestre entre los hogares de la TCO, dando cuenta de que sin la conservación del PNANMI Madidi y los corredores de conexión entre ambas unidades de manejo, sería imposible mantener en el largo plazo, la fuente de proteínas que, a través de la cacería de subsistencia, requería la población indígena. Así planteada la problemática al CIPTA y a las comunidades tacanas, estas decidieron: 1) desplegar todos los esfuerzos posibles para asegurar que los corredores quedaran dentro de la TCO durante el proceso de titulación y 2) designar a estas áreas, la condición de reservas con altas limitaciones de uso, en la zonificación de su territorio (CIPTA y WCS, 2009). 
Este constituye un ejemplo sobre cómo, por un lado, los estudios biológicos y el estudio de las necesidades de la población local, en este caso, la provisión de proteína a través de la cacería y por otro su difusión y análisis en los diferentes niveles de la organización indígena, produjeron acciones de conservación lideradas por la población local.

\section{CONSTRUCCIÓN DE REDES SOCIALES VERTICALES Y HORIZONTALES DE TIPO "PUENTE": GESTIÓN COMPARTIDA EN ÁREAS SOBREPUESTAS ENTRE TERRITORIOS INDÍGENAS Y ÁREAS PROTEGIDAS}

El enfoque de conservación a nivel de paisaje, intrínsecamente exige la vinculación entre unidades de gestión y actores sociales diferentes. Para WCS, este enfoque implicó desarrollar complejas líneas de acción para vincular al PNANMI Madidi con los territorios indígenas. Como se vio, un aspecto estaba referido a la necesidad de conservar la conectividad entre estas unidades de gestión, pero, además, tanto en el caso de la TCO Tacana I y aún más en el caso de la TCO Leco de Apolo existen superposiciones territoriales con el PNANMI Madidi. En el primer caso, el Área de Manejo Integrado se superpone a la TCO en una superficie de 26746 ha y el Parque Nacional en 12683 ha, haciendo un total de 39429 ha sobrepuestas entre el territorio indígena Tacana y el área protegida, lo que significa el $10 \%$ de la TCO titulada hasta 2008.

En el caso del territorio indígena Leco de Apolo, la superposición del PNANMI Madidi asciende a 231638 ha y constituye el 97 \% de la TCO titulada hasta 2007, a favor del pueblo indígena Leco de Apolo (CIPLA, 2010; Muiba Núñez, Loayza Cossio, Durán Laura, \& Gonzales Buitrago, 2011)?.

En 2002, en circunstancias en que WCS apoyaba al PNANMI Madidi para la elaboración de su Plan de Manejo, se desarrollaron las primeras acciones de compatibilización tanto de la Estrategia de Desarrollo tacana como del Plan de Manejo del PNANMI Madidi. En el proceso participaron tanto el Director del Área Protegida y miembros de su equipo técnico como los dirigentes del CIPTA y representantes de las comunidades cuyas áreas de uso estaban sobrepuestas con el área protegida. Dos aspectos se buscaron compatibilizar: las zonificaciones de ambas unidades de gestión y las acciones en las cuáles ambos actores requiriesen coordinar o apoyarse mutuamente.

Se puede considerar que se estaban dando pasos para la construcción de una red social tipo "puente" entre actores diferentes: el Estado y las organizaciones indígenas. Aquí es necesario destacar que, en Bolivia, al igual que en muchos países de América Latina, la población local y en particular los pueblos indígenas tienen marcadas desconfianzas en las autoridades estatales. ¿Cómo era posible construir esta relación? Uno de los factores clave sería que tanto las organizaciones indígenas como el Servicio Nacional de Áreas Protegidas contaban con instrumentos de gestión tales como la Estrategia, el Plan de Manejo y sus respectivas zonificaciones.

La posesión de los instrumentos de gestión por cada una de las partes implicadas en la relación, contribuía a un escenario en el que al reducir la incertidumbre se reducían los niveles de desconfianza. Estos instrumentos daban seguridad a las partes para conocer los límites de lo negociable a partir de tener claramente identificadas sus prioridades e intereses.

9 En Bolivia, la Ley del Medio Ambiente aprobada en 1992, el Reglamento de Áreas Protegidas y más recientemente una nueva Constitución Política del Estado de 2009 establecen la compatibilidad entre territorios indígenas y áreas protegidas, por lo que admite la titulación de Tierras Comunitarias de Origen en Áreas Protegidas, es más la nueva Constitución establece la Gestión Compartida entre el Estado y los pueblos indígenas allí donde exista superposición. 
De hecho, durante uno de los talleres relacionados con la compatibilización entre el Plan de Manejo del PNANMI Madidi y la estrategia tacana, una vez que el Director del Parque dio su explicación, uno de los dirigentes del CIPTA señaló:

"Deseo recalcar la importancia de su explicación, pero quisiera compartir el trabajo que nosotros también tenemos. Quisiéramos ver si hay compatibilidad y ver qué podemos hacer conjuntamente. Siempre pensando que el Parque y la TCO deberían estar juntos" (Darío Chuqui, Secretario de Tierra y Territorio del CIPTA) (WCS, 2002, pág. 6) (El resaltado en negrillas es nuestro).

Aún de manera más profunda, WCS consideraba el Plan de Manejo del Área Protegida como un acuerdo social para la conservación del área (WCS, 2002, pág. 6). De ahí que la metodología que WCS ayudó a delinear para la elaboración del Plan de Manejo, se basaba, al igual que se había hecho en la TCO Tacana, en la consulta y la facilitación de diagnósticos participativos y planes en cada una de las más de 50 comunidades relacionadas con el PNANMI Madidi. Con la experiencia en la TCO Tacana I, se utilizó la "matriz de compatibilidad de usos de los recursos naturales" como instrumento para la resolución de conflictos. Con ello, se buscaba integrar las demandas comunales, recogidas desde abajo, en la planificación del área protegida. De esta manera, el actor estatal, pero sobretodo las comunidades y sus organizaciones llegaban a las negociaciones con aspectos bastante precisos para resolver.

Un desafío mayor constituía la construcción de una relación sistemática y más profunda entre el SERNAP y el pueblo indígena Leco de Apolo, precisamente en atención a la mayor superficie sobrepuesta entre la TCO y el PNANMI Madidi. Este desafío sería encarado por WCS a través del apoyo, tanto al SERNAP como a las organizaciones indígenas en sus diferentes niveles orgánicos, para la construcción de una propuesta de gestión compartida de las áreas protegidas y territorios indígenas sobrepuestos.

\section{Construyendo una propuesta de gestión compartida entre los pueblos indígenas y el Servicio Nacional de Áreas Protegidas}

Para comprender la importancia y la magnitud del desafío de construir una propuesta de gestión compartida entre los pueblos indígenas y el Servicio Nacional de Áreas Protegidas es necesario remitirse al hecho de que, en Bolivia, en 1992, se promulgara una Ley del Medio Ambiente, mediante la cual el Estado reconoció la compatibilidad entre territorios indígenas y áreas protegidas. En atención a esta determinación, la legislación agraria, reformulada en 1996, tuvo la potestad de titular territorios indígenas en las áreas protegidas. De esta manera, de 22 áreas protegidas de orden nacional, 14 tienen algún tipo de superposición con territorios indígenas.

Por otro lado, desde su creación, se estableció la participación de la población local, como un principio del Sistema Nacional de Áreas Protegidas. Dos mecanismos fueron considerados para hacer posible la participación de la población local y la sociedad civil: los Comités de Gestión y los contratos de coadministración. En el primer caso, se trata de una instancia de participación de autoridades y actores locales que se relacionan con la Dirección del Área Protegida. Los Comités de Gestión constituyen instancias consultivas para la toma de decisiones, pero esta última en definitiva es privilegio del Estado.

La segunda, se basa en contratos formales entre el Servicio Nacional de Áreas Protegidas y entidades de la sociedad civil sean organizaciones indígenas, entidades académicas, instituciones privadas, mediante los cuales, el Estado comparte (no cede, ni delega) las 
entidades coadministradoras importantes capacidades gerenciales, técnicas, financieras y de relacionamiento con la población local (Mason, y otros, 2004).

Aunque entre 1995 y 2005, dos áreas protegidas sobrepuestas a territorios indígenas fueron coadministradas por organizaciones indígenas, la propiedad colectiva de los territorios indígenas plantea una problemática que no se resuelve ni con los Comités de Gestión, en los que participan una diversidad de actores junto con los propietarios de las tierras y entre esta diversidad se incluyen actores con posiciones frecuentemente enfrentadas a los territorios indígenas e incluso a los objetivos de las áreas protegidas, ni por los Contratos de Coadministración, cuya definición está basada más en las capacidades técnicas y financieras de las entidades coadministradoras que en los derechos territoriales de los pueblos indígenas.

Frente a esta situación, la Confederación Indígena de Bolivia (CIDOB), máxima instancia nacional de los pueblos indígenas de las tierras bajas de Bolivia, en 2007, suscribió un convenio con el Viceministerio de Biodiversidad, Recursos Forestales y Medio Ambiente (VBRFMA), el Servicio Nacional de Áreas Protegidas (SERNAP) y la CIDOB con el objetivo de:

"Trabajar conjuntamente en el desarrollo, promoción e implementación de la gestión compartida de las áreas protegidas del SNAP, como un instrumento para la conservación del patrimonio natural y cultural existente en las mismas, así como para el desarrollo económico y social y la consolidación de los derechos territoriales de los pueblos y comunidades indígenas de las áreas protegidas, relacionadas orgánicamente con la CIDOB" (VBRFMA; SERNAP y CIDOB, 2007, pág. 2).
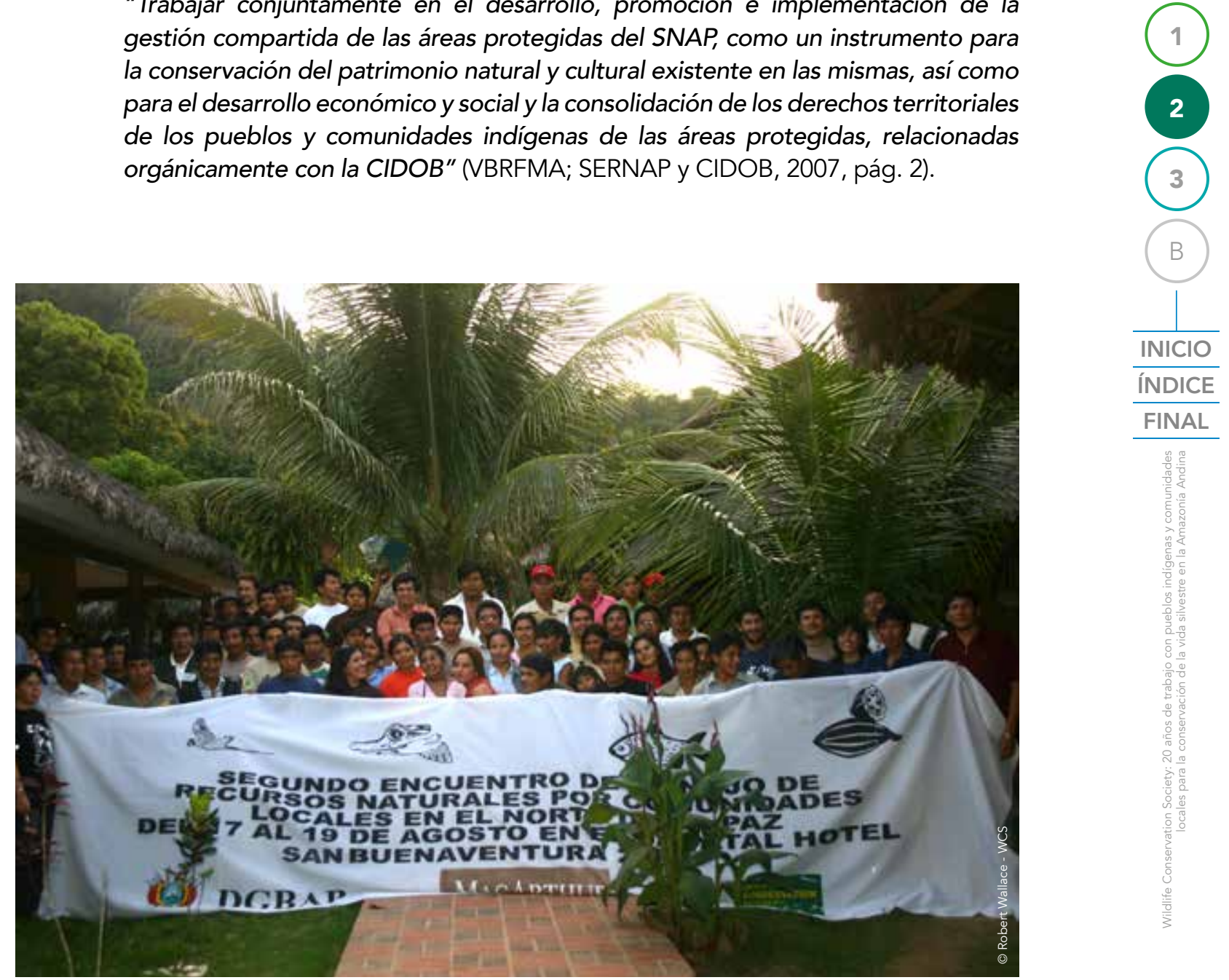
Entre los ámbitos de trabajo conjunto destacan el desarrollo de un modelo de Gestión Compartida y el apoyo mutuo para la inclusión del concepto de Gestión Compartida en la nueva Constitución Política del Estado y la modificación de la legislación anterior de acuerdo a los nuevos preceptos constitucionales ${ }^{10}$.

Como resultado, el artículo 385 Num. II, la Nueva Constitución Política del Estado Plurinacional establece:

"II. Donde exista sobreposición de áreas protegidas y territorios indígena originario campesinos, la gestión compartida se realizará con sujeción a las normas y procedimientos propios de las naciones y pueblos indígena originaria campesinos, respetando el objeto de creación de estas áreas" (Estado Plurinacional de Bolivia, 2009, pág. 92).

En este contexto, CIDOB solicitó a WCS apoyo técnico para que, en colaboración con su propio equipo técnico, facilitara la elaboración de una "Estrategia de la Confederación Indígena del Oriente Boliviano (CIDOB) para la Gestión Compartida del Sistema Nacional de Áreas Protegidas". La estrategia de CIDOB define un marco institucional y estratégico para que los Pueblos Indígenas específicos en coordinación con las Direcciones de las Áreas Protegidas desarrollen mecanismos adecuados para la Gestión Compartida (CIDOB, 2008).

En el caso de PNANMI Madidi, la gestión compartida demandaría un proceso de concreción en los niveles departamental y local. En un contexto, en el que algunos actores sociales de orientación urbana intentaban una propuesta de gestión del PNANMI Madidi por los gobiernos municipales, nuevamente, el apoyo técnico de WCS en Bolivia fue requerido por la Central de Pueblos Indígenas de La Paz (CPILAP) que representa a cinco pueblos indígenas del norte paceño: tacanas, lecos, mosetenes, ese ejjas y t'simanes 11, para elaborar una propuesta de gestión compartida entre el SERNAP y los pueblos indígenas.

De esta manera, entre 2005 y 2007 se construyó una Propuesta de Cogestión del Parque Nacional y Área Natural de Manejo Integrado Madidi de la Central de Pueblos Indígenas de La Paz (CPILAP), para ello, se realizaron varios eventos locales, nacionales e internacionales (Central de Pueblos Indígenas de La Paz, 2009, págs. 28-29).

La cogestión fue definida por CPILAP como:

"una instancia privilegiada de participación, conformada por actores sociales con derechos territoriales pre constituidos sobre la jurisdicción de las áreas protegidas, que tienen visiones compartidas respecto a su existencia y conservación y que asumen su gestión en corresponsabilidad con el Estado, con capacidad de decisión en los ámbitos político, estratégico y normativo" (Central de Pueblos Indígenas de La Paz, 2009, pág. 30).

10 En Bolivia, entre 2006 y 2007, año del convenio, sesionó una Asamblea Constituyente que elaboró una Nueva Constitución del Estado Plurinacional de Bolivia, aprobada a fines de 2007 fue sometida a un referéndum constitucional y entró en vigencia a partir de 2009.

11 Las organizaciones de segundo nivel, a las que representa la CPILAP son: Consejo Regional T'simane Mosetene (CRTM) de Pilón Lajas, Consejo Indígena del Pueblo Tacana (CIPTA), Organización Indígena del Pueblo Mosetene (OPIM), Central Indígena del Pueblo Leco Aguachile de Apolo (CIPLA), Pueblo Indígena Leco y Comunidades Originarias de Larecaja (PILCOL), Organización del Pueblo Indígena Quechua Tacana de San José de Uchupiamonas (OPIQT-SJU), Comunidad Agroecológica Originaria Mosetene de Palos Blancos y Comunidad Ese Ejja de Eyiyoquibo (Central de Pueblos Indígenas de La Paz, 2008) 
En el documento, se refiere a un nuevo enfoque acuñado por el Estado relativo a "áreas protegidas de la gente" (Central de Pueblos Indígenas de La Paz, 2009), denotando el reconocimiento de los derechos de los pueblos indígenas, este concepto constituye un importante argumento para reforzar la gestión compartida. Relacionando esto con los paradigmas de conservación y la población local y específicamente en relación a los pueblos indígenas es posible la combinación conceptual de "áreas protegidas de la gente" y "conservación por la gente" como atributos de la Gestión Compartida.

El planteamiento más importante de la Propuesta de Cogestión de CPILAP es la creación de un mecanismo o instancia institucional que se ubica por encima de la Dirección del PNANMI Madidi y está conformada por las organizaciones que representan a los titulares de derechos territoriales pre-constituidos. Al mismo tiempo, destaca el relacionamiento con otras instancias de participación como el Comité de Gestión, la Coordinadora Interinstitucional y prevé también la incorporación de entidades que, bajo convenios o contratos de coadministración, pudiesen hacerse cargo de implementar aspectos programáticos de la gestión del área.

Un tercer nivel de concreción de la gestión compartida entre pueblos indígenas y el Estado en relación a las áreas protegidas, fue desarrollado por la Central Indígena del Pueblo Leco de Apolo. En noviembre de 2009, dos instrumentos de gestión territorial fueron comparados, la zonificación contenida en el Plan de Vida del Pueblo Leco y la zonificación del Plan de Manejo del PNANMI Madidi. Con la participación de dirigentes y sus equipos técnicos y las autoridades del SERNAP, WCS facilitó el proceso técnico de comparación de ambos instrumentos. Se identificaron incompatibilidades en al menos nueve áreas. El proceso consistió en el análisis de cada área una por una, cada parte en la negociación presentó sus justificaciones sobre los usos que habían establecido.

En síntesis, de las nueve zonas con incompatibilidad de usos entre la zonificación del PNANMI Madidi y el territorio indígena Leco de Apolo, en seis, el PN decidió ajustar su zonificación y en tres de ellas, el CIPLA. En general, las áreas cuyos usos estuvieron en discusión tenían que ver con: 1) el reconocimiento de áreas de uso tradicional que no fueron consideradas en la zonificación del PN Madidi, 2) reconocimiento de áreas de uso comercial condicionadas al aprovechamiento bajo planes de manejo. En el caso de CIPLA, las áreas observadas no eran áreas tradicionales de uso sino nuevas y además propuestas para usos agrícolas y nuevos asentamientos, fueron convertidas a zonas de protección de fauna y flora y de turismo, usos más amigables con la conservación y compatibles con las zonas de conservación estricta del PN (SERNAP/Madidi y CIPLA, 2009).

Finalmente, este proceso entre CIPLA y la Dirección del PNANMI Madidi incluyó la elaboración de un plan conjunto para la protección del área sobrepuesta entre el PN y el Territorio Indígena. La elaboración de este plan se basó en la identificación de amenazas actuales y potenciales comunes representadas espacialmente, la identificación de acciones prioritarias para enfrentarlas, el establecimiento de responsabilidades de cada una de las partes para la implementación de las acciones prioritarias y finalmente, un conjunto de recomendaciones sobre la modalidad cómo debían ejecutarse las acciones.

Recogiendo toda la experiencia, entre 2010 y 2011, WCS y CIPLA, con el apoyo del Programa de Investigación Estratégica en Bolivia, desarrollaron una propuesta de modelo de Gestión Territorial con Responsabilidad Compartida para el área sobrepuesta entre el PNANMI Madidi y el territorio indígena Leco de Apolo, el proceso contó con la participación de la Dirección y el equipo técnico del PNANMI Madidi.

Esta propuesta, la más completa, logra un desarrollo más profundo de los conceptos de modelo, gestión territorial indígena y de áreas protegidas. En tanto modelo, se trata de una construcción teórica, un sistema abstracto que basado en datos de la realidad es útil para orientar la acción social. 
Plantea una propuesta de institucionalidad entre la CIPLA y el SERNAP específicamente para la gestión del área sobrepuesta entre el PNANMI Madidi y el territorio indígena Leco de Apolo. Esta estructura se basa en una instancia de toma de decisiones al máximo nivel conformada por la Dirección de PNANMI Madidi y el Capitán Grande del pueblo Leco de Apolo, máximo cargo en la estructura de la CIPLA, una instancia técnica constituida por los equipos técnicos de ambas instituciones y una instancia operativa. Asimismo, establece una instancia de supervisión, seguimiento y evaluación conformada por las instancias superiores tanto del SERNAP como de las organizaciones indígenas.

En atención a que ambas entidades tienen responsabilidades territoriales que van más allá del área sobrepuesta, el modelo identifica tanto ámbitos de decisión conjunta por consenso como ámbitos de decisión exclusiva de cada una de las partes. Asimismo, señala los elementos de la realidad social, económica y política que favorecen la gestión compartida, así como los posibles conflictos. Propone un conjunto de temas de capacitación tanto para el SERNAP como para la CIPLA e instrumentos que se requeriría desarrollar para la implementación efectiva y sostenible del proceso.

Finalmente propone un plan de intervención con acciones de corto, mediano y largo plazo (Muiba Núñez, Loayza Cossio, Durán Laura, \& Gonzales Buitrago, 2011).

En abril de 2011, la propuesta de modelo desarrollada por la CIPLA y WCS fue aprobada en todos sus componentes en una Asamblea Consultiva del pueblo Leco de Apolo y sus dirigentes fueron autorizados para gestionar la suscripción de un Convenio entre CIPLA y el SERNAP a fines de su implementación (CIPLA, 2011).

La gestión por la titulación de los territorios indígenas Tacana I y Leco de Apolo así como la construcción de los planes de gestión territorial, Estrategia del Pueblo Tacana o Plan de Vida del Pueblo Leco de Apolo, incluyendo sus correspondientes zonificaciones fueron instrumentos que en sus procesos de elaboración participativa, ayudaron al fortalecimiento de las redes sociales de tipo vínculo, entre organizaciones indígenas de las tierras bajas, horizontales entre comunidades y también verticales, al haber conectado a las dirigencias de los niveles territoriales y nacional con las comunidades.

La gestión compartida, por el contrario, implica otro tipo de construcción de redes sociales de tipo "puente" entre las organizaciones indígenas y el Estado en sus diferentes niveles. En este caso, el proceso de compatibilización de los instrumentos de gestión como los planes, de manejo del PNANMI Madidi y de gestión territorial de los territorios indígenas, partiendo de sus respectivas zonificaciones que se inició entre CIPTA y la dirección del PNANMI Madidi requerían de definiciones legales y de políticas al más alto nivel. En el caso de Bolivia, la coyuntura de una Constituyente, permitió que el concepto fuese incluido en el texto constitucional.

La reconstrucción del proceso permite demostrar que las posibilidades de construir relaciones de tipo "puente" para la conservación a nivel de paisaje, tomando como base las áreas protegidas y los territorios indígenas, demandó de WCS un trabajo casi simultáneo a diferentes niveles de las estructuras organizativas de los pueblos indígenas y del Estado. Los arreglos institucionales para la gestión compartida impusieron desafíos conceptuales, visión de sistemas, pensamiento abstracto y concreto, así como la promoción de ejercicios técnicos experimentales de compatibilización de los instrumentos que tenían concordancias pero también diferencias.

El proceso demostró que la construcción de lazos de tipo "puente" entre las organizaciones indígenasy el Estado, involucraba a una diversidad de actores que habían sido incorporados en entidades participativas como los Comités de Gestión, las Coordinadoras interinstitucionales y aún los convenios de coadministración. La gestión compartida, requería, sin embargo, que los actores y los niveles de participación sean jerarquizados. 
El modelo de gestión territorial con responsabilidad compartida se basa en la delimitación clara de los actores sociales con derechos territoriales pre constituidos en las áreas protegidas. Son estos actores quienes tienen derecho junto al Estado, en el mismo nivel de importancia, a la toma de decisiones sobre las áreas compartidas. Sin embargo, precisamente esta definición puso en evidencia, que los otros actores sociales y los mecanismos que se habían creado con anterioridad, debían ser considerados. Es, pues esta complejidad social la que se pone de manifiesto en este intento de construcción de modelos compartidos entre el Estado y los pueblos indígenas para la gestión de las áreas protegidas sobrepuestas total o parcialmente a los territorios indígenas.

Finalmente, si bien los esfuerzos de concertación en los niveles superiores contribuyeron de manera importante, el proceso de trabajo conjunto y los acuerdos en el nivel más local del territorio indígena con CIPLA y sus comunidades y la Dirección del PNANMI Madidi tuvo resultados más avanzados y concretos. A pesar de ello, la pérdida de institucionalidad del SERNAP, la falta de decisión política por parte del Estado y las contradicciones en las políticas que el mismo Estado diseña y aplica en relación con las áreas protegidas determinaron que un proceso ardua y sistemáticamente trabajado haya quedado en suspenso. Por ello mismo se demuestra, una vez más que la construcción de relaciones sociales de tipo "puente" y más aún de carácter múltiple como las analizadas, son más difíciles pero entrañan los desafíos más fascinantes y difíciles de lograr (Putnam \& Feldstein, 2003).

Una vez más, es necesario destacar los instrumentos de gestión no solo como herramientas sino como procesos y vehículos para facilitar los procesos sociales. En este sentido, se descubren no solo por su contenido técnico sino por la función política y social que pueden llegar a cumplir.

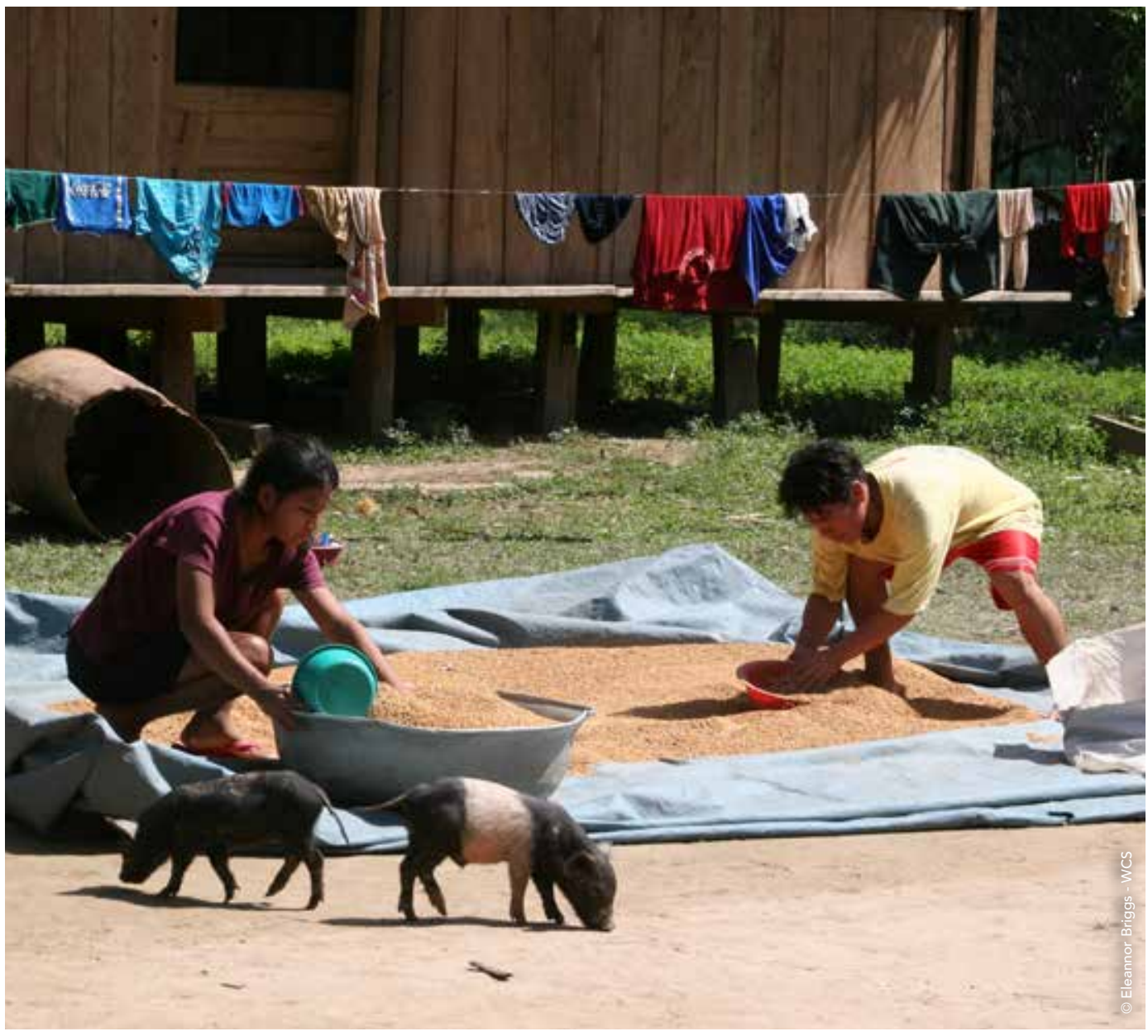




\section{REGULACIÓN PARA EL ACCESO Y USO DE LOS RECURSOS NATURALES}

Como resultado de la elaboración de los planes de gestión territorial indígena y frente a los conflictos por el uso y el acceso a la tierra y los recursos naturales, una de las propuestas más frecuentemente planteadas por las comunidades fue la elaboración de reglamentos que ayudaran a resolverlos. Estos conflictos estaban referidos a los terceros (a pesar de los avances en el saneamiento y la titulación, continuaban invadiendo las tierras o extrayendo ilegalmente los recursos naturales de las TCO), entre comunidades o aún entre vecinos al interior de las comunidades. WCS encaró el desafío de facilitar, junto a CIPTA y CIPLA procesos de autorregulación al interior y entre comunidades hasta la formulación de reglamentos de acceso y uso de los recursos naturales a nivel territorial.

En el caso de la TCO Tacana I, en 2004, el CIPTA y WCS diseñaron una estrategia que buscaba combinar dos aspectos: 1) la regulación y 2) la creación de un fondo concursable para pequeños proyectos basados en el manejo de los recursos naturales, al que, administrado por CIPTA y con la contribución técnica y financiera de WCS, las comunidades pudiesen acceder como un incentivo que se combinaba con la reglamentación.

WCS propuso una metodología participativa a través de preguntas que buscaban promover la reflexión en cada comunidad sobre: 1. ¿Qué se entendía por territorio indígena? 2. ¿Qué significa ser indígena y tacana? 3. ¿Quiénes tienen derecho a acceder a la tierra y los recursos naturales en la TCO? 4. ¿Cuáles son esos deberes y derechos? 5. ¿Cuáles son la prácticas permitidas y no permitidas según cada tipo de recurso: tierra (agricultura, pecuaria, cría de animales menores y ganado), fauna (caza y pesca), forestales (madera y no maderables) otros usos como el turismo? 5. ¿Debe permitirse el acceso a los recursos que se encuentran en las TCO a terceros?, ¿en qué circunstancias y bajo qué condiciones? 6. ¿Cómo se debe proceder en caso de que el uso de los recursos tenga fines comerciales? 7. ¿Cómo deben distribuirse los beneficios? 8. En caso de incumplimiento de los acuerdos ¿cómo se debe sancionar a las personas infractoras? 9. ¿Cómo y cuándo se podrán cambiar estas reglas? De esta manera, una vez más, el equipo técnico de WCS, dirigentes y personal técnico del CIPTA recorrieron cada una de las 20 comunidades. La facilitación de la reflexión dio como resultado un reglamento para cada comunidad de la TCO.

La compatibilización de 20 reglamentos comunales resultó en un verdadero dolor de cabeza. Para ello, el CIPTA convocó en varias oportunidades a representantes comunales. Cada representante presentaba su propuesta con base en las preguntas de la metodología, luego de las presentaciones de cada comunidad, la facilitación técnica de WCS y CIPTA presentaba los puntos comunes y los disensos, los representantes comunales ingresaban al debate hasta encontrar un común acuerdo. De esta manera, se construyó un reglamento que, basado en 20 reglamentos comunales, regularía el uso y el acceso a los recursos naturales en toda la TCO Tacana I. Este proceso se extendió desde 2004 hasta 2008. El Reglamento de Acceso y Uso de los Recursos Naturales del Territorio Indígena Tacana incluye la zonificación y las recomendaciones de acceso y uso para cada tipo de zona de la TCO (CIPTA, 2008).

Un proceso de sistematización de la experiencia, en 2012, mostró que mujeres y hombres de cada comunidad conocían y recordaban, con sorprendente precisión, las reglas que se habían establecido en el reglamento. También se constató que el conocimiento del reglamento no era el resultado de un aprendizaje recientemente adquirido, sino que el reglamento expresaba las prácticas de auto regulación que las comunidades habían desarrollado a lo largo del tiempo, especialmente en relación a los usos tradicionales.

Al mismo tiempo, se demostró que se habían incorporado nuevos conceptos como los planes de manejo para el aprovechamiento de recursos específicos con fines comerciales. En términos de la aplicación de las normas se mostraba una gradación en la que se 
observaba que era más frecuente la aplicación de las sanciones a los terceros provenientes de otro lado quienes invadían la TCO o ingresaban para extraer los recursos naturales. En cambio, se presentaban más dificultades en la aplicación de las sanciones a quienes se consideraban comunarios nativos o fundadores de las comunidades, principalmente debido a la primacía de las relaciones de parentesco (Lehm, 2016 b).

\section{GRÁFICO 5:}

\section{REGLAMENTACIÓN TACANA. SUJETOS Y GRADACIÓN EN LA APLICACIÓN} DE LAS SANCIONES

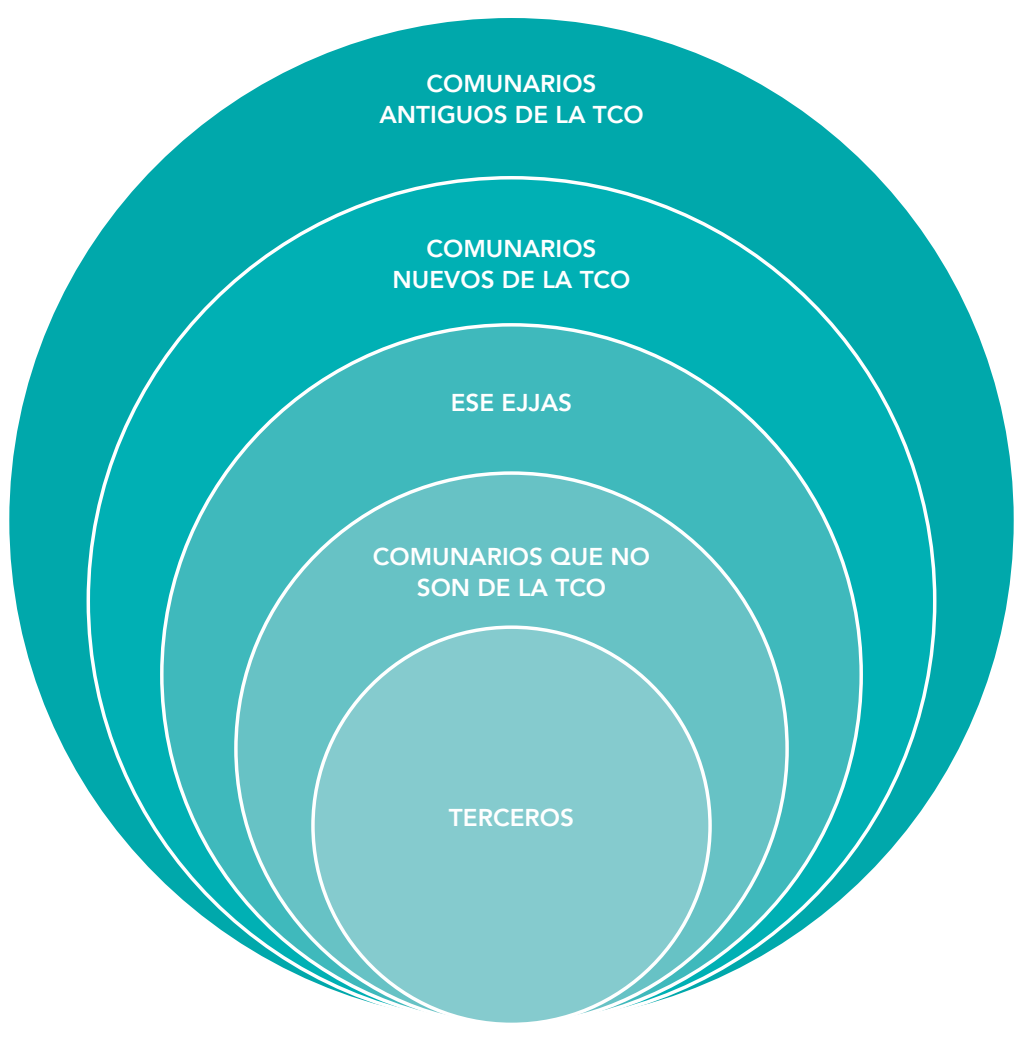


Finalmente, otro aspecto se destaca en la sistematización: el hecho de que el pueblo tacana históricamente fue una sociedad extremadamente regulada con base en la tradición y sobre todo en su religiosidad. Un nutrido universo mítico y de "Edutzis", amos de las aguas, los montes, los cerros, cada especie y aún cada actividad humana habían regulado la vida tradicional de cada persona hasta la década de 1950. Con posterioridad, la invasión masiva de población colonizadora de otras culturas, así como los booms extractivistas de los recursos naturales habían determinado el resquebrajamiento de dicho sistema de reglas. Sin embargo, quedaban aún huellas de este sistema y el recuerdo de su fuerza reguladora contrastaba con la nueva regulación formal y secular.

Si las deidades habían aplicado castigos y sanciones a las personas ambiciosas que aprovechaban los recursos más allá de sus necesidades, ¿quiénes eran pues los seres humanos, aun siendo máximas autoridades de las comunidades como los Corregidores, para aplicar sanciones que antes eran impuestas, a su modo, por las deidades? Plantease aquí, un debate de pluralismo jurídico relativo al acceso y uso de los recursos naturales que en Bolivia no ha merecido mayor atención (Lehm, 2016 b).

En el caso del pueblo Leco de Apolo, siguiendo en parte la metodología desarrollada por WCS y CIPTA para el pueblo Tacana, la elaboración del "Reglamento de Uso, Acceso, Manejo y Aprovechamiento de los Recursos Naturales en el Territorio Indígena Originario Campesino (TIOC) Leco de Apolo" se desarrolló en 2011, también, con la facilitación de reglamentos a nivel de las comunidades de la TCO. Sin embargo, en este caso, los reglamentos que se facilitaron en las comunidades, a diferencia de los de la TCO Tacana que se enfocaban centralmente en la definición de los sujetos, de los derechos y deberes y en las prácticas permitidas y no permitidas en relación a cada tipo de recurso natural, hicieron énfasis en los aspectos orgánicos.

Los reglamentos orgánicos de la comunidad leca de Apolo, al igual que en el caso tacana, contienen las definiciones fundamentales que hacen a los sujetos del derecho: ¿quiénes son considerados miembros de la comunidad y quiénes no?, ¿en qué casos y de qué manera pueden adscribirse nuevos miembros, sean individuales o colectivos? Además, los reglamentos de carácter orgánico establecen los órganos del gobierno comunal, los cargos, sus funciones, las faltas leves, graves y muy graves en la vida comunal, así como sus sanciones. En estos reglamentos comunales, las referencias a los recursos naturales son más bien puntuales. Con base en estos reglamentos comunales, en 2013, el CIPLA aprobó un Reglamento interno para normar la vida orgánica de la organización. En relación a este instrumento, es importante destacar el esfuerzo de adecuación del sistema orgánico a las necesidades de implementación del Plan de Vida del Pueblo Leco (CIPLA, 2013).

Adicionalmente, en 2011, la CIPLA desarrolló y aprobó además un Reglamento de Uso, Acceso, Manejo y Aprovechamiento de los Recursos Naturales en el Territorio Indígena Originario Lecos de Apolo. Este documento se enmarca en la nueva Constitución Política del Estado Plurinacional de Bolivia, incluye definiciones, reglas y procedimientos relativos tanto a los recursos naturales renovables como no renovables, además se encuadra en el Plan de Vida del Pueblo Leco, incluye la definición de los sujetos de los derechos y deberes colectivos e individuales (tomando como base los reglamentos orgánicos), vincula las normas con la microzonificación de las comunidades y macrozonificación a nivel del territorio (CIPLA, 2011).

El instrumento normativo establece las prohibiciones y obligaciones respecto del uso y la protección de los recursos naturales, consideraciones de uso y control para los recursos de agua y caza, pesca, recolección, para el uso de recursos maderables, no maderables, el turismo, la agricultura y la crianza de animales domésticos, incluyendo las sanciones a su incumplimiento según las faltas sean leves, graves o muy graves. 
específicamente mineros e hidrocarburíferos. Establece también los procedimientos para la consulta y la participación en el marco de los derechos constitucionales y convenios internacionales sobre los pueblos indígenas. Define procedimientos para la fiscalización y la distribución de regalías y los procedimientos administrativos y para la rendición de cuentas en relación a los beneficios y regalías obtenidos (CIPLA, 2011).

En 2014, el reglamento anterior fue adecuado a una nueva Ley de la Madre Tierra y Desarrollo Integral para Vivir Bien aprobada en 2012 (CIPLA, 2014).

Si se consideran las recomendaciones para que las reglas garanticen la sostenibilidad del acceso y uso común de los recursos naturales, entre las que se han mencionado: a) los límites del recurso deben ser claros; b) los criterios para decidir quién podrá formar parte del grupo de usuarios también deben ser claros; c) los usuarios deben tener derecho a modificar sus normas de utilización a lo largo del tiempo; d) las reglas de uso deben corresponder a la capacidad de carga del sistema, ser conservadoras desde el punto de vista del medio ambiente, y prever un margen de error y e) las normas de uso deben ser claras y de fácil aplicación (McKean \& Ostrom, 1994), se podrá observar que tanto en el proceso de los tacanas como de los lecos de Apolo, la zonificación contribuyó en gran medida a clarificar los límites de los recursos. En el caso tacana, este proceso fue reforzado con la demarcación de más de $252 \mathrm{~km}$ en el perímetro de la TCO. En segundo término, las definiciones sobre quiénes son considerados comunarios y comunarias, la amplia tipología de sujetos de derechos en el caso tacana y la definición de los procedimientos para la adscripción de nuevos miembros de las comunidades, contribuyeron a la clarificación de los criterios para la decisión de quiénes podrán ser parte del grupo de usuarios.

En términos de la flexibilidad de cambio de las reglas, la modalidad de elaboración de reglamenos publicados como se aplicó en las TCO's tacana y lecos de Apolo, tiene limitaciones, en la medida que los procesos de ajuste, si bien están considerados en los reglamentos, tendrán que ser bastante espaciados en el tiempo dadas las características de estos reglamentos. Esta modalidad, presenta también una distancia bastante acusada respecto de los sistemas de regulación tradicional de los pueblos indígenas. Como se observará en el caso de Perú, en relación a este aspecto en particular, la modalidad desarrollada con base en acuerdos que se plasman en los libros de actas de las comunidades, y no tanto así en reglamentos publicados, constituye una de tipo más flexible y adecuado a las características de las poblaciones tradicionales amazónicas.

La correspondencia de las reglas con la capacidad de carga de los ecosistemas y su carácter conservador, es un principio dominante en las regulaciones tanto tacanas como lecas y en el caso del uso para fines comerciales deben atenerse a la elaboración de planes de manejo. Muchas de las reglas específicas son de fácil aplicación, especialmente aquellas que están relacionadas con el uso para la subsistencia y con las prácticas habituales de las comunidades, sin embargo, las normas se tornan más complejas y de difícil aplicación cuando se trata de los planes de manejo con fines comerciales. Es precisamente por esta razón que se hacen necesarios los procesos de fortalecimiento de capacidades.

Mientras el proceso tacana mantiene coherencia entre los reglamentos comunales de acceso y uso de los recursos naturales desde el nivel comunal hasta el territorial, el caso leco contribuye con las definiciones más de tipo orgánico pero el desarrollo es desigual respecto de las reglas de acceso y uso de los recursos naturales, entre el nivel comunal y el territorial. Entretanto, el reglamento tacana se refiere exclusivamente a los recursos naturales renovables, el de los lecos también se refiere a los recursos no renovables, establece los procedimientos de consulta y criterios para el acceso a los beneficios.

En términos de la aplicación de los reglamentos, tanto entre los tacanas como entre los lecos, se observa que las sanciones se aplican con mayor rigor a los terceros en tanto que esta aplicación tiende a diluirse cuando se trata de los miembros de las comunidades. 


\title{
ARTICULACIÓN DE CADENAS PRODUCTIVAS CON BASE EN EL MANEJO DE LOS RECURSOS NATURALES Y DE LAS REDES SOCIALES VERTICALES
}

En la TCO Tacana, el proceso de fortalecimiento de iniciativas productivas comunitarias, se inició como parte de una estrategia que buscaba compensar el proceso de autorregulación del uso de los recursos naturales de acceso común. Para ello, desde el año 2000 se promovió la reflexión sobre la importancia de asegurar la sostenibilidad en el uso de los recursos naturales. Se estima que en este proceso de discusión sobre la sostenibilidad y la formulación de planes de manejo participaron alrededor de 1100 personas, de las cuales un $29 \%$ era mujer, cifra significativa si se considera que la población mayor de 14 años en la TCO alcanzaba a 1593 personas (CIPTA - WCS, 2012; Lehm, 2016 b). Uno de los resultados iniciales, en 2002, fue la construcción colectiva de una definición de sostenibilidad desde el punto de vista del pueblo Tacana y la identificación de sus propios principios y criterios.

\begin{abstract}
"Usar los recursos naturales cuidando de que no se acaben y que aumenten para las futuras generaciones, realizando actividades de manera racional y ordenada, de acuerdo a la vocación de las áreas y manteniendo la diversidad productiva, con equidad, generando ingresos económicos, e incentivando a nuestros hijos y comunidades para que valoren los recursos naturales" (CIPTA y WCS, 2002).
\end{abstract}

Sobre esas bases, entre 2003 y 2004, se diseñó un programa de capacitación y una metodología para que grupos comunitarios de usuarios y usuarias elaboren ideas de proyectos sobre manejo de recursos naturales. El resultado inicial fueron 30 documentos de ideas de proyectos. Estos proyectos fueron evaluados por una comisión técnica conformada por dirigentes del CIPTA y personal técnico de WCS. Además de proporcionar fondos para que los grupos de usuarios y usuarias inicien sus actividades, el proceso tuvo dos objetivos uno de carácter pedagógico para lograr que el CIPTA desarrollara capacidades para la evaluación de propuestas y otro de carácter orgánico para asegurar que el acceso a recursos financieros por las comunidades no fuera discrecional sino por medio de evaluaciones objetivas basadas en los propios principios y criterios de sostenibilidad que el CIPTA y sus comunidades habían formulado con anterioridad.

El financiamiento de los proyectos se inició con USD 1500 por iniciativa en 2004 y ascendió hasta USD 15000 en 2012. Este proceso, a la vez, demandó el fortalecimiento de las capacidades administrativas y técnicas de la organización indígena y las comunidades.

Simultáneamente, en el CIPTA iría creciendo la preocupación sobre cómo articular los diferentes niveles orgánicos al interior del territorio indígena. Debe recordarse que en el pueblo Tacana, el sistema de organización vigente está relacionado con la experiencia misional del siglo XVIII. En el marco de esta herencia, las comunidades tienen sus propios sistemas de organización basados en corregimientos que cumplen funciones de gobierno comunal. El fortalecimiento de CIPTA como entidad representativa de dichas comunidades, y ahora la emergencia de nuevas formas de organización para la producción y el manejo de los recursos naturales, planteaba la problemática de cómo articular todos estos niveles de manera coherente y atendiendo al hecho de que los recursos naturales corresponden a un régimen de acceso común reforzado por el hecho de encontrarse dentro de la Tierra Comunitaria de Origen, titulada a favor de las 20 comunidades.

De otro lado, las experiencias de iniciativas comerciales basadas en el manejo de los recursos naturales entre los pueblos indígenas de la Amazonía presentaban serias dificultades especialmente en términos de la administración de los fondos y debilidades en el control social sobre su desenvolvimiento (Lehm, 2002). 
Con la finalidad de dar respuesta a estas problemáticas, en el caso tacana se diseñó un modelo de sistema que articula los diferentes niveles orgánicos a través de la distribución de los beneficios y al mismo tiempo promueve la transparencia. Ese modelo, quedó representado de la siguiente manera:

\section{GRÁFICO 6:}

ARTICULACIÓN DE NIVELES ORGANIZATIVOS A TRAVÉS DE LA DISTRIBUCIÓN DE BENEFICIOS Y RENDICIÓN DE CUENTAS

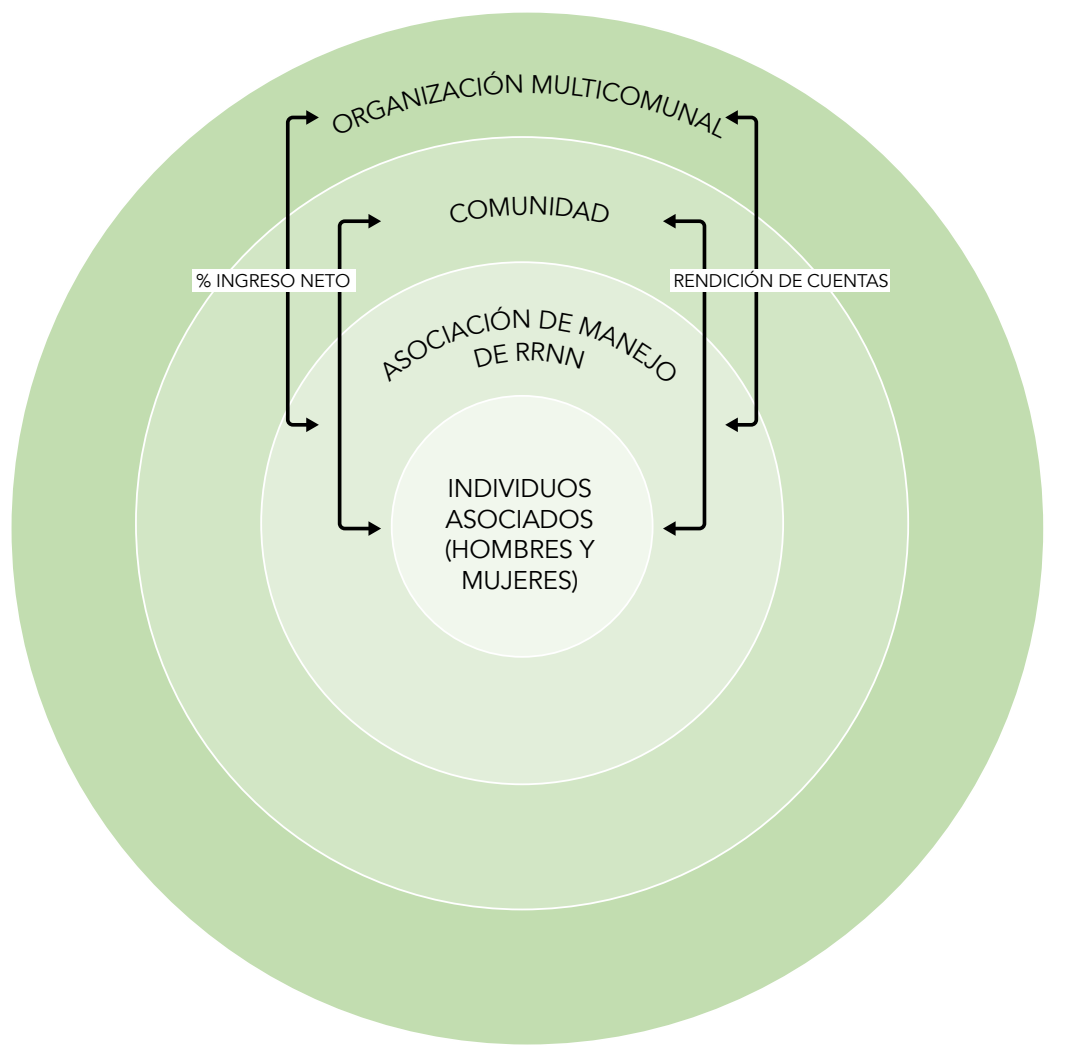


El modelo se basa en los siguientes principios: 1) los beneficios son utilidades netas que generan los emprendimientos productivos, 2) estos beneficios se distribuyen en porcentajes variables (según el tipo de actividad) entre los socios y socias, la reinversión en las propias asociaciones, las comunidades representadas por sus autoridades y las 20 comunidades representadas por el directorio del CIPTA y 3) se basa en un sistema de pesos y contrapesos para el control social, la función de las autoridades comunales y de las dirigencias del CIPTA es la del control tanto del manejo de los recursos naturales como de los recursos económicos generados por la actividad productiva, las funciones gerenciales y ejecutivas son atribuciones exclusivas de las asociaciones con su propia organización, ningún dirigente puede pertenecer simultáneamente al directorio del CIPTA y de alguna asociación productiva. La distribución de los beneficios basada en las utilidades netas generaría un mecanismo de control de las comunidades y el CIPTA sobre los costos de las asociaciones, de esa suerte, la contabilidad de los emprendimientos tiene un carácter abierto y se establece un sistema de rendición de cuentas periódicas de los emprendimientos tanto a sus socios y socias como a las comunidades y al CIPTA.

De esta manera, el sistema de organización multinivel o anidado quedaba articulado verticalmente tanto por el flujo de los beneficios como por las rendiciones de cuentas recíprocas.

Tanto en el caso de los tacanas como de los lecos de Apolo, la promoción del manejo de los recursos naturales por comunidades o grupos de usuarios y usuarias se realizó en el marco de la Estrategia de Desarrollo Sostenible de la TCO Tacana I y del Plan de Vida del Pueblo Indígena Leco de Apolo.

3

Entre 2000 y 2014, en la TCO Tacana y en la TCO Lecos de Apolo se desarrollaron alrededor de 27 iniciativas comunitarias de manejo de los recursos naturales. El número de estos emprendimientos según su año de creación se presenta en el Gráfico 7. En la TCO Tacana, la mayor parte de ellas se dedican al manejo forestal maderable, seguidas por las iniciativas de cacao (en unos casos silvestre y en otros cultivado bajo sistemas agroforestales) y el manejo de la fauna silvestre entre las que destaca el lagarto (Caimán yacaré). En la TCO Lecos de Apolo, una iniciativa se refiere al manejo del incienso (Clusia pachamamae).

\section{GRÁFICO 7:}

\section{NÚMERO DE ASOCIACIONES PRODUCTIVAS SEGÚN AÑO DE CREACIÓN EN LA TCO TACANA I Y TCO LECO DE APOLO}

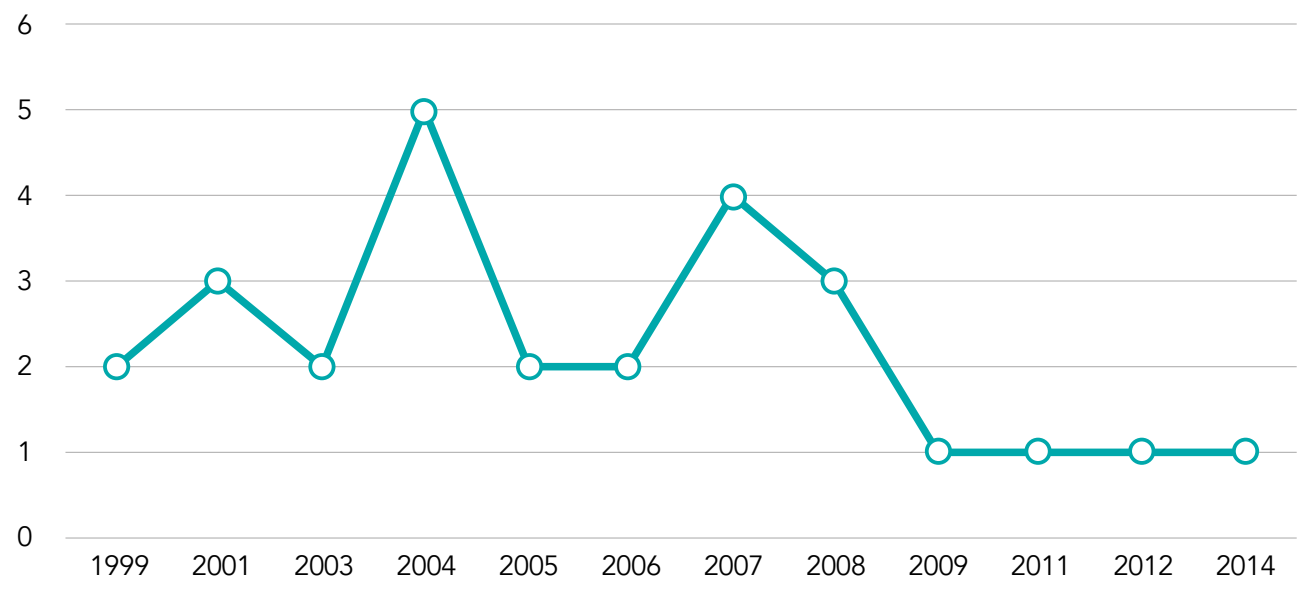




\section{GRÁFICO 8: \\ DISTRIBUCIÓN DE LAS ASOCIACIONES SEGÚN ACTIVIDAD O RECURSO UTILIZADO ( $\mathrm{N}=\mathbf{2 7})$}

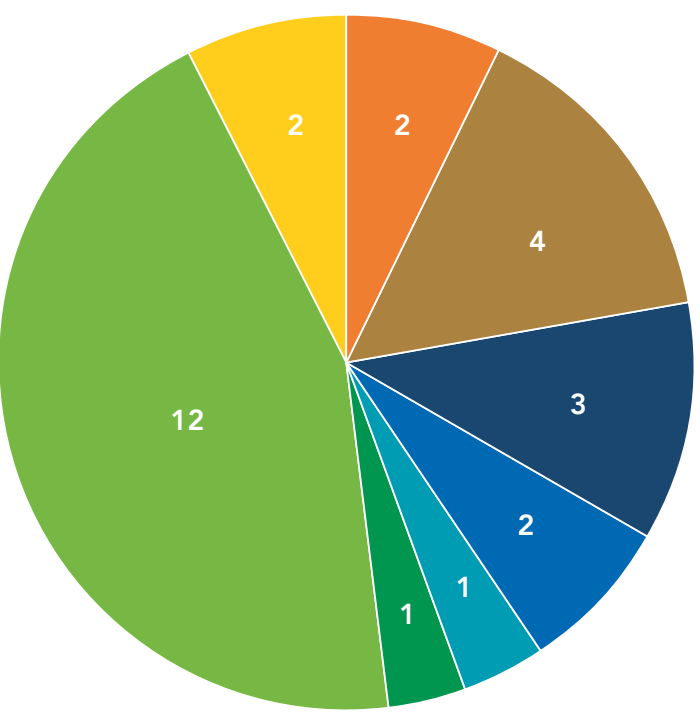

- ARTESANÍA

- cacao

- fauna silvestre

O gANADERÍA MAYOR

- ganadería menor

- incienso

- madera

TURISMO

Fuente: (WCS, 2017)

El apoyo de WCS, especialmente a las iniciativas más destacadas de manejo de lagarto (Caiman yacaré) y del incienso (Clusia pachamamae), se ha caracterizado por una secuencia de acciones basadas en un enfoque de cadena productiva. La ruta crítica de estas acciones puede sintetizarse en: 1 . Demanda de o consulta a las organizaciones y comunidades interesadas. 2. Estudios sobre la distribución, densidad y estructura de las poblaciones silvestres y su ecología, aspectos socio-económicos y culturales y sondeos de mercado. 3 . Análisis de los resultados con las comunidades involucradas. 4. Inicio de apoyo al proceso de organización de asociaciones comunitarias y a los procesos de su legalización (bajo diferentes modalidades según el tipo de recurso, el tiempo que la gente quiere dedicar a la actividad, etc.). 5. Elaboración de los planes de manejo y acompañamiento a las asociaciones para gestionar su aprobación ante las entidades estatales competentes. 6 . Asistencia en servicio y capacitación técnica tanto en las labores de cosecha como de post cosecha según el tipo de producto y de acuerdo a las exigencias del mercado (por ejemplo, en el caso del descuerado de los lagartos o la sanidad e inocuidad alimentaria en el caso de carne del lagarto), así como en aspectos administrativos, contables, de comercialización y monitoreo. 7. Identificación de nichos de mercado adecuados. 8. Diseño, establecimiento y apoyo en la implementación de sistemas de monitoreo. 9. Promoción del intercambio de experiencias entre productores y productoras, sea en el mismo rubro o entre rubros diferentes a través de propiciar Encuentros de Manejo de Recursos Naturales por las comunidades locales.

El apoyo de WCS en Bolivia a estas iniciativas se realiza durante 10 años, pero se observa un retiro paulatino de su personal técnico según el proceso de consolidación de las capacidades en los diferentes rubros. Sin embargo, este no es un proceso lineal, existen ocasiones cuando el personal técnico tiene que volver para reforzar aspectos que, se suponía, estaban consolidados, por ejemplo, la inclusión de nuevas generaciones de cazadores en la iniciativa de manejo de lagarto, en ese caso, el papel de WCS fue generar puentes de comunicación entre los antiguos y los nuevos cazadores. 


\section{EL CASO TACANA Y LAS ESFERAS ECONÓMICAS DE LA RECIPROCIDAD Y EL MERCADO}

Con la finalidad de contribuir al sistema de monitoreo del Plan de Gestión Territorial del pueblo Tacana, WCS realizó un estudio sobre ingresos económicos entre los hogares de la TCO Tacana. Este estudio fue encarado a través de conjugar diferentes enfoques teórico - metodológicos, entre ellos el de la Gestión Territorial Indígena entendida no solo como un instrumento de administración del territorio sino como una propuesta metodológica basada en la consideración de la diversidad de fuentes de ingresos de los hogares indígenas amazónicos, el de las "esferas económicas" entendidas estas como la articulación de la "esfera de la reciprocidad y del mercado" como partes constitutivas del sistema económico indígena y en tercer lugar, enfoques relacionados con la equidad social en general y de género en particular.

Entre los resultados más relevantes de este estudio, destacan:

1. La evidencia empírica, basada en los ingresos, demuestra que un rasgo que distingue al sistema económico del pueblo Tacana, es la diversidad de fuentes de ingreso, una característica compartida con otros pueblos indígenas de la Amazonía. A su vez, demuestra que a pesar de más de un siglo de vinculación con la economía monetaria o de mercado, la economía de los hogares tacanas aún articula la esfera de la reciprocidad con la esfera del mercado. En esta articulación, el sistema económico tacana presenta una predominancia de la esfera de la reciprocidad debido a la importancia de la mano de obra familiar y comunal no remunerada.

2. El enfoque basado en la Gestión Territorial Indígena, acorde con el carácter diverso de la economía indígena, ha permitido identificar y determinar la contribución de 12 fuentes de ingreso. Los ingresos medios netos anuales por hogar alcanzan a Bs 23 111, equivalentes a USD 3349; y los ingresos medios brutos anuales totales, a Bs 34 876, equivalentes a USD 5053. Entre las fuentes que más contribuyen a los ingresos netos se encuentran el trabajo para otros, el aprovechamiento forestal maderable, la pesca y la cacería. En segundo lugar, la pecuaria, otros ingresos donde se incluyen las jubilaciones, bonos estatales y remesas, y los negocios comerciales; en tercer lugar, la agricultura y el turismo; y en cuarto lugar los subproductos y artesanías, el aprovechamiento forestal no maderable y la producción/recolección de mieles nativas. La fauna silvestre, a través de la caza y la pesca, contribuye con un $29 \%$ a los ingresos medios netos.

3. El análisis de los ingresos y costos medios brutos anuales demuestra que, en términos de los ingresos, el $40 \%$ es no monetario y $60 \%$ es monetario, en tanto que, en términos de los costos, solo el $33 \%$ es monetario y $67 \%$ es no monetario, mayormente referidos al costo de la mano de obra familiar y comunal no remunerada.

4. Comparando la diferencia de los ingresos brutos entre 2000 y 2012 se constató que el ingreso medio bruto anual por hogar se incrementó en $94 \%$ y los ingresos brutos per cápita mensuales en $109 \%$. A este incremento debe añadirse la contribución a los ingresos medios netos del $14,36 \%$ que proviene de los emprendimientos económicos que se han desarrollado con posterioridad al 2000, incremento directamente relacionado con la Gestión Territorial Indígena, que el CIPTA y sus comunidades, han implementado desde el año 2000. Al mismo tiempo, en 2012, el ingreso bruto medio mensual de los hogares tacanas es superior al de los trabajadores agrícolas a nivel nacional en un $16 \%$.

5. El incremento en los ingresos familiares entre los hogares tacanas no ha redundado en inversiones o en servicios, sino en bienes de consumo, especialmente alimentos, 
con el agravante, en los casos más destacados, de tratarse de alimentos que tradicionalmente los hogares tacanas producían y que ahora, con una mayor disponibilidad de ingresos monetarios, se adquieren en el mercado.

6. Adicionalmente, tomando en cuenta una clasificación de las actividades, según su grado de dependencia de ecosistemas bien conservados, se estableció que la Gestión Territorial Indígena y las acciones de conservación realizadas, tanto en la TCO como en el vecino PNANMI Madidi, han ayudado a la generación del $44 \%$ de los ingresos brutos que provienen de las actividades que requieren de ecosistemas y conectividad bien conservados. El $56 \%$ de estos ingresos es no monetario. Si lo anterior se refiere a los ingresos brutos, en términos de los ingresos netos, la contribución de estas actividades de menor impacto asciende al $52 \%$, demostrando que además requieren menores costos en mano de obra. En contraste, si se considera que la agricultura y la pecuaria contribuyen solo con el $23 \%$ a los ingresos medios brutos, puede sugerirse que la sobrevaloración estatal y social de estas actividades se funda más en su consideración como instrumentos civilizatorios, de raíz colonial, impuestos y a la larga aceptados por las poblaciones indígenas amazónicas.

7. Relacionado con lo anterior y en la perspectiva del asfaltado de una carretera que atraviesa la región, el estudio de los ingresos de los hogares de la TCO Tacana I demuestra que, a pesar de los 30 años transcurridos desde la apertura de la carretera, los ingresos netos de las comunidades de la carretera no superan los de las comunidades ribereñas, existiendo una diferencia del $6 \%$ a favor de las segundas. Esto se debe al mejor estado de conservación de los recursos naturales en la zona ribereña y a los menores costos en la generación de dichos ingresos. La comparación entre la composición de los ingresos brutos no monetarios y monetarios entre ambos tipos de comunidades demuestra que los primeros son un $37 \%$ más significativos entre las comunidades ribereñas a diferencia de los segundos, que son $36 \%$ superiores entre las comunidades de la carretera.

8. El análisis de la concentración del ingreso, a través del coeficiente Gini, demuestra que aquellas actividades más vinculadas al mercado tienen índices de concentración más altos que aquellas menos vinculadas al mercado. Al mismo tiempo, esta distribución está marcada por la mayor o menor participación de los hogares en las actividades generadoras del ingreso. En general, el análisis de la concentración del ingreso total y del gasto o consumo muestra que el sistema económico indígena tacana es significativamente igualitario en términos de la distribución del ingreso entre los hogares, dos puntos por debajo del coeficiente de concentración en el nivel nacional.

9. Lo anterior no debería oscurecer la existencia de marcadas desigualdades en términos de la distribución inequitativa de los costos y beneficios entre hombres y mujeres, en las diferentes actividades. El precio medio del jornal pagado a las mujeres es $6 \%$ menor que el pagado a los hombres. Sin considerar su contribución en las labores del cuidado, las mujeres aportan con el $40 \%$ del valor de la mano de obra para la generación de los ingresos de los hogares, 46 \% si se considerara la diferencia en el pago de los jornales. Esta desigualdad no se funda más que en la injusticia, no es atribuible a diferencias en el esfuerzo o en la calidad del trabajo que ellas, al igual que los hombres, desempeñan. Asimismo, los hogares unipersonales, constituidos por personas mayores y con jefatura femenina son los que, en mayor proporción, reciben los ingresos más bajos.

10. En el análisis de los niveles de pobreza de la región, si se consideran únicamente los ingresos monetarios, el 60 \% de los hogares tacanas se encuentra en la categoría de pobreza extrema. En cambio, si se toman en cuenta tanto los ingresos monetarios 
y los ingresos no monetarios, este porcentaje se reduce al $18 \%$. Esta comparación, muestra que el discurso sobre la pobreza y el desarrollo niega una dimensión importante de los sistemas económicos indígenas, en particular de la Amazonía, relacionada con la esfera de la reciprocidad, del autoconsumo y de la autonomía económica.

11. La consideración solo de la esfera del mercado reproduce dependencias que profundizan la pobreza, recrean la imagen de los pueblos indígenas como pobres, miserables, marginales, improductivos, ineficientes, antieconómicos, sumiéndolos injustamente en lo que podría denominarse una pobreza absoluta. Lo que aquí se ha demostrado es que los sistemas económicos indígenas, tal es el caso del pueblo Tacana, articulan de manera sofisticada tanto la esfera de la reciprocidad como la del mercado, asumiéndolas como partes co-constitutivas de dichos sistemas.

12. En sus estrategias, los hogares tacanas, hoy por hoy, combinan el uso de una gran diversidad de recursos naturales, la agricultura, la pecuaria, con fines de autoconsumo. Al mismo tiempo, aprovechan las oportunidades que les brinda la esfera del mercado en términos del trabajo para otros, los negocios de carácter más urbano, así como otros ingresos provenientes de las remesas, bonos, etc. Sin embargo, la base fundamental de este sistema económico indígena se encuentra en la disponibilidad de los recursos naturales y en la seguridad de su acceso gracias a la titulación de una porción de su territorio como propiedad colectiva del pueblo Tacana.

13. Las correlaciones y la aplicación de un modelo de regresión lineal jerárquica entre las variables tamaño de hogar, edad media y años de estudio, tanto a nivel de los hogares como de los jefes y jefas de hogar, y la variable ingresos, muestra que la relación más significativa se refiere a los años de estudio: a más años de estudio, los hogares obtienen ingresos más altos. Esto indica que entre las estrategias más importantes para reducir la pobreza en comunidades indígenas debería considerarse la reducción de las brechas de inequidad en al acceso adecuado y de calidad a los servicios, especialmente el que se refiere a la educación. Una aproximación a las Necesidades Básicas desde el punto de vista de las comunidades tacanas demuestra precisamente que ellas consideran estos servicios como indispensables para la vida de la gente y sin los cuales ningún hogar debería tener que vivir.

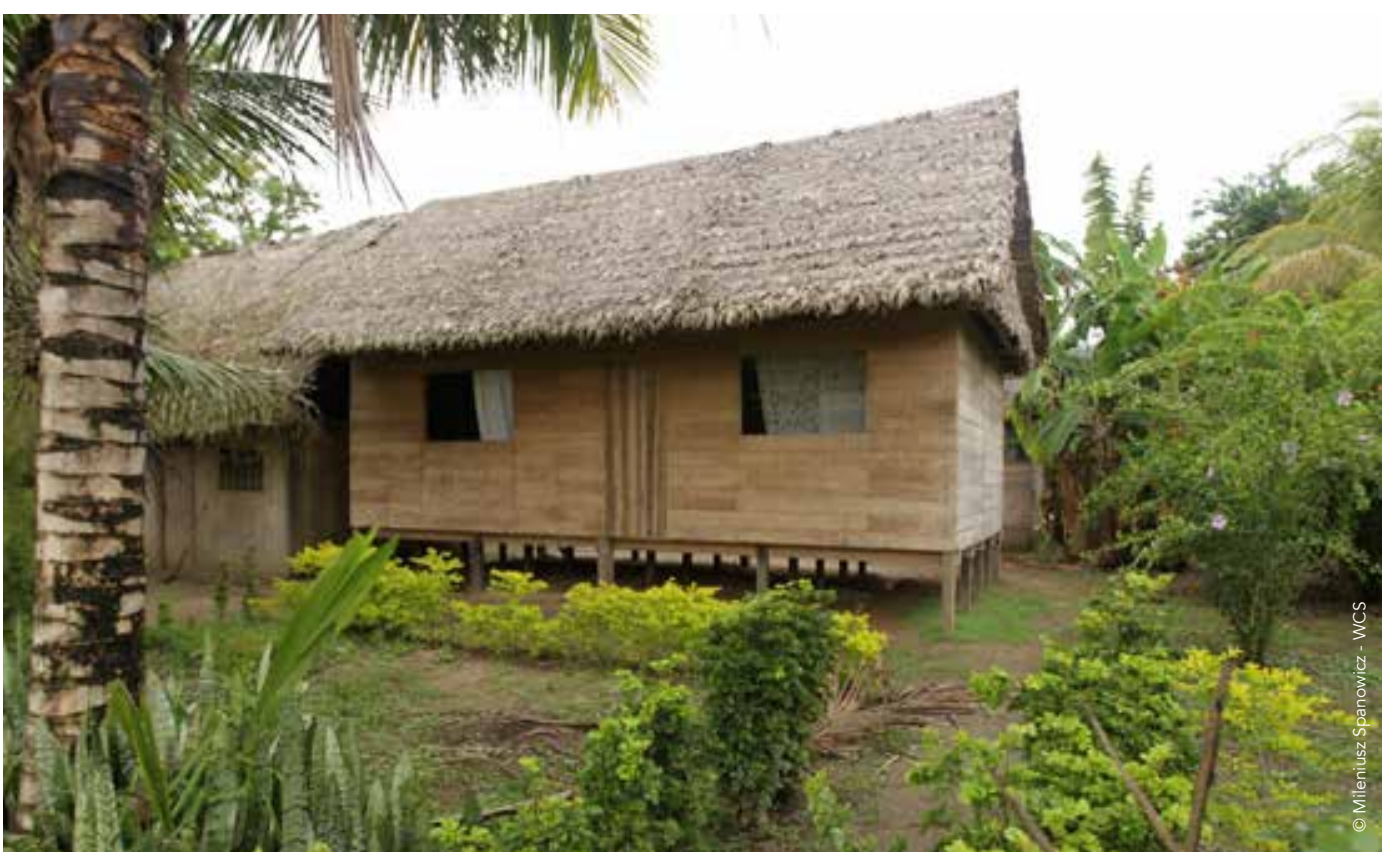


14. El análisis de las Necesidades Básicas identificadas por las comunidades tacanas con base en la metodología "Basic Necessities Survey" (NBS) ha permitido establecer un ingreso anual básico de Bs 26 209, que es $25 \%$ inferior al ingreso bruto medio anual que se ha podido determinar que reciben efectivamente los hogares tacanas. Sin embargo, también se ha podido establecer que este ingreso es $43 \%$ menor que el ingreso medio nacional establecido por el INE para 2012, mismo año del relevamiento de la información sobre ingresos y Necesidades Básicas por WCS y CIPTA. Asimismo, a pesar del crecimiento económico que Bolivia ha experimentado en los últimos años, aún el país se ubica entre los más rezagados en el contexto de los países vecinos y de Latinoamérica. Al mismo tiempo, es necesario destacar el hecho de que la composición del ingreso medio anual nacional está constituido en buena parte por fuentes de ingresos no renovables como la minería y los hidrocarburos, a diferencia de las fuentes de ingreso a las que acceden los hogares tacanas.

15. La Gestión Territorial Indígena de la TCO Tacana I demuestra haber reducido las tendencias de deforestación en 4,6 veces respecto de las áreas aledañas no sometidas a procesos de manejo integral territorial, lo que contribuye adicionalmente a la sostenibilidad de los ingresos que hasta ahora se han reportado para los hogares tacanas. Sin embargo, queda pendiente resolver la pregunta sobre ¿cuál debiera ser el nivel de ingreso adecuado para los hogares tacanas, más allá de cubrir las necesidades básicas identificadas como tales por el $30 \%$ y más de las comunidades de la TCO? Y, ¿cuánto más pueden contribuir sosteniblemente los ecosistemas de la TCO Tacana para alcanzar aún mejores ingresos? Es necesario que la profundización del monitoreo sobre los recursos naturales, las Necesidades Básicas y los ingresos, que se viene implementando como parte de la Gestión Territorial Indígena Tacana pueda contribuir a resolver estas cuestiones fundamentales.

\section{LOS ESFUERZOS DE CAPACITACIÓN Y ASISTENCIA TÉCNICA}

Entre 2000 y 2013, en la TCO Tacana I y entre 2001 y 2012 en la TCO Lecos de Apolo, WCS apoyó en el desarrollo de 451 eventos de capacitación y asistencia técnica, 309 eventos se desarrollaron en la TCO Tacana I y 142 en la TCO Lecos de Apolo.

\section{GRÁFICO 9: \\ NÚMERO DE EVENTOS DE CAPACITACIÓN Y ASISTENCIA TÉCNICA SEGÚN TERRITORIO INDÍGENA (2000 - 2015)}

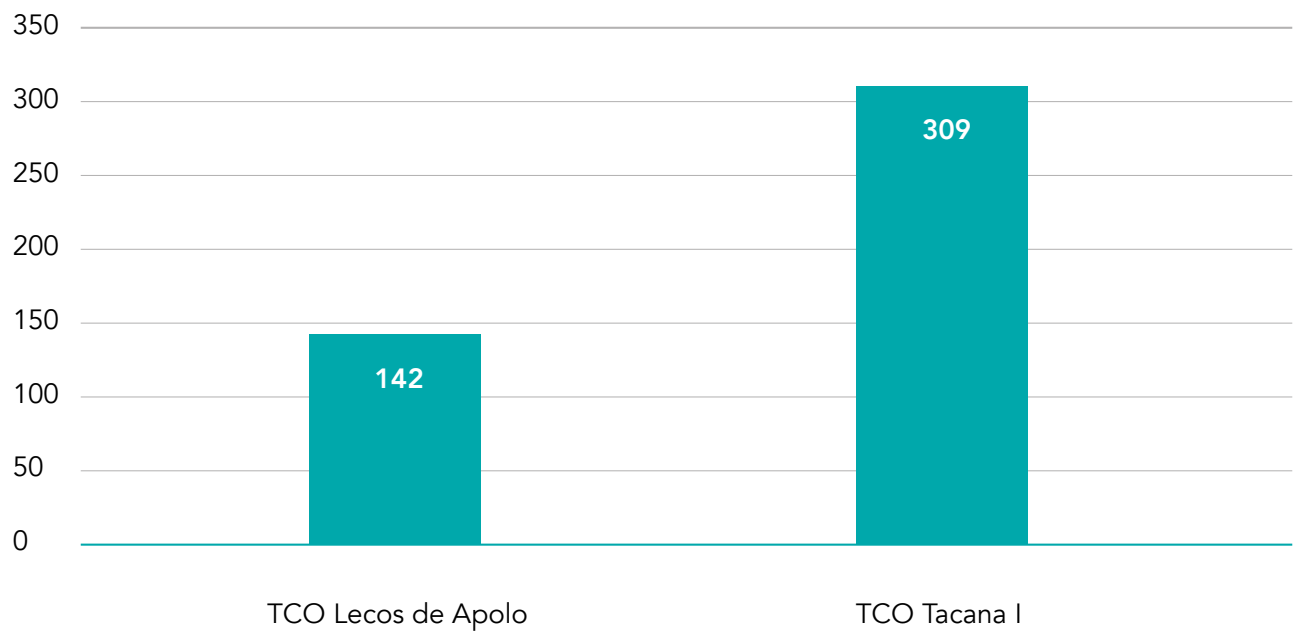


La gama de tipos de eventos se refiere a la gestión territorial, entendida esta como un proceso articulado de acciones que se inicia con la gestión por la titulación de las TCO y continúa con: la planificación territorial, la implementación de los planes de gestión territorial, la elaboración de reglas de acceso y uso de los recursos naturales, el manejo de recursos naturales específicos, la investigación y el monitoreo y la administración financiera. Relaciona los enfoques de equidad de género y la administración de conflictos con la gestión territorial. Desarrolla acciones en relación a proyectos específicos como la capacitación en sanidad y manejo de animales domésticos (salud). Si bien la gama de acciones es más amplia y el número de eventos es mayor en la TCO Tacana I, esta estrategia, de alguna manera se replica en la TCO Lecos de Apolo.

En el caso de la TCO Tacana I, en términos del número de eventos según su tipo destacan en primer lugar, los que se refieren al manejo de los recursos naturales. Aquí se incluyen las capacitaciones a grupos de usuarios y usuarias de las comunidades para la elaboración de ideas de proyectos basados en el manejo sostenible de los recursos naturales, eventos de difusión y análisis sobre la sostenibilidad del manejo, la elaboración de planes de manejo de recursos naturales en general y de determinadas especies o recursos en particular como el manejo forestal maderable, de lagartos, de la pesca y otros.

En segundo lugar, un importante número de eventos estuvo referido a la sanidad y el manejo de los animales domésticos; un proyecto, entre cuyos objetivos se encuentran el establecimiento de una red para el control sanitario de la región y el fortalecimiento de las capacidades para la prevención y atención de los animales domésticos.

En tercer lugar, se encuentran los eventos de capacitación relacionados con la planificación territorial que incluye el apoyo a la elaboración de planes comunales, la zonificación tanto a nivel comunal como territorial y la elaboración de los planes de gestión territorial o planes de vida.

En cuarto lugar, se ubican los eventos relacionados con el proceso de autorregulación del acceso y uso de los recursos naturales, tanto a nivel comunal como territorial.

En quinto lugar, están los eventos relacionados con la investigación participativa y el monitoreo, tanto a nivel de la gestión territorial como de las asociaciones productivas basadas en el manejo sostenible de recursos naturales.

En sexto lugar, se ubican los eventos relacionados con género, orientados al fortalecimiento de las organizaciones de mujeres indígenas.

En séptimo lugar, los eventos relacionados con la implementación de la gestión territorial y el fortalecimiento de las capacidades administrativas y financieras sobre procedimientos administrativos y contabilidad para diferentes niveles de la organización indígena tales como el directorio del CIPTA y las asociaciones o emprendimientos productivos.

En el caso de la TCO Lecos de Apolo, el número más significativo, en primer lugar, fueron los eventos relacionados con la planificación territorial, que al igual que en la TCO Tacana, incluye el apoyo a la elaboración de planes comunales y plan de vida a nivel territorial, así como a los procesos de zonificación. En segundo lugar, el manejo de los recursos naturales, especialmente en relación al incienso, café, artesanías y jatata. En tercer lugar, los eventos relacionados con la implementación de la gestión territorial junto al fortalecimiento de las capacidades administrativas y financieras. Y, en cuarto lugar, los eventos relacionados con la autorregulación del acceso y uso de los recursos naturales junto a los eventos sobre investigación y monitoreo, y finalmente los eventos relacionados con salud, que al igual que en el caso de la TCO Tacana I se refieren a la sanidad y el manejo de los animales domésticos. 


\section{GRÁFICO 10: \\ NÚMERO DE EVENTOS DE CAPACITACIÓN SEGÚN TEMA Y TERRITORIO INDÍGENA}

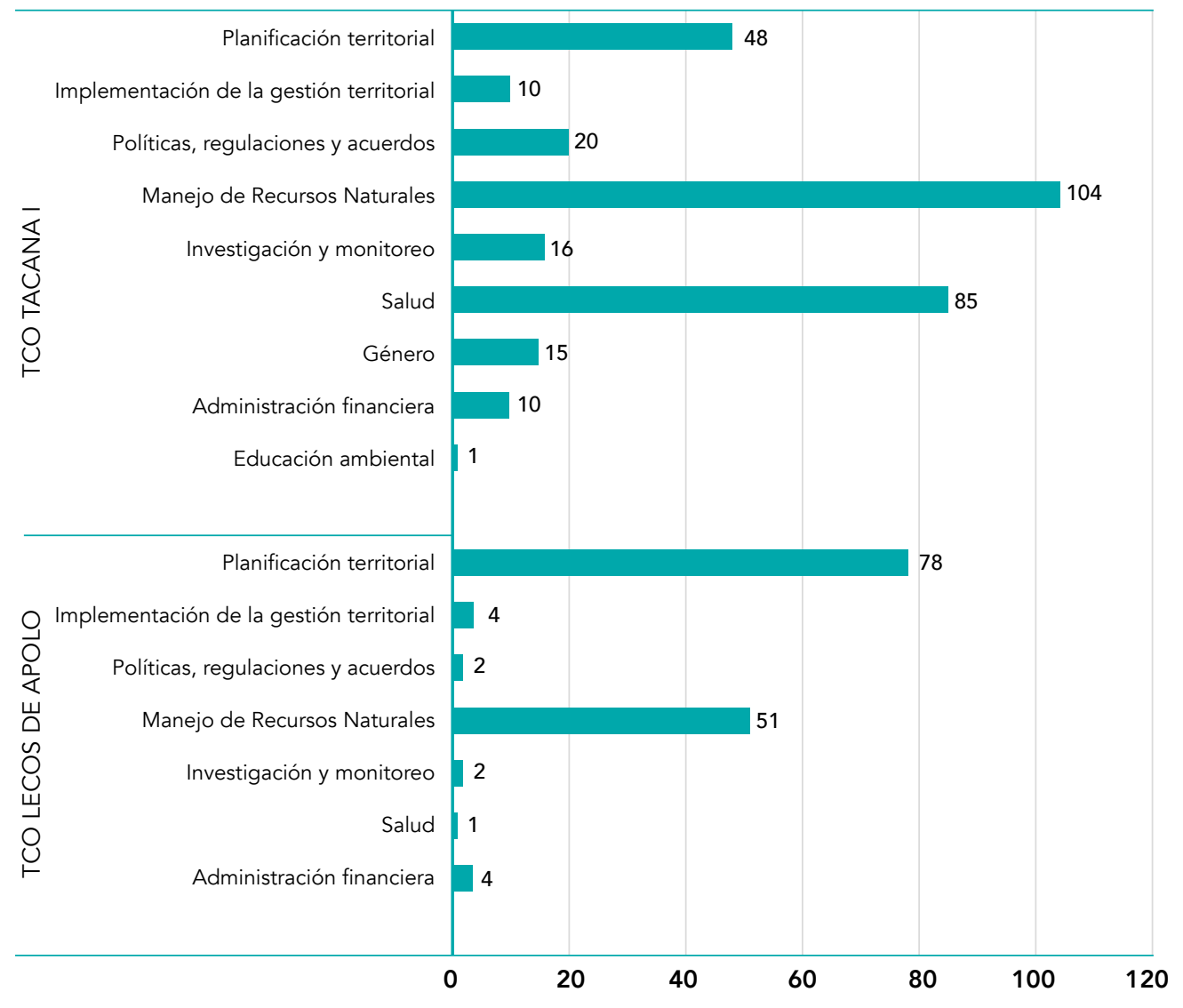

Fuente: (WCS, 2017)

En el Gráfico 10 relativo a la TCO Tacana I, se expresa con mayor claridad el ciclo de la capacitación y asistencia técnica según temas, mostrando la estrategia de apoyo de WCS en Bolivia a la gestión territorial indígena.

El primer año, el apoyo estuvo concentrado en la planificación para la gestión territorial y aunque la incidencia de los eventos en este tema se reduce notablemente en los siguientes años, se mantiene, aunque con menor intensidad. Una vez elaborados y aprobados los planes comunales, zonificación y plan de gestión territorial, en los años sucesivos se mantiene el apoyo a la elaboración de los planes anuales, semestrales o trimestrales incluyendo la capacitación para la elaboración de informes de gestión especialmente al directorio del CIPTA. En el doceavo año, este tema vuelve a tener incidencia como resultado del apoyo de WCS a la sistematización de la experiencia del primer plan y la elaboración del segundo plan de gestión territorial del pueblo Tacana.

Entre tanto, el segundo año se inicia y va en ascenso la asistencia técnica para el manejo de recursos naturales específicos en el marco del plan de gestión territorial. Este tema de capacitación y asistencia técnica encontrará su nivel más alto de incidencia en el quinto año y mantendrá su preeminencia sobre otros temas hasta el final.

El proceso de apoyo a la autorregulación tiene su nivel más alto en el cuarto año. Las acciones de capacitación y asistencia técnica en relación a la investigación y monitoreo, 
tanto en el nivel territorial como de los emprendimientos productivos, se inicia en el segundo año, pero tendrá su nivel más alto de incidencia en el doceavo año. En tanto que la asistencia en administración financiera tendrá el mayor nivel de intensidad en el sexto año, aquí es necesario destacar que el registro de este tipo de eventos se refiere más a eventos formales que a la asistencia en servicio que de manera regular y constante desarrolla WCS en Bolivia. La capacitación para la implementación de un enfoque de género o apoyo específico a la organización de las mujeres tacanas (CIMTA) se inicia en 2007, se mantiene constante con la realización de uno a dos eventos anuales hasta el 2013, pero se incrementa notablemente entre 2014 y 2015 con la finalidad de apoyar a la consolidación del Consejo Indígena de Mujeres Tacanas (CIMTA).

La capacitación y asistencia técnica en sanidad y manejo de animales domésticos se inició en 2005, alcanzando niveles altos de incidencia en 2008 y reduciéndose progresivamente hacia 2011, para incrementarse nuevamente en 2013 y 2014. Este caso, demuestra también que existiendo una estrategia general para apoyar la gestión territorial indígena por parte de WCS en Bolivia, la dinámica de los eventos también está marcada por la disponibilidad de fondos para proyectos específicos.

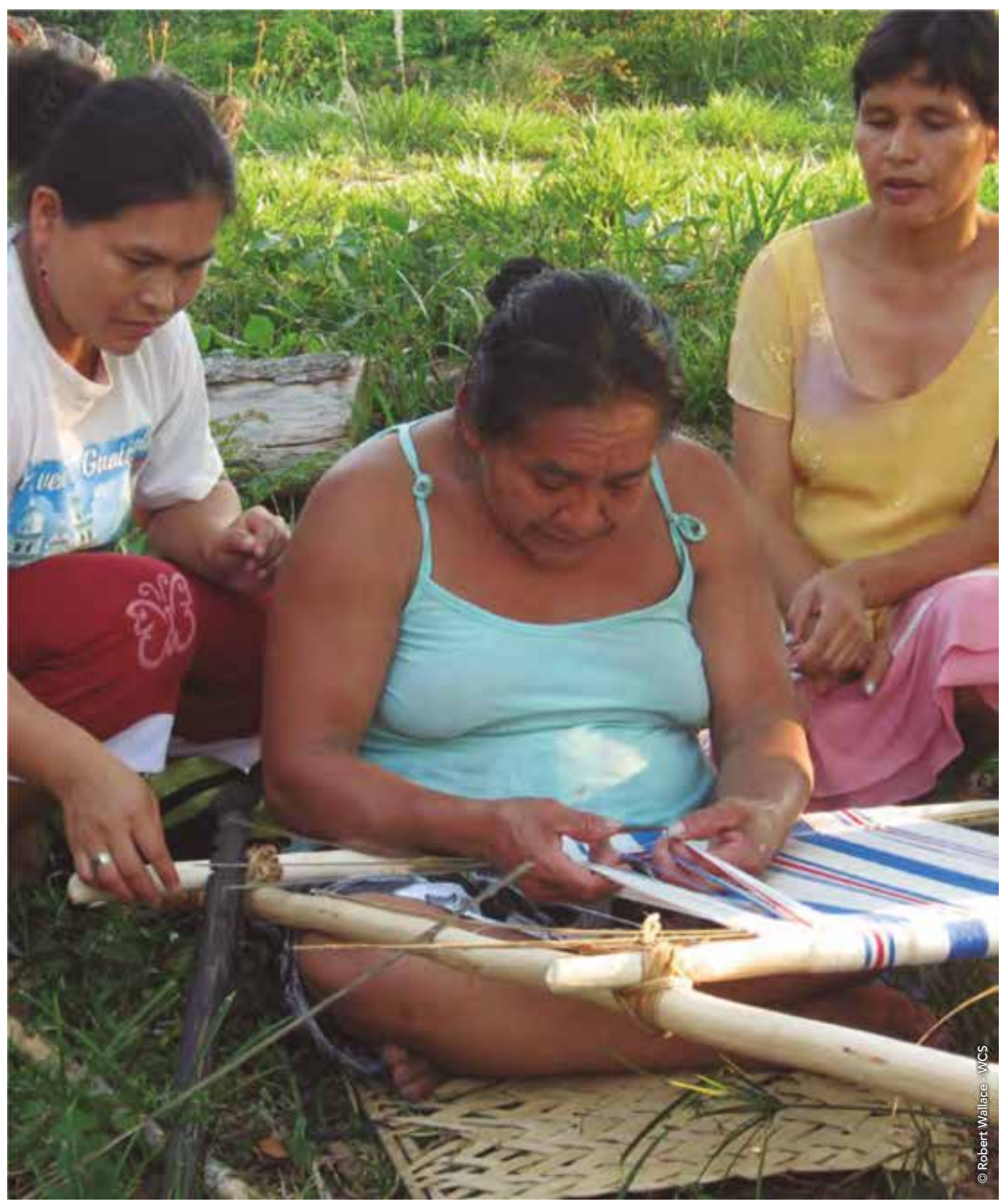


GRÁFICO 11:

TCO TACANA I: NÚMERO DE EVENTOS DE CAPACITACIÓN Y ASISTENCIA TÉCNICA SEGÚN TEMA Y AÑO
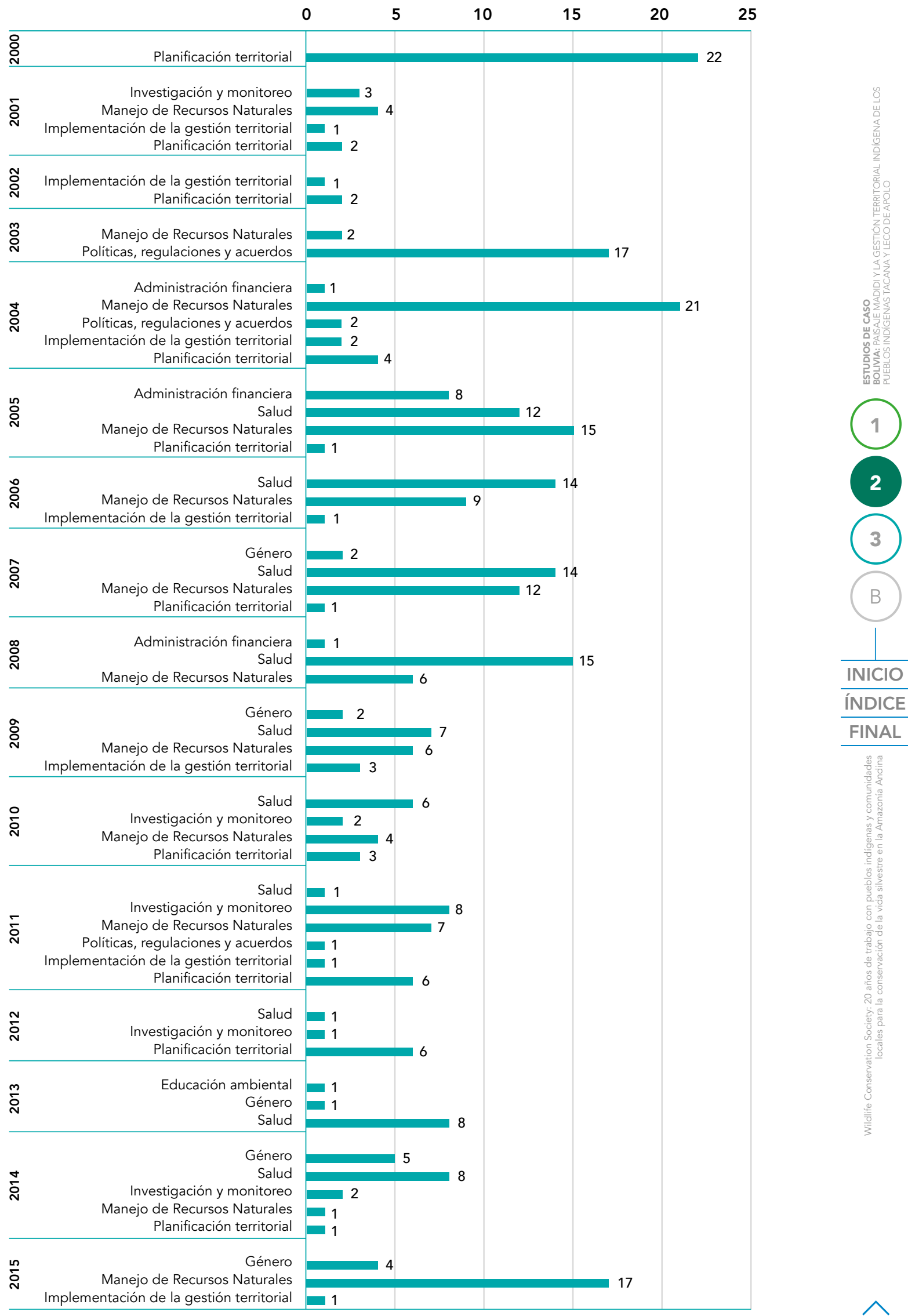
En el caso de los lecos de Apolo, la capacitación y asistencia técnica brindada por WCS, se inicia en 2001 con la planificación territorial, proceso que avanza tímidamente hasta encontrar sus picos más altos en 2007, 2009 y aún 2010. Al igual que en el caso tacana, la asistencia para la planificación territorial es constante y, como se señaló, se refiere a la elaboración de planes comunales como planes de vida a nivel territorial, a los procesos de planificación más operativos, así como a la elaboración de informes sobre la gestión territorial, asistencia brindada principalmente al CIPLA. Simultáneamente a la planificación territorial, en 2007, se inicia y desarrolla la asistencia para la autorregulación tanto orgánica como del acceso y uso de los recursos naturales. La capacitación y la asistencia técnica para el manejo de los recursos naturales específicos inician en 2007, se mantiene en un nivel relativamente bajo hasta 2010 y se incrementa notablemente entre 2013 y 2015. La capacitación en administración financiera, especialmente al directorio del CIPLA, se inicia en 2010 y se mantiene constante hasta el final. Los procesos de capacitación y asistencia técnica fueron más intensivos en la TCO Tacana I que en la TCO Lecos de Apolo.

GRÁFICO 12:

\section{TCO LECOS DE APOLO: NÚMERO DE EVENTOS DE CAPACITACIÓN Y ASISTENCIA TÉCNICA SEGÚN TEMA Y AÑO}

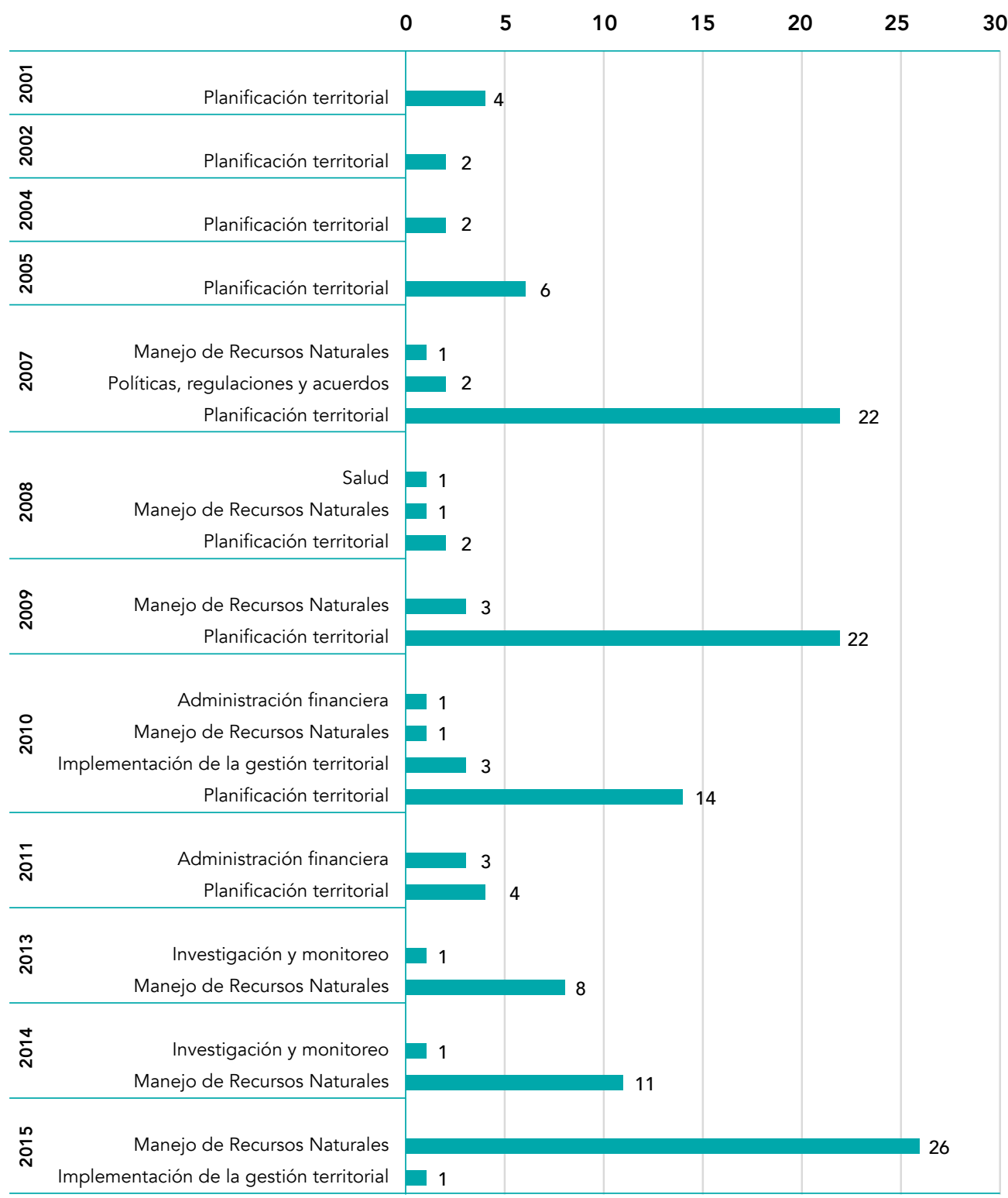


En ambos territorios indígenas, entre 2000 y 2015, los eventos de capacitación y asistencia técnica para la gestión territorial indígena, promovidos por WCS en Bolivia alcanzaron a 11338 participantes ${ }^{12}, 7004$ en la TCO Tacana I y 4334 en la TCO Lecos de Apolo. Se estima que el $59 \%$ de los participantes fueron hombres, el $38 \%$ mujeres y en el $3 \%$ no se registró el sexo de las personas participantes.

\section{GRÁFICO 13: \\ NÚMERO DE PARTICIPANTES EN EVENTOS SEGÚN SEXO (2000 - 2015)}

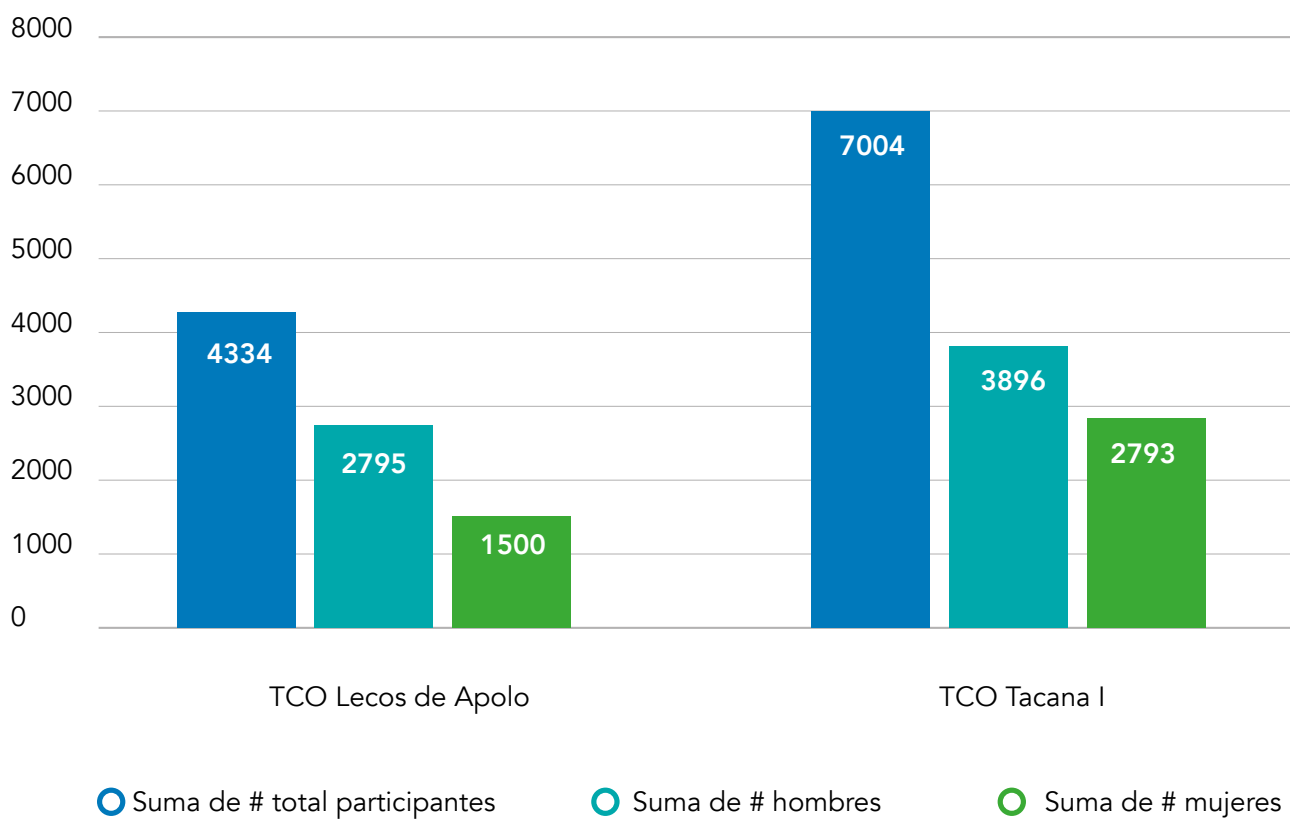

Fuente: (WCS, 2017)

Acorde con las diferencias entre el número de eventos de asistencia técnica y capacitación entre la TCO Tacana I y la TCO Lecos de Apolo, el número de participantes es mayor en la primera respecto de la segunda. En términos de la participación de las mujeres existen importantes diferencias entre ambas TCO, mientras en el caso de los tacanas el porcentaje asciende al $45 \%$, en el caso de los lecos alcanza $35 \%$. Esto se debe al esfuerzo que WCS en Bolivia ha puesto, particularmente en los últimos años, en el fortalecimiento de la organización de mujeres tacanas.

12 En varios casos, se registra a las mismas personas que participaron en diferentes eventos. Aquí se considera la totalidad de participantes en cada evento independientemente de que las mismas personas hubiesen participado en diferentes eventos. 


\section{CONCLUSIONES}

Los procesos organizativos de los tacanas y lecos, base de la gestión territorial indígena y el manejo de los recursos naturales por las comunidades se basó en el fortalecimiento de las redes horizontales y verticales de tipo vínculo. Es decir, se fortalecieron las relaciones entre comunidades de cada pueblo indígena y entre estas y sus entidades representativas a nivel de cada territorio indígena, así como con los niveles orgánicos departamentales y nacionales. A este proceso, iniciado por el movimiento indígena desde los años ochenta en las tierras bajas de Bolivia, WCS contribuyó en la región de Madidi a partir de 1999, en el marco de convenios de cooperación suscritos periódicamente desde 1999 con el CIPTA y desde 2004 con la CIPLA.

Los vínculos horizontales y verticales de las organizaciones indígenas se vieron fortalecidos a través de los conflictivos procesos de saneamiento y titulación de las tierras, la planificación, zonificación y reglamentación en cada territorio indígena. WCS en Bolivia contribuyó tanto técnica como financieramente a estos procesos.

Resultados tangibles como la titulación de 389304 ha y de 238162 ha a favor de CIPTA y CIPLA respectivamente, los documentos de planes de "gestión" o "de vida", incluyendo las zonificaciones de ambos territorios y los reglamentos tanto orgánicos en el caso de CIPLA como de acceso y uso de los recursos naturales de CIPTA y CIPLA constituyen importantes contribuciones. Sin embargo, tanto o igualmente relevantes fueron los procesos intangibles como el fortalecimiento de las redes orgánicas y de las identidades indígenas. Estos últimos fueron posibles gracias a los procedimientos de implementación de las acciones y fueron determinantes para asegurar la sostenibilidad social tanto de la gestión territorial como del manejo de los recursos naturales.

En el cómo se desarrollaron estos procesos destacan: 1) el trabajo conjunto entre las dirigencias indígenas y el personal técnico de WCS, 2) el trabajo realizado en cada comunidad, 3) la promoción del encuentro entre comunidades y de estas con sus dirigentes y 4) la continuidad del apoyo a los procesos de implementación de los planes de gestión territorial de manera sistemática, periódica y durante varios años.

El enfoque de los "paisajes vivientes" como en el caso del Paisaje Madidi implica la conservación de las áreas protegidas, al mismo tiempo que otras unidades de gestión como los territorios indígenas y las conexiones entre estas unidades. $\mathrm{Si}$, lo anterior se realiza en el plano geográfico, en términos sociales implica la construcción de relaciones de tipo "puente" entre actores sociales o grupos de gobernanza diferentes.

En el contexto anterior y entre el conjunto de unidades de gestión y grupos de gobernanza que constituyen el "gran paisaje Madidi", WCS en Bolivia estableció relaciones preferentes con el SERNAP en relación a las Áreas Protegidas y las organizaciones indígenas titulares de los derechos pre constituidos sobre los territorios indígenas. Esta preferencia se funda en el reconocimiento de los derechos de los pueblos indígenas a su territorio, así como a su probada vocación por la conservación, en contraste con otros actores sociales del "gran paisaje".

La relación entre una entidad de conservación como WCS y las organizaciones indígenas constituye precisamente un lazo de tipo "puente", donde cada entidad tiene sus propias agendas: las organizaciones indígenas, la titulación de sus territorios y la ONG, la conservación de la vida silvestre y los ecosistemas. Además, las organizaciones indígenas representan los intereses de particulares formas de desarrollo que demandan sus comunidades. El logro de acuerdos de largo plazo entre WCS en Bolivia y el CIPTA y la CPILAP, además del reconocimiento del derecho preferente de los pueblos indígenas y el compromiso de largo plazo ha demandado la construcción de instrumentos y mecanismos que están orientados a tender puentes entre la conservación y el desarrollo de las 
comunidades: la zonificación, los procesos de autorregulación, la identificación de los corredores biológicos entre las áreas protegidas y los territorios indígenas, la aplicación del enfoque "fuente" - "sumidero" en el manejo de la fauna silvestre, constituyen algunos de estos mecanismos.

El apoyo a la titulación de los territorios indígenas, una propuesta de gestión de desarrollo sustentable construida conjuntamente desde las mismas comunidades y no menos importante el haber enfrentado juntos la conflictividad social desatada por los procesos de saneamiento y la titulación de las tierras principalmente de los pueblos indígenas pero también de las propiedades de terceros, también serían determinantes para la construcción de una relación de "tipo puente", cuya complejidad es advertida por la teoría del capital social (Putnam \& Feldstein, 2003).

De cara a la compatibilización entre las necesidades de conservación de las "especies paisajes" y las necesidades de las comunidades indígenas de gozar de la fauna silvestre como principal fuente de proteínas, WCS desarrolló las investigaciones científicas en ambos polos de esta cadena y en el camino necesario para unirlos. Por un lado, la determinación de la fuente de la cacería en el PNANMI Madidi y la estimación del nivel de consumo de las comunidades y la identificación de los "corredores" de las especies animales entre el área protegida y el territorio indígena, la presentación de los resultados al CIPTA y sus comunidades así como la toma de decisiones del pueblo indígena con la finalidad de proteger estos corredores, expresan claramente una forma de demostrar que la compatibilidad entre conservación y bienestar de las comunidades no solo es posible sino imperativa para lograr que la conservación se convierta, no en acciones asiladas de comando y control, sino en "acción social" de las comunidades y sus organizaciones territoriales.

La construcción de relaciones de "tipo puente" entre el Servicio Nacional de Áreas Protegidas (SERNAP) y las organizaciones indígenas requirió: 1) que cada actor involucrado cuente con instrumentos de gestión comparables y para ello, trabajar primero con cada uno por separado, 2) considerar los planes de gestión territorial o planes de manejo de las áreas protegidas como "acuerdos sociales", 3) a partir de lo anterior, establecer espacios de negociación donde ambos actores son considerados como iguales: la propuesta para la gestión compartida de las áreas protegidas sobrepuestas a territorios indígenas expresa ese tipo de relación.

La "gestión compartida" de las áreas protegidas parcial o totalmente sobrepuestas a territorios indígenas constituye uno de los mecanismos posibles que hacen operativo el paradigma de conservación "por la gente", a diferencia de los programas que se generan desde las áreas protegidas para beneficiar a las poblaciones locales o de los Comités de Gestión o Contratos de coadministración que responden más bien a los paradigmas de conservación "para la gente", en el primer caso o "con la gente" en el segundo. Ninguno de estos tiene la profundidad que significa una relación entre el Estado y los pueblos indígenas como entidades que se relacionan en términos de igualdad como el mecanismo de la "gestión compartida".

A diferencia de los Comités de Gestión donde todos los actores sociales pretenden relacionarse como iguales entre ellos, pero en una relación jerárquica con el Estado, la "gestión compartida" discrimina afirmativamente a los pueblos indígenas en tanto sujetos con derechos territoriales "pre constituidos" y establece el marco para una relación de iguales entre ellos y el Estado. Sin embargo, la complejidad y dificultades para construir esta relación de "tipo puente" entre el Estado y las organizaciones indígenas para la gestión compartida derivan en gran medida de la propia complejidad del Estado y de las relaciones de este con una diversidad de otros sectores estatales o actores sociales con intereses frecuentemente contrapuestos a los derechos territoriales indígenas y a la conservación de las áreas protegidas. La experiencia de construcción de la propuesta 
de modelo de gestión compartida entre WCS en Bolivia y las organizaciones indígenas demostró la necesidad de trabajar en los diferentes niveles (locales, departamentales y nacionales) tanto del Estado como de las organizaciones indígenas y en múltiples sentidos tanto "de arriba hacia abajo" como de "abajo hacia arriba".

Frente a los procesos de desestructuración de los sistemas tradicionales de regulación indígena respecto del acceso y uso de los recursos naturales, la construcción colectiva de reglamentos formales demostró ser efectiva para paliar los conflictos al interior de las comunidades pero sobre todo como mecanismo de empoderamiento de las comunidades frente a terceros que invaden o ingresan a los territorios indígenas para extraer recursos naturales de manera ilegal. La persistencia de huellas del sistema tradicional comparado con los reglamentos formales y la constatación de las dificultades para que las autoridades comunales impongan las sanciones contenidas en ellos, permitió demostrar la naturaleza diferente de las reglas tradicionales regidas por las deidades de los pueblos indígenas frente al secular carácter de los reglamentos formales y por tanto las limitaciones en el alcance de estos últimos. De esta discusión deriva la importancia del debate en torno al pluralismo jurídico relacionado específicamente con el acceso y el uso de los recursos naturales.

Tomando en cuenta las características de las reglas de acceso común y que aseguran la sostenibilidad de los recursos naturales evitando la "tragedia de los comunes", la experiencia de WCS y los tacanas y lecos de Apolo, permite establecer que la titulación, la zonificación, la demarcación territorial y los planes de manejo de recursos específicos, contribuyeron a establecer con mayor claridad los límites de los recursos en cuestión. Los reglamentos, por su parte, contribuyeron a la clarificación de los criterios para la definición de quiénes tienen los derechos de acceso y uso. Las reglas de uso están claramente orientadas a la sostenibilidad del recurso, pero se hace necesario reforzar los sistemas de monitoreo para asegurar que sean conservadoras y prevean un margen de error para evitar la extinción de las especies. Finalmente, si bien los reglamentos formales prevén los periodos de cambio de las reglas, el carácter de estos, hace que sean un poco rígidos en su adaptabilidad. Aspecto que será considerado nuevamente al tratar el sistema de acuerdos comunales que WCS en Perú ha venido apoyando en la región de Tamshiyacu - Tahuayo.

En el caso de WCS en Bolivia, destaca el hecho de que el apoyo a las iniciativas de manejo de los recursos naturales por las comunidades se enmarca en la gestión territorial indígena, es decir: se relaciona con los Planes de Gestión Territorial o Planes de Vida, las zonificaciones territoriales y, particularmente en el caso tacana, busca que las asociaciones productivas estén articuladas con las comunidades y la organización territorial a través de la distribución de las utilidades netas que produzcan los emprendimientos, la separación clara de las funciones de apoyo y control en manos de las dirigencias del nivel territorial y comunal respecto de las funciones gerenciales propias de las asociaciones productivas, generándose de esta manera un modelo que busca orientar todo el sistema hacia la gestión transparente y las rendiciones de cuentas recíprocas entre los diferentes niveles orgánicos.

Lo anterior requiere a su vez, el fortalecimiento técnico, administrativo y financiero y de las organizaciones indígenas del nivel territorial y su empoderamiento, lo que WCS en Bolivia buscó hacer también a través de la creación de un fondo concursable de proyectos de manejo de recursos naturales a ser ejecutados por las comunidades y coadministrado por CIPTA y WCS.

Los procesos de capacitación y asistencia técnica de WCS en Bolivia para el manejo sostenible de los recursos naturales se ha basado en un enfoque de cadena que, en los casos más exitosos se caracteriza por haber seguido la siguiente ruta crítica: 1. Demanda o consulta a las organizaciones y comunidades interesadas. 2. Estudios de la distribución, 
densidad y estructura de las poblaciones silvestres y su ecología, aspectos socio-económicos y culturales y sondeos de mercado. 3. Análisis de los resultados con las comunidades involucradas. 4. Apoyo al proceso de organización de asociaciones comunitarias (bajo diferentes modalidades según el tipo de recurso, el tiempo que la gente quiere dedicar a la actividad, etc.). 5. Elaboración de los planes de manejo y acompañamiento a las asociaciones para gestionar su aprobación ante las entidades estatales competentes. 6 . Asistencia en servicio y capacitación técnica tanto en las labores de cosecha como de post cosecha según el tipo de producto y de acuerdo a las exigencias del mercado, y en aspectos administrativos, contables, de comercialización y monitoreo. 7. Identificación de nichos de mercado caracterizados por sus altos precios y responsabilidad social. 8. Diseño, establecimiento y apoyo en la implementación de sistemas de monitoreo. 9. Promoción del intercambio de experiencias entre productores y productoras. El apoyo de WCS en Bolivia a estas iniciativas se realiza al menos durante 10 años. De esta manera, desde 2000 hasta 2015, WCS ha apoyado con diferentes grados de intensidad a 27 asociaciones productivas en la TCO Tacana I y la TCO Lecos de Apolo.

La gestión territorial indígena no solo como instrumento de gobernanza sino como enfoque teórico junto al de las "esferas económicas" de las economías indígenas y los referidos a la equidad social y de género han permitido a WCS en Bolivia una mejor comprensión de las dinámicas económicas de los hogares tacanas, mostrando su alta dependencia, en términos de los ingresos, de los ecosistemas bien conservados, al mismo tiempo de poner en evidencia el carácter aún dominante de la "esfera de la reciprocidad" en un contexto, sin embargo, donde también se aprovechan las oportunidades del mercado. Estos enfoques han permitido demostrar la importancia de la educación en la generación de los ingresos de los hogares tacanas y de la necesidad de reducir brechas de inequidad evidentes en términos de género y según tipos de familias.

El establecimiento y desarrollo de la Gestión Territorial Indígena incluyendo el manejo de recursos naturales específicos, en el caso de Bolivia, ha demandado considerables esfuerzos de capacitación y asistencia técnica y financiera especialmente a las comunidades y asociaciones productivas del pueblo Tacana. Estos procesos se han desarrollado con la participación plena de los directorios tanto del CIPTA como del CIMTA.

La secuencia de estos procesos de asistencia técnica marca una ruta crítica (encadenamiento de acciones para el logro de resultados) entre cuyas acciones destacan: 1. La facilitación de asistencia legal y capacitación para optimizar la participación indígena durante el proceso de saneamiento y titulación de las TCO. 2. El acompañamiento y la asistencia técnica en servicio para la formulación de planes de gestión territorial incluyendo los procesos de mapeo comunal y las zonificaciones a nivel de los territorios indígenas (con el correspondiente diseño de metodologías participativas, su aplicación y la formulación de planes comunales de cuya agregación resultaron los Planes de Gestión Territorial o Planes de Vida). 3. Promoción de la discusión sobre la sostenibilidad en el uso de los recursos naturales incluyendo la facilitación de la construcción de conceptos, principios y criterios propios del pueblo Tacana sobre la sostenibilidad y la elaboración participativa de planes de manejo de recursos naturales específicos. 4. Promoción y facilitación de procesos de autorregulación respecto del uso de los recursos naturales (definiendo y clarificando los límites de las áreas de uso de los recursos, la clarificación de los sujetos de los derechos, la definición de las prácticas permitidas y no permitidas en el acceso y uso de los recursos naturales, la distribución de beneficios y las sanciones). En el caso del pueblo Leco de Apolo, la autorregulación comprende también la definición de los procesos de consulta frente a proyectos externos de infraestructura o extracción de recursos no renovables. 5 . Asistencia técnica y capacitación en aspectos administrativos y financieros. 6. Asistencia para el monitoreo y la investigación. 7. Capacitación y promoción de la discusión sobre temas transversales relevantes para la gestión territorial indígena como la equidad de género. 
La sistematización de los procesos de Gestión Territorial Indígena y de manejo de los recursos naturales que ha apoyado WCS en el "Gran Paisaje Madidi" ha permitido identificar un modelo general de colaboración de una entidad de conservación como WCS en Bolivia con las organizaciones indígenas y la promoción de relaciones de "tipo puente" con el Estado para asegurar la conservación a una escala que trasciende tanto a las áreas protegidas como a los territorios indígenas. Sin embargo, aquí es necesario destacar que este proceso no ha sido lineal, se ha forjado con avances, retrocesos y altibajos. En este quehacer, es necesario destacar aspectos o momentos críticos de este proceso. Uno de ellos, referido al hecho de que mientras la organización de conservación ha ido vislumbrando una secuencia de procesos e identificando metas, la complejidad de construir procesos sociales impone sus propios ritmos, incluso con frecuencia, las dificultades que surgen están más allá de la voluntad de los propios actores sociales, el ejemplo más claro de esto son los procesos de saneamiento y titulación de los territorios indígenas, donde la conflictividad social, está más allá de la voluntad de las propias comunidades y organizaciones indígenas, e impone su propio devenir y ritmo al proceso. En el mismo sentido, la "conservación por la gente" implica cambios en las relaciones sociales, en los comportamientos y en la cultura política de los actores sociales no solo en los territorios indígenas sino fundamentalmente también de su entorno. Todo esto, demanda trabajo intenso y conciencia de que se trata de procesos de largo plazo.

Es necesario además reconocer, que estos procesos requieren liderazgos indígenas lúcidos con visión estratégica y fundamentalmente con altos niveles de legitimidad, es decir con gran arraigo en las comunidades. Esta condición facilita enormemente los procesos, su ausencia no solo los desacelera, sino que puede conducir a su descalabro. En este campo, WCS en Bolivia ha desarrollado esfuerzos para la capacitación y asistencia en los aspectos más técnicos de los procesos. La formación de líderes y lideresas se ha dejado librada al quehacer de las propias organizaciones indígenas, sin embargo, la experiencia de los vaivenes y altibajos en los procesos de la Gestión Territorial Indígena y el manejo de los recursos naturales demuestran que aún, las organizaciones indígenas requieren ser apoyadas para desarrollar sus propios procesos de formación de liderazgos. El trabajo de la organización de conservación con una visión de "abajo" hacia "arriba", articulando a los líderes y sus comunidades, sin duda ayuda a procesos más sostenibles y resilientes. Sin embargo, ese proceso requiere la formación de líderes con visión territorial y de defensa de los territorios indígenas, lo que implica, además, ampliar y profundizar los mecanismos de "balance de pesos y contrapesos" en la relación de los líderes con sus bases para asegurar sistemas de gobernanza con vocación de transparencia, representatividad y legitimidad.

Lo anterior destaca en su importancia si se considera que tanto las áreas protegidas como los territorios indígenas enfrentan renovadas, crecientes y nuevas amenazas relacionadas con proyectos desarrollistas de gran escala y la expansión del "extractivismo".

Finalmente, pero no menos importante, es necesario destacar que, pese a los esfuerzos e intentos diversos por asegurar mecanismos de financiamiento sostenible para los procesos de Gestión Territorial Indígena, ninguno de estos ha logrado consolidarse, aunque este aspecto constituye una condición fundamental para el ejercicio de la autonomía indígena. 


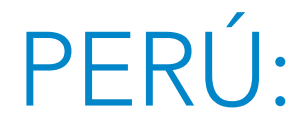

\section{ÁREA DE CONSERVACIÓN REGIONAL COMUNAL TAMSHIYACU TAHUAYO. LA CONSERVACIÓN POR LAS COMUNIDADES RIBEREÑAS}

El Área de Conservación Regional Comunal Tamshiyacu Tahuayo (ACRCTT) tiene una superficie de 420 080,25 ha y se ubica en los distritos Fernando Lores de la provincia de Maynas, Yavarí de la provincia Mariscal Ramón Castilla y Sapuena y Yaquerana de la provincia de Requena, en el departamento de Loreto. Está limitada al oeste por los ríos Alto Tahuayo y Quebrada Blanco, por el sur con el Alto Yarapa, por el este por el Alto Yavari Mirin y por el norte con el Alto Tamshiyacu. Se encuentra a una distancia de 90 $\mathrm{km}$ de la ciudad de lquitos y es accesible solo por vía fluvial. El transporte, entre lquitos y la localidad de Tamshiyacu sede del Distrito Fernando Lores, es frecuente, existen botes comerciales o privados que transitan diariamente por la zona (Bodmer, y otros, 2006; GOREL y PROCREL, 2010). La ciudad próxima más grande es lquitos con 432476 habitantes (INEI, 2016, pág. 7).

En el área habita una especie de primate endémica del Perú y vulnerable: el huapo rojo (Cacajao calvus ucayalii). Desde la década de 1970, su presencia atrajo a investigadores tanto peruanos como de otras partes del mundo y fue determinante para el reconocimiento de la región como área protegida. Tamshiyacu - Tahuayo es un área de alta diversidad biológica especialmente de primates. Alberga extensos palmares entre los que destacan los aguajales (Mauritia flexuosa) y parches de comunidades de plantas propias de las "campiñas" en suelos pobres en nutrientes y de arenas blancas. Está conformada por bosques de tierra firme y bosques inundados de várzea que dividen el valle del Amazonas y el del Yavari, bañados por ríos de aguas blancas como el Tamshiyacu y de aguas parcialmente negras (mixtas entre blancas y negras) como el Tahuayo.

En términos de su representatividad ecosistémica, debido a la presencia de los bosques de tierra firme, el ACRCTT es complementaria a la Reserva Nacional Pacaya Samiria donde predominan los bosques inundables de várzea y cumple una función de corredor para aves migrantes boreales, australes y transamazónicas (Bodmer, Penn, Puertas, Moya, \& Fang, 1995; Comité de Gestión del ACRCTT, Wildlife Conservation Society, Instituto DICE de la Universidad de Kent, 2005; Bodmer, y otros, 2006; GOREL y PROCREL, 2010). El ACRCTT forma parte de una región más extensa, la amplia región interfluvial entre el Ucayali, Amazonas y Yavarí. A primera vista es una región bastante homogénea, sin embargo, presenta heterogeneidad en términos topográficos, suelos y tipos de bosque. Esta variabilidad deriva en alguna medida de una estructura elevada de la zona conocida como el Arco de lquitos (The Field Museum, 2003, pág. 33).

En la región próxima a la ACRTT existen aproximadamente 62 comunidades ribereñas, 33 de las cuales se encuentran más vinculadas a la Reserva y fueron identificadas en 1993 y 2015 (Flores, Antúnez, Padilla, Silva, \& Lehm, 2016; Bodmer, Penn, Puertas, Moya, \& Fang, 1995). La población de estas comunidades asciende a 6238 habitantes de diferente procedencia, mayormente descendientes de una diversidad de pueblos indígenas amazónicos (Chirif, 2012). En adelante, denominaremos a toda esta región "Tamshiyacu - Tahuayo". 
MAPA 3: ÁREA DE CONSERVACIÓN REGIONAL COMUNAL TAMSHIYACU TAHUAYO

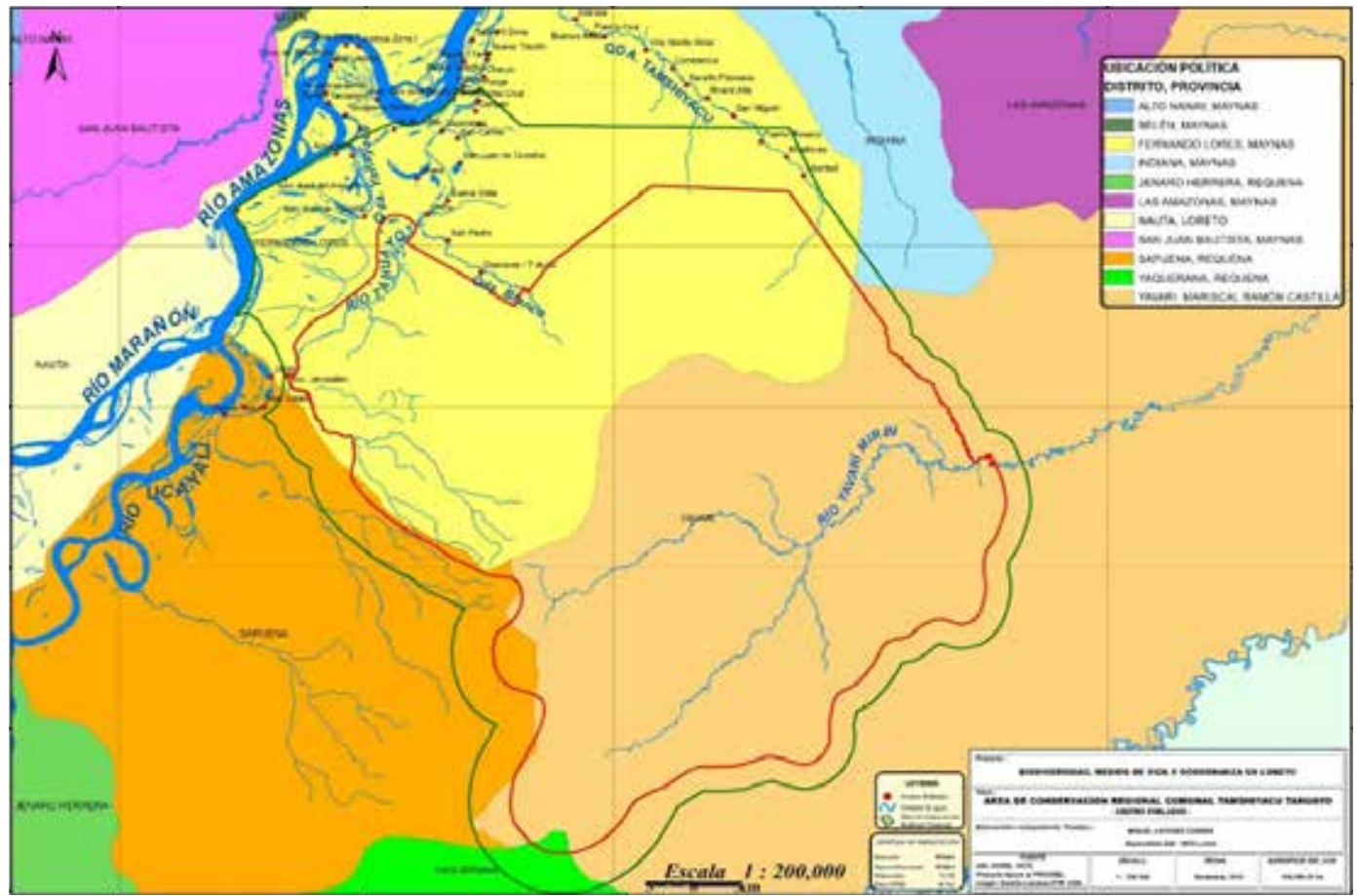

Fuente: (Flores, Antúnez, Padilla, Silva, \& Lehm, 2016)

La región de Tamshiyacu - Tahuayo es una zona núcleo de conservación dentro del "Gran Paisaje Yavarí-Samiria" por WCS, el cual comprende 8 623,890 hectáreas en la porción central de la Región Loreto en el noreste de Perú. 


\section{EL ENFOQUE ECONÓMICO PARA EL USO SOSTENIBLE DE LOS RECURSOS NATURALES SOBRE LA BASE DE LA FAUNA SILVESTRE}

En relación a la región del Tamshiyacu - Tahuayo, especialmente desde fines de los años 1980, sobre la base de las acciones tomadas por las comunidades a favor de la conservación, investigadores vinculados a WCS y otras instituciones y universidades peruanas y extranjeras venían discutiendo la problemática de la sostenibilidad del uso de los recursos naturales por las comunidades y la conservación (Bodmer, 1993; Bodmer, Penn, Puertas, Moya, \& Fang, 1995; GOREL y PROCREL, 2010).

El criterio central de esta discusión, muy difundido en la actualidad, está referido al valor económico que los recursos naturales tienen para la población local. Si los recursos naturales pierden el interés económico de la población local, entonces, esta no tendrá incentivos para su conservación y más bien se inclinará por actividades menos sostenibles, más orientadas al cambio del uso del suelo. Esto significa que la conservación debe considerar el uso sostenible de los recursos naturales por la población local.

Lo anterior supone la discusión sobre los límites del uso para asegurar la permanencia de las especies, pero al mismo tiempo un ingreso económico monetario y no monetario suficientemente atractivo como para asegurar que los hogares de las comunidades ribereñas no opten por actividades menos amigables para la conservación de las especies. Asimismo, este enfoque económico aborda la problemática de los ingresos de corto y largo plazo. Entendiendo que la sostenibilidad implica ingresos moderados en largos periodos de tiempo frente a usos menos sostenibles que generan ingresos extraordinarios en el corto plazo, pero con reducciones sistemáticas por el agotamiento de los recursos en el largo plazo. El manejo constituye el medio para asegurar la sostenibilidad en el uso de los recursos naturales. El aprovechamiento por encima de la capacidad de los sistemas naturales para la reposición de las especies conduce a la pérdida de la biodiversidad y simultáneamente al empobrecimiento de la población local.

Al mismo tiempo, esta propuesta implica considerar las múltiples interrelaciones entre las condiciones ambientales específicas de la región y sus variaciones subregionales, entre las especies de flora y fauna, así como la vinculación de todo lo anterior con las diferentes actividades económicas de los hogares y comunidades: la agricultura, la caza, la pesca, el aprovechamiento de la madera y de los recursos forestales no maderables, y en el caso del Tamshiyacu - Tahuayo principalmente las palmeras.

Entre los factores más importantes de la propuesta que articula el uso de los recursos naturales por la población local y la conservación, se encuentra el ordenamiento de la tierra, buscando establecer una gradiente de zonas de uso que va desde las áreas bajo conservación estricta donde los usos están completamente restringidos, zonas para usos de subsistencia, y zonas de uso intensivo para agricultura y otros usos con fines tanto de subsistencia como de mercado. Simultáneamente, se considera a las zonas de conservación estricta como fuentes de recursos naturales (particularmente cuando se refiere a la fauna silvestre sujeta a la cacería) y las áreas de uso como "sumideros", en una relación de dependencia de la segunda frente a la primera.

Finalmente, aunque no menos importantes en esta perspectiva, es el análisis del marco legal y de las políticas estatales relacionadas con los recursos naturales así como de la historia ambiental y económica, para comprender tanto las oportunidades o identificar los cuellos de botella legales y las deficiencias en las políticas como los procesos demográficos y las decisiones económicas de la población local (Coomes, 1991; Bodmer, 1993; Bodmer, Penn, Puertas, Moya, \& Fang, 1995). 


\section{BREVE HISTORIA SOBRE EL USO DE LOS RECURSOS EN LA REGIÓN}

Probablemente, la "historia larga" del ACRCTT es más comprensible en su referencia a la subcuenca del Yavarí. En las tempranas descripciones sobre el Amazonas (1639), en el contexto del asombro general por la riqueza de toda la cuenca, de la diversidad, multitud y crecidas poblaciones nativas, sus habilidades e ingenio en el manejo de su entorno, destaca el que se refiere a la región del Yavarí por su abundancia en pesca y caza (D'Acuña, 1865, pág. 228; The Field Museum, 2003, pág. 92).

Mucho más tarde, en el siglo XIX, las descripciones refieren a la ocupación de la región del Yavarí por los "mayorunas" también conocidos como matsés. Puede comprenderse al Yavarí como el eje central del territorio de dicho pueblo indígena, en tanto que al Yavari Mirin y la Quebrada Blanco (que son parte de la actual ACRCTT) como áreas de expansión. En las descripciones destacaba la intrepidez de los mayorunas y su mayor dedicación a la caza y a la pesca que a la agricultura (The Field Museum, 2003, pág. 92).

Durante los siglos XVII y XVIII, toda la región de Loreto fue sometida a procesos extractivos con fines comerciales principalmente de copaiba (Copaifera reticulata), provisiones navales como el copal (Dacryodes sp) y condimentos como la zarzaparrilla (Smilax spp) y la vainilla (Vanilla planifolia), además de otros productos como ceras, miel y huevos de tortuga (Villarejo, 1979: 128 - 129 cit en (Padoch, 1990, pág. 166).

Entre 1880 y 1915, el auge de las gomas elásticas cambió la configuración de la región completamente. En la década de 1860, el establecimiento de la ciudad de lquitos como centro administrativo y de gobierno, la intensificación de la navegación por los ríos y el arribo de importantes contingentes de población serían solo los aspectos más evidentes de estos cambios (Padoch, 1990). En la subcuenca del Yavarí, hacia 1903, se registraban 55 establecimientos gomeros con más de 1000 estradas (The Field Museum, 2003). La población matsés fue empujada a los bosques interiores y sus otrora numerosas poblaciones se redujeron drásticamente. La región en general, fue ocupada por pobladores de diversos lugares. La configuración social actual de las comunidades ribereñas en Loreto, debe su característica multiétnica al periodo gomero.

La caída del boom gomero hacia 1915 debido al derrumbe de los precios internacionales por la producción de goma en las plantaciones asiáticas, determinó la salida de los patrones gomeros. La consolidación de los asentamientos más antiguos del Tamshiyacu - Tahuayo se remonta a ese periodo, especialmente hacia 1930 (Coomes, 1991; Bodmer, Penn, Puertas, Moya, \& Fang, 1995; Chirif, 2012; Flores, Antúnez, Padilla, Silva, \& Lehm, 2016).

En adelante, sin alcanzar la espectacularidad del boom gomero, se sucedieron cortos auges de otros recursos forestales con precios altos en el mercado internacional, tales como: hacia 1925 la exportación de tahua o marfil vegetal, semilla de la palma de yarina (Phytelephas macroscarpa), para la fabricación de botones o piezas de juego a cuya caída, le seguiría la explotación de balata (Manilka rabindetata) o leche caspi (Couma macrocarpa); entre 1930 y 1940, la exportación de barbasco (Lonchocarpus spp) para la producción de insecticidas cuya caída se debió a la producción sintética del DDT y otros; asimismo, se exportó en cantidades significativas el aceite de palo rosa (Aniba rosaedora) para perfumar jabones y el ojé (Ficus insípida) como antihelmíntico (Padoch, 1990); la cacería intensiva de animales silvestres, particularmente de jaguar y lobo de río, por las pieles duró hasta 1973, cuando Perú suscribió la Convención sobre el Comercio Internacional de Especies Amenazadas de Fauna y Flora Silvestres (CITES) y maderas con alto valor comercial como la caoba (Swietenia macrophyla) y el cedro (Cedrela) (Bodmer, Penn, Puertas, Moya, \& Fang, 1995; The Field Museum, 2003). Una característica común de estos procesos extractivos ha sido la sobreexplotación de los recolectores (Padoch, 1990). 
En la región de lquitos, en 1969, con la promulgación de la Ley Agraria y la expropiación de fundos rústicos se habrían creado las condiciones de un régimen de acceso abierto y desregulado a los recursos naturales, acompañado de un proceso inmigratorio e incremento de la población influido por la expectativa de la distribución de las tierras. Sin alcanzar la espectacularidad del auge gomero, esto estimuló el aprovechamiento desmedido de una diversidad de recursos naturales tanto por los habitantes de Tamshiyacu - Tahuayo como por comerciantes residentes en lquitos. Si bien al principio esto generó ganancias extraordinarias, progresivamente irían menguando con el agotamiento de los recursos naturales. Los empresarios de lquitos que al principio generaban empleo para la población de las comunidades, progresivamente se vieron en la situación de constreñir sus costos de producción y basaron sus operaciones en "un selecto grupo de trabajadores de lquitos, eludiendo a menudo a los trabajadores locales y generando por tanto, menos beneficios" (Bodmer, 1993, págs. 8-9; Bodmer, Penn, Puertas, Moya, \& Fang, 1995).

Aunque aún importantes para la economía de la región, entre 1950 y 1980, las industrias extractivas habían dejado de ser la principal fuente de ingresos, para ceder su importancia a las actividades agropecuarias, en alguna medida debido al incentivo estatal para la producción de arroz y ganadería a través de préstamos (Padoch, 1990, pág. 171; Coomes, 1991). Cuando concluyeron los programas de préstamos, la importancia de la agropecuaria decayó y los productos del bosque recuperaron relativamente su relevancia económica (Bodmer, Penn, Puertas, Moya, \& Fang, 1995, pág. 41)

Las epidemias y la difusión de las enfermedades fueron uno de los factores determinantes en las caídas demográficas de las poblaciones indígenas amazónicas (Denevan, 1980). Aún en la historia reciente, las comunidades del Tamshiyacu Tahuayo recuerdan el impacto que sufrieron con las epidemias: en la década de 1960 de varicela y en 1990 de cólera y malaria (Flores, Antúnez, Padilla, Silva, \& Lehm, 2016). En 1995, una epidemia de malaria cerebral afectó a la región del Yavarí (The Field Museum, 2003). La mortandad y emigración de la población rural determinaron importantes caídas demográficas en las comunidades.

La historia de la región amazónica y de Loreto en general y del Yavarí y Tamshiyacu Tahuayo en particular ha estado marcada por la explotación de sus recursos naturales. Este aprovechamiento basado en los flujos de los precios y la competencia internacional generaron ingresos considerables a la región, sin embargo, los costos en términos de la existencia de las especies y la explotación de la fuerza de trabajo han sido muy altos y su duración limitada.

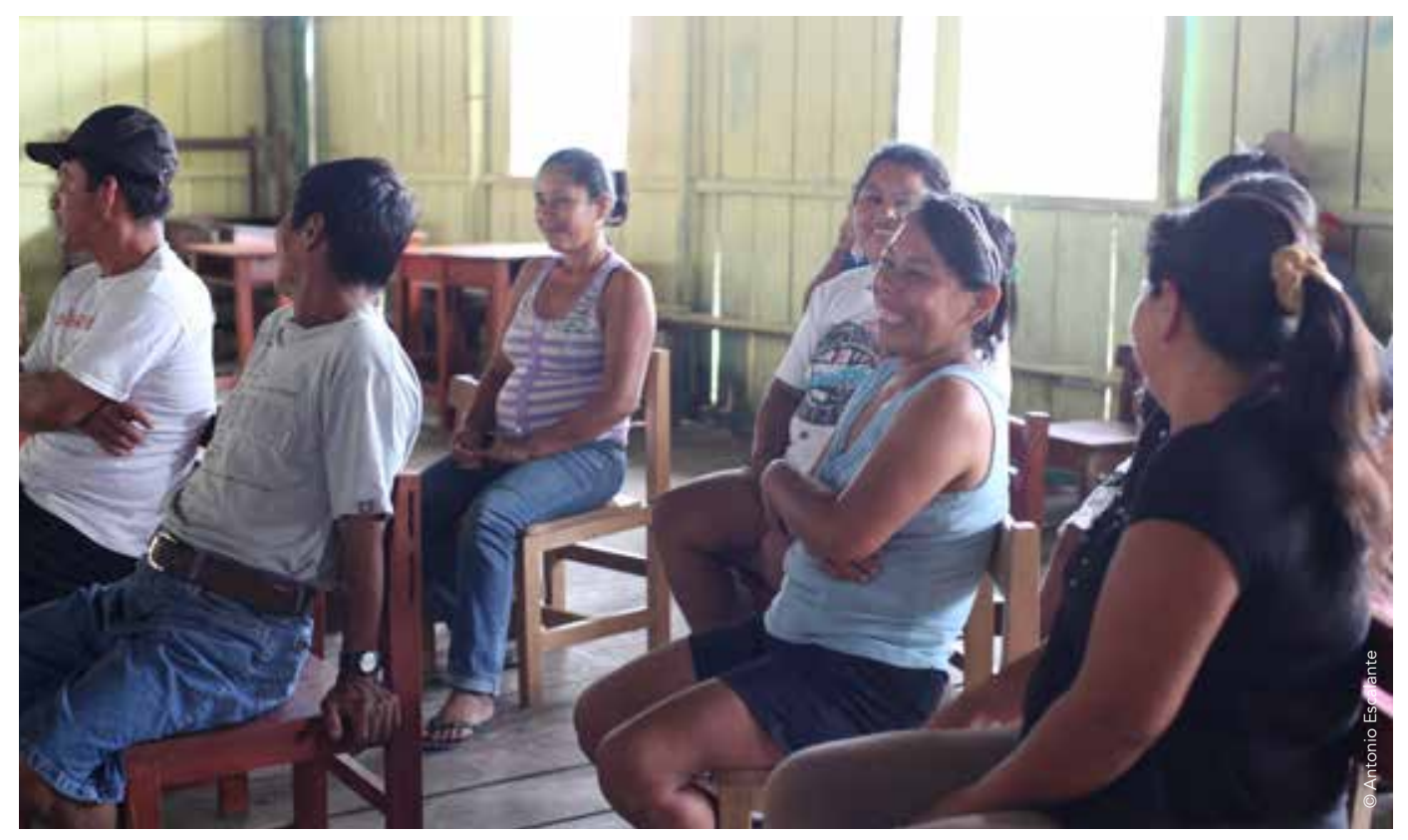




\section{CREACIÓN DE LA RESERVA COMUNAL TAMSHIYACU - TAHUAYO Y LA CONSTRUCCIÓN DE REDES SOCIALES}

Como consecuencia, en los años 80 , la población local empezó a sufrir los efectos de una drástica reducción de los recursos naturales de los cuales dependía para su subsistencia y la generación de ingresos monetarios y de la falta de empleo. Es, en esta circunstancia que las comunidades ribereñas del Tamshiyacu - Tahuayo, motivadas por esta escasez, mucho antes de que se creara la Reserva, inician el manejo del área basado en sistemas de control y de autorregulación de sus propios usos. Posteriormente tramitan ante el gobierno Regional del Amazonas, la declaratoria de una Reserva Comunal, que fue establecida en 1991, mediante una Resolución Ejecutiva, inicialmente con una superficie de 322500 ha (Bodmer, 1993, pág. 8; Bodmer, Penn, Puertas, Moya, \& Fang, 1995; Comité de Gestión del ACRCTT, Wildlife Conservation Society, Instituto DICE de la Universidad de Kent, 2005, pág. 10; GOREL y PROCREL, 2010).

Una confluencia de factores adicionales hicieron esto posible: por un lado, a pesar de la explotación a la que fue sometida la región y dando razón a los exploradores del siglo XVII, aún la región del Yavarí, incluida el área del Tamshiyacu - Tahuayo, conserva una biodiversidad extraordinaria, y al mismo tiempo, el deseo de los pobladores por convertirse en propietarios legales de sus tierras (The Field Museum, 2003).

Al parecer, las comunidades del Tamshiyacu - Tahuayo fueron exitosas en su propósito de crear la Reserva Comunal debido a que buscaron alianzas entre el personal del Ministerio de Agricultura y las personas dedicadas a la ciencia que se encontraban haciendo investigaciones en la región. Acciones sociales de cuatro sectores confluyeron para el establecimiento de la Reserva y su conservación: 1) las comunidades locales, 2) organismos estatales, 3) organizaciones no gubernamentales que realizaban actividades de extensión en la zona y 4) un importante número de investigadores que se encontraban trabajando en la zona (Bodmer, Penn, Puertas, Moya, \& Fang, 1995, pág. 11; Comité de Gestión del ACRCTT, Wildlife Conservation Society, Instituto DICE de la Universidad de Kent, 2005, pág. 7). Aunque cada uno de estos grupos tenía sus propias agendas e intereses, todos coincidieron en la necesidad de que fuera creada un área de conservación. La iniciativa comunal determinaba que el proceso de creación y manejo tuviera a las comunidades como actoras centrales del proceso de creación y manejo de la reserva.

La creación y el manejo del ACRCTT implicaron varios desafíos. Entre ellos y para hacer atractiva la creación de la Reserva, que la gente local tuviera la certeza de que el área podía y debía ser manejada por ella misma, esto generaría la autoridad para establecer sus propias reglas. La construcción de tales condiciones implicó el surgimiento de promotores locales que impulsaron reuniones tanto formales como informales en las comunidades y entre comunidades.

El tema central de estas reuniones estaba relacionado con los acuerdos comunales e intercomunales para el acceso y uso de los recursos naturales. El carácter razonable de los acuerdos quiere decir: aceptables para los hogares en términos de la cantidad que se podía extraer y según las particularidades de las especies. En este proceso, los resultados de las investigaciones científicas sobre la situación y la biología de las especies, con una comprensión tanto de las necesidades de las especies para su conservación como de las necesidades de la población local, coadyuvaron a estos acuerdos y a la construcción de redes sociales de tipo vínculo entre comunidades semejantes y de tipo puente entre las comunidades y los investigadores, sin embargo, una dificultad constituye la capacidad comunicativa de las personas que hacen investigaciones con las comunidades (Bodmer, Penn, Puertas, Moya, \& Fang, 1995, pág. 13 y 15). 
Desde 1989:

"...Las reuniones sobre la reserva generalmente consistieron de encuentros informales de pequeños grupos de personas. Muchas de estas reuniones se realizaron en las embarcaciones tradicionales de los ríos ("colectivos"), los cuales transportan a los residentes y sus productos a los mercados de lquitos. Otros tomaron lugar en casas particulares, escuelas y tiendas pequeñas (bodegas)" (Bodmer, Penn, Puertas, Moya, \& Fang, 1995, pág. 15)

Al igual que en el caso de Bolivia, en el de Tamshiyacu - Tahuayo en Perú, cuando se trató de la constitución de la Reserva, la construcción de redes de tipo puente entre las comunidades locales y el Estado tuvo dificultades marcadas por la desconfianza de las primeras en las autoridades estatales y viceversa:

"...hubo desconfianza hacia los representantes del gobierno que fueron recibidos sin entusiasmo por los residentes, debido a que ellos estaban todavía descontentos por los conflictos y la inmigración causada por los terratenientes patrocinados por el gobierno y los programas de crédito de mediados de 1980" (Bodmer, Penn, Puertas, Moya, \& Fang, 1995, pág. 11)

A lo que se adicionaba el hecho de declaraciones poco favorables para las comunidades ribereñas por parte de funcionarios estatales cuando se anunció la creación de la RCTT. Aquellas fueron interpretadas a la luz de la experiencia de la creación del Parque Nacional Pacaya Samiria, próximo a la Reserva, temiendo que algunas personas serían desalojadas de sus tierras (Bodmer, Penn, Puertas, Moya, \& Fang, 1995, pág. 12).

Entre los elementos que se descubre coadyuvaron a un mejor relacionamiento entre las comunidades locales y las autoridades gubernamentales están: el compromiso del gobierno regional de apoyar a las comunidades en los sistemas de protección del área que estas habían iniciado de manera independiente y autogestionaria y las visitas de los oficiales gubernamentales a todas las comunidades dos veces por año. En estas visitas, las comunidades tenían la oportunidad de expresar sus necesidades y opiniones y las autoridades de clarificar las preocupaciones que ellas tenían sobre el uso de los recursos naturales (Bodmer, Penn, Puertas, Moya, \& Fang, 1995, pág. 12 y 15).

Posteriormente, cambios en la legislación, se tradujeron en el desconocimiento estatal del área protegida. A pesar de ello, las acciones de conservación con base comunitaria se mantuvieron, en 2003 fue creado el Comité de Gestión de la Reserva y en 2007, su condición de área de conservación fue restablecida con el nombre de Área de Conservación Regional Comunal Tamshiyacu Tahuayo mediante D.S. N 010-2009- MINAM ( GOREL y PROCREL, 2010).

El proceso de la ACRCTT ha sido complejo, en 2003 el Field Museum, con aquiescencia de las comunidades del Tamshiyacu Tahuayo y otras instituciones incluida WCS, propusieron la creación de una gran Reserva Nacional abarcando toda la cuenca del Yavarí (The Field Museum, 2003) y en 2005, el Comité de Gestión del ACRCTT junto a WCS y el Instituto DICE de la Universidad de Kent elaboraron un extenso expediente buscando que el área sea reconocida como parte del Sistema Nacional de Áreas Naturales Protegidas por el Estado (SINANPE) (Comité de Gestión del ACRCTT, Wildlife Conservation Society, Instituto DICE de la Universidad de Kent, 2005, pág. 5). 


\section{LA POBLACIÓN RIBEREÑA Y EL USO DE LOS RECURSOS NATURALES}

Las comunidades rurales y el uso de los recursos naturales, en la región de lquitos fueron estudiadas desde la década de 1980. El interés surge en el contexto del ascenso del paradigma del desarrollo sostenible y la búsqueda de alternativas para las comunidades con alta dependencia de los recursos naturales de su entorno.

En aquellos años y con la finalidad de caracterizar las variaciones en el uso de los recursos naturales entre las comunidades, se identificaron algunos factores determinantes: 1) la vocación de las tierras para los cultivos intensivos, 2) las oportunidades que el entorno ofrece para el desarrollo de la caza y la pesca, 3) la ubicación del asentamiento en relación a lquitos u otros mercados, 4) la ubicación del asentamiento en relación a recursos forestales de alto valor económico, 5) los patrones de tenencia y acceso a los recursos naturales, 6) la historia del asentamiento, incluyendo el periodo de permanencia y 7) la historia de la especialización ocupacional en la región (Padoch, 1990, pág. 171). Como puede observarse, por entonces, la cultura no fue considerada como un factor determinante.

Con base en estos criterios, la indagación en 13 comunidades de la región llegó a determinar que la variación era considerable, incluso a nivel de los grupos domésticos al interior de los asentamientos, y no se podría establecer un solo patrón "típico" de producción y comercialización (Padoch, 1990, pág. 179). Las condiciones edáficas según la inundación y la provisión de nutrientes a los suelos, favorecía que algunos asentamientos tuvieran preferencia por la producción de cultivos anuales, especialmente arroz. En tanto que aquellos ubicados más próximos a las cochas o lagunas con abundante pesca, se convertían en centros importantes con base en esta actividad.

Del mismo modo, se constató que algunos asentamientos se habían especializado en ciertas producciones como por ejemplo las artesanías. El desarrollo de esta industria artesanal convocaba para que los comerciantes llegaran hasta asentamientos relativamente alejados (ningún asentamiento a más de un día de navegación en bote, fue incluido en la evaluación). A pesar de la alta variabilidad de situaciones, un aspecto común caracterizaba la producción y comercialización de las comunidades: la alta diversidad de especies del bosque y de las purmas que eran comercializadas en la ciudad de lquitos (Padoch, 1990, págs. 176, 179-180). En este contexto, ningún asentamiento realizaba una única actividad económica, sino que alguna de ellas, dependiendo de las circunstancias, se convertía en relativamente más importante que las demás.

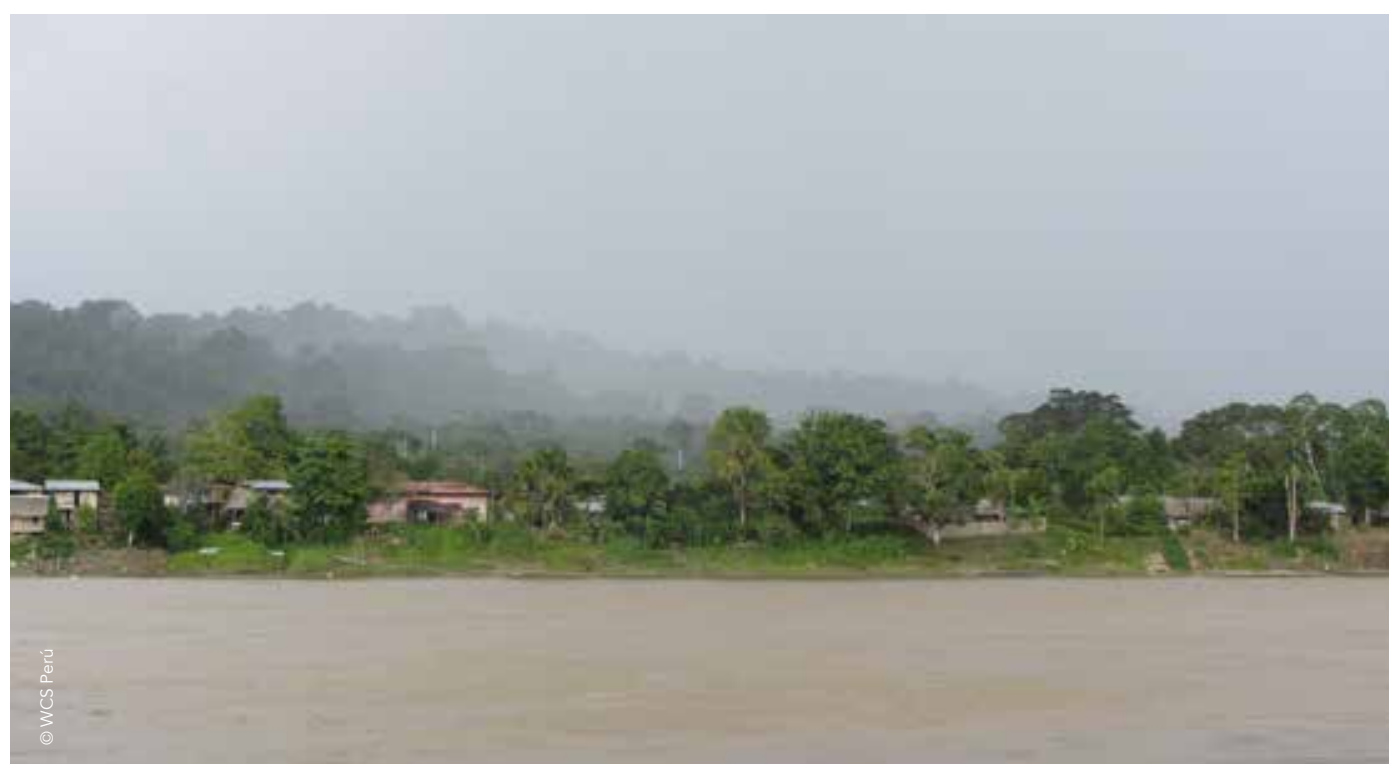


Ya por entonces, la situación de la localidad de Tamshiyacu, ubicada en el río del mismo nombre y relevante para el conjunto de las comunidades de la zona del Tamshiyacu Tahuayo, llamó la atención de los investigadores debido a la combinación de dos factores determinantes: su proximidad al mercado de lquitos y las estrategias productivas de los hogares basadas en el uso de recursos tanto de los bosques de altura como de aquellos ubicados en tierras bajas estacionalmente inundables (Padoch, 1990, pág. 197).

En Tamshiyacu, la principal actividad generadora de ingresos era la agricultura escalonada, basada en múltiples estratos donde el cultivo de frutas tropicales constituía el $60 \%$ del ingreso anual, seguida de los cultivos de cuidado intensivo como el plátano, la piña, etc.; las carnes de animales silvestres (venados y sajinos) así como de pieles; la producción de carbón y de productos basados en fibras vegetales de plantas silvestres, las frutas silvestres recolectadas en el bosque, y finalmente la comercialización de plantas medicinales.

La comparación del sistema económico de Tamshiyacu con el de otros asentamientos de la región de lquitos, mostraba la particularidad del comercio de carbón y el mantenimiento de castañas y frutos con fines comerciales (Padoch, 1990, págs. 198 - 199). Estas características y particularmente la ubicación de Tamshiyacu en las proximidades de lquitos, sin mayores dificultades para el transporte de sus productos, hacían que los ingresos económicos anuales por hogar de esta localidad se encuentren por encima del promedio regional (Padoch, 1990, pág. 204).

La localidad de Tamshiyacu se distingue de las demás comunidades de la región que encierran los ríos Tamshiyacu y Tahuayo, por su mayor tamaño demográfico, ser la capital del distrito Fernando Lores y el punto de embarque y desembarque del comercio de esta microrregión, y en general, las comunidades del Tamshiyacu Tahuayo se encuentran relativamente próximas al mercado de lquitos. Sin embargo, la variante más importante es la accesibilidad a los ríos más pequeños en tiempo de vaciante de los mismos.

A fines de los años 1980, la distribución del ingreso monetario anual de los hogares de la región del alto Tahuayo provenían de la agricultura/agroforestería (44\%), pesca (26 $\%)$, carne del monte (11\%), madera (11\%) y plantas no maderables (7 \%). Los ingresos familiares totales basados en diversas actividades económicas variaban entre USD 10000 y USD 15000 con un ingreso medio anual por hogar de USD 326 (Bodmer, Penn, Puertas, Moya, \& Fang, 1995, pág. 16; Comité de Gestión del ACRCTT, Wildlife Conservation Society, Instituto DICE de la Universidad de Kent, 2005, pág. 5 y 31).

En los años 1990, con el establecimiento de la RCTT, el análisis de la distribución de las 33 comunidades que existían en la zona, según su uso de los recursos naturales respecto de la Reserva, cobraba relevancia. De esta manera, se estableció que las comunidades ubicadas en el alto Tamshiyacu y solo algunas familias hacían uso de subsistencia en la Reserva, este uso se refería a la cacería, la pesca y el uso de productos vegetales, en tanto que las comunidades del bajo Tamshiyacu y la mayoría del Tahuayo, mayormente extraían los recursos del área próxima a sus asentamientos y una minoría lo hacía de manera permanente de la Reserva. Casi todas las familias de los asentamientos del Tahuayo extraían esporádicamente recursos de la Reserva con fines de subsistencia y de comercialización en pequeña escala (Bodmer, Penn, Puertas, Moya, \& Fang, 1995, pág. 18).

La mayoría de los hogares de la región extraían los recursos en la zona de asentamientos y uso intensivo de los recursos naturales, tanto con fines de subsistencia como de comercialización. Esta zona de uso intensivo estaba constituida por las chacras, purmas o bosques secundarios y bosques intactos o primarios alterados, fuera de los límites de la Reserva. Mientras en la zona de asentamientos las áreas de extracción de los recursos eran consideradas como propiedad sea comunal o individual, el área de la Reserva era considerada de acceso abierto, de ahí la importancia que cobrarían con el tiempo, los acuerdos comunales de uso y acceso a los recursos naturales (Bodmer, Penn, Puertas, Moya, \& Fang, 1995, pág. 18). 


\section{CACERÍA}

Como se anotó, la riqueza de fauna silvestre terrestre y acuática fue tempranamente ponderada en relación a la subcuenca del Yavarí, que incluye la RCTT. Este factor de abundancia y la presencia de una diversidad de primates y en particular del "huapo colorado" (Cacajao calvus), atrajo la atención de investigadores y con ellos, en los años de 1980, los estudios sobre la cacería por las comunidades del Tamshiyacu - Tahuayo. El enfoque de estos estudios estuvo referido a la importancia económica de la cacería para los hogares de dichas comunidades, sea para el consumo o para la venta. A fines de los años 1980, 34 cazadores del alto Tahuayo obtuvieron de la venta de carne de monte y pieles, la significativa cifra de USD 17 932, lo que constituía el $11 \%$ de su ingreso monetario total, los ungulados (especialmente sajinos) y roedores eran las especies cazadas más importantes en la generación de este ingreso (Bodmer, Penn, Puertas, Moya, \& Fang, 1995, pág. 19).

El precepto de que el valor económico de la fauna silvestre para la población constituye la medida de las posibilidades de su conservación, llevó a los investigadores a establecer con el mayor detalle la sostenibilidad del uso actual según las diferentes especies de fauna. Este análisis permitió constatar que el aprovechamiento que realizaban los cazadores del Alto Tahuayo de ungulados y roedores se encontraba dentro de los límites del uso sostenible, pero no así la cacería de primates, tapires, marsupiales, edentados y carnívoros y que, en aras de asegurar su permanencia en los ecosistemas de la región, debería reducirse considerablemente en algunos casos y suspenderse en otros. Aún la cacería de ungulados y roedores debería restringirse a los machos. Estas restricciones del manejo implicarían la afectación del $26 \%$ de los ingresos que se generaban del aprovechamiento de la fauna silvestre. A su vez, estas consideraciones implicaban el análisis de cómo distribuir estos costos entre los diferentes tipos de hogares de las comunidades (Bodmer, Penn, Puertas, Moya, \& Fang, 1995, págs. 19-21). Al final, todos estos análisis nutrieron el proceso de manejo de los recursos naturales por las comunidades y la conservación de la Reserva.

Complementariamente, a mediados de los años 1990, el enfoque de la relación "fuente" - "sumidero" en el análisis de la cacería por las comunidades permitió demostrar que era necesario considerar el Yavarí y específicamente el Yavari Mirin como una "fuente" de la cacería practicada aguas abajo en el Quebrada Blanco y el Tahuayo debiendo considerarse estas zonas como "sumidero", la diferencia en términos de la biomasa

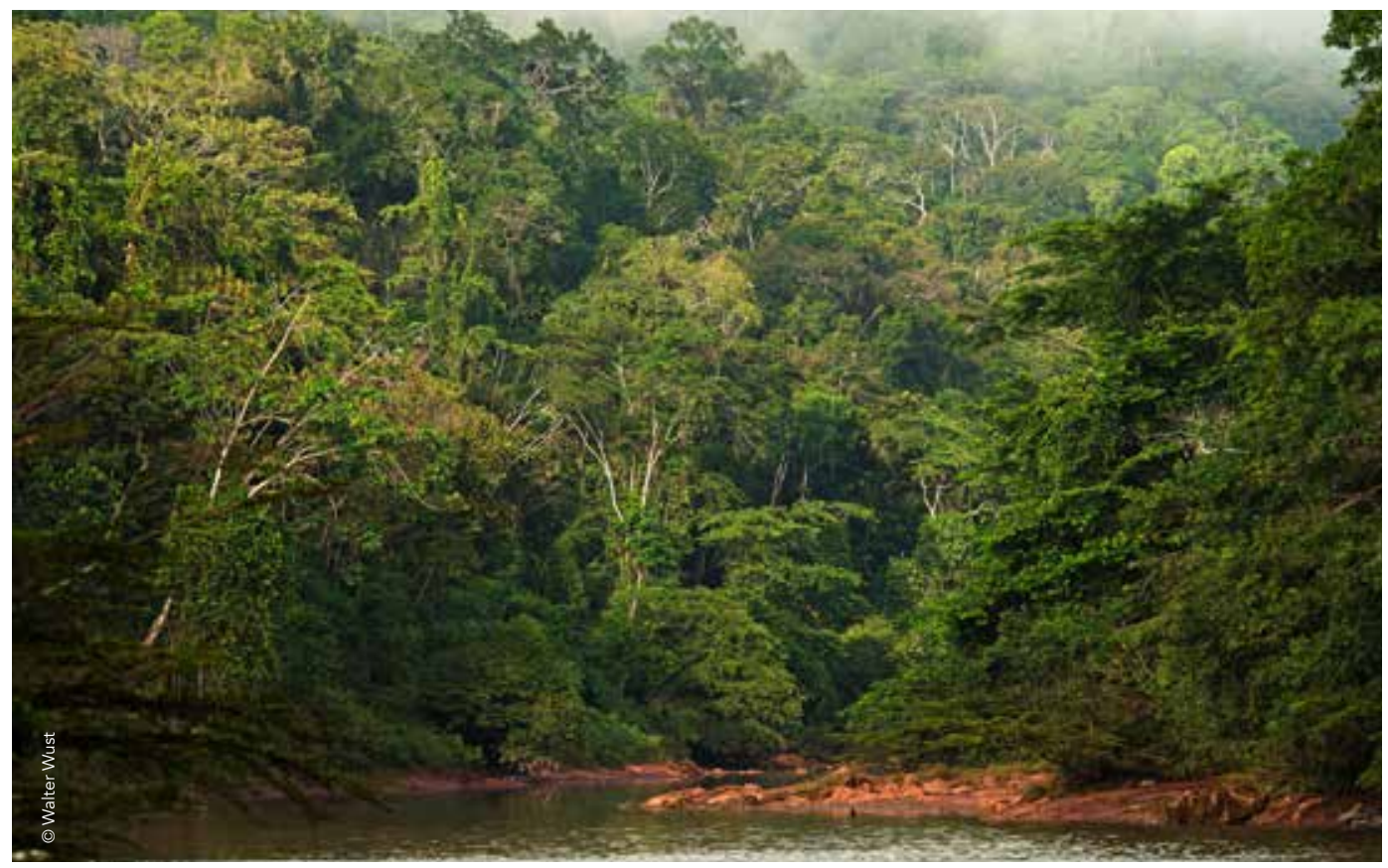


extraída era $500 \%$ y $300 \%$ en términos de ingresos económicos, superior en Quebrada Blanco en relación a la zona "fuente", el Yavari Mirin (The Field Museum, 2003, págs. 102 - 103). El análisis del aprovechamiento de cada especie de fauna silvestre, demostró que la cacería en el Yavari Mirin era más sostenible que en la Quebrada Blanco. En esta última, especialmente las especies de reproducción lenta, como el tapir de llanura y los grandes primates presentaban claros síntomas de sobrecaza (The Field Museum, 2003, pág. 103). El análisis de la relación "fuente" vs "sumidero" en relación a la cacería, apostaba en cierto sentido a que aun existiendo sobrecaza en el área "sumidero", el aprovechamiento era sostenible en el área total, siempre y cuando se conservaran las áreas "fuente" que permiten el repoblamiento del área "sumidero". De esta manera, para asegurar la cosecha sostenible en el Tamshiyacu - Tahuayo se proponía la conservación y el manejo sostenible de la cuenca del Yavarí y especialmente del valle del Yavari Mirín. A su vez, este enfoque requería el estudio a más profundidad de las migraciones de las diferentes especies, en el caso de Tamshiyacu Tahuayo, especialmente del tapir. Estos estudios deberían atender a las diferencias etáreas de la población en cuestión. Especialmente la cacería del tapir y de los grandes primates debería restringirse por su alto grado de vulnerabilidad debido a sus bajas tasas de reproducción. El manejo del tapir fue considerado más difícil debido a su tamaño, lo que determinaba la preferencia de los cazadores (The Field Museum, 2003, págs. 103 - 106).

\section{PESCA}

Como se señaló, hacia mediados de los años 1990, la segunda fuente de ingresos de los hogares en Tamshiyacu Tahuayo, después de la agricultura, era la pesca. La relación entre pesca y cacería en cuanto a la importancia en los ingresos, dependía del acceso de las comunidades a diferentes ecosistemas, mientras para las comunidades más próximas a los bosques de tierra firme, la cacería era más importante, para aquellos asentamientos ubicados en los bosques inundables de la várzea, lo sería la pesca. Los bosques de várzea favorecen esta actividad debido a la producción primaria de fitoplancton, plantas herbáceas flotantes y la producción de frutos de estos bosques específicamente adaptada para que las semillas sean dispersadas por los peces. En los bosques de várzea escasean las especies terrestres de gran porte, por lo que las poblaciones locales prefieren la pesca (Bodmer, Penn, Puertas, Moya, \& Fang, 1995, págs. 24 - 25).

En Tamshiyacu - Tahuayo, al igual que en el resto de la Alta Amazonía, la pesca se realiza en tiempo seco cuando los peces se concentran en los restringidos cuerpos de agua, a diferencia de la época lluviosa cuando con la inundación los peces se dispersan y es difícil capturarlos. Los medios de pesca más utilizados a fines de los años 1980 eran las redes, trampas, tarrafas, arpones, sogas y flechas (Bodmer, Penn, Puertas, Moya, \& Fang, 1995, pág. 26).

Una demostración de que cuando un recurso tiene valor económico para la población local, esta se encuentra más dispuesta a proteger el recurso y esto favorece a la conservación de otras especies y de los ecosistemas, es el caso de la pesca en el Tamshiyacu - Tahuayo. De hecho, la pesca comercial en la región se remota a fines del siglo XIX, pero particularmente entre 1950 y 1980, se convirtió en industria comercial en la región de lquitos y tuvo su auge entre 1970 y 1980. Este auge fue el responsable de la disminución de las especies y poblaciones de peces, especialmente de la desaparición del paiche (Arapaima gigas), apreciado por su gran tamaño, en el alto Tahuayo. La pérdida del recurso tanto para su subsistencia como para la obtención de ingresos monetarios, provocada por comerciantes residentes de lquitos, determinó que la comunidad de El Chino iniciara, a principios de los años 1980, su organización, control, vigilancia y autorregulación como medidas de manejo, primero de la pesca en sus lagos y cochas cercanas y luego planteara, junto a otras comunidades, la creación de la RCTT (Bodmer, Penn, Puertas, Moya, \& Fang, 1995, págs. 26-27). 
"Cualquier residente de los caseríos podía entrar, pero el uso de barbasco, (Lonchocarpus sp), redes grandes, y otras estratagemas fue restringido o prohibido. Los botes frigoríficos y otros tipos de pesca comercial con base en lquitos estuvieron prohibidos de entrar a cualquiera de los lagos cercanos al caserío. Se establecieron patrullas para vigilar los lagos. El caserío Chino organizó, con la aprobación de la comunidad, una fuerza policial rotativa de 5 hombres para resguardar los cinco lagos cercanos al caserío, y fueron dados derechos de usufructo por el Ministerio de Pesca Regional" (Penn \& Alvarez, 1990).

A través de estas acciones, ya hacia la segunda mitad de 1990, las comunidades habían logrado que las poblaciones de peces se recuperaran en sus lagos y ríos interiores y las evaluaciones de su pesca mostraban que ésta, en general, estaba siendo sostenible, excepto en relación a algunas especies que mostraban indicios de sobreexplotación tales como: la gamitana (Collosoma macroporum), boquichico (Prochilodus nigricans) y el fasaco (Hoplias malabaricus). El paiche (Arapaimas gigas) que había sido explotado casi hasta su extinción local, se había recuperado a niveles que podía ser extraído nuevamente bajo el sistema de manejo (Bodmer, Penn, Puertas, Moya, \& Fang, 1995, pág. 28).
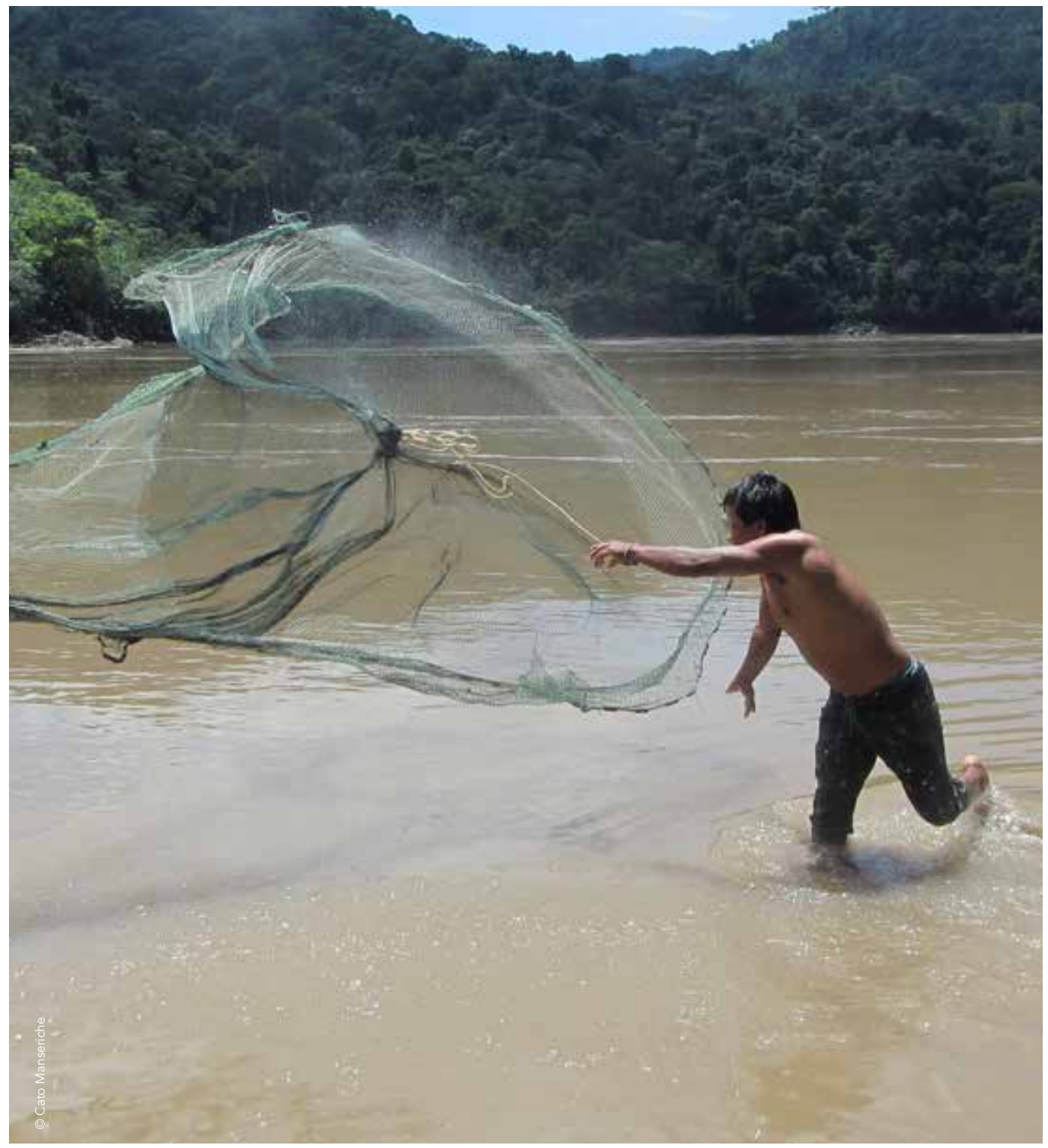


\section{USO DE RECURSOS FORESTALES NO MADERABLES}

Hacia mediados de los años 1990, la cosecha de frutos de palmas tales como el aguaje (Mauritia Flexuosa), el asaí (Euterpe precatoria) y el ungurahui (Oenocarpus bataua) en el Tamshiyacu - Tahuayo era insostenible debido a dos factores: el derribe de los árboles de palma y el sistema de acceso abierto. Los productores tumbaban los árboles de palma por la dificultad que implica trepar por los árboles para cosechar los frutos y por considerar que si no son cosechados en esa oportunidad, después podrán venir otros comunarios y aprovecharlos en la próxima cosecha. Estos frutos tenían y aún tienen gran demanda en lquitos. Además, los frutos de estas palmeras son alimento importante de los ungulados y roedores, principales especies también sometidas a la cacería.

Para su manejo, en Tamshiyacu - Tahuayo, se proponía suspender la tumba de las palmeras, promover la aplicación de tecnologías no destructivas para la cosecha, dejar una cantidad adecuada de frutos para el aprovechamiento de la fauna silvestre y la dispersión de semillas y reducir el impacto del sistema de acceso abierto a las especies silvestres a través de su cultivo en parcelas agroforestales con un sistema de acceso cerrado y controlado al ubicarse estas parcelas en tierras de propiedad comunal o individual. Este sistema de manejo propuesto, favorecería tanto a las especies forestales no maderables como a la cacería de una manera sostenible. La mayor desventaja del sistema de manejo propuesto se relacionaba con el tiempo que requieren los sistemas agroforestales basados en palmas para ser cosechables, entre seis y ocho años dependiendo de las especies (Bodmer, Penn, Puertas, Moya, \& Fang, 1995, págs. 29-34).

\section{USO DE RECURSOS FORESTALES MADERABLES}

Otro uso no sostenible, en la década de 1990, era el de la madera. En la región del Tamshiyacu - Tahuayo, ya en los años de 1950 se habían extraído las especies con alto valor comercial (Coomes, 1991). Hacia fines de 1980, los ingresos de hogar por concepto de la venta de madera ocupaban el cuarto lugar con una contribución del 11\%. En la zona de los asentamientos, la tala selectiva había conducido a la desaparición de especies tales como la caoba (Swietenia macrophyla) y el cedro (Cedrela). En términos de su manejo para asegurar un uso más sostenible, se propuso: el manejo de los bosques naturales con base en sistemas policíclicos de 20 o 35 años y el cultivo de dichas especies en chacras privadas de los pobladores. Con esto último se buscaba reducir el riesgo de sobreexplotación como resultado de un sistema de acceso abierto y desregulado que caracterizaba a la extracción de madera.

El impacto de la extracción maderera sobre la fauna silvestre era muy significativo, en la medida que los madereros se proveían de ella para su sostenimiento durante las faenas del aprovechamiento de la madera que duraban varios meses al año, pero además los trabajadores de la madera comercializaban carne en lquitos para compensar sus bajos salarios. De este modo, se proponía restringir el aprovechamiento de madera en el área de subsistencia de la Reserva. Tanto la pesca por foráneos como la extracción maderera acicatearon a las comunidades del Tamshiyacu - Tahuayo para tomar medidas que les permitieran controlar dichas actividades a fines de 1980 (Bodmer, Penn, Puertas, Moya, \& Fang, 1995, págs. 35 - 37)

\section{EL USO DE LOS SUELOS CON FINES AGRÍCOLAS Y PECUARIOS}

En Tamshiyacu - Tahuayo, la principal fuente de ingresos era la agricultura. Esta se había mantenido durante todo el periodo gomero (1980 - 1915), pues los establecimientos gomeros tenían áreas agrícolas para el mantenimiento de sus operadores y recolectores (Coomes, 1991). El sistema agrícola tradicional se basaba en el manejo agroforestal de 
una diversidad de cultivos de corto plazo combinados con árboles frutales en diferentes etapas de desarrollo, en superficies no mayores a 5 ha por hogar al año. Los árboles frutales fueron abandonados luego de 20 a 40 años y los campos rozados completamente para ser reutilizados luego de 60 u 80 años (Padoch, 1990).

En la década de 1980, los incentivos estatales a través de créditos para la fomentar la producción y comercialización de arroz y otros cultivos intensivos anuales, había atentado contra el sistema tradicional multicultivo. Sin embargo, en los años 1990, cuando se terminaron los incentivos, los agricultores retornaron nuevamente al sistema tradicional (Bodmer, Penn, Puertas, Moya, \& Fang, 1995), en gran medida debido a la fuerte demanda desde lquitos de una diversidad de más de 190 frutos y una veintena de otros productos del bosque que eran allí consumidos (Vasquez \& Gentry, 1989).

La agricultura en la región del Tamshiyacu - Tahuayo mostraba una adaptación a las tierras de várzea y de tierra firme. En los suelos inundables de la várzea, menos ácidos y más fértiles que los segundos, mayormente se producían cultivos de ciclo corto como la yuca, maíz, sandía, frejoles y pimientos (Bodmer, Penn, Puertas, Moya, \& Fang, 1995, pág. 39). En cambio, en los suelos de la tierra firme, donde los cultivos no se inundan y la producción puede ser más estable, pero el transporte resultaba más dificultoso, la producción agrícola se caracterizaba por combinaciones de cultivos de corto y de largo plazo también con la finalidad de evitar la difusión de enfermedades y plagas. El sistema se iniciaba con el cultivo de productos básicos y de corto plazo como yuca, bananas, piñas, arroz, y maíz, mezclado con cultivos de vegetales y papayas para ir cediendo progresivamente a la producción de frutales. En las zonas altas, la agricultura se combinaba con la crianza de ganado menor y mayor (Bodmer, Penn, Puertas, Moya, \& Fang, 1995, págs. 39-41).

\section{EL COMERCIO DE RECURSOS DEL BOSOUE Y DE LAS PURMAS EN TORNO A IQUITOS}

Hacia fines de los años 1980 y principios de los 1990, el costo del transporte entre Tamshiyacu e lquitos significaba el $20 \%$ de precio total de venta, en tanto que desde otros asentamientos más alejados podía alcanzar hasta el $83 \%$. La proximidad a lquitos constituía una de las ventajas comparativas más significativas de Tamshiyacu (Padoch, 1990, pág. 183).

En el comercio entre Tamshiyacu e lquitos se distinguían varios tipos de intermediarios: los mayoristas poseedores de capital que podía alcanzar, por entonces, los USD 10 000, compraban los productos del bosque en gran cantidad, tenían otras inversiones en Iquitos, mantenían agentes viajeros quienes compraban los productos en la localidad de los productores. Los minoristas, se distinguían por la menor escala de sus operaciones, pero se contaban por cientos en el puerto lquitos o recorriendo los diversos ríos de la región. Mayormente adquirían productos agrícolas y en menor medida recursos del bosque. Con frecuencia actuaban también como proveedores de bienes manufacturados para el consumo de los productores o recolectores de las comunidades (Padoch, 1990, pág. 184).

En las cadenas de comercialización también intervenían los transportistas, poseedores de botes o embarcaciones, trabajaban transportando pasajeros y carga, pero también rescataban productos del bosque que los revendían en lquitos. Tamshiyacu, por entonces al igual que ahora, constituía un punto de embarque y desembarque, especialmente en tiempo de la vaciante de los ríos, cuando las embarcaciones no alcanzan a ingresar por los ríos interiores (Padoch, 1990, pág. 185). 
funciones de comerciantes, habilitadores (adelantos por recursos naturales o productos), contratistas y hasta subcontratistas (Padoch, 1990, pág. 185).

El mercado de la región estaba dominado por lquitos. Generalmente, los mayoristas y minoristas vendían los productos de las purmas y recursos del bosque al consumidor final, sin embargo, lquitos también se ha caracterizado por el desarrollo de una industria manufacturera local que provee bienes de consumo a restaurants, heladerías y de expendio de jugos cuya oferta se basa en los productos de purmas y bosques tales como: aguaje (Mauritia flexuosa), camu camu (Myrciaria dubia), cocona (Solanum sissiliforum), arasá (Eugenia stipitata), y otros productos como chonta o carnes del monte, mayormente sajino (Tayassu sp.). A fines de los años 1980 y principios de los 1990, las panaderías, restaurantes de pollo a la brasa y la industria del ladrillo consumían importantes cantidades de carbón (Padoch, 1990, pág. 187).

A fines de los años 1980, se observó que el sistema económico de las comunidades mestizas ribereñas, derivaba en gran medida de las prácticas de los pueblos indígenas amazónicos. Dependiendo de factores determinantes como las características de los suelos, la disponibilidad de los recursos naturales de su entorno, el acceso al mercado, la historia del asentamiento y los procesos de especialización, estas comunidades articulaban una diversidad de actividades orientadas tanto a su propio consumo como al mercado en diferentes niveles. Esta diversidad de actividades se refería a la agricultura: bajo sistemas agroforestales tradicionales que combinan los cultivos anuales con otros de mayor duración especialmente frutales, así como la cría de ganado y animales domésticos, la pesca, la caza, el aprovechamiento de recursos forestales no maderables y maderables, las artesanías y plantas medicinales, entre otras. Las comunidades ribereñas, particularmente la población de Tamshiyacu, presentaba como rasgos distintivos, respecto de otras comunidades de la región: una mayor orientación al mercado, la producción de carbón (de la vegetación remanente después de la preparación del terreno) y el cultivo de algunos frutos y castañas de origen silvestre. Estos frutos, el carbón y una parte importante de la carne de especies silvestres (mayormente ungulados y roedores) estaban destinados a la venta en la ciudad de lquitos (Padoch, 1990).

En la Amazonía, la extracción de recursos naturales es y ha sido importante. Históricamente, la economía amazónica ha estado tensionada por auges extractivos que se han caracterizado por la generación de riqueza, pero solo un mínimo desarrollo local, prácticas destructivas, sobreexplotación de la fuerza de trabajo local y han tenido duración limitada. Simultáneamente, en su mayoría, la población local se mantiene y genera sus ingresos monetarios y no monetarios gracias a la biodiversidad, aunque variable, el nivel de dependencia de los asentamientos y hogares respecto de los recursos naturales, es alta. Esta variabilidad también es dependiente de las estaciones del ciclo anual.

lquitos es el centro comercial más importante en la región y se caracteriza por la alta demanda de una importante diversidad de productos y recursos de las purmas, cuerpos de agua y bosques. En las cadenas de comercialización intervienen una amplia gama de intermediarios, desde los comerciantes mayoristas, transportistas, comerciantes minoristas y regatones. 


\section{LA CONSERVACIÓN DE LA ACRCTT BASADA EN EL MANEJO DE LOS RECURSOS NATURALES POR LAS COMUNIDADES}

Desde los años 1990, la estrategia de conservación del Tamshiyacu - Tahuayo fue diseñada tomando como eje el uso de los recursos naturales por las comunidades de la región, el mismo que como se vio había sido estudiado desde los años de 1970.

Las principales consideraciones de manejo que emanaban del análisis de dichos usos de los recursos naturales por las comunidades locales estaban referidas a:

1. Establecer una zonificación del área basada en el uso de los recursos naturales considerando una gradiente en los niveles de uso que va desde zonas de protección estricta, zonas de uso para la subsistencia y zonas de asentamiento y uso intensivo (Bodmer, Penn, Puertas, Moya, \& Fang, 1995, págs. 54 - 55).

2. Mantener o aún reducir los niveles de cosecha de las especies de fauna silvestre cuyo aprovechamiento se encontraba en niveles sostenibles, tales son los casos de los venados, pecaríes y roedores grandes, suspendiendo el aprovechamiento de otras especies que estaban siendo sobreexplotadas tales como primates, tapires, marsupiales, edentados y carnívoros.

3. Mantener los niveles de pesca considerando las acciones de control y manejo establecidas por las comunidades.

4. Introducir prácticas de manejo de las palmeras: a) suspendiendo las prácticas de tumba de los árboles, b) suspender la recolección de frutos silvestres para asegurar la provisión a la fauna silvestre y la dispersión de semillas, c) promover el cultivo de palmas útiles en las chacras en tierras privadas próximas a los caseríos.

5. Promover un uso más sostenible de la madera a través de: a) disminuir el nivel de extracción, b) regenerar las especies en las chacras de propiedad privada cerca de los caseríos y c) introducir programas de manejo de los bosques naturales (Bodmer, Penn, Puertas, Moya, \& Fang, 1995, pág. 44; The Field Museum, 2003, pág. 41).

Teniendo como base el uso de los recursos de agroforestería, caza, pesca, madera y no maderables por las comunidades, se realizaron los análisis económicos de la relación costo/beneficio tomando cuatro escenarios: la mantención del sistema como se encontraba con algunos usos sostenibles, pero otros no, y el sistema de uso con manejo sostenible y proyecciones a corto plazo (0 - 5 años), y a largo plazo (6 - 35 años). Los servicios ambientales fueron incorporados al considerar los riesgos de la sobreexplotación (Bodmer, Penn, Puertas, Moya, \& Fang, 1995, pág. 45).

Los resultados de este análisis mostraron que, si se mantenían las prácticas no sostenibles, en el corto plazo, los ingresos derivados de los recursos naturales y los servicios ambientales se mantenían constantes, pero disminuían en el largo plazo en un $75 \%$ anual por el agotamiento de la madera, las plantas no maderables y la fauna silvestre. Debido a esta pérdida que afecta a los ecosistemas también se reduce el valor de los servicios ambientales. Por el contrario, con la introducción de prácticas de manejo sostenibles, los ingresos de la madera, las plantas no maderables y la cacería eran menores en el corto plazo y el valor de los servicios ambientales era igual que en el sistema sin mejoras en el manejo, pero en el largo plazo los ingresos se incrementaban en un $25 \%$ anual. En el análisis no se incluían los valores de los recursos naturales destinados al consumo ni los costos de oportunidad de la mano de obra (Bodmer, Penn, Puertas, Moya, \& Fang, 1995, págs. 47-48). 
a solventar gastos de salud, educación y transporte. En Tamshiyacu - Tahuayo el gasto en salud constituía alrededor del $34 \%$ del presupuesto anual de los hogares. Esto, a su vez, implicaba un esfuerzo para que la población local percibiera con claridad la relación entre el manejo sostenible de los recursos naturales y los incentivos relacionados con los servicios (Bodmer, Penn, Puertas, Moya, \& Fang, 1995, pág. 53).

Los usos no sostenibles eran atribuidos por una parte a la ausencia de información sobre prácticas de aprovechamiento más sostenible, así como al acceso abierto a los recursos naturales en las áreas más alejadas respecto de los asentamientos. Esta consideración orientaba al cultivo de especies maderables y no maderables en chacras de propiedad privada individual (Bodmer, Penn, Puertas, Moya, \& Fang, 1995, pág. 51). Como se verá más adelante el propio manejo del área se encargaría de demostrar que el uso sostenible también es posible en las áreas más alejadas de acceso colectivo pero regulado.

El fundamento de esta propuesta era tender puentes entre la conservación de la biodiversidad y el desarrollo socio-económico de las comunidades a través del manejo sostenible de los recursos naturales con un enfoque dominantemente económico (Bodmer, Penn, Puertas, Moya, \& Fang, 1995, pág. 54; Comité de Gestión del ACRCTT, Wildlife Conservation Society, Instituto DICE de la Universidad de Kent, 2005, pág. 5). Para hacer posible la conservación era necesario considerar que el manejo sostenible en las zonas de asentamiento y usos intensivos fuera funcional a la conservación de la zona de usos más restringidos así como a la mantención del área de protección estricta, en la medida que el agotamiento de los recursos en la zona de asentamiento y uso intensivo empujaría a los pobladores a extraer recursos de la reserva, y viceversa la no conservación de la zona restringida impediría el repoblamiento de las especies en la zona de asentamientos y uso intensivo (Bodmer, Penn, Puertas, Moya, \& Fang, 1995, págs. 54 - 55).

Una propuesta de conservación basada en el manejo sostenible de los recursos naturales por la comunidades requería el establecimiento y funcionamiento de un sistema de monitoreo constante y de largo plazo tanto sobre el estado de las especies y ecosistemas como del uso de los recursos por las comunidades, buscando la mantención de las especies y el flujo de los beneficios económicos para las comunidades (The Field Museum, 2003, pág. 47).

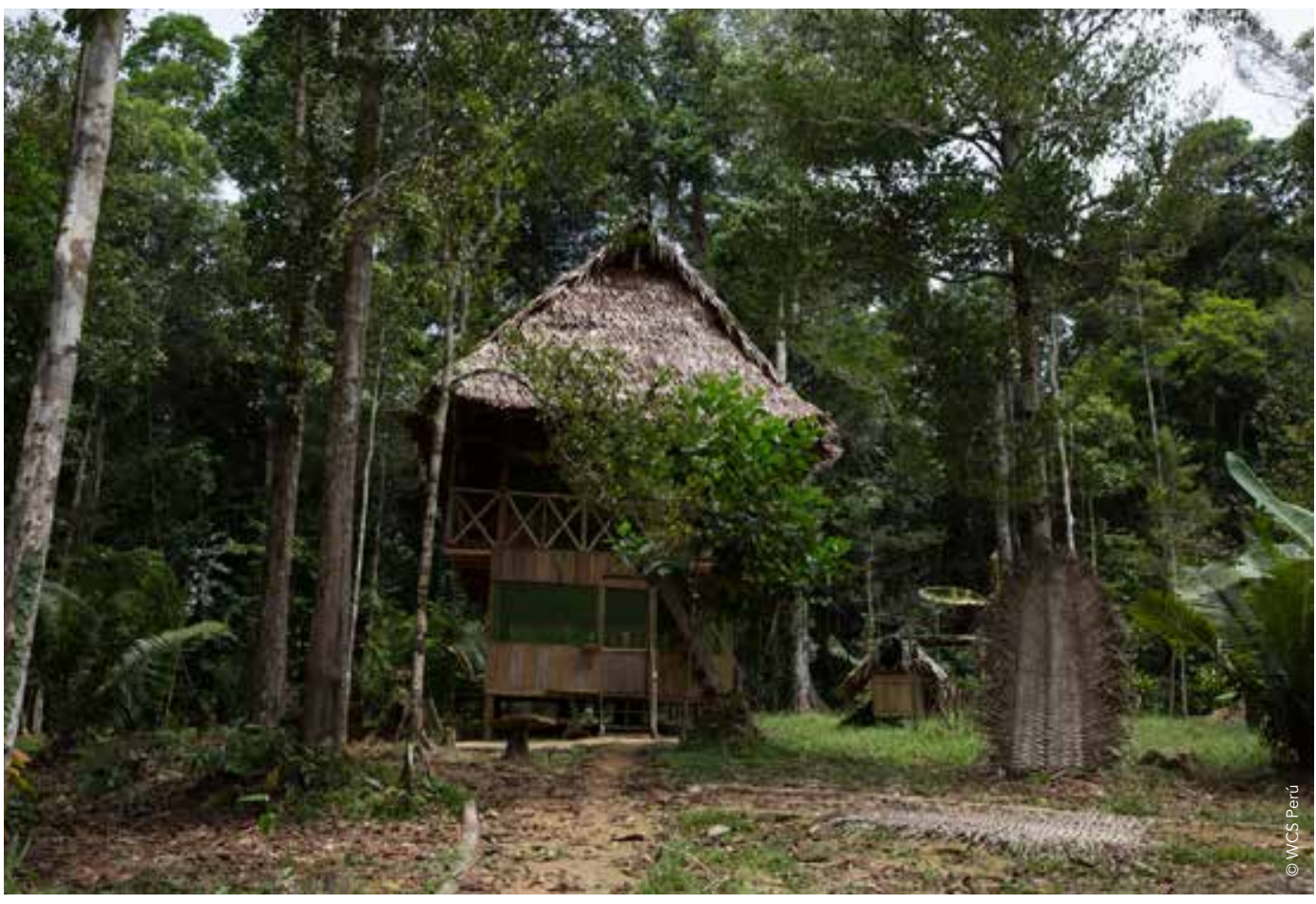




\section{LA INVESTIGACIÓN COMO BASE DE LA CONSERVACIÓN BASADA EN EL MANEJO DE LOS RECURSOS NATURALES}

Uno de los factores de éxito de la conservación de base comunitaria en Tamshiyacu - Tahuayo es la investigación, en esta región se inició en 1974. Las investigaciones relacionadas con la riqueza de las especies de fauna silvestre contribuyeron a la creación de la Reserva a principios de 1990. Al tiempo que se desarrolló una diversidad de estudios que involucraban tanto el estado de las poblaciones de las especies de fauna y flora y sus relaciones ecológicas, se realizaron los estudios socio-económico para comprender el uso de los recursos naturales por las comunidades. Los estudios sobre historia natural y del aprovechamiento de los recursos naturales contribuyeron significativamente a la comprensión colectiva de los beneficios de pensar el manejo como una alternativa de largo plazo. La articulación de la investigación científica con las necesidades de información para la toma de decisiones por las comunidades puede considerarse una orientación básica para asegurar el manejo por la población local.

Hasta 2005 se habían publicado más de cien estudios. Una tipología de los estudios realizados incluía:

"1) estudios sobre la conservación comunal bajo la perspectiva socio-económica, biológica y política, 2) estudios sobre el origen y el mantenimiento de la alta biodiversidad de la cuenca del Yavarí, 3) estudios sobre la sostenibilidad de la caza desde los puntos de vista biológico y socio-económico, 4) estudios sobre la ecología de especies bandera, tales como el tapir o sachavaca, huapo rojo, lobo de río, manatí, entre otros, 5) estudios sobre la ecología de la comunidad de mamíferos, aves, anfibios, reptiles y peces, para un mejor entendimiento de la ecología tropical del área, y 6) estudios sobre la influencia del mercado que deriva en una sobre explotación y destrucción de los bosques tropicales, y aquellos que puedan ser utilizados como incentivos para la conservación" (Comité de Gestión del ACRCTT, Wildlife Conservation Society, Instituto DICE de la Universidad de Kent, 2005, pág. 9 y 26).

Sin duda que en este quehacer primaba mucho el tipo de relación de las personas de ciencia con las comunidades. Como se ha señalado, en la conservación del Tamshiyacu - Tahuayo, la confluencia del interés de las comunidades por la conservación, de algunos funcionarios gubernamentales, de extensionistas de ONG's y de investigadores fue determinante para lograr la creación del área protegida en la categoría de Reserva Comunal. Esto implicaba el reconocimiento del papel protagónico de las comunidades. Sin embargo, la comunidad científica que trabajaba en el Tamshiyacu - Tahuayo, no era homogénea: así como había quienes respaldaban este papel protagónico de las comunidades había quienes más bien pensaban que poner el énfasis en restringir el acceso y el uso por las comunidades era mejor para la conservación del área. Esta tensión siempre está presente en la relación entre científicos y comunidades pero en Tamshiyacu - Tahuayo se definió a favor de quienes apoyaban la conservación por las comunidades y en ello, la orientación del uso de los recursos hacia el manejo sostenible era imprescindible (Comité de Gestión del ACRCTT, Wildlife Conservation Society, Instituto DICE de la Universidad de Kent, 2005, pág. 24).

Progresivamente se desarrolló un programa de investigación que incluyó la formación de investigadores provenientes de Perú así como de otras latitudes. Los temas de investigación buscaban vincular el conocimiento científico con la aplicación para el manejo de los recursos naturales por las comunidades. Con base en la modalidad de escuelas de campo, se buscaba relacionar a los jóvenes investigadores con las comunidades. Esto implica por un lado un diálogo de intercambio de información en el que se da igual 
generación de investigadores capaces de valorar la contribución de las comunidades a la conservación. De esta manera, la conservación de la Reserva Comunal Tamshiyacu Tahuayo generaría un resultado adicional: numerosas tesis de pregrado, maestría y doctorado que hasta 2005 sumaban 45 (Comité de Gestión del ACRCTT, Wildlife Conservation Society, Instituto DICE de la Universidad de Kent, 2005, pág. 26).

Finalmente, un proceso de investigación de largo aliento y que aborda las múltiples facetas de la relación entre las comunidades y la conservación de las especies y los ecosistemas requirió el establecimiento de alianzas institucionales con el concurso de las comunidades, de autoridades estatales tanto del nivel nacional como local, de universidades peruanas y otras del mundo, de instituciones nacionales e internacionales así como de centros de investigación públicos y privados (Comité de Gestión del ACRCTT, Wildlife Conservation Society, Instituto DICE de la Universidad de Kent, 2005, pág. 10).

\section{EL ORDENAMIENTO DE LA TIERRA Y EL ACRCTT}

Como se vio, la propuesta de manejo de Tamshiyacu - Tahuayo por las comunidades incluía un ordenamiento del uso de la tierra considerando una gradiente de uso que incluía zonas completamente protegidas, donde todo uso está restringido, zonas de uso de subsistencia y zonas de uso intensivo. Esta estrategia tenía como objetivo asegurar tanto la conservación de las especies y ecosistemas como el uso sostenible de los recursos naturales por las comunidades y así transitar hacia un modelo de desarrollo sostenible (Bodmer, 1993). De esta manera, en 1991, el Área de Reserva Comunal Tamshiyacu Tahuayo que tenía una superficie de 322500 ha fue zonificada contando con una zona de conservación estricta con una superficie aproximada de 160000 ha, una zona de amortiguamiento de uso de subsistencia que al igual tenía una superficie aproximada de 16000 ha y una zona de poblados permanentes sin límites definidos. Las áreas de conservación estricta y de subsistencia constituían la Reserva oficialmente establecida (Bodmer, Penn, Puertas, Moya, \& Fang, 1995).

MAPA 4: ZONIFICACIÓN DE LA RESERVA COMUNAL TAMSHIYACU TAHUAYO (1991)

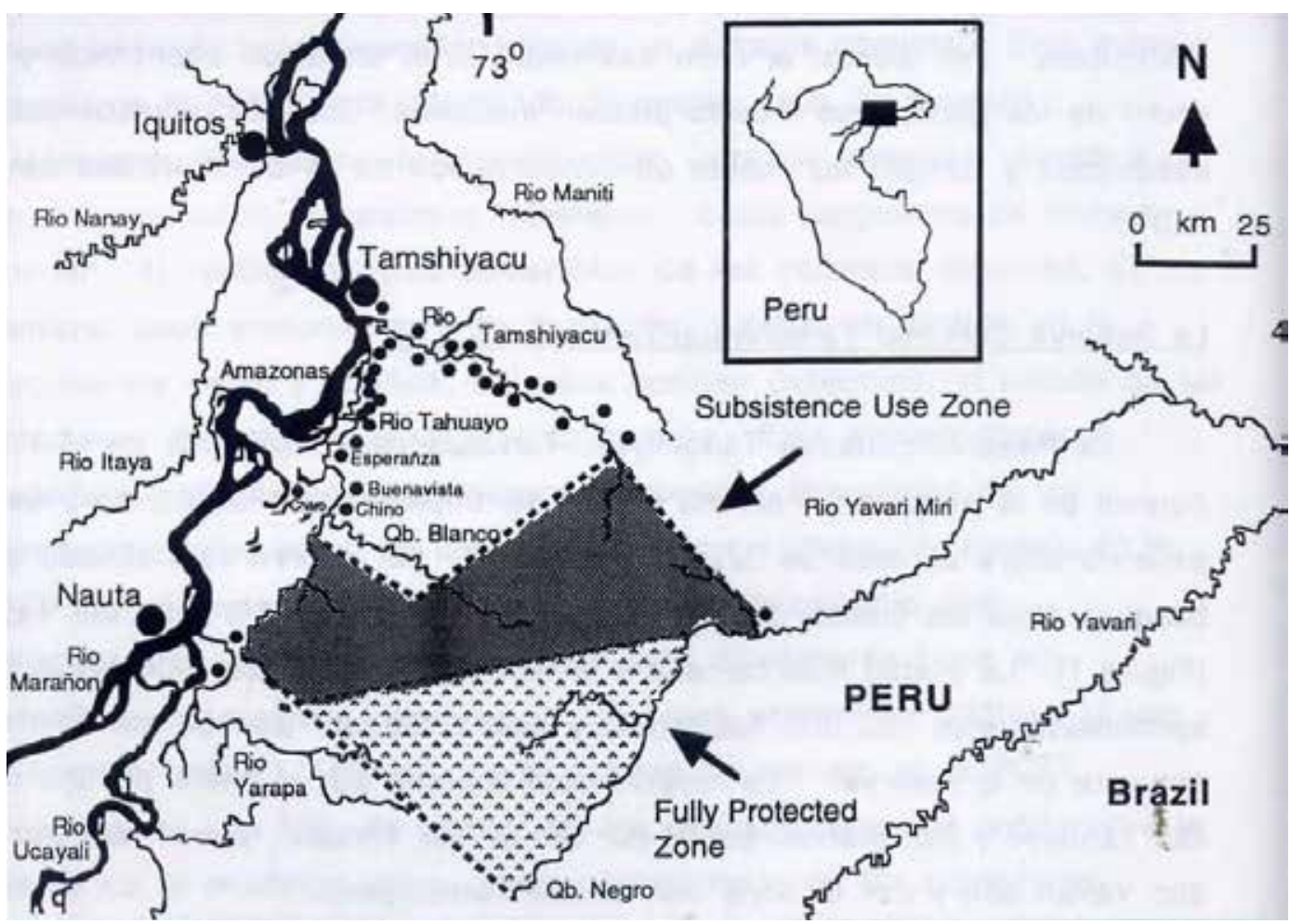

Fuentes: (Bodmer, Penn, Puertas, Moya, \& Fang, 1995; GOREL y PROCREL, 2010) 
Como se mencionó, la zonificación de la región seguía el modelo propuesto de una gradiente basada en el uso de los recursos naturales donde en la zona de conservación estricta no están permitidos ni los asentamientos ni ningún tipo de uso de los recursos naturales. En la zona de uso de subsistencia no estaban permitidos los asentamientos ni la agricultura pero sí la cacería y el uso de recursos forestales no maderables con fines del consumo de los hogares residentes en la proximidad de la Reserva. La zona de asentamientos, destinada a las viviendas y usos más intensivos como la agricultura, no formaba parte de la Reserva pero siendo contigua a ella, se constituía en área de manejo de los recursos naturales y se buscaba que aún los usos que se realicen en esta zona, sean sostenibles. Se considera que el manejo de los recursos naturales constituye un puente entre la población local y la conservación de las especies (Bodmer, Penn, Puertas, Moya, \& Fang, 1995).

En 2015, una evaluación sobre las fortalezas y debilidades de la gobernanza para la conservación de los recursos naturales en 25 comunidades del Tamshiyacu - Tahuayo incluyó un mapeo participativo del uso de los recursos naturales e indagaciones sobre la importancia atribuida a las diferentes actividades económicas según hogares y comunidades.

El Mapa 5 muestra las áreas de agricultura, pesca, uso maderable, distribución de aguaje (Mauritia flexuosa) y los puntos de cacería de los asentamientos como fueron representadas por comunarios y comunarias de la región Tamshiyacu - Tahuayo. Adicionalmente y con base en información secundaria se han incluido otras áreas que muestran la presencia de cultivos de palma aceitera, los predios de propiedad comunal y las actuales zonas administrativas del ACRCTT donde se representan: una zona de administración directa, una zona de uso turístico y una zona silvestre. La zona de administración directa hace referencia al Gobierno Regional de Loreto (GOREL), en lo que parece demostrarse cambios importantes en el concepto original de ordenamiento de la tierra con enfoque en el uso y la conservación por las comunidades. Ahora, aparece el GOREL con un rol protagónico en la administración de la zona de conservación estricta, la zona de uso de subsistencia ha cedido su lugar a una zona de turismo, también administrada por el GOREL y la zona silvestre, con áreas de cacería definidas para las comunidades, ubicadas en una zona de amortiguamiento (ver también Mapa 3).

La creación de una zona de amortiguamiento, como anillo externo de la Reserva, con un ancho de $5 \mathrm{~km}$ y $15 \mathrm{~km}$ en sus sectores más amplios, fue propuesta en 2006 con la finalidad de minimizar el impacto del uso de los recursos naturales fuera de la reserva (Bodmer, y otros, 2006, pág. 43).

Es importante destacar el hecho de que los comunarios y comunarias de las cuatro comunidades pioneras y promotoras principales de la Reserva como son El Chino, Buena Vista, Diamante/7 de Julio y San Pedro, representaron los sitios de su cacería y recolección actual mostrando que estos exceden las áreas de cacería que les han sido delimitadas. Esta representación más bien coincide con la zonificación original del Tamshiyacu Tahuayo, pero en alguna medida explica ciertas tensiones con el GOREL y sensación de pérdida de protagonismo por las comunidades en la actualidad.

Comparando esta representación gráfica y la indagación sobre la importancia que tienen las distintas actividades económicas para los hogares con aquellos usos que fueron documentados cuatro décadas atrás, a primera vista no se observan cambios drásticos en relación a los tipos de uso y la diversidad de actividades económicas que realizan, sin considerar la intensidad del uso debido a que, en esta oportunidad del 2015, esta no fue escrutada. De los hogares indagados en 25 comunidades, en veinte señalaron tener como actividad principal la agricultura, tres indicaron que la pesca y dos el carbón. Como actividades secundarias, en diez comunidades indicaron que la segunda actividad en importancia es la pesca, en siete la caza, en tres la agricultura, y en dos la crianza de animales menores. 
Finalmente en tercer lugar de importancia, en cuatro comunidades se indicó la producción de artesanías, en tres la cacería, en dos la crianza de animales menores y finalmente la extracción de madera, la ganadería, el carbón y la agricultura fueron mencionadas en una comunidad (Flores, Antúnez, Padilla, Silva, \& Lehm, 2016, pág. 87).

Al igual que en el pasado, la representación gráfica indica diferencias en los sistemas productivos entre las comunidades del Tahuayo por un lado y del Tamshiyacu por el otro, con una dominancia de la pesca, la recolección y la cacería entre las primeras frente a la agricultura y en alguna medida el corte de madera entre las segundas (incluyendo el aprovechamiento de carbón para la venta, entre estas últimas). Asimismo, la representación indica que la recolección de aguaje es importante para las comunidades de ambos ríos. Entretanto, las comunidades del Amazonas pusieron énfasis en representar sus áreas agrícolas y uno que otro punto de aprovechamiento de madera. Sin embargo, cerca y al nordeste de la reserva se observa el surgimiento de una amenaza: cultivos en gran escala de palma aceitera (Flores, Antúnez, Padilla, Silva, \& Lehm, 2016, págs. 49 - 50).

MAPA 5: ACCESO Y USO DE LOS RECURSOS NATURALES POR LAS COMUNIDADES DE LA REGIÓN DEL TAMSHIYACU Y TAHUAYO

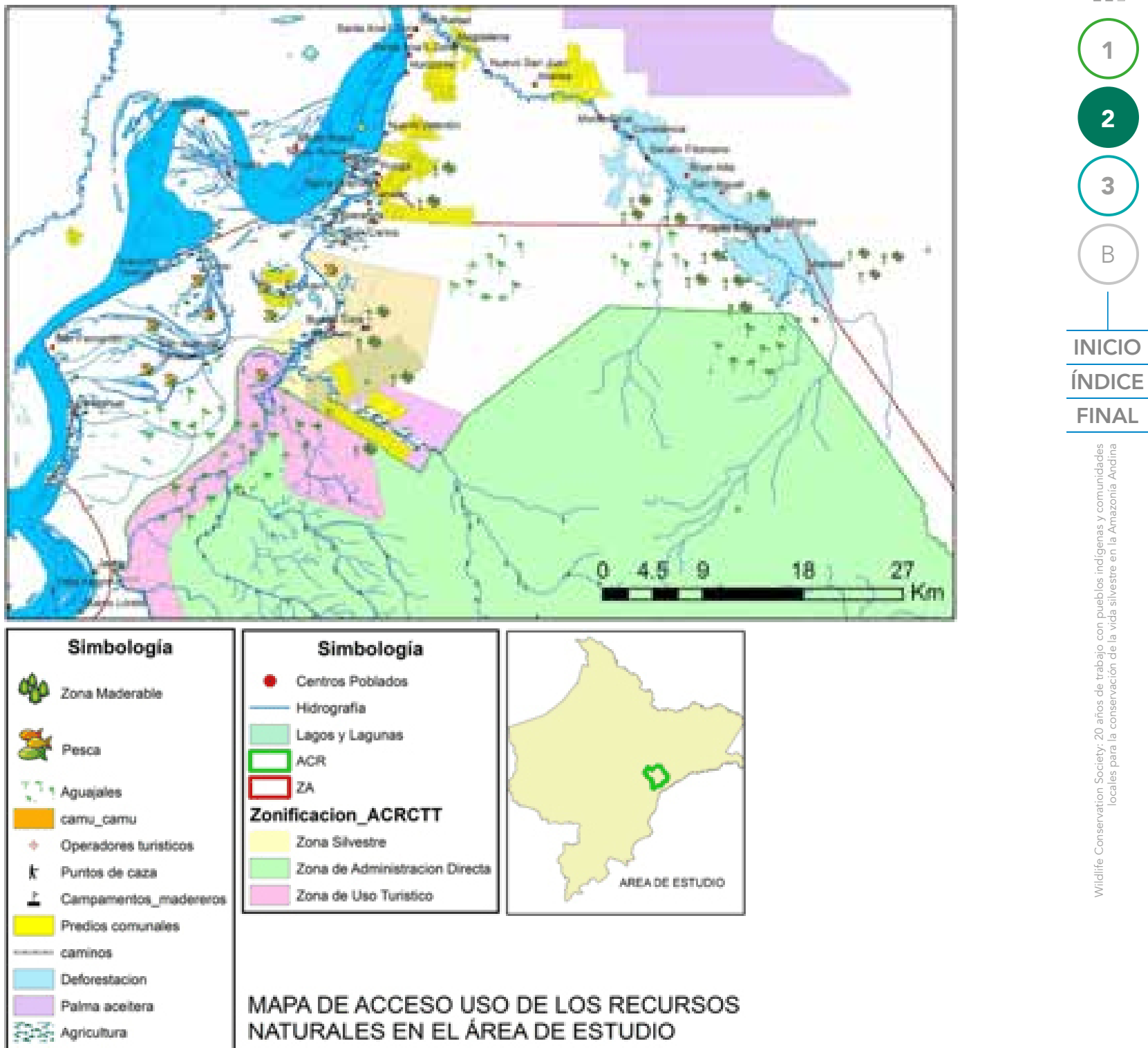

Fuente: DRP's y Evaluaciones de fortalezas y debilidades de la gobernanza en 25 


\section{REGULACIÓN PARA EL ACCESO Y USO DE LOS RECURSOS NATURALES}

Las primeras acciones de conservación de las comunidades estuvieron referidas al control y vigilancia especialmente de sus cuerpos de agua frente a la pesca excesiva de no residentes (Comité de Gestión del ACRCTT, Wildlife Conservation Society, Instituto DICE de la Universidad de Kent, 2005, pág. 7). Pronto, se dieron cuenta de que estas medidas no serían suficientes y empezaron a establecer límites a su propio uso de los recursos naturales, todo esto antes de iniciar gestiones para que el área fuese reconocida como una reserva comunal. Como se señaló, estas acciones fueron el resultado de la disminución de los recursos naturales de los que dependían para su subsistencia y obtención de ingresos monetarios mayormente para la compra de bienes de consumo.

Entre 1980 y 1984, las comunidades del alto Tahuayo empezaron a manejar cinco lagos cercanos a sus asentamientos. Este manejo se inició con la prohibición de la pesca comercial con frigoríficos especialmente a los no residentes y a los residentes de las prácticas no sostenibles de pesca que se utilizaban por entonces (Bodmer, Penn, Puertas, Moya, \& Fang, 1995; Comité de Gestión del ACRCTT, Wildlife Conservation Society, Instituto DICE de la Universidad de Kent, 2005, págs. 7 y 23 - 24).

Al inicio, en los años 1980, solo la comunidad de El Chino inició el proceso de manejo de los recursos naturales basado en la autorregulación. En el año 1992 se incorporó la comunidad de Buena Vista, ambas comunidades ubicadas en las riberas del río Tahuayo. Posteriormente, entre 1996 y 1998 se adscribió la comunidad de San Pedro y en 2000 la comunidad de Diamante $/ 7$ de Julio ubicadas en la Quebrada Blanco (Bodmer, y otros, 2006, pág. 52 y 53). De acuerdo con esta lógica primero se establecen los acuerdos al interior de cada comunidad y posteriormente se negocian intercomunalmente. Estos acuerdos entre comunidades incluyen las responsabilidades de cada comunidad en relación al control y la vigilancia (Comité de Gestión del ACRCTT, Wildlife Conservation Society, Instituto DICE de la Universidad de Kent, 2005, pág. 35; Bodmer, y otros, 2006, pág. 26).

"Durante los años 1980 los residentes que vivían más cerca de la reserva propuesta, discutieron seriamente el asunto sobre el uso acertado de los recursos naturales y acordaron establecer reglas comunales entre ellos. Los caseríos del alto Tahuayo comenzaron a manejar cinco lagos cercanos al caserío e impusieron impuestos a los residentes sobre la carne de monte, pesca y recursos vegetales que enviaban a los mercados. Algunos extractores de recursos provenientes del área del río Amazonas apoyados por empresarios de la ciudad de lquitos continuaron entrando a la reserva propuesta, pero se vieron forzados a negociar directamente con los habitantes locales del Tahuayo" (Bodmer, Penn, Puertas, Moya, \& Fang, 1995, pág. 11)

El sistema de autorregulación que empezó con la pesca, progresivamente incluyó otros recursos como la cacería, el aprovechamiento de recursos forestales no maderables y maderables. Se basó en el establecimiento de cuotas para cada hogar y el cobro o "impuestos" por la fauna silvestre y la madera extraídas para la comercialización en lquitos (Bodmer, Penn, Puertas, Moya, \& Fang, 1995, pág. 11).

El proceso de toma de decisiones para estos acuerdos que perduran desde 1992, se basó originalmente en factores tales como: 1) la existencia de un proceso relativamente detallado de información de las personas dedicadas a la investigación a las comunidades sobre el estado de conservación y el uso de las especies, 2) la decisión sobre los acuerdos definitivos es autónoma y es tomada exclusivamente por las comunidades en ausencia de 
autoridades gubernamentales, ONGs e investigadores (Bodmer, Penn, Puertas, Moya, \& Fang, 1995, pág. 15) y 3) estos acuerdos son establecidos en los libros de actas de cada comunidad y son suscritos por "los jefes de hogar". Una gran debilidad en este proceso es la ausencia en la participación de las mujeres.

Al principio, los acuerdos de control de la pesca estuvieron centrados en las áreas cercanas a los asentamientos, sin embargo, fueron ampliados en su alcance geográfico hacia las cuencas altas de los ríos, debido a que las comunidades se percataron de las amenazas que se cernían sobre las áreas más alejadas que incluían la Reserva (Comité de Gestión del ACRCTT, Wildlife Conservation Society, Instituto DICE de la Universidad de Kent, 2005, pág. 24). De esta manera, los acuerdos rigen no solo en las tierras reconocidas legalmente como propiedad de las comunidades sino también en las áreas adyacentes, de esta manera, se extienden también a las zonas de uso restringido y de uso de subsistencia de la Reserva (Bodmer, Penn, Puertas, Moya, \& Fang, 1995, pág. 8).

El contenido de los acuerdos refiere a cuatro aspectos: 1. La cantidad permitida para el uso de cada tipo de recurso natural: cacería, pesca, recolección de hojas y frutos de palmeras (según cada especie mayormente utilizada) y aprovechamiento de madera. 2. Los métodos de caza, pesca o recolección que son permitidos y los que no lo son. 3. Definición sobre quién(es) tienen derecho de acceso a los recursos de la reserva (se entiende que de la zona de subsistencia) y 4. Las sanciones a ser aplicadas a quienes incumplan los acuerdos (Comunidad Diamante/7 de Julio, Actualizado el 4 de enero de 2015; Comunidad Campesina El Chino, Actualizado el 18 de enero de 2015; Comunidad San Pedro, Actualizado el 19 de enero de 2015).

A lo largo del tiempo, el contenido de los acuerdos comunales ha tenido ciertas constantes y otras variaciones. Entre las primeras, por ejemplo, se ha mantenido la prohibición de la caza de la sachavaca o tapir (Tapirus terrestris) y de los grandes primates, en tanto que las cuotas de otros "animales grandes" como los venados y sajinos han variado. En 2005, por ejemplo, de la zona de subsistencia, solo se podían aprovechar "cuatro animales grandes" cada 60 días por hogar de las comunidades más próximas a la reserva. Esta extracción estaba sujeta a un sistema de cobros en dinero, los acuerdos especifican el valor según la especie (Comité de Gestión del ACRCTT, Wildlife Conservation Society, Instituto DICE de la Universidad de Kent, 2005, pág. 34).

También han existido variaciones entre las especies prohibidas de cacería y las cuotas establecidas en cada comunidad. Por ejemplo, entre 1996 y 1998, en la comunidad de San Pedro, inicialmente se estableció como regla el aprovechamiento de hasta tres animales grandes o cinco majases considerados animales chicos, cada dos meses, y quedó estrictamente prohibida la cacería de monos grandes Ateles chamek "maquizapa negra", Lagothrix lagothricha "choro", Tapirus terrestris "sachavaca", Priodontes maximus "yangunturo" o "carachupa mama", Myrmecophaga tridactyla "oso hormiguero" (Bodmer, y otros, 2006, pág. 52). De ahí la importancia de los acuerdos intercomunales para ver en qué medida estas cuotas se pueden conciliar entre comunidades. De hecho, para el año 1999, en las comunidades de El Chino y Buena Vista (pioneras en el proceso) se observa un ajuste a sus cuotas cuyo contenido se asemeja a lo establecido por San Pedro:

"Los animales que se cazen (sic.) en la zona de la reserva comunal para la venta en lquitos serán en número de 3 animales grandes tales como: Tayassu pecari "huangana", Tayassu tajacu "sajino", Mazama americana "venado rojo".ó 5 animales chicos tales como Agouti paca "majás" o "picuro" o Mazama guazoubira "venado gris", etc". (Bodmer, y otros, 2006, pág. 52)

Los acuerdos intercomunales cobran su mayor relevancia al establecer las jurisdicciones de cada comunidad. En 2002, se estableció que, si una persona de una comunidad extrae 
los recursos naturales de otra, el pago del impuesto debe realizarse en su comunidad de origen, la misma que debe hacer entrega de este dinero a la comunidad de donde se extrajeron los recursos naturales. Se estableció un sistema de recibos como mecanismo de control (Bodmer, y otros, 2006, pág. 53). En 2015, este aspecto estuvo siendo revisado por las cuatro comunidades involucradas: el Chino, Buena Vista, San Pedro y Diamante/7 de Julio con la finalidad de establecer que el pago se realice directamente en la comunidad de origen de los recursos naturales (obs. personal).

El pago en dinero por las cuotas de cacería debe ser legítimo y posible, gracias a la orientación de las comunidades al mercado pero también porque, como en el caso de El Chino, se establece que:

\begin{abstract}
"Las colaboraciones y aportes servirán para solventar gastos en viajes para gestiones de autoridades, trabajos o mingas comunales (bebidas, comidas), apoyo de emergencias (enfermedad o muerte), apoyo educativo (programas escolares)" (Bodmer, y otros, 2006, pág. 53).
\end{abstract}

Entre las sanciones a quienes incumplieran la regla se estableció que el excedente debía ser vendido en la propia comunidad a un precio que determinara la autoridad comunal (Bodmer, y otros, 2006, pág. 53). Así, la sanción reducía el ingreso que se hubiera alcanzado si la carne se vendía en lquitos.

En general, los acuerdos comunales incorporan algunas excepciones especialmente cuando se trata de personas enfermas, en esos casos, una cuota excepcional o más frecuente está permitida, sujeta a acuerdos entre las personas afectadas y la comunidad y debe contar con la certificación de las autoridades de la comunidad (Bodmer, y otros, 2006, pág. 52). La atención a estas particularidades denota flexibilidad en la dimensión social del sistema regulatorio, coadyuva a la legitimidad de la regla y es difícil de lograr o hacer operativo en un sistema de regulación estatal.

Sin embargo, es muy relevante destacar que el proceso de autorregulación y particularmente de aplicación de las sanciones, en Tamshiyacu - Tahuayo ha sido acompañado muy de cerca y respaldado por la Policía Nacional, existiendo un puesto en la comunidad de Buena Vista (Bodmer, y otros, 2006, pág. 53), lo que determina un relacionamiento cotidiano entre esta entidad estatal y las comunidades de la zona. De hecho, es particularmente notable que esta instancia presencie las reuniones del Comité de Gestión, pero no esté habilitada para la toma de decisiones.

Actualmente, en el detalle de los acuerdos se observa, por ejemplo, para el caso de la comunidad Diamante / 7 de Julio, en relación a la cacería: a) que está permitido aprovechar 5 animales grandes y 6 chicos cada sesenta días, además se establece que un animal será para el consumo y los demás podrán ser vendidos. Las especies grandes se refieren a sajino, huangana y venado colorado y las pequeñas a majas, venado gris y añuje; b) queda prohibida la cacería o captura para la venta de especies tales como sachavaca, oso hormiguero, carachupa mama (jungunturo), monos, vaca marina, felinos, lagartos; c) se prohíbe la captura de crías para mascotas de todas las especies así como de loros, guacamayos y garzas; d) se establece el cupo de municiones que cada cazador puede utilizar; e) se establece un cobro económico según tipo de animal; f) se establece que cazadores de otras comunidades deben pagar su contribución a la comunidad en cuya jurisdicción se haya realizado la caza; g) otras prohibiciones tal como el uso de trampas armadilleras, $h$ ) las sanciones que van desde la derivación de la persona infractora a la comisaría estatal hasta el decomiso de los animales excedentes en caso de haberse sobrepasado el cupo establecido; i) las excepciones relacionadas con el incremento de los cupos en el inicio de las actividades escolares y la navidad solo para los hogares que 
cuenten con niños, hasta dos veces al año para aniversarios $u$ otras festividades familiares, casos de enfermedad, para lo cual deberá contarse con la certificación de la autoridad comunal y finalmente, para la comunidad en caso de requerirlo para la reparación de bienes comunales. Detalle comparable se presenta para la pesca y como se señaló para cada tipo de palmera según sean los fines de uso (Comunidad Diamante/7 de Julio, Actualizado el 4 de enero de 2015).

La legitimidad del cobro de impuestos en dinero respecto de las cuotas y según las especies extraídas debe ser posible, como vimos, gracias a una mayor orientación de las comunidades ribereñas respecto del mercado, aspecto poco replicable si se trata de comunidades muy alejadas donde el circulante en dinero es escaso. Contribuye a la legitimidad del cobro, la determinación de que el dinero obtenido de las cuotas es para coadyuvar en el sistema de control así como para "contar con disponibilidad de dinero para actividades de gestión comunitaria" (Bodmer, y otros, 2006, pág. 53).

A diferencia de los reglamentos más formales, el sistema basado en acuerdos comunales ha permitido que estos sean enmendados con mayor frecuencia en las reuniones comunales. En 2006 se estableció que los acuerdos podrían ser revisados trimestralmente (Bodmer, y otros, 2006). Por un lado, esta flexibilidad aproxima este sistema de acuerdos un poco más a los sistemas no formales tradicionales de las comunidades y al mismo tiempo, se adecúa a las necesidades del manejo que requiere de ajustes periódicos basados en los resultados de nuevas investigaciones y del monitoreo. De esta manera, si bien la toma de decisiones es una prerrogativa exclusiva de las comunidades, los acuerdos también son sensibles a la influencia de investigadores, personal gubernamental e incluso instancias gubernamentales y ONGs más relacionadas con el desarrollo (Bodmer, Penn, Puertas, Moya, \& Fang, 1995, pág. 16).

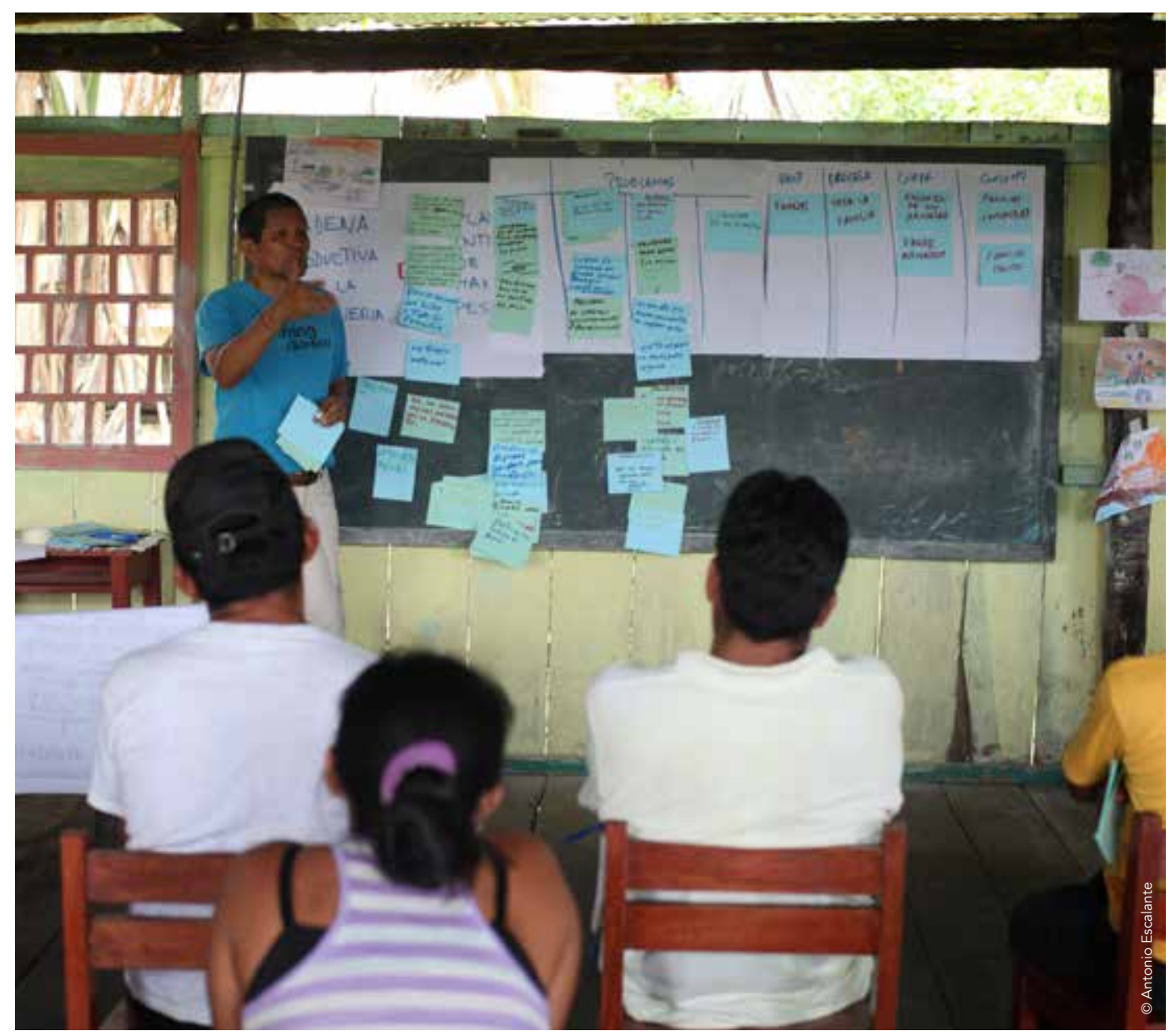


Los acuerdos comunales plasmados en los libros de actas, constituyen "planes de manejo informales" (Comité de Gestión del ACRCTT, Wildlife Conservation Society, Instituto DICE de la Universidad de Kent, 2005, pág. 62), que contrastan con aquellos que las legislaciones nacionales establecen con mucha formalidad, requerimientos de información que a veces no son tan indispensables y que sobretodo enajenan o alejan los procesos del manejo del control de las comunidades. Sin embargo, el funcionamiento del sistema regulatorio por las comunidades del Tamshiyacu - Tahuayo ha contado con el acompañamiento y respaldo de la Policía Nacional, quien ha actuado cumpliendo su función frente a infractores residentes y no residentes.

La efectividad de la autorregulación por las comunidades resalta en el contexto de la historia de la regulación estatal peruana sobre la fauna silvestre en la década de 1970:

"La primera ley de manejo legislada por el Ministerio de Agricultura Peruano en la región de la Amazonía estableció las estaciones de caza tuvo poco éxito debido a las dificultades de hacer cumplir la ley en las áreas rurales.

En respuesta a la caza excesiva durante el período de la caza profesional de pieles, el Ministerio de Agricultura promulgó en 1973 una ley de manejo nacional que prohibía la caza profesional de pieles en la Amazonía peruana. Esta ley permitió el uso de ciertas actividades de caza de subsistencia por los pobladores rurales. Las pieles obtenidas de estas especies podían ser comercializadas si las pieles se originaban de los animales matados por los cazadores de "subsistencia"

La ley de manejo de 1973 fue aparentemente más exitosa que las restricciones estacionales de pieles, porque su ejecución estuvo a un nivel de operaciones comerciales legales en los grandes centros urbanos y no en las áreas rurales aisladas

En 1976 una nueva amenaza emergió cuando el Ministerio de Agricultura notó un incremento en la venta de carne de monte en los mercados de lquitos. Para refrenar la caza profesional de carne de monte, el Ministerio de Agricultura decretó su tercera ley de manejo en 1979 que restringió la venta de carne de monte en ciudades que tuvieran menos de 3000 habitantes. Además, solamente los animales considerados como fuente de subsistencia podrían ser comercializados por su carne. Mientras la ley de caza profesional de carne de monte aparentemente refrenó la caza, su implementación estuvo cargada de dificultades. Las autoridades de manejo no pudieron controlar en forma efectiva a los pequeños vendedores ilegales de carne en los mercados de la ciudad. La demanda por carne de monte de las poblaciones urbanas se sumó al problema de control de la venta de carne" (Bodmer, Manejo de Fauna Silvestre con las Comunidades Locales: El caso de la Reserva Comunal Tamshiyacu Tahuayo, 1993, pág. 7).

Posteriormente, en 2010, el Estado Peruano promulgó una nueva Ley Forestal y de Fauna Silvestre (Ley No. 27308) donde se definió una serie de modalidades para el manejo y aprovechamiento de la fauna silvestre tanto con fines comerciales como con fines de subsistencia. La Ley No. 27308 indica que la cacería de fauna silvestre con fines de subsistencia sólo está permitida cuando está destinada al consumo directo de las poblaciones rurales, mientras que la cacería con fines comerciales sólo está permitida en predios de dominio público otorgados en concesión como áreas de manejo. Esto deja sin posibilidad de acceso legal a la cacería de bajo impacto en comunidades rurales que destinan parte de su producción a los mercados locales. Bajo esta legislación, sin embargo, no existe ninguna experiencia reportada en Perú de manejo de fauna silvestre 
En 2011, se revisó nuevamente la legislación forestal y de fauna silvestre y se aprobó una nueva ley (Ley No. 29763) que pone más énfasis que las anteriores en el manejo de fauna silvestre y en el aprovechamiento de los recursos por poblaciones rurales, particularmente poblaciones indígenas. La nueva Ley No. 29763 reconoce la posibilidad del manejo de fauna silvestre no sólo en predios de dominio público, sino también en predios privados y en predios de comunidades nativas y campesinas, para lo cual se aprobó más adelante un reglamento especial que regula la gestión forestal y de fauna silvestre en comunidades nativas y campesinas (Decreto Supremo No. 021-2015-MINAGRI). Este reglamento abre una serie de posibilidades para la población de Tamishiyacu Tahuayo, incluyendo el reconocimiento de sus formas comunitarias de manejo y autorregulación (SERFOR, 2015, pág. 279).

Todavía está por verse si esta forma de regulación estatal funciona para controlar a cientos sino miles de extractores dispersos en el área rural, especialmente de las características de la Amazonía peruana. Frente a ello, un sistema funcionando como en el Tamshiyacu - Tahuayo muestra las ventajas del sistema comunal de autorregulación para este grupo social. Recientemente, WCS completó una investigación en el ACRCTT y las comunidades circundantes que vincula el monitoreo del estado de conservación de las especies de caza con la intensidad de la cacería y el cumplimiento de los acuerdos de caza. Los resultados muestran que "el fortalecimiento y promoción del manejo comunal de la cacería ha permitido el mantenimiento del buen estado de conservación de la mayoría de las especies de caza del ACRCTT" (Isasi-Catalá, y otros, 2017).

\section{EL CONTROL Y LA VIGILANCIA COMUNAL}

En Tamshiyacu - Tahuayo, el control y la vigilancia comunal sobre los recursos naturales frente al ingreso de no residentes, mayormente provenientes de lquitos, fue la primera medida de conservación que tomaron las comunidades. Sin embargo, el control y la vigilancia cobran un sentido adicional con el establecimiento de la autorregulación.

Hacia 1980, varios recursos naturales se encontraban extintos en las áreas próximas a los asentamientos comunitarios, especies de fauna silvestre como los lagartos (Melanosuchus niger y Caiman cocrodilus) así como las londras (Pteronura brasiliensis) fueron asediados especialmente por los cueros; la sachavacan (Tapirus terrestres), varias clases de monos (Lagothrix lagothricha, Alouatta seniculus, Ateles belzebeth) por su carne; peces como el paiche (Arapaima gigas) y la vaca marina (Trichechus inungui) por el pescado; el cedro (Cedrela spp.) por la madera y la palma de aguaje (Mauritia flexuosa) por sus frutos (Bodmer, Penn, Puertas, Moya, \& Fang, 1995, pág. 10).

Como se vio, al principio, particularmente sensible fue la situación en relación a la pesca en los lagos y lagunas de donde las comunidades locales también se proveían y esta situación motivó para que empezaran a controlar sus recursos naturales. Al principio, al igual que en otros casos, tal es el de Bolivia, fue la prohibición a los no residentes, "a los otros", que aglutinó primero, en 1980, a los comunarios de El Chino (Bodmer, 1993, págs. 8-9; Bodmer, y otros, 2006, pág. 49).

"La vigilancia estuvo conformada, por cinco personas que realizaron su turno cada 24 horas. Los vigilantes comunales recibieron muchas amenazas por parte de infractores que ingresaron a la zona, pero los pobladores no se desanimaron Tres cochas se cuidaron durante dos años" (Bodmer, y otros, 2006, pág. 49).

La posibilidad de contar con pesca segura y el hecho de haber logrado en los dos años de control una cosecha comercial de peces que anteriormente escaseaban, tales como 
"gamitana" (Colossoma macropomum) y "paco" (Piaractus brachipomus) que permitió a la comunidad de El Chino comprar calaminas para el techado de su escuela, constituyeron importantes alicientes para mantener el manejo de la pesca y otros recursos naturales. El éxito primicial de El Chino también es atribuido al liderazgo respetuoso, firme y capaz de la autoridad comunal y al aún reducido tamaño poblacional de la comunidad. En 1983, la comunidad decidió acudir a la comunidad próxima de Buena Vista donde tiene su sede un puesto de la Policía Nacional, denominada por entonces "Guardia Civil" (Bodmer, y otros, 2006, pág. 49).

A pesar de lo anterior, en 1986, el impulso comunal había decaído, pero en 1988, nuevamente la escasez de los recursos de pesca y las necesidades comunales fueron el impulso para que El Chino actualizara sus acuerdos sobre la pesca (Bodmer, y otros, 2006, pág. 50).

A las decisiones sobre la construcción de puestos de control, en los acuerdos de acceso y uso al interior de cada comunidad y entre comunidades se establecieron las responsabilidades del control y la vigilancia. Posteriormente, debido a que cazadores profesionales en busca de carne de monte para comercializarla en lquitos, empezaron a ingresar al área, en 1991, la comunidad decidió prohibir estos ingresos y controlar la cacería (Bodmer, 1993, pág. 10; Bodmer, Penn, Puertas, Moya, \& Fang, 1995, pág. 10).

En 1992, se retomaron las relaciones con la comunidad de Buena Vista para ampliar el sistema de control y vigilancia, así como asegurar la participación del puesto policial con asiento en dicha comunidad, dando inicio al establecimiento de los acuerdos ya no solo al interior de una comunidad sino entre comunidades. Estos acuerdos estaban referidos al control de fauna silvestre, animales para autoconsumo y comercio, control de flora con énfasis en palmeras y madera de aserrío, control de ingreso al río Tahuayo, afluentes y lagos con fines de pesca, organización de grupos de vigilancia y se establecieron sanciones a los infractores. En este contexto se concretó la participación de la Policía Nacional en el sistema de vigilancia. (Bodmer, y otros, 2006, pág. 51).

Desde 1997, se marcaría una nueva fase en el proceso de control y vigilancia. Otra comunidad, la de San Pedro ubicada en la Quebrada Blanco, afluente del Tahuayo lideró por primera vez el decomiso de 78 troncas de madera apta para el aserrío que estaba extrayendo un foráneo, esta comunidad encontró apoyo en El Chino. De esta manera, la alianza intercomunal para la protección de sus recursos naturales incluyó una comunidad más (Bodmer, y otros, 2006, pág. 51).

Sin embargo, en 1999, se percibía un nuevo decaimiento del sistema de manejo basado en los acuerdos comunales e intercomunales. En esta ocasión debido a una baja en la asistencia técnica y financiera que las instituciones habían empezado a proporcionar desde hacían algunos años atrás (Bodmer, y otros, 2006, pág. 51).

Pero, en 2000 la comunidad Diamante / 7 de Julio decidió establecer un sistema de pagos por concepto de extracción de los recursos naturales frente a la necesidad de solventar algunos gastos comunales. Una parte de esos ingresos se destinan al funcionamiento del sistema de control y vigilancia y las comunidades empezaron a idear estrategias que den sostenibilidad financiera a sus acciones de conservación (Bodmer, y otros, 2006, pág. 51).

Con la finalidad de hacer operativos los compromisos comunales, se establecieron garitas o puestos de control en todos los puntos de ingreso y la región fue dividida por sectores que fueron asignados a las comunidades para el control y la vigilancia. Asimismo, se establecieron roles entre las familias al interior de cada comunidad y entre las comunidades para atender, cada una su sector. Se estableció el sistema de recibos por el pago de las cuotas de fauna silvestre, los mismos que servían como salvoconducto para el transporte de la carne de monte a ser presentado en los puestos de control. Por su parte, las personas 
encargadas en los puestos de vigilancia contaron con un talonario de control en el que registraban el nombre de los cazadores y el producto de su caza. Esta Ficha de Control de Ingreso a la RCTT, fue elaborada teniendo en consideración los ítems para los registros de caza (ver capítulo sobre monitoreo). Con esta ficha se pretendía controlar la extracción de animales de caza y el ingreso de cazadores a la Reserva comunal (Comité de Gestión del ACRCTT, Wildlife Conservation Society, Instituto DICE de la Universidad de Kent, 2005, pág. 34; Bodmer, y otros, 2006, pág. 54).

Asimismo, se estableció que los representantes de las comunidades se reunirían cada 55 días con la finalidad de dar cuenta acerca de las actividades de control y vigilancia e información sobre las actualizaciones de los acuerdos comunales. En 2003, esta necesidad de reunirse periódicamente entre las comunidades daría origen al Comité de Gestión de la Reserva Comunal Tamshiyacu Tahuayo (Bodmer, y otros, 2006, pág. 54).

A pesar de los esfuerzos que realizan las comunidades, la región aún es vulnerable a la extracción irracional e ilegal de los recursos naturales. Una de las mayores dificultades para la mantención del sistema de control y vigilancia comunitario ha sido y es la ausencia de financiamiento sostenible (The Field Museum, 2003, pág. 98). Aunque las comunidades asumen voluntariamente el trabajo de controlar sus recursos naturales y eso reduce grandemente los costos, existen necesidades que requieren ser cubiertas. Para comunidades rurales que viven al día con los ingresos que generan de su trabajo, destinar tiempo para el control y la vigilancia tiene impactos económicos. Debe considerarse que los turnos de control y vigilancia son asumidos por el conjunto de la familia y esta requiere alimentos por el periodo que dura su turno. Asimismo, infraestructura, equipamiento, insumos y mantenimiento son rubros indispensables para mantener funcionando el sistema de control y vigilancia comunal. El apoyo estatal es restringido y el de las instituciones privadas que apoyan esta iniciativa resulta insuficiente e inestable, en la medida que dependen de complejos y a veces lentos procesos de recaudación de fondos.

Frente a esta problemática, las comunidades e instituciones que les apoyan, entre ellas WCS, diseñaron diversas estrategias y realizaron gestiones tales como solicitar que el sistema de control y vigilancia de la Reserva Comunal Tamshiyacu Tahuayo sea reconocido por las autoridades del Servicio Nacional de Áreas Naturales Protegidas (SERNANP), sin resultados todavía. Otras, como vincular el control y vigilancia con las actividades de turismo en la zona y lograr de esta manera una contribución de los albergues turísticos que operan en la zona, han tenido mejores resultados, aunque su contribución aún resulta insuficiente.

Ya en 2003, se documentaba lo siguiente:

"Una de sus mayores preocupaciones (de las comunidades involucradas en la conservación de la RCTT) residía en la dificultad de mantener la vigilancia y protección por su propia cuenta. Afirmaron carecer del apoyo de las autoridades regionales, por lo que solicitaron apoyo a nivel nacional. Desean, asimismo, que se refuerce el control de la sobrepesca y caza en la zona. Para esto último cuentan con el apoyo de los administradores del albergue turístico local, quienes mostraron un gran interés en mejorar los esfuerzos de vigilancia y protección" (The Field Museum, 2003, pág. 91). 


\title{
ADECUACIÓN DE LOS SISTEMAS ORGÁNICOS DE LAS COMUNIDADES PARA LA AUTORREGULACIÓN Y EL CONTROL Y LA VIGILANCIA DE LOS RECURSOS NATURALES
}

Las autoridades comunales juegan un papel fundamental en la vida de las comunidades. En relación al manejo de los recursos naturales fueron ellas las que motivaron la discusión sobre la necesidad de cuidar los recursos naturales de los cuales vivían las comunidades que lideraban. En 1993, se mencionaba que:

\begin{abstract}
"Las comunidades ribereñas están actualmente organizadas en torno de autoridades políticas, a menudo con escuela primaria y algunos oficiales de salud. Las reglas sobre el uso de las tierras y la extracción de recursos naturales son determinados por consenso de los habitantes dentro de cada comunidad" (Bodmer, 1993; Comité de Gestión del ACRCTT, Wildlife Conservation Society, Instituto DICE de la Universidad de Kent, 2005, pág. 36).
\end{abstract}

A su vez, los acuerdos comunales para el manejo de los recursos naturales requieren adecuaciones en los sistemas de organización de las comunidades. En el caso de Tamshiyacu - Tahuayo por un lado se ampliaron las competencias de las autoridades comunales y por otro lado se crearon nuevas estructuras organizativas.

2
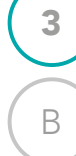

B

INICIO

ÍNDICE

FINAL

Por ejemplo, en los acuerdos se establece que las autoridades de la comunidad tienen entre sus funciones la certificación de situaciones de enfermedad $u$ otras para asegurar el correcto funcionamiento de las excepciones. Los Comités Comunales de Manejo de los Recursos Naturales constituyen instancias nuevas que antes no existían en los sistemas de organización comunal. Ahora, estos Comités tienen a su cargo el registro del uso de los recursos naturales y los vigilantes comunales quienes realizan vigilancia, patrullaje y llevan los "cuadernos de ocurrencias" (ingresos no autorizados, etc.). Finalmente, pero no de manera menos importante, los acuerdos comunales establecen los límites jurisdiccionales de la comunidad (Comunidad Diamante/7 de Julio, Actualizado el 4 de enero de 2015).

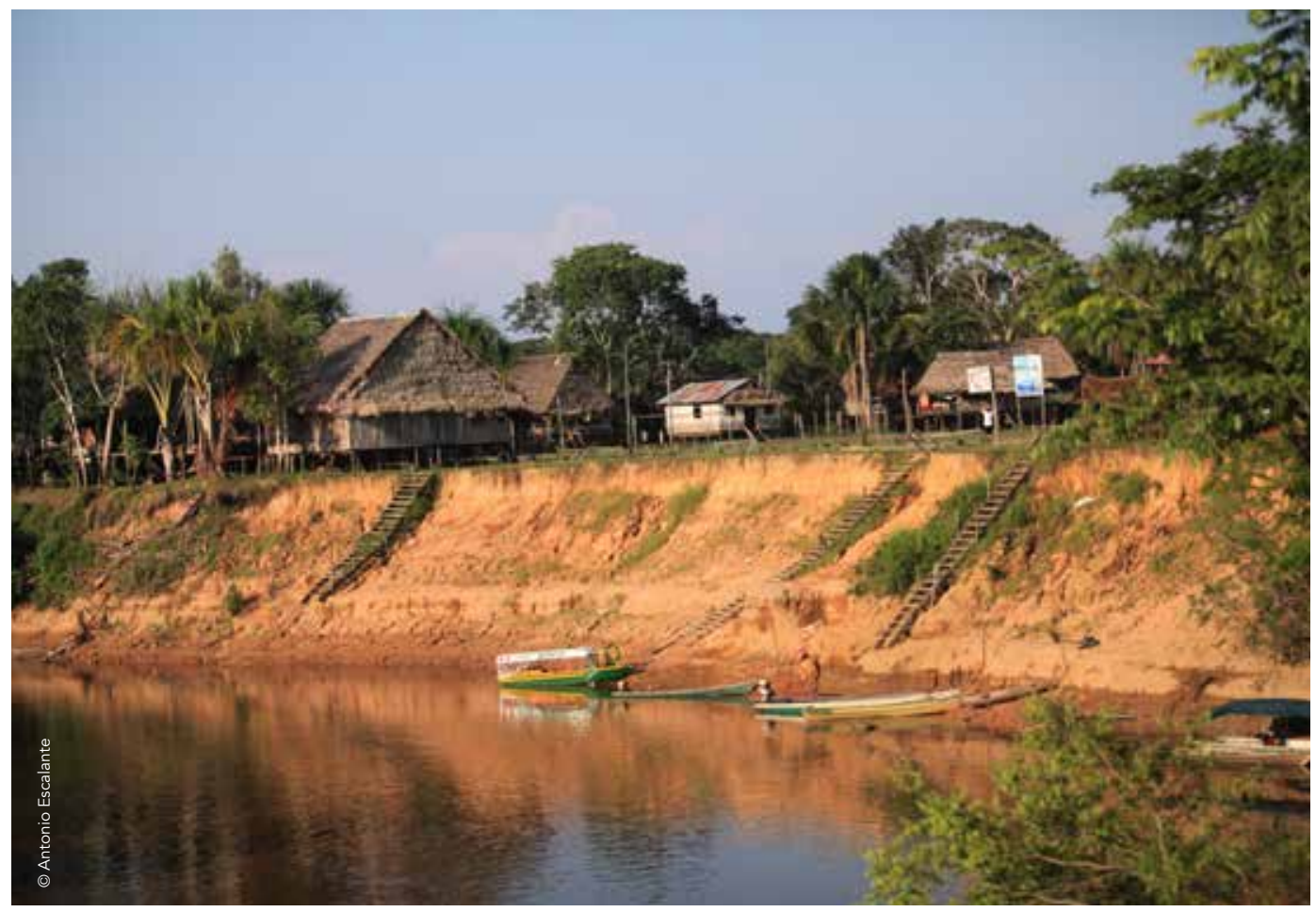


En 2015, durante una evaluación de fortalezas y debilidades de la gobernanza realizada por WCS en Perú a través de métodos participativos, el sistema de autoridades de la comunidad Diamante / 7 de Julio, quedó representada por sus pobladores mujeres y hombres de la siguiente manera:

\section{GRÁFICO 14:}

REPRESENTACIÓN DEL SISTEMA DE AUTORIDADES COMUNALES POR UN GRUPO DE MUJERES DE LA COMUNIDAD

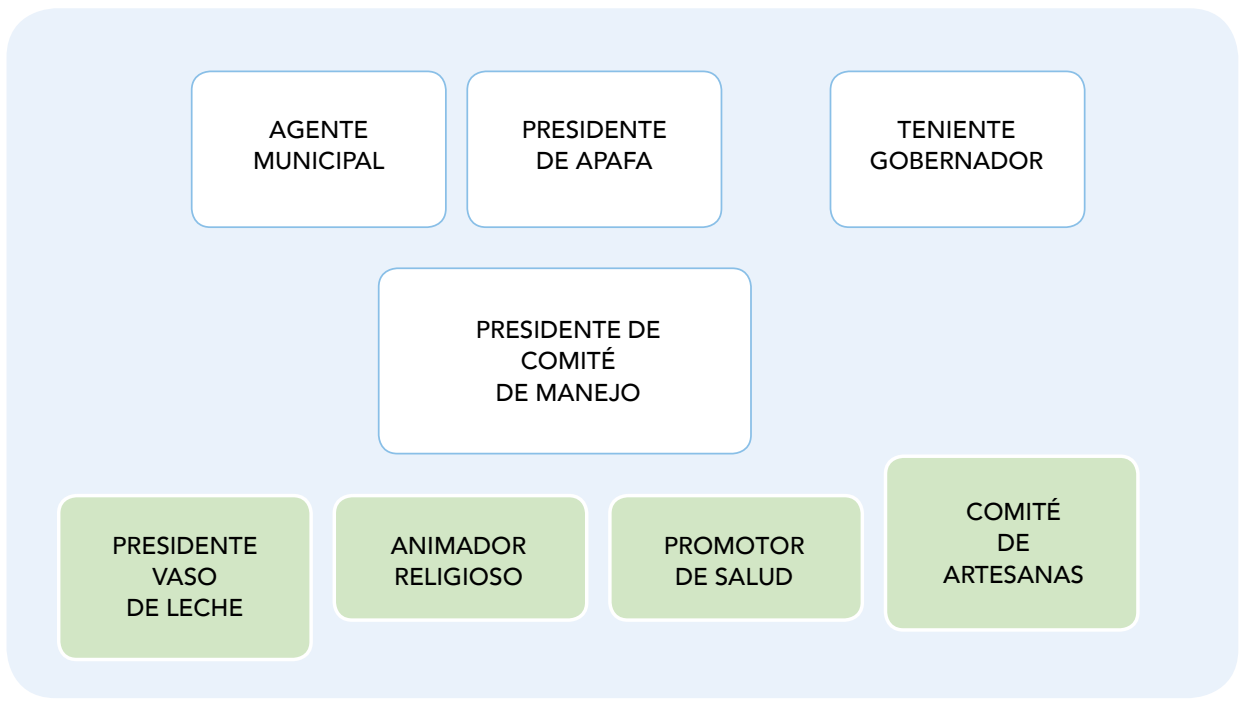

GRÁFICO 15:

REPRESENTACIÓN DEL SISTEMA DE AUTORIDADES COMUNALES POR UN GRUPO DE HOMBRES DE LA COMUNIDAD

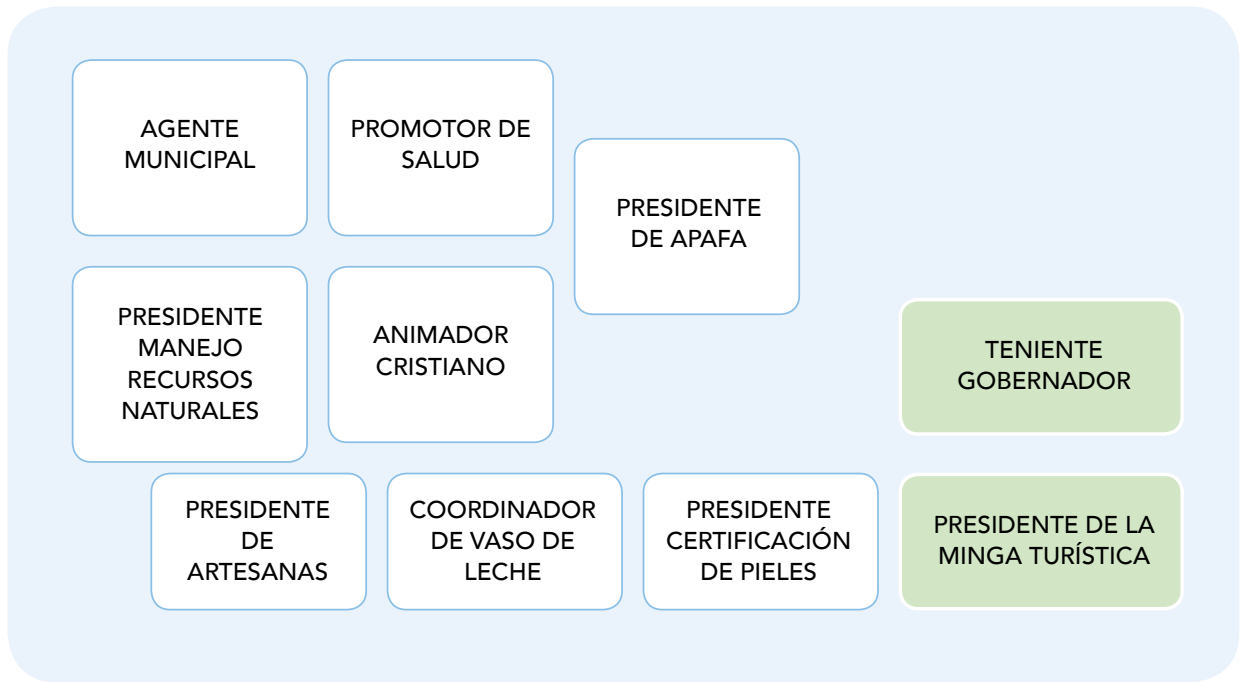

Fuente: (Flores, Antúnez, Padilla, Silva, \& Lehm, 2016) 
En ambos casos, el Comité de Manejo de los Recursos Naturales es representado como una autoridad comunal en segunda línea de importancia por debajo de las que se consideran autoridades principales como el Teniente Gobernador, Agente Municipal y la Asociación de Padres de Familia (APAFA) y por encima de otras que se consideran con menos jerarquía como la presidencia del Vaso de Leche, presidencia de artesanas, animador religioso (en el caso de los hombres considerado con mayor jerarquía que por las mujeres), promotor de salud (mujeres) y presidencias de la certificación de pieles y del emprendimiento turístico Minga (hombres).

Debido a que las autoridades comunales juegan un rol fundamental en el manejo de los recursos naturales, el entramado de sus relaciones y el estado de la gobernanza al interior de las comunidades, en 2015, WCS ha llevado a cabo una evaluación de fortalezas y debilidades de la gobernanza en las que destacan la fortaleza y legitimidad de los acuerdos relativos al manejo de los recursos naturales (Flores, Antúnez, Padilla, Silva, \& Lehm, 2016).

\section{COMITÉ DE GESTIÓN CON BASE EN LAS COMUNIDADES}

En América Latina en general, la creación de las áreas protegidas hasta los años de 1980, en la mayoría de los casos se realizó sin tomar en cuenta a las poblaciones locales, sin embargo, en la década de 1990 se observaban las tensiones que estas acciones generaban al momento de gestionar dichas áreas protegidas. De esta manera, el enfoque de conservación de las áreas protegidas bajo paradigmas que involucran a "la gente" fue tomando relevancia. De esta manera, en la década de 1990, cuando se dio el impulso a la creación de los sistemas nacionales de áreas protegidas se propuso plasmar en la normativa ciertos mecanismos que aseguraran la participación de la población local y de las instituciones involucradas en el manejo de las áreas protegidas. De esta manera, se crearon instancias como los Comités de Gestión o los mecanismos de coadministración o cogestión, etc. (Mason, y otros, 2004; Castillo, y otros, 2007).

En este marco, en Tamshiyacu - Tahuayo, como se pudo observar, la construcción de acuerdos comunales y el control y la vigilancia sobre los recursos naturales inició con la comunidad El Chino pero progresivamente se fueron involucrando otras comunidades. De manera progresiva se incorporaron Buena Vista, San Pedro y Diamante / 7 de Julio. En 2003, representantes de estas comunidades tuvieron un primer Encuentro donde habían definido sostener reuniones periódicas cada 55 días con la finalidad de coordinar las acciones de control y vigilancia, conciliar y compatibilizar los acuerdos comunales, coordinar acciones e intercambiar información y ante la necesidad de reunirse decidieron proponer la creación de un Comité de Gestión de la Reserva Comunal Tamshiyacu Tahuayo, esta propuesta pasó por un proceso de consulta a las Asambleas comunales hasta que la creación del Comité de Gestión pudo hacerse efectiva el 6 de diciembre de 2003 (Comité de Gestión del ACRCTT, Wildlife Conservation Society, Instituto DICE de la Universidad de Kent, 2005, pág. 34; Bodmer, y otros, 2006, pág. 53 y 77).

Hasta 2005, el Comité de Gestión estaba constituido solo por las cuatro comunidades pioneras, pero el mismo Comité consideraba la necesidad de involucrar a nuevas comunidades y probablemente con el ejemplo de las primeras habían comunidades interesadas en ser parte del manejo de la reserva, tales como: Jerusalén, la única comunidad que se autoidentifica indígena de la etnia Achual en la región, y Esperanza, ubicadas en el río Tahuayo, Libertad en la Quebrada Blanco y Constancia en el Tamshiyacu. Una de las mayores dificultades para el involucramiento de más comunidades provenía de la adversidad con los comerciantes y extractores ilegales quienes desorientaban a las comunidades con información malintencionada (Comité de Gestión del ACRCTT, Wildlife Conservation Society, Instituto DICE de la Universidad de Kent, 2005, pág. 34; Bodmer, y otros, 2006, pág. 77). Probablemente con las acciones de conservación y sobretodo la 
demostración de que se podía hacer uso de los recursos naturales de manera sostenible y que esto era beneficioso para el bienestar de la población, se facilitó que las comunidades reacias a la Reserva y a las prácticas de manejo, bajasen progresivamente la guardia y se enrolasen progresivamente al Comité de Gestión. De hecho, por ejemplo, Jerusalén en la actualidad es una de las comunidades con mayor interés en la conservación debido a que ha desarrollado su propia iniciativa de turismo comunitario (Comité de Gestión del ACRCTT, Wildlife Conservation Society, Instituto DICE de la Universidad de Kent, 2005, pág. 34; Comunidad Jerusalén, 2015).

El Comité de Gestión de Tamshiyacu - Tahuayo tiene la particularidad de estar conformado exclusivamente por las comunidades que realizan el manejo del ACRCTT. Desde 2004 en que se estableció el sistema de representación, en el Comité de Gestión participan las máximas autoridades de las comunidades como los Tenientes Gobernadores, Agentes Municipales, los Comités de Manejo de los Recursos Naturales y más recientemente algunos representantes de las asociaciones productivas basadas en el manejo de los recursos naturales como las asociaciones de artesanas. De esta suerte, el Comité de Gestión constituye una instancia y espacio privilegiado para la discusión sobre las acciones que competen a la Reserva Comunal Tamshiyacu Tahuayo, el control y la vigilancia y el manejo de los recursos naturales en las diferentes zonas de uso. De manera importante, en él se consensuan las cuotas para el uso de los recursos naturales a nivel intercomunal. Su estructura orgánica interna está constituida por una presidencia, vicepresidencia, tesorería y dos vocalías (Bodmer, y otros, 2006, pág. 54 y 77) (obs. personal).

En las reuniones del Comité de Gestión también participan las autoridades regionales encargadas de la conservación y el manejo de los recursos naturales, la Policía Nacional y las instituciones que apoyan el manejo de la región, estas entidades no participan en calidad de tomadores de decisiones, pero el Comité de Gestión es el espacio de coordinación con las comunidades. El Comité de Gestión emite recomendaciones para el trabajo de las instituciones con las comunidades tales como que:

"Los proyectos no solo deben animar a trabajar a la gente, también deben monitorear con regularidad los trabajos que se emprenden con el fin de asegurarse de que se cumplan los objetivos propuestos.

Los beneficios que se pueda tener de la participación de un proyecto no se deben limitar a un grupo selecto de personas que algunos consideran "privilegiados" (Bodmer, y otros, 2006, pág. 77)

Además, y no menos importante, el Comité de Gestión cumple una función de mediación entre las comunidades y el Estado en su nivel regional: el Gobierno Regional de Loreto (GOREL) a través de su Programa de Conservación, Gestión y Uso Sostenible de la Diversidad Biológica de Loreto (PROCREL). Entre las instituciones privadas invitadas a participar en el Comité de Gestión, en 2004 ya se encontraban: el albergue turístico A\&E Tours, Rainforest Conservation Society (RCFF-ACDA/Perú) y Wildlife Conservation Society (WCS en Perú) (Comité de Gestión del ACRCTT, Wildlife Conservation Society, Instituto DICE de la Universidad de Kent, 2005, pág. 62; Bodmer, y otros, 2006, pág. 5 y 77).

La mantención de este espacio con sus particulares características constituye una de las contribuciones importantes de WCS en Perú, a través de la capacitación a potenciales líderes locales de las comunidades para que integren el Comité de Gestión. Esta capacitación tiene su foco en el desarrollo y conducción de planes de manejo de recursos naturales (Bodmer, y otros, 2006, pág. 6), además del soporte para el transporte y la alimentación de las personas participantes, considerando que el Comité de Gestión se reúne de manera regular cada dos meses. 


\section{ACTIVIDADES DE MANEJO DE RECURSOS POR LAS COMUNIDADES}

Si bien todas las acciones como el ordenamiento de la tierra, la autorregulación, el control y la vigilancia y la organización comunal y del Comité de Gestión son elementos constitutivos del manejo sostenible de los recursos naturales, la base de todo aquello, son las acciones específicas relacionadas con el manejo de los recursos. Estas acciones estuvieron orientadas a asegurar por un lado la subsistencia y la generación de ingresos para cubrir necesidades básicas familiares y comunitarias, pero, por otro lado, también ingresos adicionales con base en actividades nuevas como el ecoturismo. Del mismo modo, la situación de recursos específicos como las palmas que durante décadas habían estado sometidas a prácticas destructivas de aprovechamiento requería medidas urgentes que ayudasen a su recuperación, tomando en cuenta, además, su interrelación con la fauna silvestre.

Como se señaló, los acuerdos comunales pueden considerarse "planes de manejo informales" que han resultado ser efectivos, estos se refieren a una diversidad de recursos: la pesca, cacería, recolección de los productos de las plantas no maderables, el aprovechamiento de la madera, etc. El manejo a través de los acuerdos busca regular el uso de tal manera que las comunidades involucradas puedan mantener su base de subsistencia y al mismo tiempo generar ingresos para la adquisición de bienes y servicios básicos para las familias y las comunidades.

En Tamshiyacu - Tahuayo, el manejo de la fauna silvestre constituye el pilar fundamental cuyo modelo da sentido a la conservación del área y al manejo del conjunto de los recursos naturales. El desafío más importante, encarado por WCS en Perú, ha sido determinar cuál es la cosecha sostenible de cada especie sometida a la cacería, pero más que eso lograr que en esa determinación, estén involucradas las comunidades de tal manera que nutra sus propias decisiones plasmadas en los acuerdos.

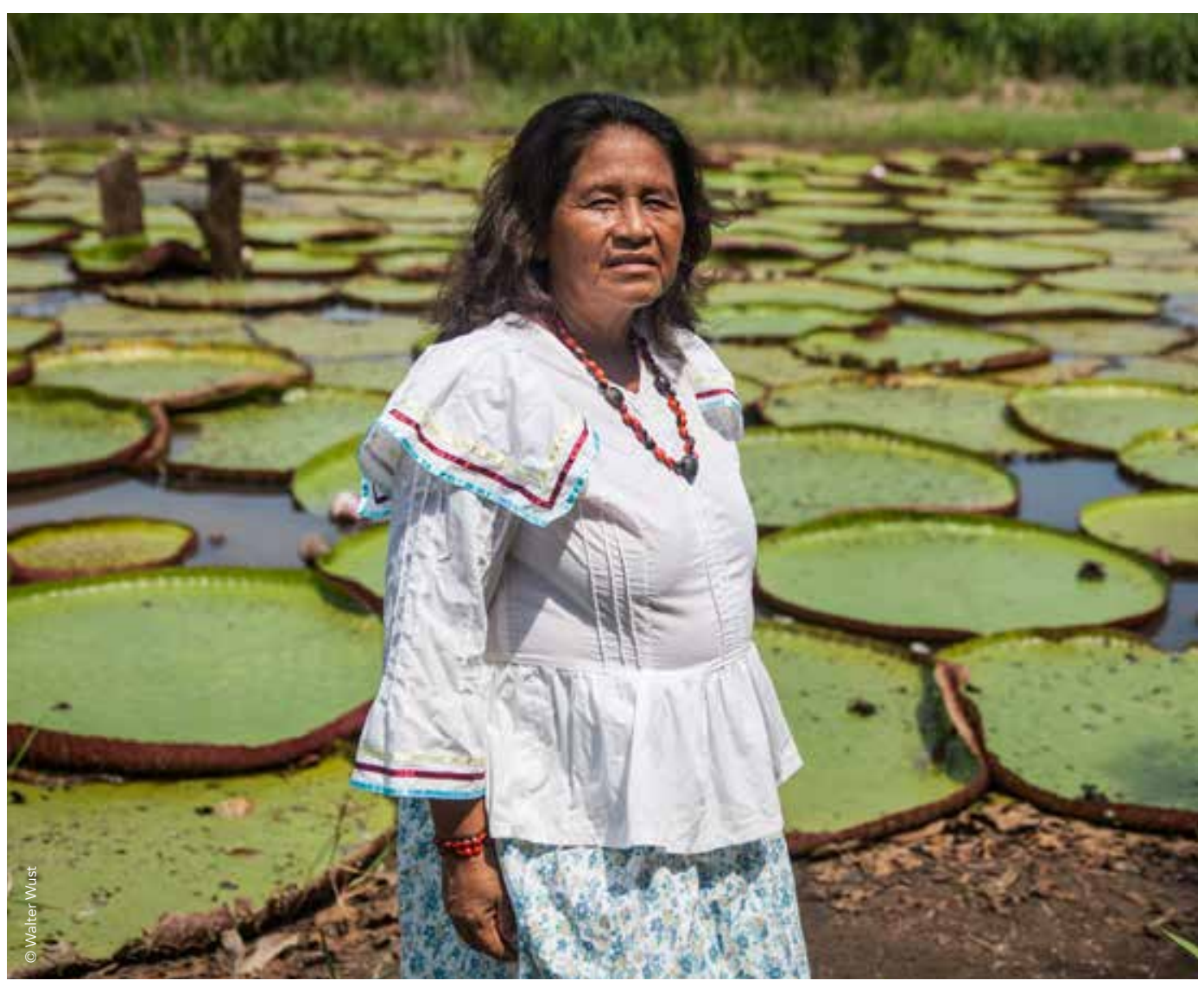


Para ello, WCS en Perú se ha basado en la recolección, durante más de dos décadas, de información sobre la presión de la cacería, la captura por unidad de esfuerzo (CPUE: catch-per-unit-effort), las densidades de animales en zonas con y sin caza, y la tasa de reproducción de las especies en las zonas de caza.

"Para la recolección de la información sobre la presión de caza se contó con la colaboración de los cazadores, por medio de reuniones en las comunidades locales y presentaciones con fines educativos, así como entrevistas informales. Esta estrategia participativa ofrece muchas ventajas que no tienen los métodos no participativos : 1) permite a los investigadores obtener información directa sobre la presión de caza; 2) fomenta el trabajo cooperativo entre investigadores y cazadores y mejora el entendimiento mutuo de las necesidades de ambos grupos; 3) da un paso previo para involucrar a toda la comunidad en el futuro manejo de vida silvestre; 4) enseña a los cazadores los métodos de recolección de información que luego les serán muy útiles en sus propios análisis de sostenibilidad de la caza; y 5) facilita la recolección de cráneos y sistemas reproductivos de los animales cazados. El método participativo ha motivado a los cazadores pensar más sobre el manejo de la vida silvestre y aprender a monitorear los registros de caza" (The Field Museum, 2003, pág. 100).

Si la población está siendo sobrecazada puede determinarse comparando la cosecha con la producción. La cosecha sostenible se estima tomando en cuenta el promedio de vida de la especie y el número de animales que mueren por causas ajenas a la intervención humana (The Field Museum, 2003, pág. 103). De esta manera, para las comunidades ubicadas en el Quebrada Blanco se logró determinar que el sajino, el venado colorado y el añuje eran cazados de manera sostenible; la huangana, el machín negro y el huapo negro igualmente estaban siendo cazados de forma sostenible; pero el tapir de llanura, el mono choro y el machín negro estaban siendo cazados de maneras no sostenibles (The Field Museum, 2003, pág. 103). Esta información fue determinante para que las comunidades establecieran la veda indefinida de estas últimas especies (Comunidad Diamante/7 de Julio, Actualizado el 4 de enero de 2015; Comunidad Campesina El Chino, Actualizado el 18 de enero de 2015; Comunidad San Pedro, Actualizado el 19 de enero de 2015).

Como se vio, los análisis de la cosecha sostenible fueron acompañados con las estimaciones del valor económico de la cacería y otros recursos naturales y su contribución a los ingresos monetarios de los hogares. Estos análisis tienen como fundamento que:

"El uso sostenible de la vida silvestre es una poderosa razón para la conservación de la biodiversidad. Si la población rural aprecia los beneficios del uso sostenible de la vida silvestre, entonces querrá mantener los hábitats de las especies, para no perder esos beneficios. Si la población conserva los hábitats de la vida silvestre, también conservará todo el espectro de biodiversidad en esos hábitats" (The Field Museum, 2003, pág. 106).

Si el establecimiento de cuotas de cacería por hogar y comunidad parece haber funcionado en el Tamshiyacu - Tahuayo, otras medidas propuestas no tuvieron igual suerte. Por ejemplo, con la finalidad de asegurar aún mejor la sostenibilidad de la cacería de los artiodáctilos, se propuso a las comunidades que fuesen cazados solo machos, para el control se diseñó un conjunto de procedimientos que fueron minuciosamente detallados (Bodmer, 1993). Incluso en 1994 se desarrolló un programa experimental con las comunidades de El Chino y Diamante / 7 de Julio. Sin embargo, esta medida no funcionó. "Los cazadores consideraron que este ejercicio era dificultoso ya que la mayoría de las veces era difícil distinguir el sexo 
de los animales durante la faena de caza" (Bodmer, y otros, 2006, pág. 51). Esto demuestra que las recomendaciones técnicas para el manejo deben tener un carácter práctico y ser de fácil aplicación, como fuera apuntado por Mc Kean y Ostrom E. (1994) al tratar sobre las reglas de acceso y uso de los recursos de régimen común.

Adicionalmente, se diseñó un "Programa de Certificación de Pieles de Pecaríes", con la finalidad de que los hogares puedan generar ingresos adicionales al permitírseles comercializar las pieles de los animales muertos para el uso de la carne. Desde 2006, se han tomado acciones en esa perspectiva (Bodmer, y otros, 2006, págs. 6 y 61 - 62). Al parecer, los impactos de esta iniciativa en la economía de las comunidades aún son poco significativos (obs. personal).

El manejo de las plantas no maderables, constituyó otro gran desafío en Tamshiyacu Tahuayo, toda vez que su ubicación mayormente en zonas bajas hace que sea común encontrar densidades importantes de árboles frutales y palmas (Penn J. ,2006, pág. 3). Existe una importante demanda desde lquitos por sus frutos como el aguaje, camu camu y otros, o son necesarios localmente para la producción de artesanías como la chambira, o para los techados de las viviendas o incluso su venta en lquitos como del irapay, hubo una tradición de prácticas destructivas para la cosecha. Y dada su importancia para la alimentación de la fauna silvestre, incluyendo la de algunos peces, al mismo tiempo que esta cumple una función de dispersión de las semillas en los bosques, implicaba que su manejo era determinante para todo el sistema de conservación en la región (Bodmer, 1993; Bodmer, Penn, Puertas, Moya, \& Fang, 1995; The Field Museum, 2003, págs. 97-98; Penn J. , 2006; GOREL y PROCREL, 2010).

En el caso del aguaje, luego de intensos periodos de explotación, las poblaciones silvestres habían quedado exhaustas, la productividad había bajado: si, en 1990, de la zona del alto Tahuayo se extraían entre 1000 a 1500 sacos de $50 \mathrm{~kg}$ de frutos de alta calidad, hacia 2006, con suerte, los recolectores conseguían uno o dos sacos de $50 \mathrm{~kg}$ de frutos de baja calidad. Esta situación fue atribuida al hecho que los aguajales remanentes estaban tan dañados que eran menos productivos, la calidad de sus frutos también era menor, y en lquitos se pagaba menos por ellos. Para entonces, los aguajales cultivados en parcelas agroforestales tenían una mejor producción que los silvestres (Penn J. , 2006, pág. 6).

Frente a esa situación, las instituciones que trabajan en la zona, particularmente, WCS en Perú y Rainforest Conservation Fund propusieron algunas medidas de manejo que luego fueron asumidas en el Plan Maestro del ACRCTT ( GOREL y PROCREL, 2010). Entre estas medidas se encuentran: la prohibición de la cosecha de los frutos silvestres especialmente de aguaje y la promoción de la siembra de estas especies de palmas y otras en las parcelas agroforestales de propiedad privada o comunal en la zona de asentamientos y uso intensivo, con la finalidad de bajar la presión sobre las poblaciones silvestres.

Dando prioridad al aguaje por su importancia como alimento para la población local, fuente de ingresos económicos y función ecológica en relación a la fauna silvestre, en 1993 se dio inicio a este proyecto. Inicialmente, se involucraron las comunidades de Buena Vista, El Chino, San Pedro, Diamante / 7 de Julio y Esperanza ubicadas en el río Tahuayo y la Quebrada Blanco, posteriormente lo hicieron San Juan de Yanacayu, Jerusalén y Santa Cruz. Hacia 2006, se habían involucrado alrededor de 42 productores que habían cultivado 4000 palmas en más de 60 parcelas agroforestales (Penn J. , 2006). En los sistemas agroforestales se incorporaron más de 40 especies de plantas y la participación de las comunidades en proyectos agroforestales fue considerada como un indicador de su compromiso con la conservación (The Field Museum, 2003, pág. 90 y 98). Sin embargo, la inseguridad en la tenencia de la tierra por muchas comunidades era un factor que inhibía el despliegue de esfuerzo requerido para establecer los sistemas agroforestales, tomando en cuenta que los hogares recién podrían aprovechar su producción varios años después de haber sido plantados (Penn J. , 2006, pág. 25) 
Otras iniciativas de conservación y manejo de recursos naturales se han desarrollado en el área, tal como el turismo, en principio por impulso de empresas privadas. En la actualidad existen algunas iniciativas comunitarias como la de la comunidad de Jerusalén, que ha llegado a considerar que el turismo le ha permitido encontrar una buena razón para conservar su área (Bodmer, y otros, 2006, págs. 20 - 21; Comunidad Jerusalén, 2015). El paulatino incremento del turismo ha puesto en valor las artesanías de chambira que produce la asociación de mujeres artesanas "Manos Amazónicas" en la comunidad de El Chino. Esto se ha logrado a través de la alianza de la comunidad con la empresa de Turismo $\mathrm{A} \& \mathrm{E}$, asegurando la visita de turistas a la comunidad donde las comunarias les venden sus artesanías. A\&E tiene su albergue en la cercanía de la comunidad. Las mujeres, para ser aceptadas como socias de la asociación "Manos Amazónicas" deben ser poseedoras de una chacra con árboles no maderables como la chambira, entre otros (Asociación de Artesanas Manos Amazónicas, 2015).

\section{MONITOREO DEL USO DE LOS RECURSOS NATURALES POR LAS COMUNIDADES}

El monitoreo aparejado a la investigación, con el concurso de las comunidades, han sido los pilares fundamentales de la experiencia de manejo de base comunitaria del Tamshiyacu - Tahuayo.

El monitoreo de la cacería, como se mencionó, se basa en los registros de caza que involucra a participantes voluntarios en cada comunidad. Estas personas han sido capacitadas por WCS en Perú para la toma de datos que se apuntan en formularios especialmente diseñados para el efecto. Entre los datos que se registra se encuentran: especies cazadas, sexo, número de ejemplares cazados, nombre del cazador, el lugar donde cazó, fecha en que salió y regresó de la cacería (Comité de Gestión del ACRCTT, Wildlife Conservation Society, Instituto DICE de la Universidad de Kent, 2005, pág. 34).

Adicionalmente, el monitoreo requiere la utilización de técnicas convencionales de investigación tales como los censos de las poblaciones silvestres, en cuya aplicación también participan uno o dos miembros de las comunidades que acompañan a un biólogo. Estos censos se basan en la técnica de los transectos lineales. Los datos que se recogen con esta metodología refieren a la densidad de la fauna silvestre de caza.

El enfoque de la relación entre áreas "fuente" y "sumidero" utilizado para comprender mejor la sostenibilidad de la cacería y la necesidad de conservar áreas más amplias que solo aquellas donde se realiza la actividad, demanda que esta determinación de la densidad de las poblaciones de fauna silvestre se realice tanto en las zonas sometidas a la cacería como en aquellas, siendo contiguas o con conectividad, en las que no se realiza dicha actividad. Asimismo, a través de técnicas convencionales de investigación, se busca establecer la biología reproductiva y ecología de las especies (Comité de Gestión del ACRCTT, Wildlife Conservation Society, Instituto DICE de la Universidad de Kent, 2005, pág. 43; Bodmer, y otros, 2006, pág. 34).

El análisis de los datos de censos, registros de caza y biología reproductiva busca determinar el uso sostenible de cada especie sometida a la cacería, "es decir, si están siendo cazados sin riesgo de acabarse" (Bodmer, y otros, 2006, pág. 35).

Como se mencionó, en la Quebrada Blanco algunas especies estaban siendo cazadas de manera sostenible, pero otras no, particularmente aquellas que naturalmente tienen bajas tasas reproductivas. Esta información sirvió para ayudar a determinar las cuotas de caza por especie, así como para decidir cuáles debían quedar prohibidas indefinidamente (Bodmer, y otros, 2006, pág. 55). 
El análisis de los datos en el periodo de una década entre 1994 y 2005 mostró que la Captura por Unidad de Esfuerzo (CPUE), determinada a partir de los registros de cacería, se incrementó durante los tres primeros años del monitoreo, luego de lo cual se mantuvo constante. Asimismo, los censos de la vida silvestre mostraron que en la zona de subsistencia ("fuente") la abundancia y cantidad de biomasa eran mayores que en la zona de asentamientos y uso intensivo ("sumidero"). Todo esto indicaba que el sistema de cacería, bajo los acuerdos comunales, estaba funcionando de tal manera de asegurar la sostenibilidad en el uso de la fauna silvestre (Bodmer, y otros, 2006, págs. 67 - 76).

Como se mencionó, más recientemente, entre 2016 y 2017, WCS desarrolló una investigación en el ACRCTT y las comunidades circundantes que vincula el monitoreo del estado de conservación de las especies de caza con la intensidad de la cacería y el cumplimiento de los acuerdos de caza. Los resultados muestran que "el fortalecimiento y promoción del manejo comunal de la cacería ha permitido el mantenimiento del buen estado de conservación de la mayoría de las especies de caza del ACRCTT" (Isasi-Catalá, y otros, 2017).

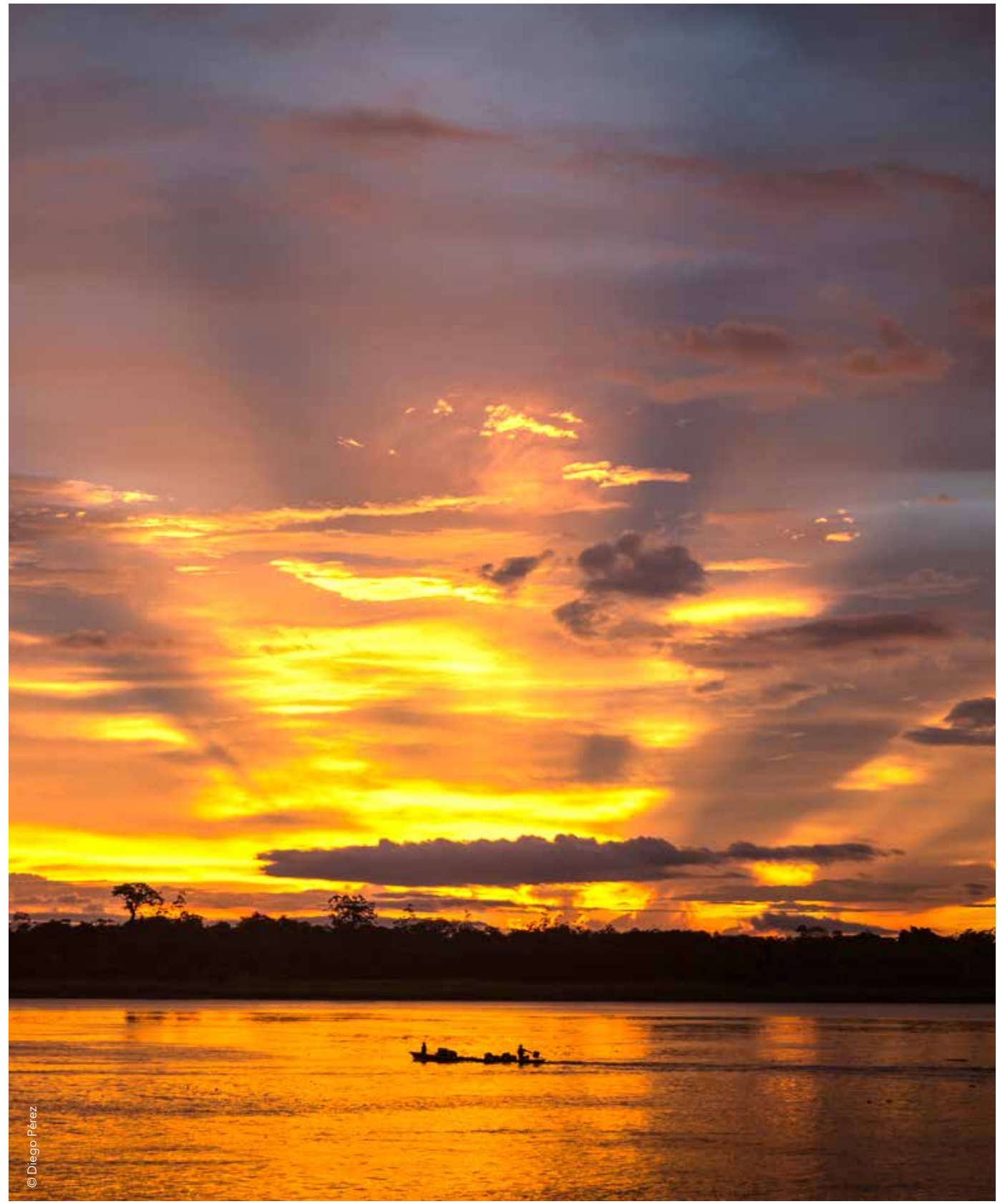




\section{CONCLUSIONES}

Si se considera el marco de paradigmas que relacionan la conservación con la población local, definidos y caracterizados en nuestro marco interpretativo como conservación "sin", "para", "con" o "por" la gente, entendiendo por "la gente" específicamente a las comunidades locales que viven en o cerca de las áreas protegidas, el caso de Tamshiyacu - Tahuayo puede comprenderse como un claro esfuerzo para que la conservación sea realizada "por" la gente y de ello deriva su carácter exitoso.

Como se pudo observar en el análisis de este caso, se trata de un modelo que combina de manera coherente la reflexión teórica y conceptual y la investigación con la aplicación de medidas específicas de conservación. Entendida esta como el uso sostenible de los recursos naturales por las poblaciones locales, en la medida que este modelo se orientó, inicialmente, por la hipótesis de que:

"El uso sostenible de la vida silvestre es una poderosa razón para la conservación de la biodiversidad. Si la población rural aprecia los beneficios del uso sostenible de la vida silvestre, entonces querrá mantener los hábitats de las especies, para no perder esos beneficios. Si la población conserva los hábitats de la vida silvestre, también conservará todo el espectro de biodiversidad en esos hábitats".

En esta propuesta destaca el enfoque económico en el análisis de la sostenibilidad del uso de los recursos naturales. Los análisis de la relación costo / beneficio en diferentes escenarios según prácticas de uso sostenibles y no sostenibles en el corto y en el largo plazo, a la vez de ser convincentes para que las comunidades acepten mejoras en sus sistemas de uso de los recursos naturales son indispensables para orientar la toma de decisiones respecto del manejo. En este enfoque, bastante trillado y sofisticado en la actualidad, WCS en Perú fue pionero.

El marco teórico y metodológico propuesto, también orienta la agenda de la investigación para el manejo. En esta agenda destaca el esfuerzo por relacionar el conocimiento sobre la vida silvestre y su ecología con el uso de los recursos por las comunidades locales. En este quehacer es importante el enfoque histórico para comprender la historia natural de la región, no solo a nivel de la macro historia amazónica sino de la micro historia del Tamshiyacu - Tahuayo y la subcuenca del Yavarí.

Es el enfoque histórico lo que permite hacer comprensible la decisión de las comunidades del Tamshiyacu - Tahuayo para conservar el área donde viven y donde se distribuyen los recursos de los cuáles hacen uso, en una época en la que a nivel global recién la idea de la conservación comenzaba a tomar vuelo y se acuñaba el concepto de "desarrollo sostenible", es decir la década 1980. La sobreexplotación histórica de los recursos naturales llevada al extremo de la escasez habría impulsado a las comunidades a tomar decisiones de control y manejo sobre los recursos naturales de su entorno, parece ser uno de los mensajes que nos deja esta experiencia.

Aún en el plano de la investigación, si uno de los esfuerzos es establecer las cosechas sostenibles de la fauna silvestre sometida a la cacería, para lo cual se han utilizado los registros de cacería, los censos y otras técnicas de investigación, el enfoque ecológico y económico ha exigido una orientación más amplia. De hecho, así como no se puede comprender la situación de las especies de fauna silvestre disociadas de las plantas como los palmares de aguaje, tampoco se puede entender la economía de los hogares y de las comunidades considerando solo los ingresos por concepto de cacería, sino que el manejo de uno u otro recurso en particular, requiere una comprensión de los ingresos que genera 
en el contexto del conjunto de los otros ingresos que provienen de la agricultura, la pesca, la madera, etc. Finalmente, pero no menos importantes han sido los estudios sobre la demanda y los mercados como determinantes de los flujos y reflujos en el uso de uno u otro recurso natural y, como se dijo, todo ello en un enfoque histórico de larga data.

El proceso y posteriormente el programa de investigación desarrollado en Tamshiyacu Tahuayo es un ejemplo de acumulación de conocimientos sobre la región y de diversidad temática que aborda aspectos biológicos y ecológicos así como socioeconómicos. Además de esto que de suyo ya es una lección aprendida, dos aspectos más destacan: 1) la necesidad del carácter inter y transdisciplinario de los equipos técnicos y de investigación que se requiere para dar soporte a la conservación de base comunitaria y 2) la articulación de la investigación científica con las necesidades de información para la toma de decisiones por las comunidades como orientación básica para asegurar el manejo por la población local.

La sistematización del caso de Tamshiyacu - Tahuayo, como experiencia de conservación basada en el manejo de los recursos naturales por las comunidades permite identificar las acciones y procesos fundamentales de conservación que se han desarrollado durante más de tres décadas: 1. Investigación. 2. Apoyo técnico a las comunidades para gestionar la creación de la Reserva Comunal. 3. Ordenamiento de la tierra, considerando una gradiente de uso de los recursos naturales que incluye zonas de protección estricta, zonas de uso de subsistencia, zonas de asentamiento y uso intensivo. 4. La regulación del uso de los recursos naturales por las comunidades. 5. El control y la vigilancia comunal. 6 . La adecuación de los sistemas de organización de las comunidades. 7. La creación y funcionamiento de instancias intercomunales como el Comité de Gestión. 8. El manejo de recursos naturales específicos por las comunidades sea con fines de consumo o de mercado. 9. El automonitoreo y monitoreo de los recursos naturales. Estos componentes articulados constituyen la estrategia de largo aliento que WCS en Perú ha ayudado a desarrollar para la conservación del Tamshiyacu - Tahuayo. Aunque aquí, estos procesos pueden plasmarse de una manera secuencial, en la práctica más bien se han sobrepuesto, han transcurrido con avances y retrocesos, pero al final, de manera acumulativa han terminado por configurar una experiencia de conservación con profundas raíces en las comunidades ribereñas.

En la fase constitutiva de la Reserva Comunal fue muy importante la relación entre comunidades e investigadores. Entre estos últimos existía una tensión entre quienes apostaban por el papel protagónico de las comunidades en la conservación de la Reserva y quienes consideraban que el énfasis en la restricción del uso de los recursos por las comunidades conduciría a una mejor conservación del área.

El desarrollo de un Programa de Investigación para la formación de investigadores de Perú y otros países fue utilizado como estrategia de posicionamiento para el diálogo sobre la conservación de base comunitaria a nivel global. La experiencia de Tamshiyacu - Tahuayo en este campo también permite destacar la importancia de las alianzas interinstitucionales para llevar adelante este tipo de programa.

La experiencia de Tamshiyacu - Tahuayo permitió demostrar positivamente la hipótesis de que el ordenamiento de la tierra considerando una gradiente de uso con zonas completamente protegidas donde todo uso está restringido, zonas de uso de subsistencia y zonas de uso intensivo, es una estrategia que hace posible la articulación de la conservación de las especies y ecosistemas con el uso de los recursos naturales por las comunidades.

La autorregulación de las comunidades en Tamshiyacu - Tahuayo es probablemente el proceso más sorprendente de esta experiencia tanto por el proceso que siguió cuanto por su contenido y forma. Aquí, es necesario destacar los siguientes elementos: 
1. El "detonante" de la regulación fueron las restricciones que las comunidades locales decidieron imponer a los "foráneos", no residentes de la zona. Esta decisión permitió que se cohesionaran primero los habitantes de una comunidad, El Chino, y luego este mismo propósito permitió la adherencia de otras comunidades de la zona.

2. La regulación comenzó en relación a uno de los recursos más sensibles para las comunidades: la pesca que proporciona recursos tanto para el consumo como para la venta.

3. El impulso generado por el éxito de las acciones anteriores se tradujo en que los mismos habitantes empezaran a dialogar sobre sus propios usos hasta llegar a consensos primero entre comuneros de una comunidad y luego entre comunidades.

4. La forma de la regulación basada en acuerdos plasmados en los libros de actas de cada comunidad y no tanto así en reglamentos formales es destacable por varias razones: a) la forma se enraíza con una práctica organizativa de estas comunidades, el resultado no es "enajenable" y permite que el proceso se mantenga bajo su control, b) coadyuva a la legitimidad del contenido de los acuerdos y c) da flexibilidad para su adecuación y responde a las necesidades de adaptabilidad que requiere el manejo de los recursos naturales.

5. El contenido de los acuerdos recoge los conocimientos de las comunidades: tradicionales y adquiridos a través de su sistema de monitoreo, al mismo tiempo que considera la información proporcionada por los investigadores.

6. Estos acuerdos refieren: a) la cantidad permitida para el uso de cada tipo de recurso natural, b) los métodos de cosecha que son permitidos y los que no lo son, c) la definición sobre quién(es) tienen derecho de acceso a los recursos de la reserva d) las sanciones a ser aplicadas a quienes incumplan los acuerdos y e) explicitan la jurisdicción o los límites geográficos de la comunidad donde rigen los acuerdos.

7. El sistema de cuotas que se establece en los acuerdos fue adoptado exitosamente por estas comunidades

8. El sistema de cobros en dinero probablemente se adecúe a comunidades como las de Tamshiyacu - Tahuayo que tienen mayor orientación al mercado.

9. El destino de los cobros o multas por sanciones para fines de interés comunal, así como la inclusión en los acuerdos de excepciones para casos de enfermedad, extrema necesidad y la identificación de momentos críticos del año para la economía de los hogares, son factores que coadyuvan a la legitimidad de los acuerdos.

10. Una condición importante es que la decisión sobre el contenido de los acuerdos constituye una atribución autónoma de las comunidades y esta condición es reconocida y respetada por otros actores como el Estado, organizaciones técnicas de apoyo, investigadores, etc.

11. El proceso de autorregulación y particularmente de aplicación de las sanciones ha sido acompañado muy de cerca y respaldado por la Policía Nacional que tiene un asiento en una de las comunidades de la zona. Esto implica que los acuerdos, además de tener significativos niveles de legitimidad también están respaldados por la autoridad del orden público.

12. Una gran debilidad en este proceso es la escasa participación de las mujeres. 
La autorregulación requiere del sistema de control y vigilancia. En el caso del Tamshiyacu Tahuayo las jurisdicciones comunales implican la responsabilidad del control y la vigilancia sobre los recursos naturales, no solo de la zona de los asentamientos sino también de la Reserva. Este sistema de control y vigilancia se basa en la organización de turnos, en muchos casos no son solo personas individuales de cada hogar sino familias que rotan para realizar la actividad. Los turnos duran desde veinticuatro horas en el periodo de creciente de los ríos hasta ocho horas en tiempo de vaciante cuando el nivel de las aguas de los afluentes menores impide el ingreso de embarcaciones a las zonas más alejadas. El involucramiento de las comunidades ha sido progresivo e influenciado por los resultados de las comunidades pioneras, así como por la solidaridad hecha manifiesta, por ejemplo, cuando se han realizado decomisos de los recursos extraídos ilegalmente del sector de alguna de ellas.

Para apoyar el sistema comunal de control y vigilancia, WCS en Perú y otras instituciones que trabajan en la zona han diseñado instrumentos de uso adecuado por las comunidades como un sistema de recibos por los cobros de las cuotas de fauna silvestre que a la vez sirven de salvoconducto para el transporte de la carne, talonarios para el control de ingreso y salida a la RCTT, diseñados tomando en consideración los ítems para los registros de cacería. Además de capacitación permanente para el uso de estos instrumentos, y también es importante la contribución para la infraestructura, el equipamiento, insumos como combustible y alimentos para las personas vigilantes.

A lo largo de los años, el proceso de control y vigilancia ha tenido periodos de ascenso, así como momentos de decaimiento, que se han caracterizado por bajas en la asistencia técnica y financiera por parte de las instituciones que apoyan a las comunidades.

3

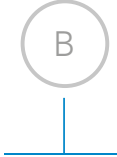

INICIO

ÍNDICE

FINAL

El tránsito hacia un sistema de conservación basado en el manejo de los recursos naturales requiere adecuaciones en los sistemas organizativos de las comunidades a través de la ampliación de competencias de las autoridades comunales y la creación de nuevas instancias orgánicas. El entramado de las relaciones entre autoridades y grupos de gobernanza al interior de las comunidades requiere una atención especializada que WCS en Perú aún no ha desarrollado.

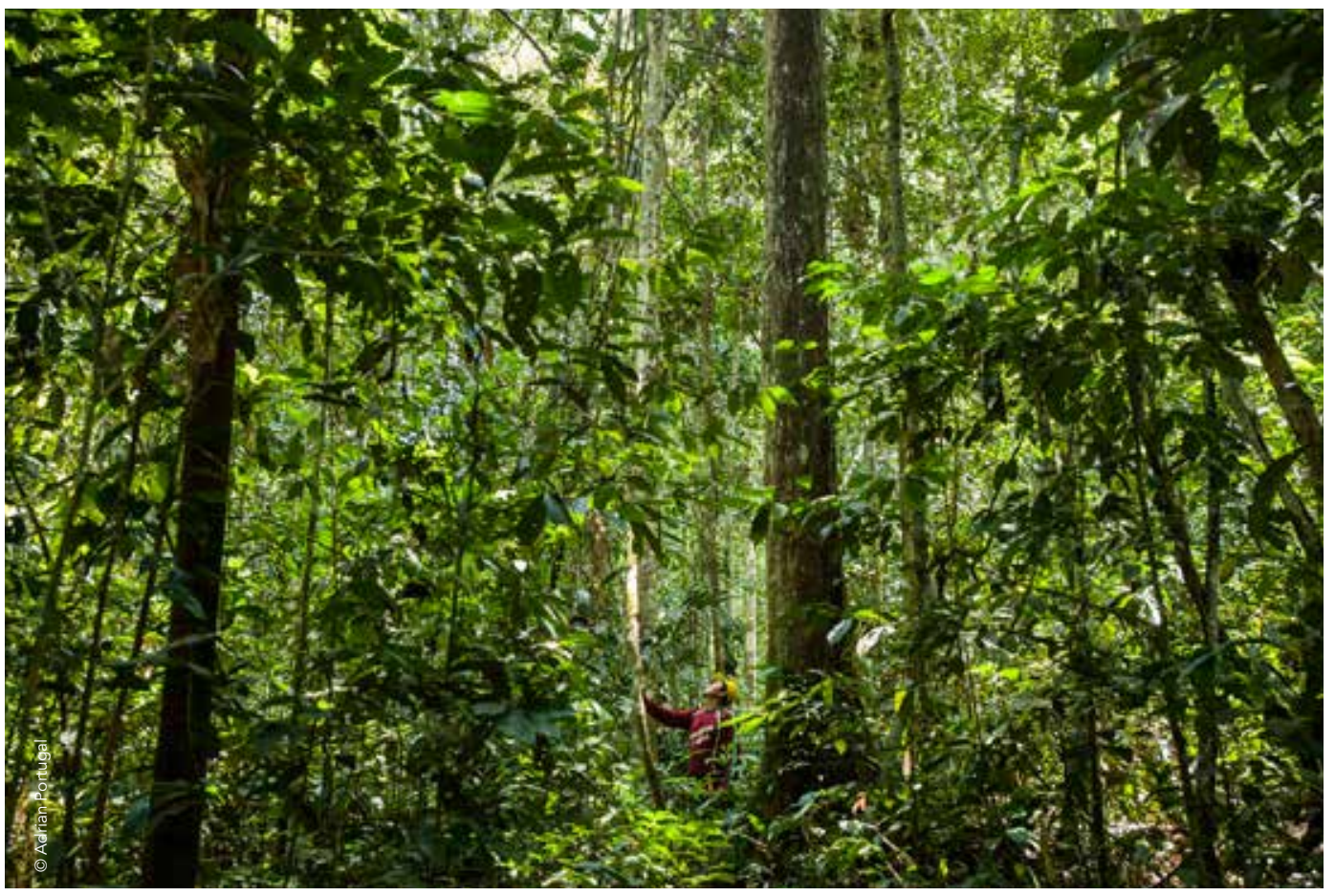


En el análisis del desempeño de cada comunidad en el cumplimiento tanto de la autorregulación como del control y la vigilancia sobre los recursos naturales se demuestra que existe una relación positiva con liderazgos respetuosos, firmes y capaces de las autoridades comunales. En términos de los Comités de Gestión como mecanismos de participación de la población en relación con las áreas protegidas, el caso del Tamshiyacu - Tahuayo demuestra que funcionan de manera efectiva cuando están conformados por las comunidades residentes y estas tienen capacidad de decisión.

En áreas como esta donde las comunidades se autodefinen como campesinas o ribereñas y donde cada una constituye una unidad autónoma sin filiaciones verticales, como sucede por ejemplo con las comunidades nativas que tienen organizaciones de segundo y hasta cuarto nivel, el Comité de Gestión ha venido a cumplir esa función de articulación entre comunidades y al mismo tiempo un rol de intermediación entre el conjunto de las comunidades y el Estado, es probable que su mejor funcionamiento también se deba a este importante factor.

La mantención de este espacio constituye también una importante contribución de WCS en Perú, a través de la capacitación a potenciales líderes locales de las comunidades para que integren el Comité de Gestión, el soporte financiero, junto a otras instituciones públicas y privadas, para el transporte y la alimentación de las personas participantes, considerando que el Comité de Gestión se reúne de manera regular cada dos meses.

Todas las acciones están orientadas al manejo de los recursos naturales y, de hecho, los acuerdos comunales pueden considerarse "planes de manejo informales", sin embargo, el sistema exige además programas específicos para el manejo de recursos orientado a la generación de ingresos adicionales. De hecho, los análisis de la relación/costo beneficio elaborados para Tamshiyacu - Tahuayo demostraron que, manteniéndose el sistema de aprovechamiento con prácticas no sostenibles, los ingresos eran superiores en el corto plazo, pero irían decayendo con el agotamiento de los recursos naturales. Por el contrario, la introducción de prácticas más sostenibles resultaba en un ingreso anual superior en 25 $\%$ al asegurarse el uso de los recursos en el largo plazo. Sin embargo, la transición de un sistema no sostenible a uno de carácter sostenible tenía un costo de $21 \%$ del ingreso que requería ser compensado sea a través de mejorar los ingresos haciendo un uso más integral de los recursos o por el acceso a mejores servicios básicos (Comité de Gestión del ACRCTT, Wildlife Conservation Society, Instituto DICE de la Universidad de Kent, 2005, pág. 66). En Tamshiyacu Tahuayo se decidió ir por la primera vía.

De esta manera, se han desarrollado programas de manejo de recursos como el de las pieles certificadas de pecaríes y otras especies cazadas por su carne para el mercado de lquitos, o el involucramiento de las comunidades en la actividad turística o la creación de asociaciones de artesanas y artesanos vinculados al mercado turístico local.

$\mathrm{Si}$, en este caso aplicamos al análisis el enfoque de las "esferas de la reciprocidad y el mercado", más ampliamente desarrollada en el capítulo sobre los enfoques de interpretación de esta sistematización, podríamos decir que en el caso del apoyo de WCS en Perú al manejo de Tamshiyacu - Tahuayo ha tenido más éxito el apoyo a la esfera de la reciprocidad que el apoyo a la esfera del mercado incluyendo la dimensión en la cual ambas esferas se superponen.

En Tamshiyacu - Tahuayo, el manejo de la fauna silvestre constituye el pilar fundamental cuyo modelo da sentido a la conservación del área y al manejo del conjunto de los recursos naturales. El desafío más importante, encarado por WCS en Perú, ha sido determinar cuál es la cosecha sostenible de cada especie sometida a la cacería, pero más que eso lograr que en esa determinación, estén involucradas las comunidades de tal manera que nutra sus propias decisiones plasmadas en los acuerdos. 
Para esto, WCS en Perú ha apoyado a las comunidades con la implementación de un sistema de monitoreo basado por un lado en los registros de cacería por personas voluntarias de las propias comunidades, proveyéndoles los cuadernos de registro y sobretodo la capacitación para el registro de la información y, por otro lado, implementando técnicas convencionales de censos para determinar la densidad poblacional de las especies tanto en zonas de cacería como de no cacería. El análisis de los datos de censos, registros de caza y biología reproductiva busca determinar el uso sostenible de cada especie sometida a la cacería. El monitoreo a lo largo de los años, primero entre 1994 y 2006 y más recientemente en 2016, demuestras que el uso de las comunidades bajo el sistema de manejo desarrollado en Tamshiyacu Tahuayo es sostenible para muchas de las especies.

Si el establecimiento de cuotas de cacería por hogar y comunidad parece haber funcionado en el Tamshiyacu - Tahuayo, otras medidas propuestas no tuvieron igual suerte. La restricción de la cacería solo de artiodáctilos machos no funcionó porque no era práctica para los cazadores, ellos consideraban que era dificultoso distinguir el sexo de los animales durante la faena de cacería.

El manejo de plantas no maderables a través de sistemas agroforestales en las parcelas de propiedad individual o comunal ha encontrado una difusión entre productores y comunidades.

Es observable que el sistema de Tamshiyacu - Tahuayo tiene un eje de cuatro comunidades pioneras El Chino, Buena Vista, San Pedro y Diamante / 7 de Julio en las que se concentra la mayor parte de las acciones. Un segundo nivel son las siete otras comunidades que actualmente conforman el Comité de Gestión, las que realizan acciones de conservación, pero de una manera menos intensiva que las cuatro primeras. Una marcada debilidad del manejo de Tamshiyacu - Tahuayo es que tanto en los ríos Tahuayo como Tamshiyacu existen muchas más comunidades, más del doble de las que están involucradas que no han ingresado aún al sistema de manejo del entorno de la Reserva, aunque las comunidades más directamente involucradas son las más próximas a la misma. 


\section{EL PAISAJE YASUNÍ, LA GESTIÓN INTEGRADA DE TERRITORIOS INDÍGENAS Y EL MANEJO DE RECURSOS POR LAS COMUNIDADES KICHWAS Y WAORANI}

El Parque Nacional Yasuní fue creado mediante Acuerdo Ministerial en 1979. En 1992, sus límites fueron redefinidos, y su superficie establecida en 982000 ha constituye la más extensa del Ecuador continental. El Parque Nacional Yasuní corresponde a la zona de vida del Bosque Húmedo Tropical, su rango altitudinal va desde los 200 a 300 m s. n.m.; el clima de la región es considerado como cálido - húmedo con un nivel de precipitación que oscila entre los 2860 y 3000 mm anuales; la región mantiene temperaturas medias de $24^{\circ}$ a $28^{\circ} \mathrm{C}$ y con una alta humedad cuyos valores anuales fluctúan entre $86 \%$ y 94 \%. En él se conservan más de 2274 especies de árboles y arbustos, 204 especies de mamíferos de los cuales más de 90 son murciélagos, al menos 121 especies de reptiles, 139 especies de anfibios, 268 especies de peces, 610 especies de aves y aunque el número de invertebrados todavía es indeterminado, se sabe que supera los cientos de miles de especies de insectos. Está catalogada como una de las zonas con mayor diversidad por metro cuadrado del planeta. Es uno de los pocos sitios caracterizados como refugios del pleistoceno que conservaron condiciones climáticas tolerables y se convirtieron en focos de diversidad vegetal y polos de inmigración animal (UNESCO/MAB, 2013, págs. 7, 17, 23; Wildlife Conservation Society - Programa Ecuador, 2014, págs. 7, 17).

Su importancia biológica y cultural ha dado lugar a que una amplia región de 2.7 millones sea reconocida en 1989 como Reserva de la Biósfera de la Humanidad por el Programa "el Hombre y la Biósfera" de la UNESCO. En esta región, se encuentran varias comunidades indígenas pertenecientes a las naciones Kichwa y Waorani, así como los denominados Tagaeri y Taromenane, en aislamiento voluntario (UNESCO/MAB, 2013, págs. 17, 23).

El Gran Paisaje Llanganates - Yasuní, definido por WCS como área prioritaria de conservación en el oriente de Ecuador, tiene como referencias a los parques nacionales Yasuní en las tierras bajas y Llanganates en las cumbres andinas. Esta definición de paisaje ha sido establecida en atención a la necesidad de conservar una gradiente altitudinal con representatividad de los ecosistemas de los Andes Orientales y la Amazonía ecuatoriana y, al mismo tiempo, de atender a un necesario enfoque de manejo de cuencas que asegure la conservación efectiva del conjunto de unidades de gestión que constituyen el paisaje. El Gran Paisaje Llanganates - Yasuní, como se observa en el Mapa 6, está constituido por una diversidad de unidades de gestión que combinan parques nacionales, territorios y tierras ancestrales o comunitarias pertenecientes a comunidades, pueblos y nacionalidades indígenas. Entre ellas se distinguen dos parques nacionales, Yasuní y Llanganates, tierras comunitarias reconocidas a comunidades representadas por la Federación Indígena de Comunidades y Comunas Kichwa de la Amazonía de la Provincia Orellana (FICCKAE) y comunidades campesinas representadas por la Federación de Comunidades Campesinas de Orellana (FOCAO), territorios ancestrales reconocidos a la Nacionalidad Waorani del Ecuador (NAWE); a la Nacionalidad Sapara del Ecuador (NASE) y a la Asociación de Comunidades Indígenas de Arajuno (ACIA). En la Reserva de la Biósfera también se encuentra una Zona Intangible para la protección de pueblos indígenas en aislamiento voluntario Tagaeri - Taromenane. 
MAPA 6: PAISAJE YASUNÍ - LLANGANATES

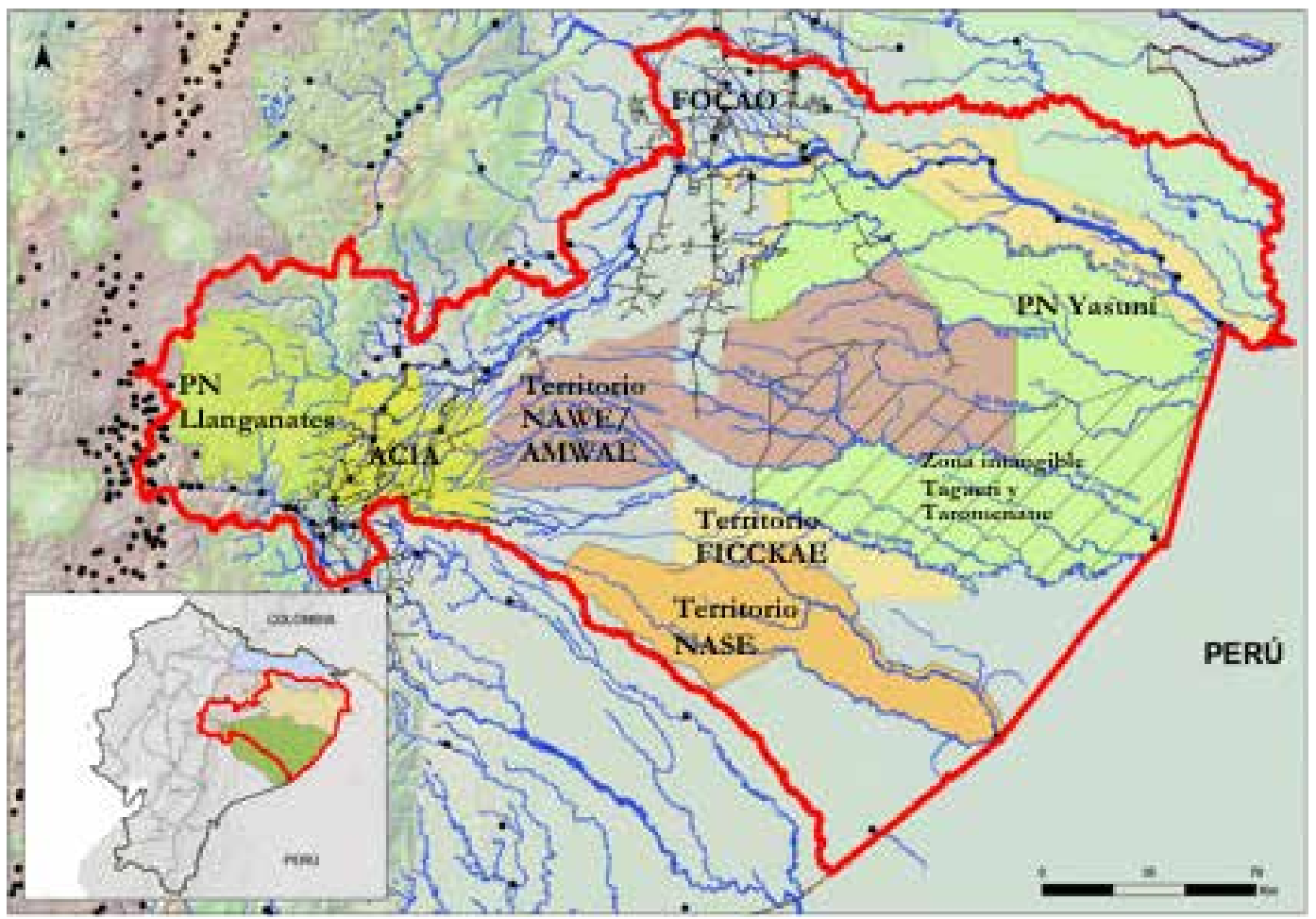

El trabajo de WCS en relación con las poblaciones indígenas y comunidades campesinas en este paisaje, si bien se inicia en 2001, se ha desarrollado con mayor énfasis desde 2007 hasta el presente, fundamentalmente en la Reserva de la Biósfera Yasuní. En tanto que el trabajo con las poblaciones locales de Llanganates y del área que conecta este Parque con Yasuní, recién comienza. Por ello, esta sistematización se referirá al trabajo de WCS en las tierras bajas del paisaje, específicamente con las comunidades kichwas ubicadas en la parte noreste del Parque Nacional Yasuní, representadas por la Federación Indígena de Comunidades y Comunas Kichwa de la Amazonía de la Provincia de Orellana (FICCKAE) y el Pueblo Waorani representado por la Nacionalidad Waorani del Ecuador (NAWE) y la Asociación de Mujeres Waorani del Ecuador (AMWAE) cuyo territorio se ubica al oeste y centro, colindante y con sobre posición del Parque Yasuní. De ahora en adelante llamaremos Paisaje Yasuní a esta porción de tierras bajas del Gran Paisaje Llanganates - Yasuní.

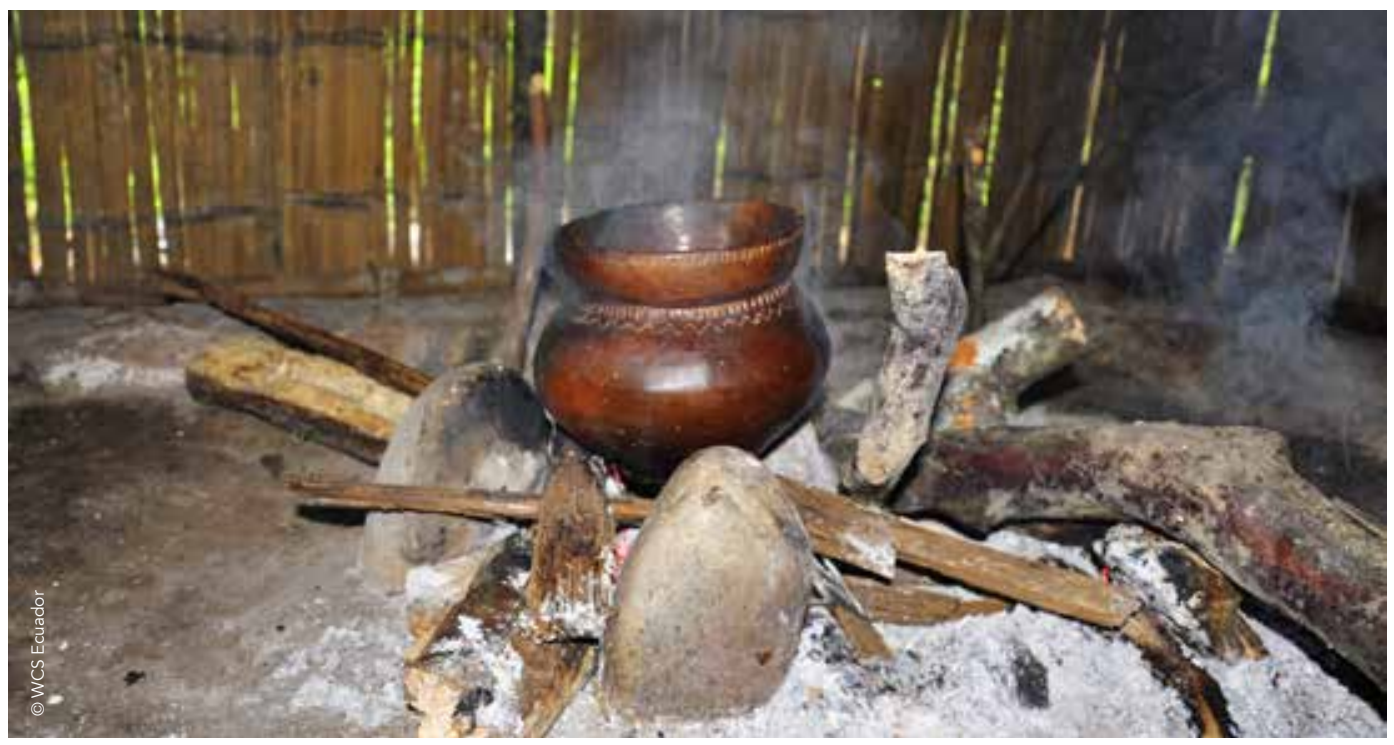




\section{EL ENFOQUE DE LA GESTIÓN INTEGRADA DE LAS TIERRAS COMUNITARIAS Y TERRITORIOS ANCESTRALES}

Si bien, la experiencia de trabajo con comunidades locales y pueblos indígenas de la Amazonía, de WCS es más reciente en comparación con Perú y Bolivia, un relevamiento de actividades realizadas entre 2009 y 2016 en el Gran Paisaje Llanganates - Yasuní da cuenta de 263 actividades. La mayoría de las cuales se han desarrollado con la FICCKAE y sus comunidades (93) y con la NAWE, AMWAE y las comunidades que estas entidades representan (83). Como referencia, un menor número de actividades se realizó con el Comité de Gestión de la Reserva de Biosfera Yasuní.

Las actividades desarrolladas en las tierras comunitarias kiwchas y el territorio ancestral waorani se han basado en un enfoque de gestión integrada cuyo conjunto de criterios fueron desarrollados entre 2009 y 2011 a través de un programa que contó con el soporte de USAID. Estos criterios fueron:

"1) Título de territorio y uso de recursos

2) Demarcación física de límites territoriales en coordinación con vecinos

3) Sistemas participativos de control y vigilancia

4) Planes de manejo comunitario, plan estratégico, plan de vida

5) Mitigación de conflictos

6) Financiamiento sostenible para la gestión y la protección

7) Incorporación formal en los planes de desarrollo gubernamentales" (WCS Programa Ecuador, 2011, pág. 3).

Con estos criterios, bajo la coordinación de WCS y contando con múltiples alianzas con entidades tanto gubernamentales y mayormente ONG's, el Programa se desarrolló en seis territorios indígenas ubicados tanto en la costa como en la Amazonía. Entre estos territorios, WCS enfocó sus acciones, como se ha señalado en las tierras de comunidades kichwas y en el territorio waorani a los que se superpone tanto el Parque como la Reserva de la Biósfera Yasuní. La suspensión de este programa y las restricciones de financiamiento determinaron que las acciones ya no abarcaran el abanico de integralidad con base en los criterios originalmente propuestos.

\section{MAPEO COMUNITARIO Y SUS MÚLTIPLES USOS}

Una de las herramientas ampliamente utilizada por WCS en el Paisaje Yasuní ha sido el "mapeo participativo" por las comunidades kichwas y waoranis. En cada caso, el proceso se desarrolló con una secuencia de acciones que van desde el relevamiento de la información bajo procedimientos participativos, hasta la digitalización, análisis y devolución de los resultados a las comunidades y sus organizaciones.

El "mapeo participativo", estuvo precedido y acompañado de intensos procesos de capacitación a personas delegadas por las organizaciones indígenas entre miembros de las mismas comunidades (WCS - Programa Ecuador, 2011, pág. 24). Las capacitaciones versaron en temas tales como: técnicas del mapeo participativo, cartografía y manejo de sistemas de posicionamiento global (GPS), manejo básico de sistemas de información geográfica (GIS), desarrollo e implementación de bases de datos socioeconómicos y biológicos con la finalidad de establecer líneas base y monitorear los impactos de sus propias actividades así como de sus necesidades básicas.

Para ello, fueron diseñados e implementados cursos de capacitación, se elaboraron y adecuaron manuales de entrenamiento en sistemas de información geográfica para hacer 
posible el uso más amplio por comuneros en proceso de entrenamiento. Como uno de los resultados, la evaluación de estos procesos permitió identificar recomendaciones y lecciones aprendidas para programas de entrenamiento en sistemas de información geográfica para organizaciones indígenas (WCS - Programa Ecuador, 2011, pág. 23).

El proceso de capacitación en servicio de estos equipos técnicos dependientes de las organizaciones indígenas estuvo dirigido, por ejemplo en el caso waorani, a "técnicos de mapeo", "guardaparques comunitarios" y "parabiólogos" encargados del manejo de tortugas de río. Implicó la capacitación tanto teórica como práctica y la capacitación en servicio: el acompañamiento en varios procesos de mapeo por parte del equipo técnico de WCS. Esto último fue particularmente necesario en el caso de la nacionalidad waorani, mientras que en el caso de las comunidades kichwas, la capacitación a comuneros a través de cursos y talleres ha sido relativamente suficiente para que ellos mismos desarrollen el proceso de mapeo en sus comunidades (WCS - Programa Ecuador, 2011, pág. 24).

Al igual que en el caso de Bolivia, el "mapeo comunitario" se ha caracterizado por el liderazgo de las organizaciones de segundo nivel de los pueblos indígenas como la NAWE o la FICCKAE. De esta manera, el procedimiento metodológico permitió fortalecer los vínculos entre los líderes y las comunidades a las cuales representan. Estas organizaciones se vieron fortalecidas también con la conformación de equipos técnicos locales dependientes de las organizaciones, capacitados por WCS.

Al igual que en otros casos documentados, el "mapeo participativo" y fundamentalmente el manejo de sistemas de información geográfica constituye una herramienta privilegiada y muy valorada por los pueblos indígenas de la Amazonía ${ }^{13}$. De esta suerte, por ejemplo, tanto en los casos de la NAWE como de la FICCKAE llegó el momento en el que decidieron contratar personal técnico especializado en sistemas de información geográfica para que les ayudase en sus procesos de mapeo y al mismo tiempo continuara la capacitación a su equipo técnico local, y buscaron comprar equipamiento adecuado para tal fin (WCS Programa Ecuador, 2011, págs. 7, 24).

Uno de los principales fines del mapeo ha sido el ordenamiento del uso de los recursos naturales por las comunidades. La designación de las zonas de uso ha estado acompañada con el establecimiento de reglas de acceso y uso para cada una de ellas. En general, en una muestra de 15 comunidades mapeadas $(9$ comunidades waorani y 6 comunidades kichwas), las zonas de uso más frecuentemente identificadas por las comunidades han sido: zonas de conservación estricta, zonas de cacería o uso extensivo y zonas de uso agrícola y asentamientos o uso intensivo, en algunos casos, también se identifican zonas de turismo. En algunas comunidades también se mapearon sitios donde se encontraron signos de la presencia de Tagaeri y Taromenane, pueblos indígenas en aislamiento voluntario. Es importante destacar que las zonas de conservación estricta son las de mayor superficie y se ubican en áreas sobrepuestas por el Parque Nacional Yasuní (WCS Programa Ecuador, 2011, págs. 7 - 9; Wildlife Conservation Society, Programa Ecuador y Ministerio del Ambiente del Ecuador, Parque Nacional Yasuní, 2015, págs. 38 - 44).

La capacitación de personal técnico conformado por comuneros dependiente de las organizaciones matrices ha sido una destacable estrategia para replicar el mapeo con diferentes finalidades, especialmente relacionadas con el manejo de los recursos naturales y el monitoreo de la vida silvestre. Por ejemplo, en 2011, técnicos de la NAWE ayudaron a las mujeres de AMWAE para que mapearan las áreas de distribución de la "chambira", materia prima que ellas utilizan para la elaboración de sus artesanías, y así formular un plan para el manejo de la especie (WCS - Programa Ecuador, 2011, págs. 9, 11, 25). El

13 En Bolivia, la Confederación Indígena de Bolivia (CIDOB) mantuvo durante muchos años un Centro de Planificación Territorial Indígena basado en el manejo de sistemas de información geográfica y en Perú, el Instituto para el Bien Común, documentó varias experiencias exitosas de manejo de SIG por organizaciones indígenas. 
"mapeo comunitario" ha sido instrumental también para trabajar con las comunidades acerca de sus percepciones y experiencias relativas al cambio climático y la búsqueda de estrategias de adaptación al mismo (WCS - Programa Ecuador, 2011, pág. 15).

Los "mapeos comunitarios" también han servido para ayudar a las comunidades a ingresar al Programa Socio Bosque del Ministerio del Medio Ambiente de Ecuador, un mecanismo que fue creado con fines de proporcionar incentivos económicos por la conservación de los bosques (Ministerio del Ambiente, 2016) ${ }^{14}$. En algunos casos, el mapeo comunitario promovido por WCS fue acompañado por funcionarios de este programa (WCS - Programa Ecuador, 2011, págs. 7 - 8). Como se verá más adelante, el trabajo conjunto con el Programa Socio - Bosque fue una estrategia desarrollada por WCS en busca de asegurar la sostenibilidad financiera de la gestión territorial integral por los pueblos indígenas y las comunidades locales.

De manera importante, el fortalecimiento de capacidades en el manejo de información geográfica, ha servido a las comunidades en sus peticiones de tierras. Así, en el caso de las comunidades kichwas de Yasuní, al menos catorce, apoyadas por la FICCKAE, utilizaron el mapeo comunitario para respaldar los procesos de petición legal de sus tierras (WCS Programa Ecuador, 2011, pág. 11).

Los mapas comunitarios, incluidos en los Planes de Manejo de las Comunidades también fueron requeridos durante el proceso de constitución de "Circunscripciones Territoriales Indígenas" (CTI).

Finalmente, en no pocos casos, los mapeos comunitarios han servido como medio de resolución de conflictos entre comunidades y aún entre pueblos indígenas vecinos (WCS - Programa Ecuador, 2011, pág. 7).

\section{DEMARCACIÓN DE TERRITORIOS INDÍGENAS, CONTROL Y VIGILANCIA TERRITORIAL}

La demarcación de límites de los territorios indígenas, el mantenimiento de los mismos y el control y la vigilancia constituyen un conjunto de medidas propias de la Gestión Territorial Indígena.

En Yasuní, los deslindes han implicado el apoyo de WCS en Ecuador a numerosas reuniones y encuentros entre las organizaciones indígenas, tanto de la NAWE con los kichwas, y de estos últimos con comunidades de la Nacionalidad Sapara (NASE). Estos procesos de diálogo frecuentemente han derivado en acuerdos de respeto mutuo entre las partes (WCS - Programa Ecuador, 2011, págs. 9, 11).

De manera importante, también se han establecido procesos de trabajo conjunto entre las organizaciones indígenas y los personeros del Ministerio del Ambiente con la finalidad de concertar el uso de los recursos por parte de las comunidades en los límites o en áreas donde el Parque Nacional Yasuní se sobrepone con las áreas de uso de las comunidades. En estos casos, los planes de manejo comunitario han sido los instrumentos que facilitaron los procesos de concertación. En 2011, diecisiete comunidades de la FICCKAE se comprometieron a respetar los límites del Parque Nacional Yasuní y otras cuatro comunidades ubicadas muy cerca o dentro del Parque a elaborar planes de manejo comunitario que permitieran conservar la zona de amortiguamiento del mismo (WCS Programa Ecuador, 2011, pág. 11).

14 En 2016, el Programa Socio Bosque suspendió sus actividades por falta de recursos económicos del Estado. 
Mientras el Parque Nacional tiene su propio sistema de guardianía, la condición de Reserva de la Biósfera que incluye varios territorios comunitarios, se constituyó en una oportunidad para diseñar un sistema integrado de control y vigilancia incluyendo a guardaparques de los territorios indígenas, dependientes de sus organizaciones matrices. Uno de los temas más importantes fue la definición de los roles específicos de los guardaparques comunitarios de la NAWE y la FICCKAE en este sistema de control y vigilancia (WCS Programa Ecuador, 2011, pág. 17).

A su vez, lo anterior requirió el diseño y la implementación de un programa de capacitación para guardaparques que, manteniendo su filiación o dependencia al área protegida o a cada territorio indígena, compartían conocimientos y experiencias. Como resultado, hacia 2010, el Parque Nacional Yasuní inició la contratación de guardaparques de origen indígena. En este proceso, WCS en Ecuador coordinó actividades tanto con el Ministerio del Ambiente como con la Fundación Randi - Randi, otra ONG involucrada en la zona (WCS - Programa Ecuador, 2011, pág. 17).

Entre los contenidos de la capacitación brindada a los guardaparques destacan en el primer nivel: relaciones comunitarias, género y medio ambiente, manejo de conflictos, aspectos forestales, manejo de la cacería y la vida silvestre, demanda de la carne del monte, gobernanza, manejo de comités, educación ambiental, interpretación y cambio climático; en un segundo nivel: biodiversidad en Ecuador, monitoreo biológico, manejo de vida silvestre y de tortugas, patrullaje, cómo enfrentar crímenes ambientales y funciones de los guardaparques comunitarios, cartografía y uso de GPS y brújulas, legislación y educación ambiental. Particularmente destacable fue la participación de algunas mujeres waorani en los cursos de entrenamiento para guardaparques. El programa de capacitación tuvo adecuaciones para su desarrollo con el pueblo Waorani y en este caso, por ejemplo, fue requerido el entrenamiento y el desempeño de intérpretes waorani (WCS - Programa Ecuador, 2011, págs. 26, 27).

Entre las funciones que cumplen los guardaparques comunitarios se encuentran precisamente el control y el mantenimiento de los límites de sus territorios, el monitoreo de la vida silvestre y de los mercados, así como el apoyo al manejo de recursos naturales como el manejo de tortugas de río (WCS - Programa Ecuador, 2011).

La formación técnica tanto de líderes como de equipos técnicos comunitarios permitió a la NAWE demarcar más de $75 \mathrm{~km}$ del borde de su territorio contando con la participación de más de veinticinco comuneros de base provenientes de distintas comunidades. En este propósito, la NAWE contó con el apoyo financiero de REPSOL (WCS - Programa Ecuador, 2011, pág. 16).

Además de la capacitación, el sistema requirió la coordinación entre el Ministerio del Ambiente y WCS en Ecuador para fortalecer los sistemas de radiocomunicación para los guardaparques comunitarios y sus comunidades.

\section{PLANES DE MANEJO COMUNITARIO}

Junto con el mapeo, los planes de manejo comunitario constituyen otra herramienta importante de la Gestión Territorial Integral. Desde 2004, WCS - Ecuador viene apoyando a comunidades waorani y kichwas a través de facilitar los procesos de elaboración de los planes de manejo comunitario, para ello, WCS - Ecuador ha desarrollado un conjunto de técnicas metodológicas participativas de tal manera de lograr que, a través de la planificación, las comunidades junto a sus dirigentes de las organizaciones de segundo nivel, discutan su problemática e identifiquen estrategias de solución a la misma. 
En el caso de los waorani, en 2011, se apoyó la elaboración de planes de manejo comunitario de al menos cuatro comunidades (Kiwado, Damointado, Guiyedo y Timpoka). En el proceso destacan seis pasos importantes: 1) acopio de la información a través de metodologías participativas en talleres realizados en cada comunidad, 2) procesamiento y análisis de la información en gabinete por el personal técnico de WCS en Ecuador, 3) una segunda ronda de talleres de validación en cada comunidad, 4) revisión y corrección de los planes incluyendo las observaciones de los comuneros, 5) entrega y difusión del documento del plan a la comunidad y 6) presentación del plan por la comunidad a la Dirección del Parque Nacional Yasuní para su aprobación, cuando el Parque se sobrepone a las comunidades.

En el contenido de estos planes destacan los temas de importancia para las comunidades, tales como: territorio y conservación, educación, salud y conocimientos ancestrales, entre otros. La identificación de problemas, en relación con los temas mencionados, busca que en cada comunidad se acuerden estrategias que permitan superar o minimizarlos. De esta manera, cada plan cuenta con programas relacionados con los temas relevantes, sus objetivos, actividades e indicadores para el monitoreo. Originalmente, y debido a la dinámica social y política, se pensó que los planes de manejo comunitario tendrían que revisarse anualmente para incorporar nuevos objetivos y actividades (WCS - Programa Ecuador, 2011, pág. 9).

En 2014, WCS en Ecuador desarrolló un nuevo proceso de actualización de un plan de manejo con seis comunidades kichwas ubicadas en la zona nororiental del Parque Nacional Yasuní. En relación a estas comunidades, el Parque Nacional Yasuní se sobrepone total o parcialmente, como se observa en el Mapa 7.

MAPA 7: UBICACIÓN DEL PARQUE NACIONAL YASUNÍ RESPECTO DE LAS COMUNIDADES KICHWAS Y ZONIFICACIÓN
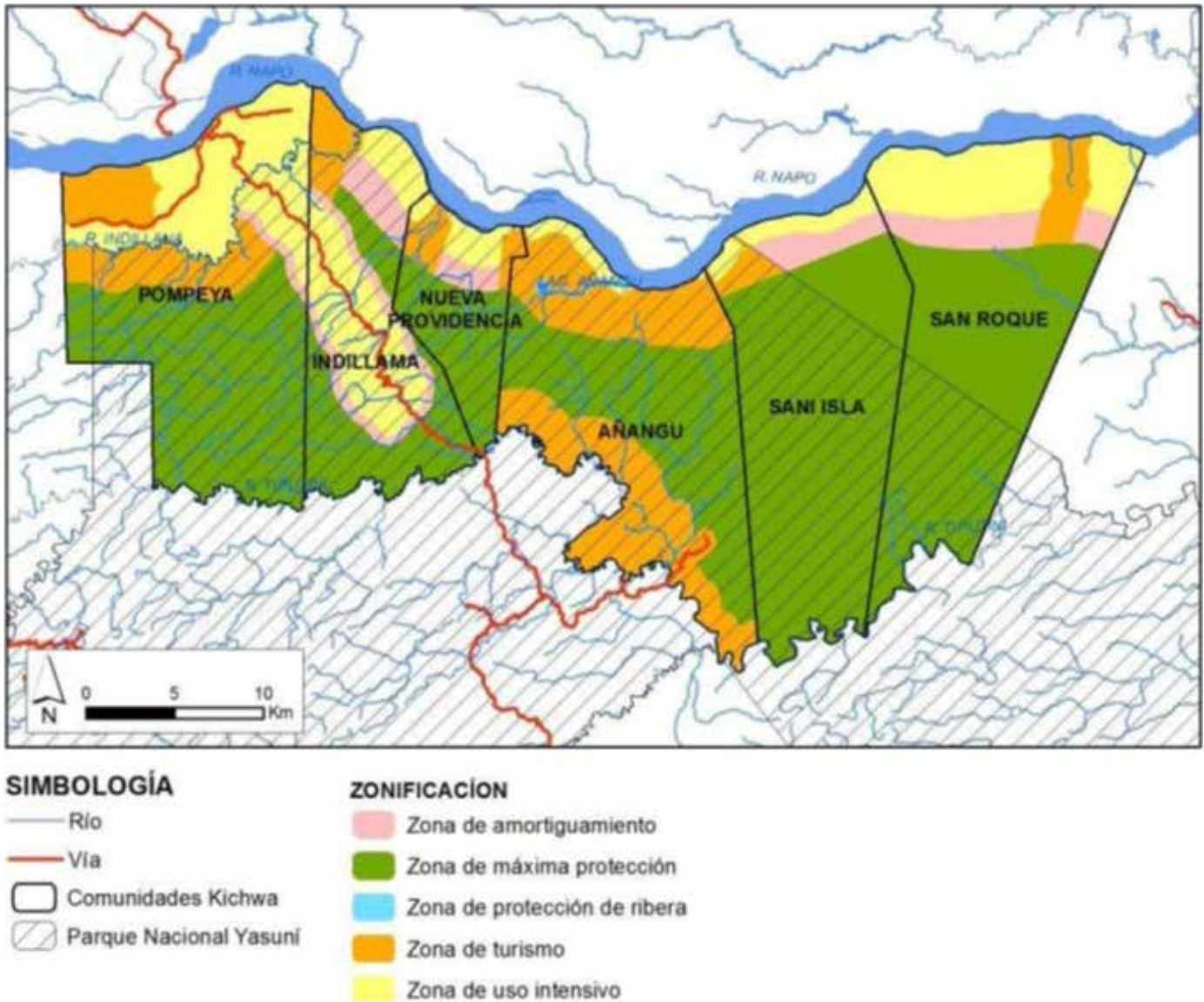

Fuente: (Wildlife Conservation Society, Programa Ecuador y Ministerio del Ambiente del Ecuador, Parque 
Entre 2003 y 2004, las comunidades de Pompeya, Indillama, Nueva Providencia, Añangu, Sani Isla y San Roque habían elaborado su primer plan de uso de los recursos naturales y manejo territorial apoyadas por el Fondo Ecuatoriano Populorum Progressio (FEPP), Wildlife Conservation Society - Programa Ecuador y el Ministerio del Ambiente (Wildlife Conservation Society - Programa Ecuador, 2014, pág. 1; Wildlife Conservation Society, Programa Ecuador y Ministerio del Ambiente del Ecuador, Parque Nacional Yasuní, 2015, pág. 9).

El origen de esta iniciativa se remonta a 1999, cuando las seis comunidades solicitaron al Ministerio del Ambiente el reconocimiento legal de su territorio entre los ríos Napo y Tiputini, frente a la amenaza de invasiones a sus tierras. El reconocimiento del Ministerio fue condicionado a la elaboración de un plan de uso de los recursos naturales y manejo territorial, con él se pretendía regular las actividades de las comunidades en el Parque Nacional Yasuní. De esta manera, a fines de 2004, las comunidades y el Ministerio suscribieron un Convenio de Cooperación por un periodo de 10 años, "para un manejo integral y participativo de los recursos naturales del Parque Nacional Yasuní" y el compromiso, por parte del Ministerio, de impedir nuevos asentamientos dentro del Parque (Wildlife Conservation Society, Programa Ecuador y Ministerio del Ambiente del Ecuador, Parque Nacional Yasuní, 2015, págs. 9, 11, 14, 34).

En 2014, correspondiendo la actualización del plan, nuevamente fue requerida la colaboración de WCS en Ecuador:

2

3

B

INICIO

ÍNDICE

FINAL

\begin{abstract}
"Después de haber transcurrido 10 años desde que fue elaborado el primer plan, y por solicitud de los dirigentes comunitarios y del Ministerio del Ambiente se hace necesaria la actualización. Tomando en cuenta que el plan no ha sido implementado en su totalidad y reconociendo los cambios socio-ambientales que se han generado tanto en el interior de los territorios comunitarios como en su área de influencia" (Wildlife Conservation Society - Programa Ecuador, 2014, pág. 1).
\end{abstract}

Para tal fin se conformó un equipo técnico coordinado por la FICCKAE y personal técnico de WCS en Ecuador y del Ministerio del Ambiente, que también contaba con la participación de dirigentes y miembros de las seis comunidades (Wildlife Conservation Society - Programa Ecuador, 2014, pág. 3).

El objetivo general fue:

\begin{abstract}
"Actualizar el plan de uso y manejo territorial de seis comunidades Kichwa, para la protección y uso sostenible de los recursos naturales, asegurando la conservación y el mejoramiento de la calidad de vida de los pobladores locales, con la implementación de estrategias de manejo" (Wildlife Conservation Society - Programa Ecuador, 2014, pág. 1).
\end{abstract}

Y, entre los objetivos específicos se señalaban la actualización de la zonificación de las comunidades, y la actualización y desarrollo de programas de manejo comunitario con estrategias para el aprovechamiento sostenible de los recursos faunísticos y florísticos (Wildlife Conservation Society - Programa Ecuador, 2014, pág. 2).

Al igual que para la elaboración de los planes comunales de las comunidades waorani, en este caso se diseñó y aplicó una metodología participativa y el proceso también se desarrolló en seis etapas: 1) Recopilación y sistematización de información biológica y social a través de los talleres participativos, reuniones comunitarias, entrevistas a dirigentes, 
profesores de escuelas y colegios y miembros de la FICCKAE. 2) Talleres participativos con dirigentes, miembros de las comunidades y técnicos del Ministerio del Ambiente para presentar, analizar, discutir y mejorar las propuestas de zonificación y manejo (12 talleres, dos por comunidad). 3) Talleres participativos con dirigentes, miembros de las comunidades y técnicos del Ministerio, para la validación de la zonificación y de los programas de manejo propuestos (seis talleres, uno por comunidad). 4) Presentación de los avances de la elaboración del Plan al Ministerio del Ambiente. 5) Revisión y aprobación por parte del Ministerio del documento de actualización del plan de uso y manejo territorial. 6) Socialización del plan actualizado a nivel comunitario y a técnicos de instituciones locales (Wildlife Conservation Society - Programa Ecuador, 2014, págs. 4 - 5).

Durante la elaboración del plan de manejo, se identificaron las amenazas presentes y potenciales a los territorios comunales y al Parque Nacional Yasuní. Entre ellas, destacaban: la apertura de la frontera agrícola por el incremento de la población, cacería ilegal por no residentes, pesca con métodos inadecuados (uso de barbasco, dinamita y productos químicos), cacería con fines comerciales, contaminación de aguas, suelo y aire por las compañías petroleras, derrumbe de la orillas del río Napo por el incremento del tráfico fluvial, estacionamiento de gabarras, apertura de vías para la explotación petrolera y pérdida de valores culturales (Wildlife Conservation Society, Programa Ecuador y Ministerio del Ambiente del Ecuador, Parque Nacional Yasuní, 2015, pág. 36).

El nuevo plan implicó la actualización de la zonificación del territorio de las seis comunidades (ver Mapa 7). Se estableció que el objetivo de este procedimiento era "ordenar el territorio en función de valores naturales, culturales y características socioeconómicas, que garantizan el cumplimiento de los objetivos de conservación, mediante una organización adecuada de las actividades humanas" (Wildlife Conservation Society, Programa Ecuador y Ministerio del Ambiente del Ecuador, Parque Nacional Yasuní, 2015, pág. 37).

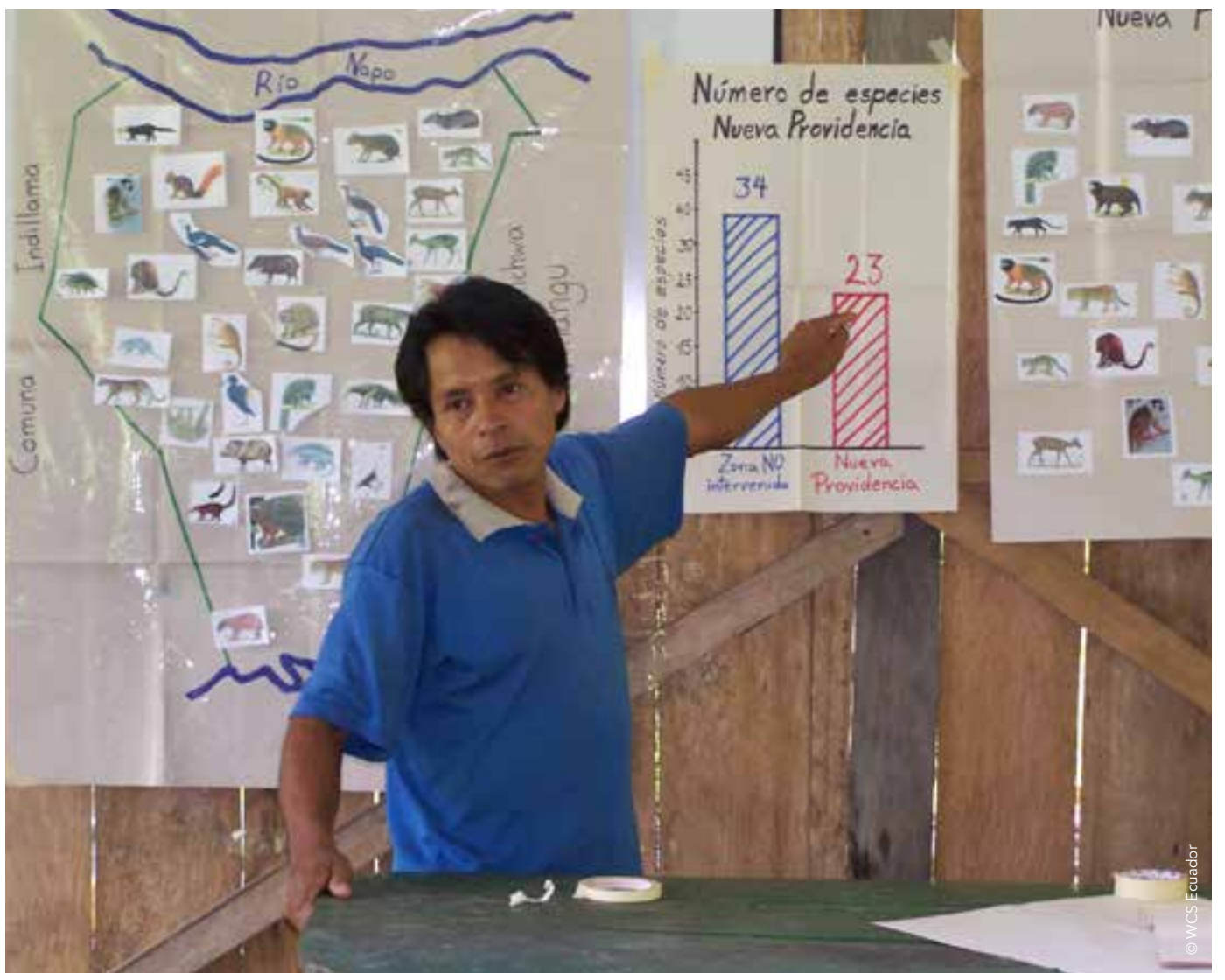


Fueron identificadas cinco zonas de uso: Zona de Uso Intensivo, Zona de Amortiguamiento, Zona de Turismo, Zona de Protección de Ribera y Zona de Máxima Protección. Para cada zona se establecieron las normas de uso en las que destaca una gradiente en el uso de los recursos naturales, desde los usos más intensivos en la zona correspondiente hasta la restricción casi total de los usos en la zona de máxima protección, esta última, mayormente ubicada en la sobre posición del Parque Nacional Yasuní. En términos generales, se establece que las actividades que se realizan dentro del Parque Nacional Yasuní son reguladas y supervisadas por la oficina administrativa del Parque y aquellas que se realizan fuera, lo son por las entidades estatales competentes (Wildlife Conservation Society, Programa Ecuador y Ministerio del Ambiente del Ecuador, Parque Nacional Yasuní, 2015, págs. 37 - 44).

El plan de manejo de las comunidades kichwas ubicadas en la zona nororiental del Parque Nacional Yasuní establece también nueve programas de manejo: Programa de Manejo de Recursos Naturales, Programa de Manejo de Fauna Silvestre, Programa de Control y Vigilancia, Programa de Educación y Capacitación Ambiental, Programa de Manejo Productivo, Programa de Investigación y Monitoreo, Programa de turismo, Programa de Fortalecimiento Socio Organizativo y Programa de cumplimiento del plan de uso y manejo. Para cada uno de ellos se establecen objetivos y actividades (Wildlife Conservation Society, Programa Ecuador y Ministerio del Ambiente del Ecuador, Parque Nacional Yasuní, 2015, págs. 44 - 53).

Además, el plan cuenta con otros sub-planes relativos a la implementación y a la evaluación y monitoreo del mismo, así como una identificación de posibles fuentes de financiamiento para su ejecución (Wildlife Conservation Society, Programa Ecuador y Ministerio del Ambiente del Ecuador, Parque Nacional Yasuní, 2015, págs. 53 - 57).

En el apoyo de WCS en Ecuador a la formulación o actualización de los planes comunitarios, como en el caso de la nacionalidad waorani o a la zonificación de un territorio de varias comunidades miembros de la FICCKAE destacan varios elementos. Entre ellos, al igual que en el caso de Bolivia, el fortalecimiento de los vínculos entre las comunidades y líderes de las organizaciones matrices de los pueblos indígenas a través del proceso de la planificación.

En este caso, además, destaca la intervención del personal técnico del Ministerio del Ambiente, tomando en cuenta que en Ecuador, es esta instancia la que debe aprobar los planes de manejo de las comunidades. La incorporación de este personal tiene un doble beneficio: facilitar el proceso de aprobación de los planes, pero al mismo tiempo, contribuir a la construcción de relaciones de tipo puente entre las comunidades y organizaciones indígenas y el Estado.

A diferencia de los casos de Bolivia y Perú, donde las comunidades son las que elaboran, aprueban y ejecutan sus planes de manejo comunitario, con alta independencia del Estado, en el caso del Ecuador, los instrumentos de gestión comunitarios son elaborados por las comunidades, pero están sujetos a la aprobación del Estado a través del Ministerio del Ambiente.

El análisis del contenido de los planes de manejo comunitario desarrollados entre 2009 y 2011 y las actualizaciones más recientes, permite constatar diferencias, por un lado en relación a la problemática territorial y de manejo de los recursos naturales que es tratada con mayor amplitud en los instrumentos más recientemente elaborados pero, por otro lado, una pérdida en relación a otras problemáticas que también hacen al bienestar de las comunidades como las relativas a la salud, educación y conocimientos ancestrales.

Lo anterior puede tener repercusiones en el proceso de apropiación de los instrumentos de planificación por las comunidades. El hecho que en el Programa de cumplimiento del plan de uso y manejo de las seis comunidades kichwas, se identifiquen responsabilidades 
solo para las autoridades del Ministerio del Ambiente y de otras instancias estatales relacionadas con el uso de los recursos naturales, y no así de las autoridades comunales indica el riesgo, siempre presente, de que los planes de manejo comunitario, se conviertan más en una formalidad legal, requisito para el reconocimiento de derechos, que en instrumentos de gestión propios de las comunidades.

Al igual que en Bolivia, los planes comunitarios y los planes de gestión territorial, en Ecuador, contienen tanto la zonificación de los territorios con sus normas de uso, como los programas de acción. En ambos casos, los procesos de zonificación a nivel de territorios mancomunados (que incluyen a conjuntos de comunidades) se inician con el mapeo a nivel de cada comunidad. Uno de los desafíos en este proceso es la compatibilización de las propuestas entre comunidades diferentes. Estos procesos parecen haber seguido distintos caminos entre los Programas de Ecuador y Bolivia, abriéndose un campo para el intercambio de experiencias entre ambos países. Uno de los temas destacables, en este ámbito, se refiere a la flexibilidad de la zonificación por y para las comunidades indígenas. Uno de los factores que ha influido en proporcionar un carácter más flexible y por tanto más adaptable a las necesidades de las comunidades en Bolivia ha sido la identificación de la compatibilidad de usos para cada tipo de zona. En tanto que los resultados de la zonificación en Ecuador, denotan mayor rigidez y un énfasis mayor en las prohibiciones que en las posibilidades de adaptación y manejo.

En síntesis, los planes de manejo a nivel de comunidades o de territorios mancomunados son fundamentales para la gestión territorial, fortalecen el ejercicio del autogobierno de las comunidades locales y pueblos indígenas, al mismo tiempo que expresan el consenso al interior de las comunidades, entre comunidades y de estas con sus líderes para asegurar un mejor manejo de los recursos naturales y su conservación. Sin embargo, para asegurar que esto efectivamente sea así, como se vio en el caso del apoyo que brinda WCS en Ecuador a las comunidades y organizaciones indígenas, se requiere del diseño de rutas críticas de acciones donde se consideran varios ciclos de reuniones y talleres (al menos 18 talleres para seis comunidades), solo para el caso de las comunidades kichwas ubicadas en el nororiente del Parque Nacional Yasuní.

\section{MONITOREO DE LA VIDA SILVESTRE, LA CAZA Y LA PESCA POR LAS COMUNIDADES}

El Programa de WCS en Ecuador, comparte con los de Bolivia y Perú, la fortaleza en el desarrollo de metodologías y experiencia para el monitoreo de la vida silvestre, la caza y la pesca por las comunidades. La investigación y el monitoreo están en la base de las propuestas de trabajo de WCS con las comunidades locales y pueblos Indígenas.

Entre 2009 y 2011, WCS en Ecuador capacitó al menos a 13 miembros de las comunidades kichwas de Añangu, Nueva Providencia y Sani Isla, mismas comunidades del nororiente del Parque Nacional Yasuní con las que trabajó el mapeo y los planes de manejo comunitario, así como a 20 miembros de la nacionalidad waorani. El entrenamiento de los "monitores comunales" se realizó a través de cursos y la asistencia en servicio durante un mes y dos veces por año y, al menos en el caso de los kichwas estos procesos de capacitación y asistencia se dieron en cada una de sus comunidades. Al final del año, los resultados de los datos colectados sobre la fauna silvestre, la cacería y la pesca, fueron reportados a cada comunidad para contribuir a sus decisiones respecto del uso y manejo de la fauna silvestre (WCS - Programa Ecuador, 2011, págs. 11, 12, 25).

El contenido de los cursos de capacitación estaba referido al manejo de la vida silvestre, monitoreo ambiental, uso de brújula y manejo de instrumentos del sistema de posicionamiento global (GPS). El entrenamiento en servicio, "enseñar haciendo" en las comunidades versó sobre el manejo y registro de datos sobre la cacería y la pesca en formularios didácticos (WCS - Programa Ecuador, 2011, pág. 25). 
Una alianza con instituciones académicas de alto nivel como la Facultad Latinoamericana de Ciencias Sociales (FLACSO - Ecuador) y la Universidad San Francisco de Quito, permitió diseñar un programa de entrenamiento para guardaparques comunitarios, "parabiólogos comunitarios", profesores de escuela y guías de turismo comunitario, en temas tales como: manejo de recursos naturales, conservación de la biodiversidad, desarrollo sostenible y monitoreo ambiental (WCS - Programa Ecuador, 2011, pág. 25).

Como se señaló, los grupos de guardaparques, tanto del área protegida como de los territorios indígenas, fueron sistemáticamente entrenados, entre otras funciones, para cumplir una de las más importantes, el monitoreo de la vida silvestre (WCS - Programa Ecuador, 2011, pág. 27).

Del mismo modo, miembros de las comunidades encargadas del manejo de tortugas fueron entrenados para el monitoreo de las poblaciones de estas especies (WCS Programa Ecuador, 2011, pág. 17).

La capacitación de monitores comunitarios en aspectos biológicos, permitió a algunos miembros de la nacionalidad waorani junto a técnicos de WCS en Ecuador, ejercer como entrenadores en el programa de capacitación del Programa Socio Bosque del Ministerio del Ambiente. En 2011, más de treinta personas en la comunidad de Kiwaro, vinculadas al programa, participaron de este entrenamiento. Entre sus actividades de capacitación, la liberación de tortugas de río concitó su interés para desarrollar un programa de manejo de estas especies en su comunidad (WCS - Programa Ecuador, 2011, pág. 27).

Los resultados de los registros de cacería realizados durante 2006 y 2011 por comunidades kichwas de la zona nororiental del Parque Nacional Yasuní, nutrieron su Plan de Uso de los Recursos Naturales y Manejo Territorial. De esta manera, se pudo establecer que:

1. En tres comunidades kichwas, los cazadores utilizaron 29 especies diferentes de mamíferos. Las especies más importantes en términos de biomasa fueron: el pecarí de labio blanco (Tayassu pecari), el pecarí de collar (Pecari tajacu), la guatusa (Dasyprocta fuliginosa), el tapir (Tapirus terrestris), el venado colorado (Mazama americana) y la guanta (Cuniculus paca).

2. Las anteriores seis especies de mamíferos representaban el $90 \%$ de la biomasa total extraída.

3. En relación a las aves, los pobladores de las comunidades kichwa utilizaron 17 especies. Las más importantes fueron la perdiz grande (Tinamus major), la pava colorada (Penelope jacquacu) y la pava negra (Pipile pipile).

4. En cuanto a reptiles utilizan cuatro especies, la más importante fue la tortuga motelo (Chelonoides denticulata).

5. Más del $90 \%$ de la carne extraída del bosque se destinó al consumo, solo en ciertas ocasiones a la comercialización dentro de las comunidades y en una feria semanal de Pompeya.

6. Basadas en el monitoreo de la fauna silvestre y la cacería, algunas comunidades, tal es el caso de Añangu, acordó prohibir la cacería. Esta decisión fue reforzada por el interés de garantizar la presencia de fauna silvestre para su programa de turismo comunitario.

7. Entre 2006 y 2011, la extracción de la fauna silvestre se redujo como resultado de decisiones como la anterior. 
8. El monitoreo de la pesca en cuatro comunidades kichwas mostró que, entre 2006 y 2012, estas comunidades habían utilizado 50 especies de peces. Sin embargo, 10 de ellas, capturadas con mayor frecuencia, alcanzaban al $67 \%$ del total extraído, entre las que contribuyeron más individuos, se encontraban: el bocachico (Prochilodus nigricans), la palometa roja (Mylossoma duriventre) y las viejas (Aequidens tetramerus) (Wildlife Conservation Society, Programa Ecuador y Ministerio del Ambiente del Ecuador, Parque Nacional Yasuní, 2015, págs. 19 - 20).

Hasta aquí, la titulación y demarcación de los territorios indígenas, el intento de establecer sistemas de control y vigilancia de los territorios, el mapeo y la zonificación, con su correspondiente establecimiento de normas de uso, la elaboración de planes comunales y mancomunados y el monitoreo constituyen condiciones e instrumentos de gestión territorial a los que WCS en Ecuador ha contribuido significativamente. A su vez, al haber facilitado la participación de líderes de las organizaciones indígenas de segundo nivel como la FICCKAE y la NAWE en todas las acciones, WCS ha contribuido a fortalecer los nexos entre comunidades y de estas con sus organizaciones representativas. Además, en el caso de WCS en Ecuador se hace más evidente que en Bolivia y Perú, el involucramiento del Ministerio del Ambiente en casi todas las actividades desarrolladas con las comunidades. Sin embargo, la gestión territorial integral de los pueblos indígenas requirió aún acciones adicionales de fortalecimiento de las organizaciones.

\section{FORTALECIENDO LAS ORGANIZACIONES INDÍGENAS Y CAMPESINAS, LAS CAPACIDADES DE LIDERAZGO}

De manera similar a Bolivia y Perú, en la Amazonía ecuatoriana y particularmente entre las comunidades con las que trabaja WCS en Ecuador, se distingue un nivel organizativo que está referido a las comunidades o asentamientos. Este sistema comunal, en el caso de las comunidades kichwas ubicadas en la zona nororiental del Parque Nacional Yasuní está constituido por una Asamblea General a la que se considera como máxima instancia de organización, en ella participan los dirigentes y miembros de base, asimismo, cada comunidad cuenta con una directiva que está constituida por un presidente, vicepresidente, secretario, tesorero, vocales y un síndico. Estas directivas comunales son las que se relacionan con la Federación Indígena de Comunidades y Comunas de la Amazonía Ecuatoriana de la Provincia de Orellana (FICCKAE). A su vez, son responsables de canalizar las propuestas comunales ante las instituciones públicas y privadas. En las comunidades también existen otras organizaciones como los "Comités de Padres de Familias" y las organizaciones de mujeres (WCS - Programa Ecuador, 2011, pág. 27).

Debido a la distancia entre las comunidades y los escasos recursos para la movilización y la comunicación entre los líderes de las organizaciones matrices y las comunidades, cobra relevancia la contribución de WCS en Ecuador para el desplazamiento de estos líderes entre las comunidades a través de las actividades que hemos descrito anteriormente.

Del mismo modo, ha sido importante el apoyo técnico y financiero para facilitar la elaboración, revisión, discusión, aprobación y legalización de los estatutos orgánicos y planes estratégicos de la FICCKAE, NAWE, AMWAE y FOCAO (WCS - Programa Ecuador, 2011, págs. $35,36,40$ ).

Las Asambleas de representantes comunales constituyen espacios de rendición de cuentas por parte de los líderes de las organizaciones y de presentación de demandas y necesidades de las comunidades. Aquí destacan los informes relacionados con los convenios que algunas organizaciones, como la NAWE, han suscrito con empresas petroleras (WCS - Programa Ecuador, 2011, págs. 33, 34, 35). 
Asimismo, entre las actividades de fortalecimiento organizativo que WCS en Ecuador desarrolló entre 2009 y 2011, se encuentra un programa de formación de líderes. En este campo destaca la contribución de WCS, junto a otras instituciones, en el fortalecimiento de la Asociación de Mujeres Waorani del Ecuador (AMWAE).

De hecho, al menos entre 2009 y 2011, WCS en Ecuador apoyó a la AMWAE en temas tan importantes para su fortalecimiento como el apoyo técnico para facilitar la elaboración, revisión y aprobación de sus estatutos orgánicos. En este quehacer, destaca la participación de más de 100 mujeres waorani representando a 32 comunidades (WCS - Programa Ecuador, 2011, pág. 33).

Los procesos de fortalecimiento de la organización de las mujeres waorani han estado acompañados de la promoción y facilitación de la participación de las mujeres en diferentes eventos de capacitación relacionados con sus derechos como mujeres indígenas, con la importancia de su involucramiento en la gestión de su territorio y en la toma de decisiones (incluyendo la comprensión sobre la relevancia de su participación informada sobre Medidas Cautelares y representación de sus intereses ante las empresas petroleras), y talleres y cursos de entrenamiento sobre liderazgo. Asimismo, se ha facilitado su participación en encuentros con otras organizaciones de mujeres rurales y urbanas (WCS - Programa Ecuador, 2011, pág. 33).

En el contenido de los eventos de capacitación sobre liderazgo en los que han participado las mujeres waorani destacan: la planificación personal para atender y representar las demandas de las comunidades en general y de las mujeres en particular, las implicancias de los gobiernos territoriales indígenas, la importancia de la titulación, demarcación y mapeo de los territorios indígenas, así como el rol de las mujeres líderes en estos procesos. Estos espacios han sido privilegiados para analizar, junto con los derechos colectivos e individuales de los pueblos indígenas en general y de las mujeres indígenas en particular, también los derechos de la naturaleza. En los eventos también se han abordado temas relacionados con el desarrollo sostenible (WCS - Programa Ecuador, 2011, pág. 34).

En esta estrategia de WCS en Ecuador de fortalecer la organización de las mujeres waorani destaca el esfuerzo por mantener canales de comunicación y asegurar también la participación de la NAWE, la organización matriz de la nacionalidad waorani. En este caso, resulta importante señalar que si bien la mayoría de los cargos en la NAWE son ocupados por hombres, las mujeres han ocupado cargos importantes como la Vicepresidencia o en algunos momentos también la Presidencia, con una visibilidad destacable (WCS Programa Ecuador, 2011, pág. 34).

El factor estructurante del fortalecimiento organizativo de las mujeres waorani ha sido el apoyo de WCS en Ecuador y otras instituciones, a sus procesos de producción de artesanías de chambira y de cacao. De hecho, en 2014, entre 1234 postulaciones de 121 países, la AMWAE ganó, entre otras 35 iniciativas, el premio Ecuatorial de las Naciones Unidas, por su respuesta a la intensificación de la cacería ilegal en la Reserva de la Biósfera Yasuní, a través de promover el cultivo de cacao orgánico como una medida de protección de la vida silvestre y establecer una vía para el desarrollo sostenible. El establecimiento de sistemas agroforestales con base en cacao y chambira, así como el desarrollo del plan de gestión del territorio de la nacionalidad waorani para reducir la deforestación y el manejo de la cacería de subsistencia para disminuir las amenazas contra la fauna silvestre, también fueron considerados aspectos relevantes para hacer, a la AMWAE, acreedora a dicho premio (Equator Initiative, 2016).

El apoyo de WCS en Ecuador a la AMWAE, enfocado en el fortalecimiento de la participación política, social y económica de las mujeres waorani ha implicado, además, otros procesos de capacitación relacionados con: el manejo de la chambira, materia prima de sus artesanías, a través del establecimiento de viveros y sistemas agroforestales 
biodiversos; contratación de servicios para la asistencia técnica para el mejoramiento de la calidad de las artesanías; capacitación en la comercialización; y el financiamiento de tres tiendas de expendio de las artesanías ubicadas en diferentes centros urbanos de la Amazonía ecuatoriana. Esta última iniciativa no logró establecerse de manera sostenible. El fortalecimiento de las organizaciones indígenas y campesinas relacionadas con la Reserva de la Biósfera Yasuní, ha requerido, además de WCS en Ecuador, el concurso de muchas otras instituciones. Entre ellas destacan: ECOLEX, ALTROPICO, ONU - Mujeres, FEPP, Ibis de Dinamarca, UICN, Fundación Natura, Proyecto MIES, ECORAE, CSF, Cl, GIZ, FLACSO y muchas otras.

\section{DESARROLLANDO CAPACIDADES ADMINISTRATIVAS Y FINANCIERAS PARA LA SOSTENIBILIDAD DE LA GESTIÓN TERRITORIAL INDÍGENA}

Uno de los aspectos más importante y crítico a la vez, es el desarrollo de capacidades administrativas y financieras entre las organizaciones indígenas, sus comunidades y emprendimientos productivos.

En este propósito WCS en Ecuador ha combinado la capacitación a través de cursos y talleres con la "asistencia técnica en servicio" y la entrega de fondos, a través de subacuerdos con las organizaciones indígenas como FICCKAE, NAWE y AMWAE.

Estos procesos de aprendizaje han incluido desde la elaboración de presupuestos y planes de gastos hasta aspectos relacionados con el manejo de los fondos, procedimientos contables, la gestión impositiva y las auditorías periódicas. Los procesos de capacitación han requerido la adquisición de software contable y el diseño de manuales de administración y contabilidad adecuados a las condiciones de los pueblos indígenas y sus comunidades, incluyendo el acompañamiento para su implementación.

Asimismo, WCS en Ecuador ha financiado la contratación de personal administrativo y contable dependiente de las organizaciones indígenas. Especialistas en administración, contabilidad, secretaría y técnicos en diseño de proyectos han sido contratados con fondos canalizados por WCS en Ecuador. A su vez, este tipo de contratación, implica el fortalecimiento de las capacidades para el manejo de personal por parte de las organizaciones indígenas.

Uno de los mayores desafíos es que todos los fondos, de las diferentes fuentes de financiamiento, que manejan las organizaciones indígenas sean ingresados en un solo sistema administrativo y contable con definiciones claras para cada fuente de financiamiento. Esto favorece la transparencia del manejo administrativo, sin embargo, frecuentemente cada entidad financiera exige que sus fondos sean manejados en un sistema separado. En 2010 y 2011 fue un logro que la NAWE hubiese alcanzado un manejo administrativo centralizado (WCS - Programa Ecuador, 2011, pág. 22).

Aunque finalmente no se concretaron, la posibilidad de que las organizaciones indígenas asuman nuevas responsabilidades político administrativas en el marco del proceso de descentralización y autonomías del Estado ecuatoriano y la constitución de "Circunscripciones Territoriales Indígenas", de acuerdo a la Constitución Política del Ecuador, requirió la asistencia en el diseño e implementación de nuevos modelos administrativos, de tal manera que las organizaciones indígenas socias de WCS en Ecuador estén en condiciones de asumir esas nuevas responsabilidades. Es importante destacar por qué WCS en Ecuador, una entidad para la conservación de la vida silvestre se ve involucrada en este ámbito de acción. De hecho, el soporte para el fortalecimiento de las organizaciones indígenas como sujetos de la conservación así lo exige para enfrentar el riesgo de que al asumir nuevas responsabilidades político administrativas sin previa preparación, las organizaciones terminen completamente desestructuradas. En 2011, la 
FICCKAE accedió a un proceso de auditoría por la Contraloría de la República de fondos públicos manejados entre 2004 y 2010 (WCS - Programa Ecuador, 2011, pág. 23).

En este trabajo, WCS en Ecuador no ha estado sola, ha colaborado para que otras instituciones coadyuven en la formación de capacidades administrativas y financieras. El Programa Socio Bosque también realizó cursos de entrenamiento para el manejo de fondos, en previsión de los fondos que por concepto de conservación de los bosques entregaría, por ejemplo, a la NAWE y a la comunidad de Kiwaro en 2011 (WCS - Programa Ecuador, 2011, pág. 22).

Otras instituciones que trabajaron apoyando a la NAWE y FICCKAE en temas administrativos fueron ECOLEX e IBIS - Dinamarca, entre otras. La actualización en aspectos legales y procedimientos impositivos es constante y ha requerido el concurso de diversas instituciones (WCS - Programa Ecuador, 2011, pág. 23). Como resultado de la experiencia de trabajo conjunto entre WCS en Ecuador y ECOLEX, en 2014, suscribieron un convenio para desarrollar procesos de capacitación relacionados con los derechos indígenas (Convenio de cooperación interinstitucional WCS - ECOLEX, 2014).

Particularmente interesante también es la alianza de WCS en Ecuador con el Fondo Ecuatoriano Populorum Progressio - Regional Coca (FEPP), debido a que esta entidad con una base en Coca (Puerto Francisco de Orellana), cuenta con líneas de crédito que incluye redes nacionales de apoyo a Estructuras Financieras Locales (EFL), con programas establecidos de capacitación y asistencia en aspectos administrativos y financieros: manejo de bancos y relaciones con organizaciones financieras formales, contabilidad e incluso aspectos organizativos (WCS - Programa Ecuador, 2011, pág. 23).

3

B

ÍNDICE

FINAL

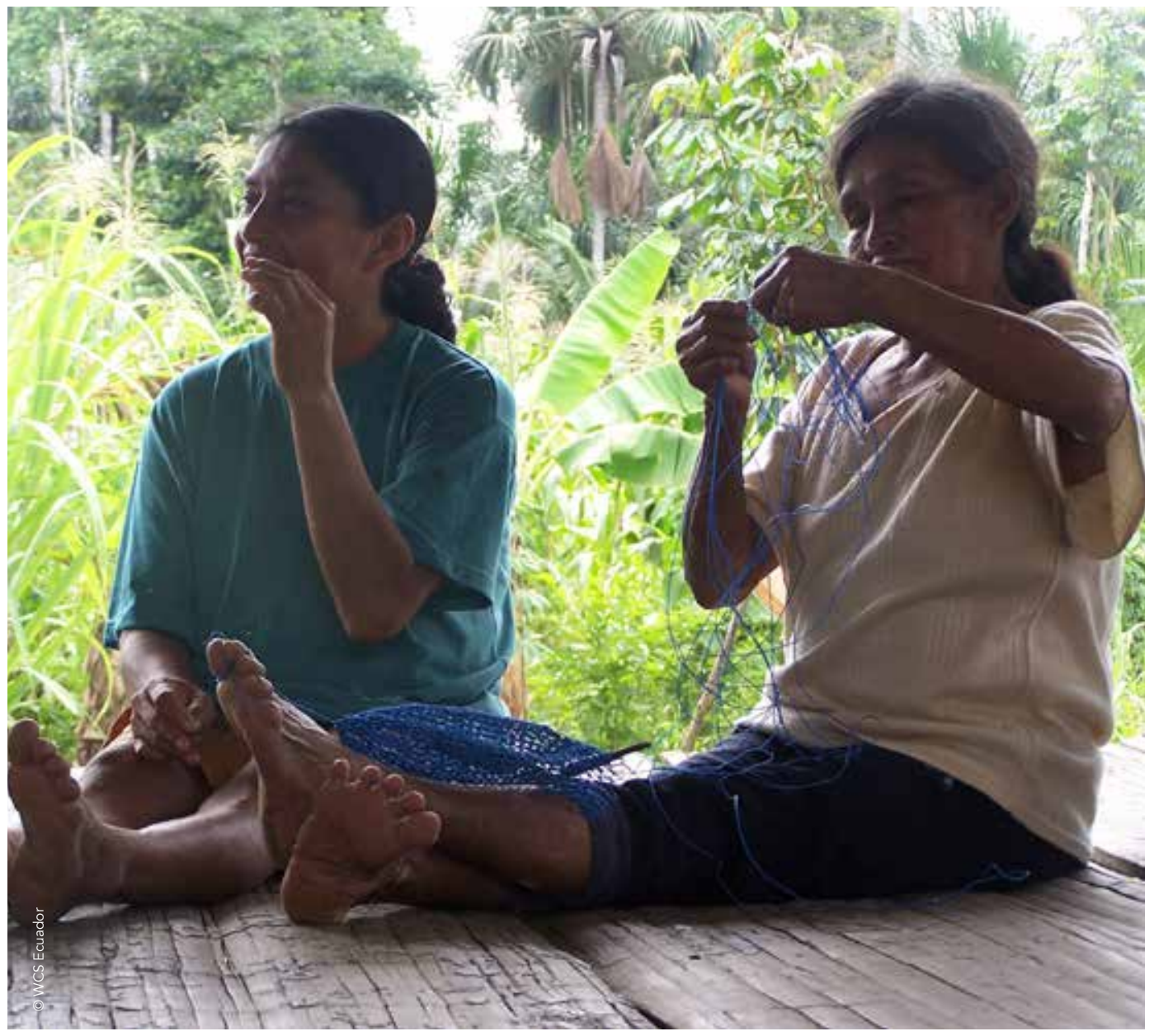




\section{LA BÚSOUEDA DE SOSTENIBILIDAD FINANCIERA PARA LA GESTIÓN TERRITORIAL INDÍGENA}

La búsqueda de mecanismos que aseguren la sostenibilidad financiera de los procesos de gestión territorial indígena es un aspecto crítico para la Gestión Territorial Indígena. Ha demandado de WCS en Ecuador esfuerzos para identificar e implementar diferentes estrategias y aunque han existido avances interesantes, hasta ahora no se ha podido alcanzar.

Una de las estrategias desarrolladas porWCS en Ecuador, ha sido apoyar a las comunidades, junto con sus organizaciones matrices, para que sean incluidas en el Programa Socio Bosque del Ministerio del Ambiente. Esta iniciativa empezó a funcionar en 2008. Con la finalidad de reducir las emisiones de carbono por deforestación, el Programa trabaja fundamentalmente con comunidades locales y pueblos indígenas especialmente de la costa y la Amazonía. El mecanismo se basa en la suscripción de convenios entre personas o comunidades con el Ministerio del Ambiente por 20 años, mediante los cuales se establece el compromiso de conservar áreas de bosques. A cambio el Ministerio realiza un pago monetario por hectárea conservada. El cumplimiento de estos convenios es monitoreado por el Ministerio del Ambiente (Ministerio del Ambiente, 2016; Programa Derechos, Cambio Climático y Bosques. CEPLAES, 2015).

En esa perspectiva, aunque el objetivo principal de todos los procesos apoyados por WCS en Ecuador tales como los mapeos comunales y zonificaciones con sus normas de acceso y uso de los recursos naturales, la titulación y delimitación de los territorios indígenas y comunitarios, la elaboración de los planes de manejo, el establecimiento y funcionamiento de los sistemas de guardaparques comunitarios indígenas y de los sistemas de monitoreo, así como el fortalecimiento de las capacidades administrativas, es fortalecer la gestión territorial indígena como expresión de la autodeterminación de los pueblos y comunidades indígenas, también son requisitos exigidos por el Programa Socio Bosque.

La adscripción de las comunidades indígenas a este programa, sin embargo, exige además procesos adecuados de consulta y toma de decisiones para asumir compromisos que deben involucrar desde los individuos (hombres y mujeres), los hogares, las comunidades, los líderes comunales, y de manera fundamental el liderazgo de las organizaciones matrices como NAWE - AMWAE y FICCKAE. WCS en Ecuador ha coadyuvado en la promoción de estos espacios de consulta a través de la realización de talleres en las comunidades tanto kichwas como waorani (WCS - Programa Ecuador, 2011, págs. 7, 8).

En general, en diferentes territorios indígenas se ha observado que por un lado el Programa Socio Bosque trae beneficios a las familias y comunidades, sin embargo también se presentan debilidades fundamentalmente en el alcance de la información a todos los niveles que se han señalado, desde las personas individuales incluyendo a las mujeres, los hogares, las comunidades, los líderes comunales y las organizaciones matrices así como en la participación para la toma de decisiones sobre las áreas que deberán ser conservadas, pero fundamentalmente en términos de la información sobre la cantidad de dinero a ser percibida y las decisiones sobre la distribución y el destino del mismo. Estas dificultades han generado problemas y conflictos al interior de las comunidades, entre comunidades y de estas con algunos de sus líderes (Programa Derechos, Cambio Climático y Bosques. CEPLAES, 2015, págs. 71 - 72).

Del mismo modo, en esta búsqueda de sostenibilidad financiera para la Gestión Territorial Indígena, WCS en Ecuador apoyó a las organizaciones indígenas con las cuales tiene convenios suscritos para que sus territorios sean reconocidos como parte de las "Circunscripciones Territoriales Indígenas". Los planes de manejo comunitario que WCS ha apoyado a elaborar, así como los esfuerzos por fortalecer las capacidades administrativas 
y financieras, constituyen insumos importantes para el ejercicio de gobiernos indígenas en sus circunscripciones.

Esta estrategia se enmarca en un precepto constitucional que establece:

"Art. 257.- En el marco de la organización político administrativa podrán conformarse circunscripciones territoriales indígenas o afroecuatorianas, que ejercerán las competencias del gobierno territorial autónomo correspondiente, y se regirán por principios de interculturalidad, plurinacionalidad y de acuerdo con los derechos colectivos" (República del Ecuador, 2008).

Establecidas como un régimen especial en el marco de la descentralización y gobiernos autónomos, su conformación, funcionamiento y competencias quedó sujeta a una legislación específica.

De esta suerte, los años posteriores a la promulgación de la Constitución fueron de amplio debate y reuniones frecuentes entre las organizaciones indígenas y los funcionarios estatales. En este contexto, WCS en Ecuador documentó y dio seguimiento al proceso de dichas reuniones y a los resultados que se fueron generando (WCS - Programa Ecuador, 2011), con la finalidad de apoyar técnicamente, especialmente en el fortalecimiento de capacidades administrativas, a las organizaciones indígenas con las que trabaja para asumir nuevas responsabilidades en sus territorios. Como se señaló, esto implicaría el manejo de fondos públicos que podrían asegurar financieramente la Gestión Territorial Integral de los Territorios Indígenas. Entre 2011 y 2012, la NAWE fue atendida con fondos públicos por el Instituto para el Ecodesarrollo Regional Amazónico (ECORAE) para desarrollar algunos elementos de su propuesta de "Circunscripción Territorial Indígena" (CTI) (WCS - Programa Ecuador, 2011, pág. 14). La dinámica de las "Circunscripciones Territoriales Indígenas" actualmente se ha desacelerado, dejando incluso por esta vía, pendiente el desafío de la sostenibilidad financiera de la gestión territorial indígena.

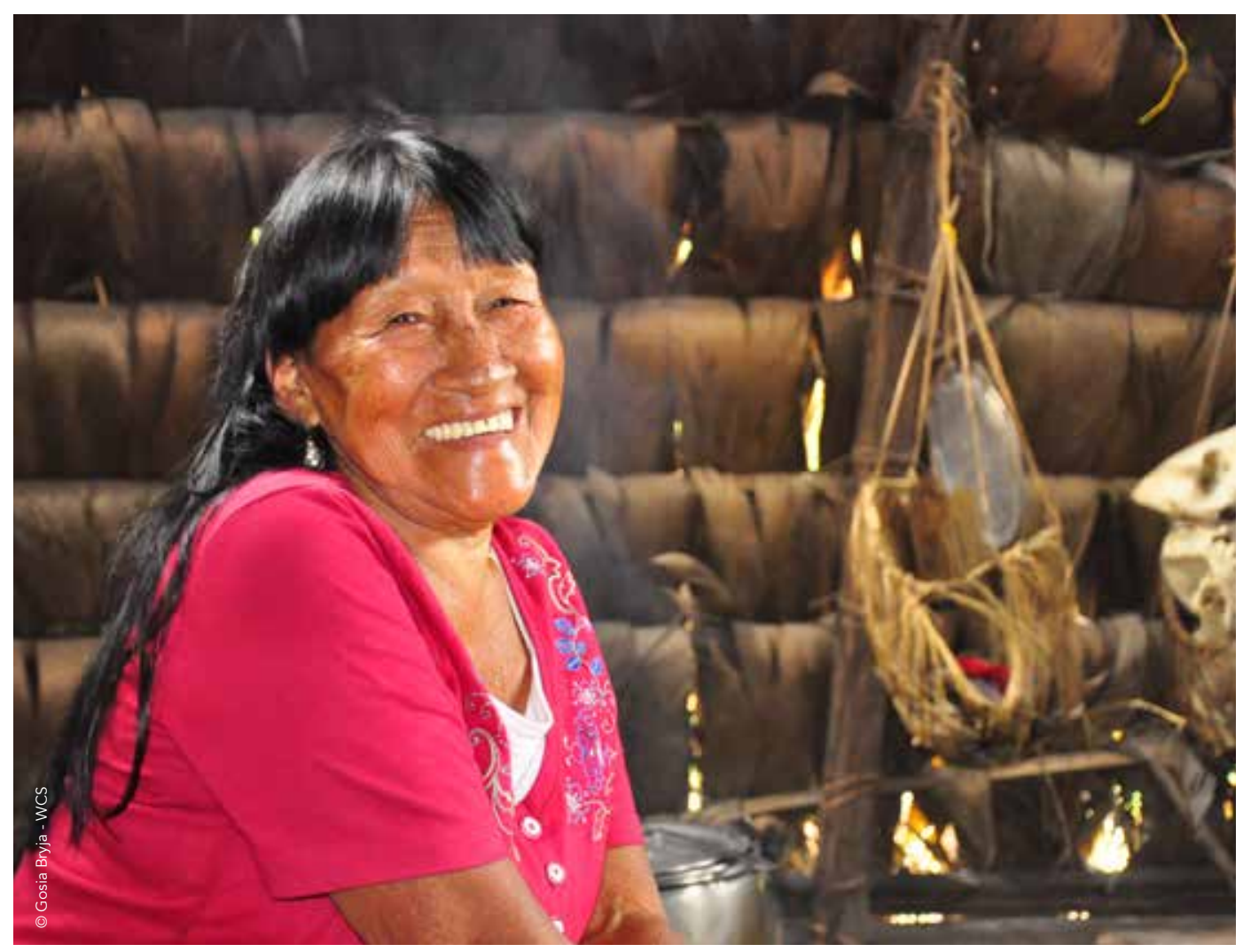




\section{TENDIENDO "PUENTES" ENTRE LAS COMUNIDADES INDÍGENAS Y EL ESTADO PARA LA CONSERVACIÓN}

En Ecuador, al igual que en Bolivia y Perú, WCS ha trabajado tendiendo "puentes" entre el Estado y las comunidades. En este caso, entre el Ministerio del Ambiente, las organizaciones indígenas y sus comunidades.

A diferencia de Bolivia, donde la Constitución Política del Estado reconoce la compatibilidad entre áreas protegidas y territorios indígenas, y de Perú donde se reconocen Reservas Comunales como una categoría del Sistema Nacional de Áreas Protegidas, en Ecuador, por un lado, la Constitución reconoce a las comunas, comunidades, pueblos y nacionalidades indígenas los derechos de "conservar la propiedad imprescriptible de sus tierras comunitarias, que serán inalienables, inembargables e indivisibles" y a "mantener la posesión de las tierras y territorios ancestrales y obtener su adjudicación gratuita", por otro lado, establece que la gestión de las Áreas Naturales Protegidas es una competencia exclusiva del Estado central. Entre sus responsabilidades, el Estado debe fomentar "la participación de las comunidades, pueblos y nacionalidades que han habitado ancestralmente las áreas protegidas en su administración y gestión" (República del Ecuador, 2008, págs. 24, 80, 116: Art. 57, incs. 4 y 5; Art. 261, inc. 7; Art. 405).

Por su parte, el régimen agrario establece que "las tierras rurales que forman parte del Sistema Nacional de Áreas Naturales Protegidas, conforman el patrimonio natural del Estado y se rigen por su propia Ley" (República del Ecuador, 2016, págs. 8, Art. 17). Así, el reconocimiento legal, delimitación y adjudicación de las tierras comunitarias y territorios ancestrales en las Áreas Naturales Protegidas se realiza por la Autoridad Ambiental Nacional: el Ministerio del Ambiente, en coordinación con la Autoridad Agraria Nacional. Del mismo modo, de "existir actividades agropecuarias o forestales en tales tierras y territorios, las autoridades competentes con la participación de los y las beneficiarias de la adjudicación formularán el plan de manejo que establezca las condiciones ambientales y técnicas que deben cumplir estas actividades" (República del Ecuador, 2016, págs. 20, Art. 80). Como se observa, las comunidades, pueblos y nacionalidades indígenas quedan sujetas al Ministerio del Ambiente, cuando sus tierras o territorios ancestrales se encuentran en las Áreas Naturales Protegidas.

El marco legal específico de Ecuador, permite comprender el quehacer de WCS en Ecuador en su relación con el Ministerio del Ambiente y las comunidades, pueblos y nacionalidades Indígenas, especialmente cuando los territorios ancestrales han sido sobrepuestos por las áreas protegidas.

"En la región nororiental del PNY, se encuentran asentadas seis comunidades Kichwa que son reconocidas por el Estado en posesión ancestral, mantienen la totalidad o parte de sus territorios dentro del Parque Nacional Yasuní" (Wildlife Conservation Society, Programa Ecuador y Ministerio del Ambiente del Ecuador, Parque Nacional Yasuní, 2015, pág. 9).

En el contexto anterior, pueden entenderse los esfuerzos de WCS en Ecuador por incorporar al Ministerio en los procesos de planificación, mapeo y zonificación de las comunidades y territorios ancestrales, así como el establecimiento y fortalecimiento de los sistemas de guardianía, control y vigilancia tanto del Parque Nacional Yasuní como de los territorios comunitarios. Estos complejos procesos de "tender puentes", coadyuvan, por un lado, a fortalecer las relaciones entre las comunidades y de estas con sus organizaciones matrices como la NAWE /AMWAE y la FICCKAE y por otro lado, las relaciones con el Ministerio del Ambiente. De ahí que la conformación de los equipos técnicos para la realización de las 
actividades mencionadas hubiese requerido la participación tanto de técnicos de WCS en Ecuador como de las organizaciones indígenas y del Ministerio.

En el caso de las seis comunidades kichwas ubicadas en el nororiente del Parque Nacional Yasuní, al principio, las comunidades buscaban la protección de sus tierras ancestrales por parte del Estado frente a invasiones de poblaciones inmigrantes al área (Wildlife Conservation Society, Programa Ecuador y Ministerio del Ambiente del Ecuador, Parque Nacional Yasuní, 2015, pág. 34). El proceso, mediado por la elaboración de planes de manejo comunitario como gesto de compromiso de las comunidades para la conservación del área, tuvo como resultado la suscripción de un convenio entre las comunidades y el Ministerio del Ambiente. En el contexto del Ecuador, se consideró a este proceso como un "modelo de gestión compartida" (Wildlife Conservation Society, Programa Ecuador y Ministerio del Ambiente del Ecuador, Parque Nacional Yasuní, 2015, págs. 9 - 11).

Esta construcción de relaciones de tipo "puente" entre las comunidades y el Estado, en una relación de ida y vuelta, requirió el apoyo para que las seis comunidades kichwas, así como de cuarenta mujeres de catorce comunidades de la AMWAE y otros tantos representantes de la NAWE, participaran en la actualización del Plan de Manejo del Parque Nacional Yasuní, en 2011. Esta participación se realizó en talleres convocados por el Ministerio del Ambiente y el objetivo fue involucrar directamente a las comunidades y representantes en la actualización del Plan de Manejo del Parque Nacional Yasuní (Wildlife Conservation Society, Programa Ecuador y Ministerio del Ambiente del Ecuador, Parque Nacional Yasuní, 2015, pág. 24).

Otro proceso relevante en la construcción de relaciones de tipo "puente" entre las comunidades y el Ministerio fueron los esfuerzos por construir un sistema integrado de protección a nivel de la Reserva de la Biósfera Yasuní. Un aspecto fundamental fue la definición participativa de los roles y funciones de los guardaparques comunitarios, de cara a los intereses comunitarios. Su participación en la demarcación y mantenimiento de los límites territoriales comunitarios constituyó una función importante, al mismo tiempo que las acciones de guardianía y protección de los ecosistemas y las especies, lo eran para la conservación (Wildlife Conservation Society, Programa Ecuador y Ministerio del Ambiente del Ecuador, Parque Nacional Yasuní, 2015, pág. 17). Esta condición del área favorece las relaciones entre lo que puede considerarse unidades de gestión diferentes, en torno al Parque Nacional Yasuní, incluyendo las tierras comunitarias y los territorios ancestrales. La creación de sistemas de guardaparques comunitarios y su capacitación sistemática, basada en la elaboración previa de un programa de capacitación adecuado para que guardaparques comunitarios puedan cumplir las funciones de control, protección, demarcación y monitoreo bajo el liderazgo del Ministerio constituye otra experiencia destacable (Wildlife Conservation Society, Programa Ecuador y Ministerio del Ambiente del Ecuador, Parque Nacional Yasuní, 2015, pág. 25).

El entrenamiento de guardaparques comunitarios se realizó a través de al menos dos talleres anuales y la diseminación de materiales pedagógicos adecuados a las condiciones de dichos guardaparques. En el proceso participaron diferentes instituciones como la Fundación Randi - Randi y WCS en Ecuador. Además de la coordinación con el Ministerio del Ambiente y las comunidades y organizaciones indígenas, fue importante la participación del personal técnico de WCS en Ecuador como entrenadores. Los temas de las capacitaciones estuvieron referidos a temas tales como: relaciones comunitarias, género y medio ambiente, manejo de conflictos, estudios de caso, aspectos forestales en el Parque Nacional Yasuní, manejo de la cacería y la vida silvestre, demanda de carne silvestre, gobernanza, manejo de comités, educación ambiental e interpretación (Wildlife Conservation Society, Programa Ecuador y Ministerio del Ambiente del Ecuador, Parque Nacional Yasuní, 2015, pág. 26). 
Además, de la participación del programa de capacitación para guardaparques comunitarios, WCS en Ecuador, junto al Ministerio del Ambiente, promovieron la participación de estos guardaparques comunitarios en otros eventos de capacitación. Tanto en el curso de la implementación del Programa como de estos otros eventos de capacitación, destaca la interrelación de los guardaparques comunitarios con los guardaparques del Parque Nacional Yasuní (Wildlife Conservation Society, Programa Ecuador y Ministerio del Ambiente del Ecuador, Parque Nacional Yasuní, 2015, págs. 16, 18)

Otro aspecto llamativo en la construcción de relaciones de "tipo puente" entre el Ministerio del Ambiente, las fuerzas policiales y militares así como la consideración a los pueblos indígenas, fue la capacitación al personal policial y militar destacado en la región de Yasuní. Entre los temas de capacitación que destacan para este tipo de personal se encuentran: protección ambiental, áreas naturales protegidas, Parque Nacional y Reserva de la Biósfera Yasuní, indígenas en aislamiento voluntario, ecología y conservación, especies amenazadas y tráfico, explotación forestal, calidad ambiental, legislación ambiental y manejo de conflictos. Si bien el objetivo principal era lograr una mejor coordinación entre el Ministerio del Ambiente y las fuerzas del orden para la protección del Parque Nacional y la Reserva de la Biósfera Yasuní, la inclusión de temas relacionados con la situación de los Pueblos Indígenas en aislamiento voluntario constituye la posibilidad de una mejor comprensión de las condiciones de estos pueblos por parte de un sector estatal importante en la región (Wildlife Conservation Society, Programa Ecuador y Ministerio del Ambiente del Ecuador, Parque Nacional Yasuní, 2015, pág. 26)

En síntesis, la construcción de relaciones de tipo "puente" para la conservación del Parque Nacional y la Reserva de la Biósfera Yasuní, en el caso de Ecuador se constituye en un imperativo por el hecho gravitante de su legislación, en la cual se asigna al Ministerio del Ambiente la potestad del reconocimiento legal de las tierras comunitarias y territorios ancestrales en Áreas Naturales Protegidas. En este quehacer destacan dos tipos de procesos que han sido coadyuvados por WCS en Ecuador: 1) los procesos de planificación para el manejo tanto de las comunidades y territorios ancestrales como del propio Parque Nacional Yasuní, contando con la participación y liderazgo del Ministerio del Ambiente, de las organizaciones indígenas y sus comunidades y 2) el intento por constituir un sistema integrado de protección y vigilancia a través de la formación, capacitación y entrenamiento tanto de guardaparques comunitarios como del área protegida. Estos procesos han demandado la formulación de un programa de capacitación y entrenamiento sobre la base de la definición participativa de los roles y funciones de los guardaparques comunitarios. Entre las debilidades de este proceso se puede advertir la ausencia de sostenibilidad financiera de este sistema integrado, en el que los guardaparques comunitarios en muchos casos cumplen sus funciones ad honorem. Ello ha determinado, que algunos de ellos pasen a ser contratados como guardaparques del área protegida. 


\section{MANEJO DE RECURSOS NATURALES Y EXPERIENCIAS DE TURISMO COMUNITARIO}

\section{LA ASOCIACIÓN DE MUJERES WAORANI DE LA AMAZONÍA ECUATORIANA (AMWAE) Y LA PRODUCCIÓN DE ARTESANÍAS DE CHAMBIRA (ASTROCARYUM CHAMBIRA)}

La nacionalidad waorani es conocida por su casi legendaria "bravura", en algún caso ha sido caracterizada como "la sociedad más violenta conocida por la antropología" (Robarchek \& Robarchek, 2008). Entre los investigadores, la cuestión sobre las raíces de esta característica está lejos de alcanzar un consenso entre quienes consideran que se debe a profundas causas culturales (Robarchek \& Robarchek, 2008) y quienes consideran que es el resultado de la historia de las relaciones de esta nacionalidad indígena y el entorno social, en un momento fundacional marcado por la violencia del boom de las gomas elásticas y reproducido con variantes hasta la actualidad. Estas condiciones habrían determinado no solo las relaciones externas de la sociedad waorani sino también las relaciones internas (Wasserstrom, 2016). Bástenos aquí estas referencias para dar a conocer e intentar dimensionar la complejidad del trabajo de WCS en Ecuador con una nacionalidad indígena de tales características.

En la actualidad, la nacionalidad waorani cuenta con 3500 personas distribuidas en 40 comunidades que se ubican mayormente en la Reserva Étnica Waorani con una extensión aproximada de 678220 ha, a la que, parcialmente, se superpone el Parque Nacional Yasuní y es parte de la Reserva de la Biósfera Yasuní (Ima Omene, 2012). A nivel general, estas comunidades están representadas por la NAWE, reconocida como la principal organización y la AMWAE que representa específicamente a las mujeres.

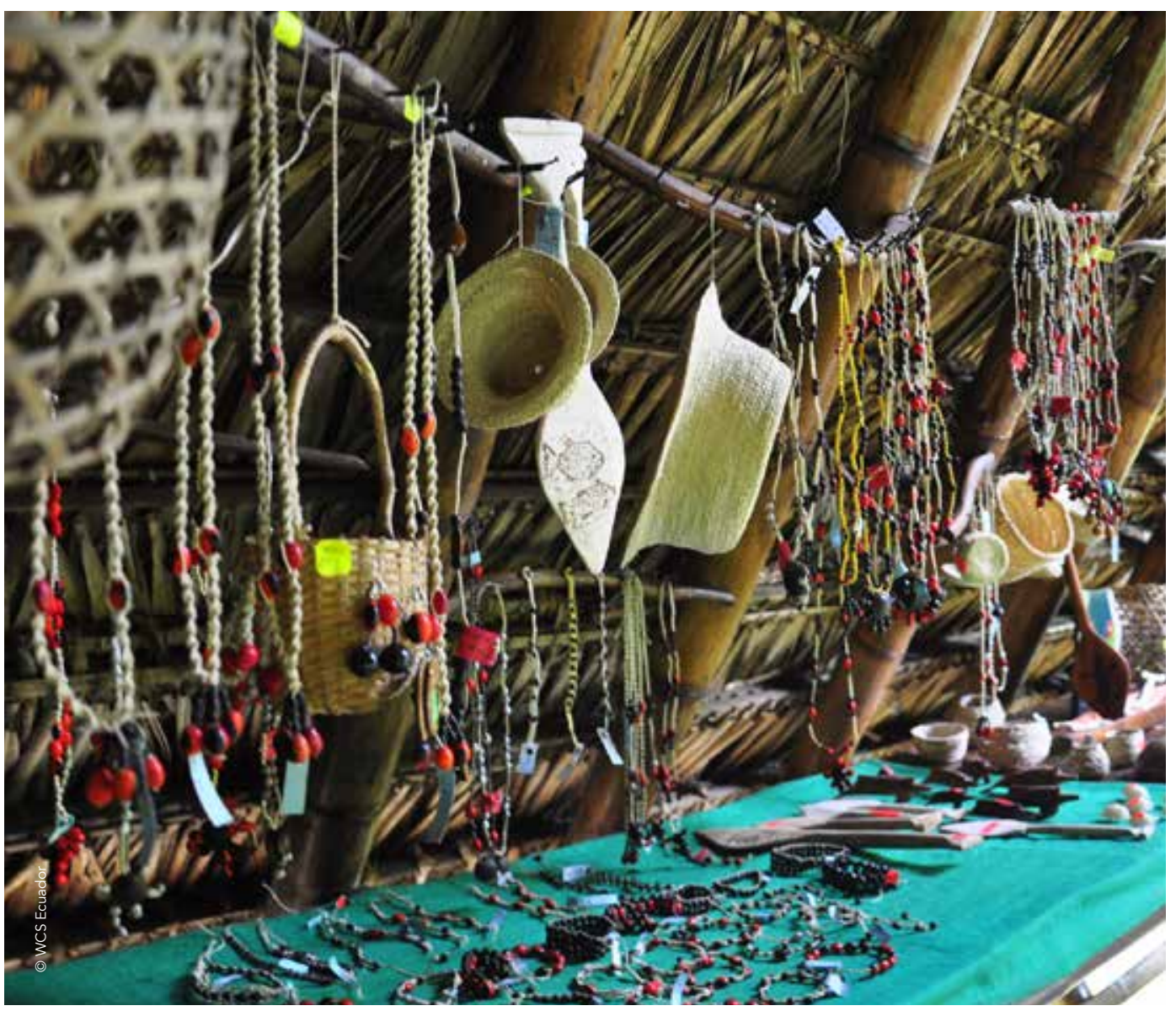


En la sociedad waorani, las relaciones entre las personas se caracterizan por una muy marcada autonomía individual y exigencia de igualdad y flexibilidad en las relaciones de género "una persona nunca impone su voluntad sobre la otra sea ésta hombre o mujer" (Ima Omene, 2012, pág. 29). Tradicionalmente, los grupos domésticos fueron endogámicos, bajo la fuerte oposición entre el grupo de quienes se consideran consanguíneos y "los otros" alternando su vida en periodos de paz y de la guerra, con una marcada división del trabajo entre hombres y mujeres pero al mismo sentido colaborativo entre ambos. Las mujeres demuestran fortaleza de carácter y marcada independencia para el desarrollo de sus actividades, como expresión cultural de esta independencia, en las festividades, hombres y mujeres bailan formando grupos separados (Ima Omene, 2012, pág. 34).

La AMWAE fue creada en 2005 (AMWAE, 2015):

"son siete las mujeres que decidieron crearla con los objetivos de mejorar la salud, educación, alimentación y buen vivir de toda la nacionalidad" (Ima Omene, 2012)

Basada en el interés sobre problemáticas que afectan particularmente a las mujeres, "al contar con donaciones", alrededor de 2007, la AMWAE decidió iniciar un proyecto de producción de artesanías con la finalidad de fortalecer sus capacidades organizativas y económicas:

"Nosotras incursionamos en la manufactura de diversos artículos con fines de biocomercio y solicitamos apoyo técnico para elaborar planes de manejo de plantas silvestres más utilizadas como es ?tewe? y para establecer viveros de recursos vegetales con potencial de colorantes. Las dos acciones son estratégicas, tanto para nuestros bosques como para la Nacionalidad Waorani" (Ima Omene, 2012, pág. 34).

Posteriormente, la AMWAE encaró otro proyecto de promoción de la producción de cacao en diez comunidades waorani ubicadas en la Reserva de la Biósfera Yasuní. Al 2015, contaban con 23,7 ha bajo producción con la participación de 135 familias. Para entonces, la AMWAE comercializaba artesanías, chocolate e incluso plantas forestales (AMWAE, 2015, pág. 3).

En este contexto, al menos desde 2009, WCS en Ecuador ha venido apoyando a la AMWAE en actividades específicas. Inicialmente, con el mapeo de las áreas de distribución de las palmas de chambira, materia prima para la producción de las artesanías. De manera relevante, este mapeo fue realizado por personal técnico de la NAWE, capacitado por WCS en las técnicas del mapeo y el manejo de información geográfica y ahora apoyando a la AMWAE. De esta manera, se reforzaba un vínculo entre la organización matriz de la Nacionalidad Waorani y la organización de las mujeres. Entre 2009 y 2010, se lograron mapear alrededor de 300 ha correspondientes a las comunidades de Miwaguno (106 ha), Yawepade (133 ha) y Tiwino (95 ha). Para entonces, ya se observaba la escasez de esta materia prima en la cercanía de las comunidades y se buscaba contribuir al manejo del recurso (WCS - Programa Ecuador, 2011, pág. 9).

También por aquellos años, se inició un proceso de establecimiento de viveros para el cultivo de las palmas de chambira, bajo sistemas agroforestales, en las áreas de manejo agrícola de las comunidades, con la finalidad de reducir la presión sobre las poblaciones silvestres. Esta actividad estuvo acompañada de un proceso de sistematización por las 
propias mujeres waorani acerca de las mejores combinaciones de plantas en sus parcelas (WCS - Programa Ecuador, 2011, págs. 9, 32).

En el periodo de 2009 a 2011, la AMWAE, con el acompañamiento de WCS en Ecuador, desarrollaría catorce talleres de capacitación e intercambio de conocimientos en 35 comunidades diferentes que contaron con la presencia de más de 600 mujeres participantes ${ }^{15}$, provenientes de 35 de las 40 comunidades Waorani existentes en la Reserva de la Biósfera Yasuní. El contenido de estos talleres estuvo referido a la producción de las artesanías, el mejoramiento y el control de la calidad, el diseño de los productos, conocimientos y habilidades micro-empresariales, capacitación a entrenadoras artesanas, uso de tintes y resinas, elaboración de vasijas de arcilla, técnicas y habilidades de comercialización, cultivo y aprovechamiento de plantas útiles (WCS - Programa Ecuador, 2011, págs. 31 - 32).

Como parte del apoyo a la comercialización de las artesanías, WCS en Ecuador apoyó el establecimiento de tres tiendas para el expendio de las artesanías waorani, en las localidades de Tena, Puyo y Coca. Al finalizar los talleres de entrenamiento, los productos fueron llevados para ser vendidos en dichas tiendas. Asimismo facilitó la participación de las artesanas de la AMWAE en varias ferias artesanales en diferentes lugares de la región amazónica y del país (WCS - Programa Ecuador, 2011, págs. 31 - 32).

En 2011, la AMWAE ayudó a más de 265 mujeres en la apertura de sus cuentas bancarias individuales para el depósito de sus ganancias, resultado de la venta de sus artesanías en las tiendas que WCS en Ecuador ayudó establecer (WCS - Programa Ecuador, 2011, pág. 33). Hacia 2012, la AMWAE contaba con 455 mujeres asociadas (Ima Omene, 2012, pág. 34).

En 2014, WCS en Ecuador colaboró con la AMWAE a elaborar un plan de manejo de la chambira. En este documento se identifican los problemas persistentes respecto del proceso de agotamiento de la especie en algunas comunidades y la drástica reducción de la misma en otras como consecuencia del incremento en la demanda por las artesanías. El acopio de la materia prima implicaba el recorrido de largas distancias. Entre otros aspectos, este también estaba incidiendo en la provisión de proteínas de la población indígena, al ser, la chambira, también parte de la dieta de la fauna silvestre. Del mismo modo, los métodos de cosecha de las cortezas de los árboles utilizados como tintes requerían ser mejorados (Ortiz Cruz, 2014, pág. 3).

En consideración a lo anterior, el plan de manejo de la chambira propuso medidas relacionadas con: a) el fortalecimiento de la organización a través del registro de las personas usuarias del recurso y de las capacidades para establecer acuerdos no solo entre las artesanas integrantes de la AMWAE sino a nivel de todas las personas integrantes de cada comunidad, para ello, se requería también la participación de la NAWE; b) la suspensión del aprovechamiento de las especies silvestres de la chambira; c) el enriquecimiento de los sistemas agroforestales con especies de chambira, otros árboles frutales y aptos para tintes, con instrucciones técnicas para la identificación de las áreas para el cultivo en parcelas ya utilizadas por los hogares waorani, la cosecha y el cuidado de plantones o de semillas asegurando la regeneración de las especies silvestres, el establecimiento de viveros, la ubicación de las diferentes especies en las parcelas; d) el establecimiento de técnicas de cosecha de las hojas de chambira que aseguren la mantención de las plantas y la regeneración de las hojas; e) procesos de capacitación que deberían incidir tanto en el manejo técnico de las plantaciones y las plantas como de la cosecha y también sobre aspectos relacionados con: "mejores técnicas de elaboración de los productos artesanales, percepción de la importancia de la calidad, alza de la autoestima y merecido disfrute de su trabajo" (Ortiz Cruz, 2014, pág. 7). 
En 2015, WCS en Ecuador promovió una evaluación participativa de la AMWAE sobre sus fortalezas y debilidades de la gobernanza y un análisis de la cadena productiva de las artesanías de chambira, siguiendo y ajustando la metodología diseñada por D. Wilkie de WCS y el Programa de WCS en Perú (Wilkie \& Cowles, 2014; Flores, Antúnez, Padilla, Silva, \& Lehm, 2016).

El proceso de análisis de la cadena productiva de las artesanías de chambira y la evaluación de gobernanza con la AMWAE se realizó a través de un taller con una duración de dos días. Entre los aspectos más interesantes de este proceso se encuentra la constatación del contraste entre un sistema analítico propuesto por la metodología (en lo que refiere al análisis de la cadena productiva) y la forma concreta de representación de la misma por las mujeres waorani. De manera sorprendente para el personal técnico tanto de WCS como de la AMWAE y de otra institución que se encontraba presente, la identificación de la cadena fue representada, por iniciativa propia, a través de dibujos:

\section{GRÁFICO 16:}

\section{REPRESENTACIÓN DE LA CADENA PRODUCTIVA DE LAS ARTESANÍAS DE CHAMBIRA POR LAS MUJERES DE LA AMWAE}

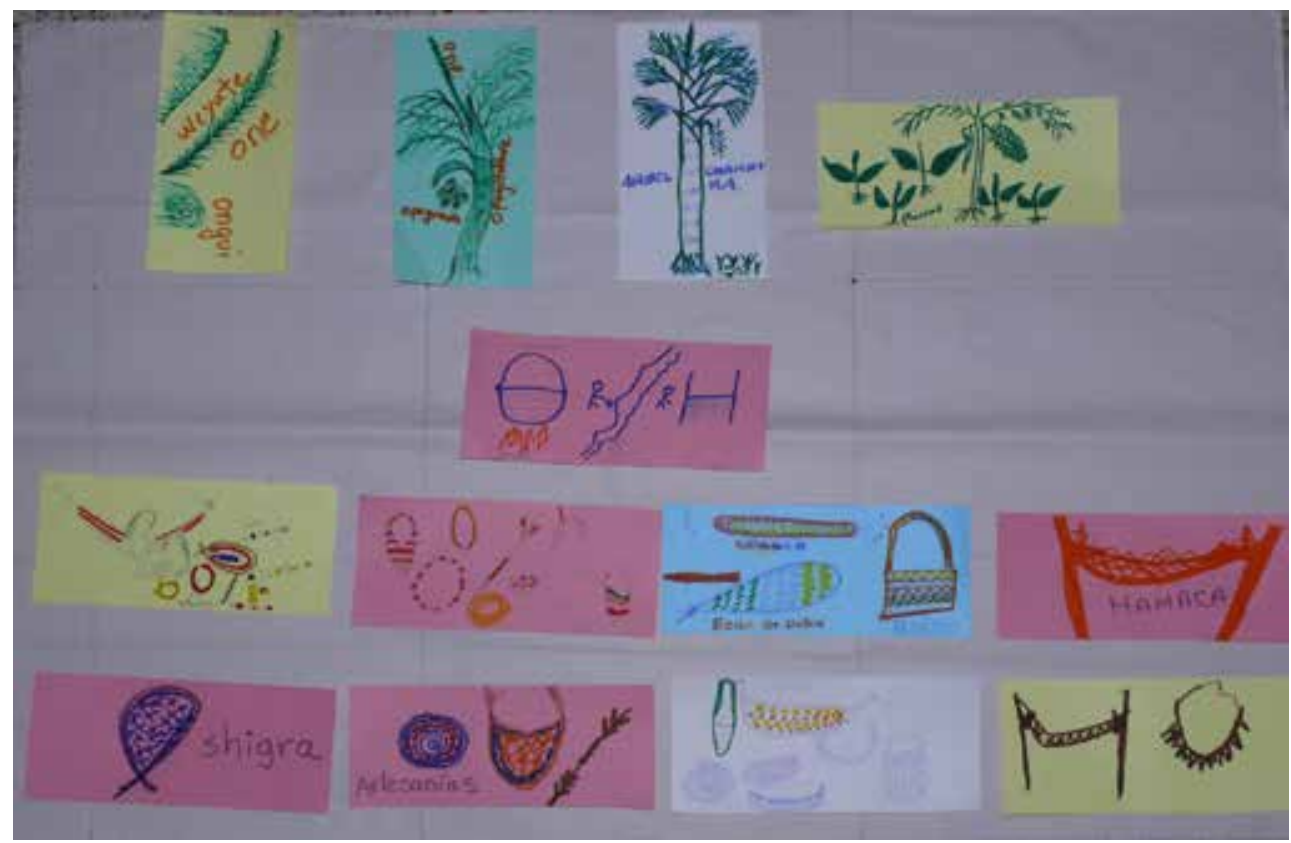

Fuente: (AMWAE, 2015) 
El análisis de las fortalezas y debilidades para cada actividad de la cadena representada, tuvo que ser dictada a las mujeres líderes y técnicas que sí tenían dominio de la escritura. De esta manera, el análisis que incluía la identificación de las personas según género y edad que participaban en cada fase y la época del año en la que se realizan, obviando aquí esta parte por razones de espacio, quedó descrito de la siguiente manera:

\section{TABLA 3:}

\section{FORTALEZAS Y DEBILIDADES EN LA CADENA PRODUCTIVA DE LAS ARTESANÍAS DE LA}

\section{AMWAE}

\begin{tabular}{|c|c|c|c|}
\hline NO & $\begin{array}{l}\text { ACTIVIDADES } \\
\text { DE LA CADENA } \\
\text { PRODUCTIVA }\end{array}$ & FORTALEZAS & DEBILIDADES \\
\hline 1 & $\begin{array}{l}\text { Buscar semillas } \\
\text { y plántulas de } \\
\text { chambira. }\end{array}$ & $\begin{array}{l}\text { Conocimientos } \\
\text { ancestrales }\end{array}$ & $\begin{array}{l}\text { Palmas muy lejos. } \\
\text { Niños y animales dañan las semillas. }\end{array}$ \\
\hline 2 & $\begin{array}{l}\text { Sembrar en viveros } \\
\text { y cerca de sus } \\
\text { casas. }\end{array}$ & $\begin{array}{l}\text { Experiencias } \\
\text { Algunos recibieron } \\
\text { técnicas de afuera. }\end{array}$ & $\begin{array}{l}\text { No se cuida bien de los viveros, poca } \\
\text { constancia en el cuidado. }\end{array}$ \\
\hline 3 & Reforestación & $\begin{array}{l}\text { Solo en algunas } \\
\text { comunidades }\end{array}$ & $\begin{array}{l}\text { Plagas (mosquitos gusanos) } \\
\text { Mala selección de plantas }\end{array}$ \\
\hline 4 & $\begin{array}{l}\text { Cosecha de la } \\
\text { chambira } \\
3 \text { años } \\
6 \text { años en adelante }\end{array}$ & $\begin{array}{l}\text { Algunas comunidades } \\
\text { tienen herramientas } \\
\text { para las cosechas. }\end{array}$ & $\begin{array}{l}\text { Distribución desigual de chambira en } \\
\text { el territorio waorani. }\end{array}$ \\
\hline 5 & $\begin{array}{l}\text { Lavamos y } \\
\text { cocinamos la } \\
\text { chambira. }\end{array}$ & $\begin{array}{l}\text { Se ha mejorado y se } \\
\text { usan otros elementos } \\
\text { p.e. jabón, para } \\
\text { mejorar la calidad. }\end{array}$ & $\begin{array}{l}\text { Distintas calidades de la chambira. } \\
\text { De la cosecha depende la calidad. } \\
\text { Cosecha inadecuada se refleja en mala } \\
\text { calidad del producto. }\end{array}$ \\
\hline 6 & $\begin{array}{l}\text { Secado de la } \\
\text { chambira }\end{array}$ & $\begin{array}{l}\text { De manera natural a } \\
\text { la antigua. }\end{array}$ & Lluvias prolongadas durante secado \\
\hline 7 & $\begin{array}{l}\text { Colores de corteza } \\
\text { para el teñido } \\
\text { de la fibra de } \\
\text { chambira } \\
\text { - Raíz } \\
\text { - Hojas } \\
\text { - Pepas }\end{array}$ & $\begin{array}{l}\text { Se ha mejorado la } \\
\text { diversidad (13 colores) } \\
\text { pero con tintes de } \\
\text { afuera, algunas usan } \\
\text { tintes naturales. }\end{array}$ & $\begin{array}{l}\text { Poca capacitación a mujeres en la } \\
\text { recolección de tintes naturales y débil } \\
\text { transmisión de conocimientos entre } \\
\text { generaciones. } \\
\text { Las artesanas cerca de las vías en } \\
\text { Orellana tienen más acceso a tintes no } \\
\text { naturales. } \\
\text { Temor a equivocarse en la recolección } \\
\text { de tintes naturales. }\end{array}$ \\
\hline 8 & $\begin{array}{l}\text { Tinturado de la } \\
\text { chambira }\end{array}$ & Formas tradicionales & $\begin{array}{l}\text { Diferencia en la calidad del tejido. } \\
\text { Colores que se pierden y manchan. }\end{array}$ \\
\hline 9 & $\begin{array}{l}\text { Hilado de la } \\
\text { chambira }\end{array}$ & Formas tradicionales & ------ \\
\hline
\end{tabular}

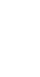

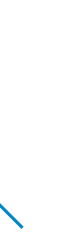




\begin{tabular}{|c|c|c|c|}
\hline NO & $\begin{array}{l}\text { ACTIVIDADES } \\
\text { DE LA CADENA } \\
\text { PRODUCTIVA }\end{array}$ & FORTALEZAS & DEBILIDADES \\
\hline 10 & $\begin{array}{l}\text { Tejido de la } \\
\text { chambira }\end{array}$ & $\begin{array}{l}\text { Diseños nuevos } \\
\text { Diseños tradicionales } \\
\text { Diversificación de } \\
\text { productos }\end{array}$ & $\begin{array}{l}\text { Si no está bien hecha la artesanía es } \\
\text { devuelta. } \\
\text { Tiempo diferente de elaboración. } \\
\text { Piden medidas diferentes y se demora } \\
\text { más. } \\
\text { No todas tienen la misma destreza. }\end{array}$ \\
\hline 11 & $\begin{array}{l}\text { Entregar en tienda } \\
\text { del Puyo }\end{array}$ & $\begin{array}{l}\text { Conocimientos y } \\
\text { dinero para salir a la } \\
\text { ciudad } \\
\text { Conocimientos } \\
\text { administrativos }\end{array}$ & $\begin{array}{l}\text { Transporte, distancia, tiempo, } \\
\text { embalaje } \\
\text { Falta de comunicación entre tienda y } \\
\text { comunidades }\end{array}$ \\
\hline 12 & $\begin{array}{l}\text { Comercializar en } \\
\text { otras tiendas }\end{array}$ & $\begin{array}{l}\text { Capacitaciones para } \\
\text { mejorar la calidad } \\
\text { No manchas } \\
\text { Producto hecho a } \\
\text { mano } \\
\text { Puntos de venta }\end{array}$ & $\begin{array}{l}\text { Artesanas no entregan a tiempo } \\
\text { pedidos, falta publicidad, atraso de los } \\
\text { pedidos, falta información. } \\
\text { Insuficiente información sobre ferias y } \\
\text { eventos. } \\
\text { No hay planificación adecuada. }\end{array}$ \\
\hline 13 & $\begin{array}{l}\text { Búsqueda de } \\
\text { mercado }\end{array}$ & $\begin{array}{l}\text { Mejorar la calidad } \\
\text { Respetar los } \\
\text { productos hechos por } \\
\text { las abuelas. }\end{array}$ & $\begin{array}{l}\text { Siendo artesanas se paga impuestos } \\
\text { altos. } \\
\text { Los informes no llegan a todas las } \\
\text { socias. } \\
\text { No se entiende los requisitos. } \\
\text { No se socializa sobre las facturas. }\end{array}$ \\
\hline 14 & $\begin{array}{l}\text { Las artesanas } \\
\text { cobran el } 70 \% .\end{array}$ & $\begin{array}{l}\text { Acuerdos previos (70 } \\
\text { \%) para la productora. } \\
\text { Mejor pago para } \\
\text { abuelas. } \\
\text { Informes mensuales } \\
\text { a la dirigencia por la } \\
\text { encargada. } \\
\text { Informes en } \\
\text { asambleas. }\end{array}$ & $\begin{array}{l}\text { Pérdida de confianza por incumplir los } \\
\text { pedidos. } \\
\text { Abrir nuevos mercados en Quito. }\end{array}$ \\
\hline
\end{tabular}

Fuente: (AMWAE, 2015)

En la priorización de los problemas que enfrentan tanto a nivel de la cadena productiva como de la gobernanza como organización, las mujeres de la AMWAE señalaron que si bien habían logrado grandes fortalezas a lo largo del tiempo, aún los problemas organizativos que encaraban eran considerados de primera importancia y urgencia para ser resueltos. En segundo lugar, debían ser atendidas las debilidades relacionadas con los aspectos administrativos y de la comercialización. En tercer lugar, los problemas relacionados con el tratamiento de la materia prima y la elaboración de las artesanías. En cuarto lugar, se encontraban los problemas relacionados con la producción de la materia prima, al considerarse que si bien aún tenían dificultades en esta fase, era en la que más habían avanzado al identificar estrategias que les permitirían cultivar su materia prima (AMWAE, 2015). 
En términos de las fortalezas y debilidades de la gobernanza, entre las primeras destacaban el hecho de tener una organización, contar con sus estatutos, tener un reconocimiento legal (aunque inadecuado a su condición de organización social y productiva simultáneamente), contar con un territorio propio donde se encuentran los recursos naturales necesarios para sus producciones e incluso, destacaron el hecho de que la mayoría de las artesanas cuenta con sus documentos de identificación personal. Asimismo, destacaron el hecho de contar con hasta siete instrumentos legales que les permiten funcionar, desde su personería jurídica, planes de manejo de recursos naturales elaborados (relacionados con el manejo de la fauna silvestre, la chambira y el cacao), las autorizaciones de venta de especies forestales y aún los registros sanitarios para la comercialización de su chocolate.

Una debilidad notable identificada estaba referida al hecho de que al ser una entidad representativa de las mujeres waorani, su estructura de cargos estaba enfocada dominantemente a la gestión de problemas de orden social y político. Paradójicamente en esta estructura orgánica no existen cargos relacionados con las producciones que ellas realizan.

Adicionalmente a lo anterior, entre las dificultades que enfrenta la AMWAE, se identificó la problemática compartida por otros emprendimientos productivos comunitarios en la Cuenca Amazónica, el hecho de que siendo entidades que cumplen doble función: social y económica, no tienen la posibilidad de un registro adecuado en los marcos legales nacionales. De esta manera, están sometidas a condiciones como si se tratase exclusivamente de empresas lucrativas, o exclusivamente de fines sociales (AMWAE, 2015, pág. 3).

\begin{abstract}
"La AMWAE ha recibido los siguientes premios: en el 2014 premio a las iniciativas productivas comunitarias por parte ONU-PPD, en 25 de septiembre de 2015, el Primer Premio Latinoamérica Verde- Sección Biodiversidad de Naciones Unidas, entre 24 países; en 3 de septiembre de 2015, en el salón internacional del cacao y chocolate, obtuvo el segundo lugar en "Sabores de Chocolate"; en 26 de septiembre de 2015, obtuvo el segundo puesto en exposición de artesanía y chocolate, en la localidad de Archidona" (AMWAE, 2015, pág. 3).
\end{abstract}

Como se ha podido ver, la AMWAE ha recorrido un largo camino, en él ha tenido el apoyo de varias instituciones estatales y no gubernamentales, entre ellas, de WCS en Ecuador. Lo que destaca aquí es el apoyo a una organización de mujeres, y de una de las nacionalidades indígenas más complejas del Ecuador y probablemente, entre las más complejas de la Cuenca Amazónica.

En este marco general, resalta la articulación de los fines de representación social y política con el quehacer económico de la AMWAE. WCS en Ecuador ha encontrado en el apoyo a este quehacer económico y al manejo de los recursos naturales una forma de también coadyuvar a fortalecer la dimensión de los derechos de las mujeres indígenas. Con delicadeza ha venido manejando la relación entre la NAWE, que representa a toda la nacionalidad waorani y está mayormente compuesta por hombres, y la AMWAE, a través de promover el servicio técnico de la NAWE a la AMWAE y cuidando que en los eventos patrocinados por WCS en Ecuador estén presentes líderes de la NAWE. Sin que ello signifique que ejerzan influencia sobre las decisiones de las mujeres, manteniendo la línea que al parecer marca la tradición en la propia cultura waorani.

En los primeros años, WCS en Ecuador apoyó a la AMWAE con actividades de los diferentes eslabones de la cadena productiva, aunque su enfoque nunca fue de cadena. Sin embargo, probablemente con debilidades en un enfoque teórico para la intervención, que se agudiza con una menor disponibilidad de recursos financieros, el apoyo se ha 
traducido en acciones concretas pero dispersas, con productos más que procesos como resultados.

Considerando las esferas económicas de nuestro marco interpretativo, el apoyo de WCS en Ecuador a las mujeres de la AMWAE tiene un enfoque orientado al mercado. Sin embargo, si bien se trata de generar mejores ingresos sostenibles buscando la conservación de la especie, su asociación con la fauna silvestre y un plan de manejo para esta última entre comunidades waorani, con fines de asegurar la provisión de proteínas en la dieta de los hogares indígenas, demuestra también una relación con la esfera de la reciprocidad.

\section{MANEJO DE TORTUGAS CHARAPAS Y TURISMO COMUNITARIO CON COMUNIDADES KICHWAS}

Como se vio en relación al número de actividades que WCS en Ecuador ha desarrollado desde 2009 con comunidades y Nacionalidades Indígenas de la Reserva de la Biósfera Yasuní, ha existido una concentración de trabajo con las comunidades kichwas relacionadas con la FICCKAE, especialmente en aquellas que colindan o están sobrepuestas por el Parque Nacional Yasuní en la zona nororiental del mismo. Así, WCS en Ecuador, por un lado ha colaborado con las comunidades de Indillama, Nueva Providencia, Añangu, Sani Isla y San Roque, en la elaboración de su plan de manejo comunitario (en dos oportunidades), capacitando a algunos de sus miembros en el mapeo participativo y las adquisición de conocimientos y habilidades para el manejo de sistemas de información geográfica, la zonificación de las áreas y el establecimiento de sus reglas de uso de los recursos naturales, así como en la capacitación y entrenamiento para la formación de guardaparques y promotores de monitoreo comunitario.

En este contexto, uno de los proyectos, al que WCS en Ecuador ha dedicado mayores esfuerzos es el del manejo de las tortugas charapas por las comunidades indígenas, en este caso, con las comunidades kichwas, aunque también lo hace con comunidades de la nacionalidad waorani

En la zonificación y el Plan de Uso y Manejo Territorial de las comunidades kichwas del río Napo, tanto la zona de uso intensivo como la de turismo presentan entre las normas de uso, la promoción de la recuperación de la fauna silvestre, específicamente de las tortugas charapa (Wildlife Conservation Society, Programa Ecuador y Ministerio del Ambiente del Ecuador, Parque Nacional Yasuní, 2015, págs. 39, 41).

Esta iniciativa se inició en 2008, en tres comunidades kichwas del río Napo: Nueva Providencia, Sani Isla y San Roque, y dos comunidades waorani del río Tiputini: Guiyero y Timpoca; tenía y aún tiene como objetivos:

"Mitigar la disminución de las poblaciones de charapas, en la región noroccidental del Parque Nacional Yasuní (PNY) y su área de influencia.

Fortalecer el trabajo de monitores locales en el manejo de charapas.

Sensibilizar a pobladores locales, a través de talleres de capacitación, sobre la importancia de conservar las tortugas de río y su ecosistema para su subsistencia" (Cueva, Utreras, \& Muñoz, 2010, pág. 4).

El proyecto se relaciona con dos especies de tortugas de río (charapas) Podocnemis unifilis y Podocnemis expansa. Su importancia en el ecosistema amazónico ha sido destacada debido a su función como dispersoras de semillas, ser limpiadoras del ecosistema acuático, 
constituir alimento para otras especies, ser fuente importante de proteínas para la población local a través del consumo de su carne y huevos, ser un atractivo turístico y fuente de ingresos para las poblaciones locales. Son especies amenazadas tanto por su sobreexplotación para la comercialización de los huevos como por la contaminación de su hábitat.

A través de los varios años de experiencia WCS en Ecuador y las comunidades han logrado establecer una ruta crítica de acciones para lograr su conservación:

1. Información del proyecto a las comunidades.

2. Control y protección de las playas naturales.

3. Construcción de playas artificiales.

4. Colecta y transporte de los huevos.

5. Siembra de huevos.

6. Mantenimiento de la playa artificial.

7. Construcción de estanques.

8. Eclosión de los huevos.

9. Cuidado de las charapas en las piscinas, pesaje y medición.

10. Marcaje y liberación de las charapas en las mismas playas donde los huevos fueron recogidos.

11. Monitoreo en los ríos.

En términos de la participación, y para lograr que el proceso sea exitoso, es necesario que toda la comunidad esté debidamente informada incluyendo el personal docente de las escuelas comunitarias. Cada comunidad elige sus monitores comunitarios, los que son capacitados por WCS en Ecuador y se convierten en las personas responsables de implementar y dar seguimiento a todo el proceso, al mismo tiempo de mantener informadas a sus comunidades. Asimismo, con la finalidad de facilitar el proceso, WCS en Ecuador ha producido guías didácticas que indican todas las especificaciones técnicas y mejores prácticas que se requieren para cada una de las acciones del proceso (Cueva, Utreras, \& Muñoz, 2010).

Al principio, además de los talleres de capacitación, la formación de los monitores comunales demandó la presencia constante del personal técnico de WCS en Ecuador en las comunidades realizando la asistencia en servicio en todas las actividades requeridas. Simultáneamente, las actividades del manejo, son acompañadas por otras de educación ambiental enfocadas especialmente en el personal educativo y estudiantes de las escuelas y colegios comunales. Para tal fin, ha sido necesario producir una diversidad de materiales didácticos incluido material audiovisual (WCS - Programa Ecuador, 2011, pág. 28).

Con la finalidad de empoderar a las comunidades con el manejo, se ha hecho posible que en el momento de liberación de las pequeñas tortugas, estén presentes autoridades, personalidades y medios de comunicación, de esta manera, las tortuguitas despliegan su potencial carismático ${ }^{16}$. Al final de cada campaña, las comunidades son informadas de los resultados. Finalmente, también se ha promovido el intercambio de experiencias entre comunidades y nacionalidades indígenas de la Amazonía ecuatoriana, lo que ha generado que más comunidades se interesen bajo la coordinación del Ministerio del Ambiente. De hecho, como se mencionó anteriormente, también en la formación y el quehacer de los guardaparques del Parque Nacional Yasuni y de los guardaparques comunitarios se incluye el manejo y el control y patrullaje de las playas de nidificación durante los periodos de desove de las tortugas (WCS - Programa Ecuador, 2011, págs. 17, 25).

Con la finalidad de optimizar los incentivos a las comunidades para el manejo de las tortugas, el personal técnico de WCS en Ecuador ha desarrollado también capacidades en acuicultura, de tal manera que las personas de las comunidades que se involucran en 
la conservación de las tortugas reciben alevines de cachama (Piaractus brachypomus) y entrenamiento para su cría y consumo. Asimismo, como compensación por la reducción del consumo de las tortugas y sus huevos, se hace entrega de pollos para la cría. De esta manera, el manejo de las tortugas, encadena otras actividades orientadas a promover la sustitución del consumo de proteínas de las tortugas y sus huevos por otros recursos más eficientes en términos de su provisión proteica, la generación de ingresos y aprovechando la infraestructura de los estanques de agua donde las tortugas son manejadas (WCS Programa Ecuador, 2011, pág. 12; WCS - Ecuador, 2015, pág. 7).

El monitoreo de las poblaciones de tortugas en los ríos Napo y Tiputini, dio cuenta de que en el Río Napo, la estimación de abundancia relativa de charapas en 2009 (antes de las liberaciones) fue de 1,2 ind $/ \mathrm{km}$ de río. Luego de cuatro períodos de liberación, la abundancia relativa fue de $2,42 \mathrm{ind} / \mathrm{km}$. En el Río Tiputini, en muestreos realizados entre 2008 y 2009, antes de las liberaciones, la tasa de encuentro fue de $1,0 \mathrm{ind} / \mathrm{km}$ de río y luego de tres liberaciones la tasa fue de 2,18 ind/km (WCS - Ecuador, 2015, pág. 4).

En la zonificación realizada por las comunidades, se establecieron zonas de turismo en cada una de las comunidades (Mapa 7) y en la actualización del Plan de Uso y Manejo Territorial de las seis comunidades, realizada en 2014, se incluyó un Programa de Turismo en el que se reconocía a la actividad turística como lana herramienta de manejo que aporta al mejoramiento de la calidad de vida de las comunidades locales, aprovechando los recursos escénicos, naturales y culturales, proporcionando ingresos económicos y orientando el manejo sostenible de los recursos naturales? (Wildlife Conservation Society, Programa Ecuador y Ministerio del Ambiente del Ecuador, Parque Nacional Yasuní, 2015, pág. 50). Sus objetivos fueron establecidos en los siguientes términos:

"Contribuir a la conservación de los territorios de las seis comunidades Kichwa y del Parque Nacional Yasuní, a través del fortalecimiento de la actividad turística y contribuir al mejoramiento de las condiciones de vida de los pobladores locales.

Brindar al visitante las condiciones apropiadas en cuanto a infraestructura, servicios y seguridad, para que disfrute de los atractivos naturales y culturales que presenta el territorio de las comunidades Kichwa". (Wildlife Conservation Society, Programa Ecuador y Ministerio del Ambiente del Ecuador, Parque Nacional Yasuní, 2015, pág. 50).

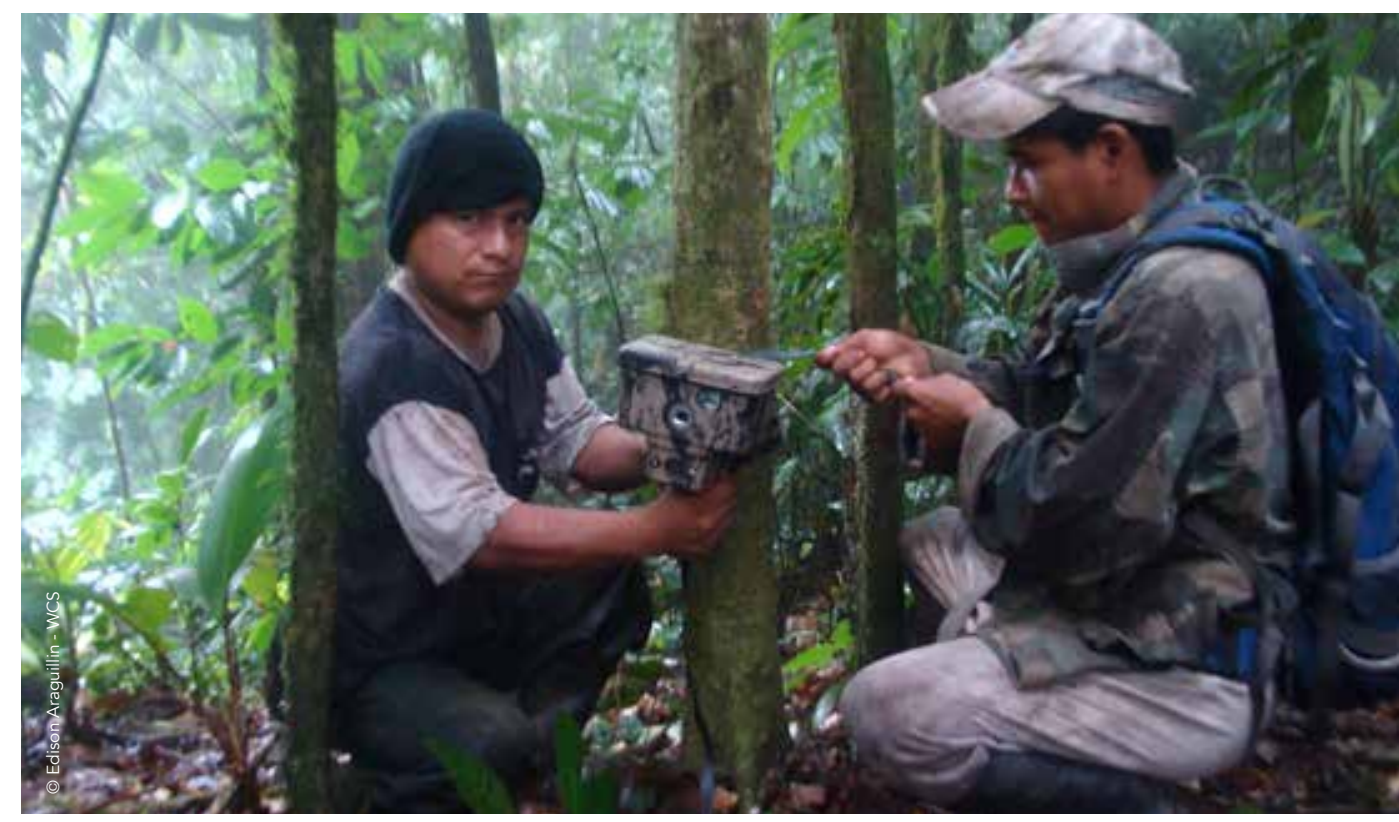


Entre las actividades del Programa se propuso:

- "Elaboración de proyectos turísticos comunitarios, basados en la experiencia alcanzado por las comunidades de Añangu y Sani Isla.

- Elaborar una normativa (reglamento de turismo) para el ordenamiento del turismo, reducción de impactos, mejorar la calidad y proveer beneficios locales.

- Difundir los atractivos turísticos de las comunidades a nivel provincial, nacional e internacional.

- Capacitar a la gente local para proveer servicios como: guías naturalistas, preparación de alimentos, transporte y alojamiento.

- Señalización de senderos e infraestructura como cabañas, baños, basureros, miradores.

- Organizar el flujo de turistas y visitantes para armonizar las actividades de las diferentes operadoras y minimizar los impactos que podrían ocasionar las mismas.

- Los beneficios provenientes de las actividades turísticas serán utilizados en el mantenimiento y mejoramiento de la infraestructura y beneficio de los pobladores locales" (Wildlife Conservation Society, Programa Ecuador y Ministerio del Ambiente del Ecuador, Parque Nacional Yasuní, 2015, pág. 51).

En este sentido, el apoyo a las iniciativas de ecoturismo de las comunidades se enmarca en el Plan de Uso y Manejo Territorial Comunitario pero sobretodo coadyuva a la implementación del mismo. En realidad, las acciones de apoyo al ecoturismo desarrollado por las comunidades son anteriores a la actualización del Plan de Uso y Manejo Territorial.

En 2005, la comunidad de Nueva Providencia, con el afán de desarrollarse económicamente, se alió con WCS en Ecuador para crear un Centro de Interpretación Ambiental como una iniciativa de turismo, "decisión que fue apoyada por la Asamblea General Comunitaria, el 13 de marzo 2007". Por su parte WCS, a su vez, decidió aliarse con la Fundación Latinoamericana del Hábitat Humano FLAHU, y aprovechando la experiencia en diseño participativo y acción solidaria con voluntarios, emprendió la construcción del Yaku Kawsay. En este proceso AL BORDE participa y se encarga del diseño arquitectónico, promoviendo la utilización de los materiales propios de la zona. En la construcción también se contó con el apoyo de la comunidad con su mano de obra. La construcción del Centro de Interpretación Ambiental, fue financiada por el proyecto: "Apoyo al Sistema de Control y Vigilancia del Parque Nacional Yasuní" del EcoFondo. Este atractivo turístico fue inaugurado en el año 2010 (Rojas Almeida, 2014, pág. 11). También contó con el apoyo financiero del Gobierno Autónomo Descentralizado Municipal de Orellana (Wildlife Conservation Society, Programa Ecuador y Ministerio del Ambiente del Ecuador, Parque Nacional Yasuní, 2015, pág. 29).

Entre 2010 y 2011, personal técnico de WCS participó como instructor en cursos organizados por el Ministerio del Ambiente para la formación de guías locales. En estos programas destaca la participación de miembros de las comunidades de Sani Isla y de Nueva Providencia, en este último caso en relación al manejo de un Centro de Interpretación ubicado en dicha comunidad, denominado: "Yaku Kawsay" o "Mundo Bajo el Agua". Al finalizar el curso, los guías fueron legalmente acreditados por el Ministerio del 
Ambiente para operar en las Áreas Naturales Protegidas del Ecuador" (WCS - Programa Ecuador, 2011, pág. 31).

El Centro de Interpretación "Yaku Kawsay" ("Mundo bajo el Agua") tiene la ventaja de encontrarse en el ingreso al Parque Nacional Yasuní por el rio Napo, donde también desarrollan actividades turísticas las otras comunidades kichwas de la región así como operadores privados. En 2014, WCS en Ecuador apoyó a la comunidad con una consultoría para actualizar su Plan de Negocios que inicialmente se había elaborado en 2009. Entre las debilidades, se destacaron las de carácter organizativo y un aún débil empoderamiento de la comunidad respecto del Centro, lo que había determinado que a cuatro años de su inauguración, todavía no había logrado arrancar como iniciativa de ecoturismo comunitario y tanto la infraestructura como los bienes se encontraban deteriorados. También se señalaron debilidades de orden legal y administrativo (Rojas Almeida, 2014, págs. 13 - 17).

El mayor valor del Centro de Interpretación es un museo de tallas en madera de las especies acuáticas más representativas del Parque Nacional Yasuní, realizadas por pobladores locales con el asesoramiento de WCS y la experticia de talladores reconocidos en la región (WCS - Ecuador, 2014). Además de este atractivo central, la comunidad ofrece otros, entre ellos, la visita a las áreas de manejo de las tortugas charapa (Rojas Almeida, 2014).

Aquí, es importante destacar, en la estrategia de WCS para el apoyo a las comunidades, la búsqueda de articular diferentes tipos de actividades con la finalidad de generar círculos virtuosos que logren alcanzar mejores ingresos para las comunidades y al mismo tiempo la conservación de la vida silvestre.

De esta manera, reforzando la articulación entre el manejo de las tortugas charapas y el turismo, WCS diseñó y viene implementando un "Programa de adopción de tortugas charapas". Mediante este programa los turistas que visitan la región tienen la oportunidad de participar en la liberación de las charapas, recibiendo un certificado de padrinazgo así como algún suvenir (pulsera), al mismo tiempo que dejan un donativo para el programa comunal de manejo de las tortugas. Esta actividad ha requerido la coordinación entre WCS, las comunidades, el Ministerio del Ambiente y las empresas de turismo que operan en el rio Napo y sus afluentes (WCS - Ecuador, 2016). 


\section{CONCLUSIONES}

De manera similar al caso del Paisaje Madidi en Bolivia, en el Paisaje Yasuní en Ecuador, WCS ha trabajado con las comunidades y pueblos indígenas coadyuvando a la gestión territorial y al manejo de recursos naturales.

La identificación de sus actividades, específicamente en la Reserva de la Biósfera Yasuní, muestra un proceso que se inicia en 2001 con algunas acciones aisladas que se intensifican desde 2007. Entre 2009 y 2011, WCS apoya al desarrollo e implementación de un modelo de gestión integral de territorios indígenas y luego, por razones de financiamiento continúa apoyando los procesos de gestión territorial en el marco del modelo propuesto, pero con acciones determinadas hasta la actualidad. Entre tanto mantiene y fortalece sus actividades de apoyo al manejo de recursos naturales específicos.

Inicialmente, el modelo de gestión integral de territorios indígenas, contempló siete líneas de acción: 1. Titulación y uso de recursos naturales. 2. Demarcación física de límites territoriales. 3. Sistemas participativos de control y vigilancia. 4. Planes de manejo comunitario, planes estratégicos y/o planes de vida. 5. Mitigación de conflictos. 6. Financiamiento sostenible para la gestión y la protección. 7. Incorporación formal de los instrumentos de gestión indígena a los planes de desarrollo gubernamental.

La sistematización de las actividades de WCS en la aplicación del modelo permite precisar mejor la ruta crítica de la Gestión Territorial Indígena en los siguientes pasos:

1. Mapeo comunitario y zonificación a nivel de comunidades y territorios mancomunados incluyendo el establecimiento de reglas de uso según las zonas.

2. Demarcación, legalización, titulación de territorios indígenas.

3. Control y vigilancia territorial.

4. Formulación de planes comunales y planes de vida a nivel de territorios mancomunados.

5. Monitoreo de la vida silvestre, la caza y la pesca por las comunidades.

La implementación de los planes de manejo comunitarios requirió acciones adicionales:

6. Fortalecimiento organizativo.

7. Desarrollo de capacidades administrativas y financieras.

8. Búsqueda de sostenibilidad financiera para la gestión territorial.

En relación al "mapeo" comunal, WCS desarrolló un programa de capacitación a personas delegadas por las comunidades. Este programa incluyó talleres de capacitación y "asistencia en servicio", es decir el acompañamiento en procesos donde las personas capacitadas prestaban servicios a sus propias comunidades o grupos de usuarios y la producción de materiales didácticos accesibles para comuneros. La capacitación incluyó desde las técnicas participativas y el manejo de instrumentos de posicionamiento geográfico (GPS) hasta el manejo básico de Sistemas de Información Geográfica, para el relevamiento de la información, su procesamiento, análisis y devolución de resultados a las comunidades. 
Asimismo, la experiencia en este campo demostró los diversos ámbitos de aplicación del mapeo y el uso del SIG por los pueblos indígenas, desde el ordenamiento de sus tierras, la delimitación de las mismas, el soporte técnico a los procesos de legalización territorial, el control y la vigilancia, la contribución al manejo de los recursos naturales y la resolución de conflictos.

El fortalecimiento de las capacidades en este campo especialmente a nivel de las organizaciones de segundo nivel como la NAWE y la FICCKAE les permitió prestar servicios a sus comunidades. De esta manera se fortalecieron las relaciones verticales de tipo vínculo entre los líderes y sus bases, al mismo tiempo que se fortalecían los vínculos entre comunidades.

La zonificación de los territorios comunitarios, al ordenar el uso de las tierras de manera consensual en las comunidades, contribuye a la conservación tanto de las áreas comunales como del Parque Nacional Yasuní.

En el apoyo de WCS, al control y vigilancia de los territorios indígenas, dos aspectos se deben resaltar: 1) el intento por establecer un sistema integrado de control y vigilancia entre el Ministerio del Ambiente y las comunidades, donde se establecieron roles específicos de los guardaparques comunitarios, coadyuvando de manera importante al establecimiento de relaciones de tipo "puente" entre las organizaciones indígenas, sus comunidades y el Ministerio del Ambiente y 2) el diseño e implementación de un programa de formación de guardaparques del Parque Nacional como de guardaparques comunitarios.

La formulación de los planes de manejo comunitario se convirtió en otro ámbito de capacitación a líderes y miembros de las comunidades en el manejo de técnicas participativas. Seis pasos importantes destacan: 1. Talleres para el acopio de la información a través de técnicas participativas en cada comunidad. 2. Procesamiento y análisis de la información. 3. Segunda ronda de talleres de validación de la información en cada comunidad. 4. Revisión y corrección de los planes incluyendo las observaciones de los comuneros. 5. Entrega del plan a la comunidad y apoyo para su difusión. 6. Presentación del plan por la comunidad al Ministerio del Ambiente para su aprobación.

Una vez más, a través de los planes de uso y manejo territorial de las comunidades, por la metodología adoptada de trabajar en cada comunidad y entre comunidades para la obtención de un solo plan para las seis comunidades kichwas del río Napo, y habiendo participado dirigentes de la FICCKAE en el proceso, se fortalecieron las relaciones de tipo vínculo entre las comunidades y de estas con su organización representativa. En este caso, al igual que en el caso de Bolivia, es necesario destacar que los planes son instrumentos importantes para la gestión territorial pero su aplicabilidad en el tiempo, está marcada por el fortalecimiento del tejido social durante el proceso de su elaboración.

También se debe destacar la participación del personal técnico del Ministerio del Ambiente en la formulación de los planes de manejo comunitario. Dado que es la entidad encargada de la aprobación de los mismos, podría pensarse que se trata de una estrategia adecuada para facilitar la aprobación. Por otro lado, sería importante verificar si esta presencia no entorpece los procesos propios de toma de decisiones de las comunidades.

Otro proceso intenso de fortalecimiento de capacidades fue a "monitores comunitarios" para el monitoreo de la vida silvestre, la caza y la pesca. La delegación de personas por las comunidades para que cumplan esta función, su formación como "para biólogos" a través de talleres y nuevamente el acompañamiento en servicio, capacitación también dirigida a los guardaparques comunitarios, incidiendo en los conceptos del manejo sostenible de la vida silvestre y el manejo del registro de datos en formularios didácticos, son parte de las estrategias y acciones desarrolladas por WCS en Ecuador con tal fin. En la formación de los guardaparques y "parabiólogos" es necesario destacar el involucramiento, junto a WCS, 
de instituciones de alto nivel académico del Ecuador como la Facultad Latinoamericana de Ciencias Sociales (FLACSO) y la Universidad de San Francisco de Quito.

La comunicación y difusión periódica de los resultados del monitoreo a las comunidades es una tarea ineludible para favorecer la adecuada toma de decisiones sobre el uso de los recursos naturales y su conservación.

La gestión territorial indígena, además de la cooperación para la elaboración de instrumentos de gestión y para el reforzamiento de las redes sociales de "tipo vínculo" horizontales y verticales, requiere el apoyo para el fortalecimiento organizativo que ayude a la sostenibilidad de todos los procesos. Entre los aspectos de este campo, es necesario destacar el apoyo a las organizaciones para la formación de liderazgos con visión de gestión territorial indígena y manejo sostenible de los recursos naturales. En el contexto de la dispersión de los asentamientos comunales, las dificultades y costos del transporte, la promoción de que sean las personas líderes de las organizaciones indígenas de segundo nivel quienes lideren los procesos de elaboración de los instrumentos de gestión recorriendo cada una de las comunidades, contribuye de manera significativa al fortalecimiento de las relaciones entre estos líderes y las comunidades de base. Asimismo, en este quehacer ha sido necesario facilitar la elaboración de estatutos, reglamentos y estrategias de las organizaciones con las que trabaja WCS en el Paisaje Yasuní en Ecuador. En el fortalecimiento de la organización de mujeres, AMWAE, destacan aspectos importantes tales como: el tomar como base su propia decisión de visibilizar y fortalecer su rol económico como creadoras de artesanías, productoras de chocolate y especies forestales; colaborar en mantener y fortalecer los puentes entre la organización matriz de la Nacionalidad Waorani, NAWE, mayormente representada por hombres, sin generar dependencias o relaciones de subordinación entre ambas organizaciones; considerando estos elementos, la formación de lideresas destacando su participación en la toma de decisiones respecto de la gestión territorial y la promoción de su participación en eventos de formación, capacitación e intercambio de conocimiento y experiencias relacionados con los derechos de las mujeres, de los pueblos indígenas y de las mujeres indígenas, así como de la naturaleza.

El fortalecimiento de las capacidades administrativas y financieras de las organizaciones y emprendimientos económicos indígenas constituye una piedra angular del proceso. Este fortalecimiento requiere cursos de capacitación pero sobre todo la transferencia de fondos bajo su administración y con ello, la "asistencia en servicio", es decir el "enseñar haciendo".

Para los programas de WCS en Ecuador y Bolivia, que encaran este fortalecimiento de esa manera, entraña una serie de riesgos pero al mismo tiempo implica un voto de confianza en las organizaciones, el establecimiento de relaciones más horizontales, y la conciencia de un desafío mayor que requiere ser encarado de manera sistemática y constante. La suscripción de sub-acuerdos de financiación, la capacitación y asistencia en servicio, la contratación de personal administrativo y contable idóneo para trabajar con las organizaciones indígenas, el desarrollo de sistemas incluyendo el diseño de manuales administrativos y contables adecuados a las condiciones de los pueblos indígenas son algunos de los elementos que se han tenido que desarrollar en este proceso. Una de las dificultades es el manejo administrativo centralizado de todas las fuentes de financiamiento propias y externas de las organizaciones indígenas, que requiere la coordinación entre todas las entidades financieras para favorecer sistemas transparentes y la rendición de cuentas en su sentido más amplio.

Todo el sistema de gestión territorial indígena requiere de fuentes de financiamiento sostenible. En el Paisaje Yasuní, WCS ha intentado varias estrategias que han incluido el apoyo a las organizaciones territoriales y comunidades para su adscripción al Programa Socio Bosque, mecanismo de compensación por la conservación de los bosques de 
carácter nacional en el Ecuador, hasta el fortalecimiento administrativo y el seguimiento a los procesos de constitución de las Circunscripciones Territoriales Indígenas, mediante las cuales, las organizaciones indígenas podrían asumir nuevas responsabilidades al mismo tiempo de administrar fondos públicos y constituirse en gobiernos autónomos. Hasta ahora, este sigue siendo una de las metas más importantes pero difíciles de alcanzar tanto por las organizaciones indígenas como por WCS.

El contexto legal del Ecuador donde el reconocimiento de los territorios comunitarios (tierras comunales y territorios ancestrales) en áreas naturales protegidas es competencia de la autoridad ambiental, delimita el accionar de WCS en su trabajo con las comunidades locales y pueblos Indígenas. Aquí, WCS ha trabajado, facilitando y buscando cuidadosamente no entorpecer de manera alguna, las relaciones de "tipo puente" entre el Estado y las organizaciones indígenas y sus comunidades, a través de hacer posible la participación del personal técnico del Ministerio del Ambiente en las actividades de elaboración de los instrumentos de gestión de las comunidades: los mapeos comunitarios y zonificaciones territoriales, los planes comunitarios y fundamentalmente el establecimiento de un sistema integrado de guardaparques de las áreas protegidas, de las tierras comunitarias y territorios o reservas ancestrales, en el contexto de la Reserva de la Biósfera Yasuní.

La elaboración de los planes de uso de los recursos y manejo territorial de las comunidades, incluyendo el ordenamiento territorial de las comunidades, se constituyó en gesto de compromiso de las comunidades sobrepuestas por el Parque Nacional Yasuní para la conservación del mismo y en requisito para la suscripción de un convenio entre el Ministerio del Ambiente y las comunidades por un periodo de 20 años. En Ecuador, a este proceso se le ha denominado "modelo de gestión compartida" de las áreas sobrepuestas entre el Área Natural Protegida y las áreas de uso de las comunidades, entre el Ministerio del Ambiente y las comunidades.

Otro proceso importante para la construcción de relaciones de tipo "puente" entre las comunidades y el Estado, ha sido la promoción de la participación de las comunidades en la actualización del Plan de Manejo del Parque Nacional Yasuní, en 2011. De esta manera, se estableció una relación de "ida y vuelta" a través, por un lado, de la participación del Ministerio del Ambiente en la elaboración de los planes comunitarios y, por el otro lado, de las comunidades en la elaboración del Plan de Manejo del Área Protegida. Las reuniones para la elaboración de estos instrumentos se convierten en espacios de diálogo donde tanto las comunidades como el Estado plantean sus problemas, necesidades y desafíos.

El diseño e implementación del sistema integrado de control y vigilancia a nivel de la Reserva de la Biósfera, y especialmente el diseño e implementación del programa de formación tanto de los guardaparques dependientes del Ministerio como de las comunidades y territorios ancestrales, se convirtieron en otros espacios importantes para la construcción de relaciones de tipo "puente" entre el Estado y las comunidades.

En términos de programas específicos de manejo de los recursos naturales por las comunidades en el Paisaje Yasuní, en el trabajo de WCS destacan al menos tres procesos: el manejo de chambira y de la producción de artesanías por la AMWAE, el manejo de las tortugas "charapas" y el apoyo a iniciativas de turismo comunitario por algunas comunidades kichwas y waorani.

Aunque inicialmente, su enfoque no fue de cadena productiva, WCS ha apoyado con diferentes acciones al fortalecimiento de las mismas. En el caso de la producción de artesanías de chambira por las mujeres de la AMWAE, ha contribuido en diferentes momentos aunque no necesariamente de manera secuencial en: 1. La conservación de la chambira como especie al propiciar acuerdos que reduzcan progresivamente el aprovechamiento de las especies silvestres y promoviendo su cultivo en las áreas de 
producción agrícola bajo sistemas agroforestales que combinen esta especie con otras también relacionadas con el uso de los tintes naturales, además de las especies cultivadas normalmente por los hogares waorani. Esta fase de la cadena ha requerido la capacitación en técnicas de recolección y cuidado de las semillas, el establecimiento de viveros, el diseño de las áreas de cultivo y el mantenimiento de las mismas. 2. El mejoramiento de las técnicas de cosecha de las hojas así como de la recolección del material para los tintes naturales. 3. El mejoramiento de las técnicas de producción de las artesanías, con base en criterios de control de la calidad. 4. La comercialización a través de ayudar al establecimiento de tres tiendas artesanales ubicadas en diferentes centros urbanos de la Amazonía así como de la promoción de la participación en ferias artesanales. 5. Todo ello ha requerido el fortalecimiento organizativo y la capacitación en aspectos técnicos administrativos. La comercialización a través de las tiendas artesanales no fue sostenible, por lo que, hacia fines de 2015, dos de ellas tuvieron que cerrar por déficits económicos para su mantenimiento.

Una evaluación de las fortalezas y debilidades de la cadena productiva de las artesanías de chambira y de la gobernanza de AMWAE mostró la necesidad de pensar las metodologías considerando el carácter concreto del pensamiento de las poblaciones locales, y particularmente de las mujeres waorani. La forma en que mejor se expresó este pensamiento concreto fue a través del dibujo.

Una discusión surge de la experiencia de trabajo con la AMWAE y está referida por un lado a la separación de las funciones sociales y políticas de las económicas en las organizaciones indígenas, tema recurrente en la discusión sobre emprendimientos productivos por pueblos y comunidades indígenas de la Amazonía desde la segunda mitad de los años 1990 (Lehm, Avizorando los retos para los pueblos indígenas de América Latina en el nuevo milenio. Economía indígena y mercados en la Amazonia Andina: avances, limitaciones y retos, 2002). Esta discusión, señala la necesidad de que, en el caso de los emprendimientos y proyectos productivos con fines de mercado, las organizaciones de representación política de los pueblos indígenas deben encargarse exclusivamente del control sobre el manejo de los recursos naturales, la producción y la administración; en tanto que las organizaciones económicas, formadas por grupos de usuarios y usuarias de los recursos naturales de las comunidades, deben hacerse cargo de las responsabilidades gerenciales, administrativas, productivas y del manejo de los recursos naturales específicos y rendir cuentas a las organizaciones matrices, sus comunidades y las personas integrantes de estas asociaciones.

El caso de la AMWAE replantea la problemática, al menos en dos sentidos: 1. Se trata de una iniciativa de mujeres que combina la representación política y social con su quehacer económico. Esta combinación por un lado visibiliza la contribución económica de las mujeres al tiempo que las empodera, pero por otro lado, plantea el dilema de una estructura orgánica que si bien responde a los quehaceres de la gestión política y social, descuida los procesos productivos. 2. En su relación con el Estado, pone sobre la mesa, la problemática de entidades económicas indígenas que a pesar de su carácter económico cumplen funciones tanto sociales como económicas, sin encontrar en los marcos legales canales de reconocimiento que les faciliten su labor.

El apoyo al manejo de las tortugas charapas por las comunidades, si bien tiene como finalidad la conservación de las especies (Podocnemis unifilis y expansa) y para ello, se ha realizado grandes esfuerzos de fortalecimiento a las comunidades en términos de: 1) la información y consulta sobre el proyecto, 2) el control y la protección de las playas naturales, 3) la construcción de playas artificiales, 4) La colecta, el transporte y la siembra de los huevos, 5) el mantenimiento de las playas artificiales, 6) la construcción de estanques, 7) el control de la eclosión de los huevos, 8) el cuidado de las charapas bebés, su pesaje y medición, 9) el marcaje y liberación y 10) el monitoreo de las poblaciones en los ríos; también fue necesario identificar incentivos para las personas participantes en la 
actividad. Entre estos incentivos se realizó la entrega de alevines de cachama (Piaractus brachypomus) y de pollos.

Esta actividad de conservación ha sido acompañada por intensos procesos de educación ambiental y finalmente, se ha buscado articularla con el desarrollo del turismo por las comunidades, una actividad a la cual WCS también ha apoyado. El diseño, construcción e implementación de un centro de interpretación como atractivo turístico con un museo de tallas en madera que muestra la fauna acuática más representativa del Parque Nacional Yasuní, en la comunidad kichwa de Nueva Providencia, constituye un ejemplo del apoyo a este tipo de iniciativa comunitaria.

El manejo de recursos naturales con fines de contribuir a los ingresos o medios de vida de las comunidades, se ha enmarcado en los planes de uso y manejo territorial de las comunidades. Esto es relevante en la medida que contribuye a la apropiación de los instrumentos de gestión por las comunidades y coadyuva a su implementación.

Desde el punto de vista de las esferas económicas de nuestro marco interpretativo, si bien el apoyo a la producción de las artesanías de chambira se orienta hacia la esfera del mercado, su articulación, a través del manejo y la conservación de la especie que también favorece a la conservación de la fauna silvestre de la cual los hogares waorani se abastecen de cacería y el establecimiento de sistemas agroforestales, favorecen el consumo y la esfera de la reciprocidad.

Del mismo modo, mientras el manejo de las charapas con fines de conservación de la especie y el desarrollo de incentivos con otras especies que son utilizadas para el consumo de los hogares se enmarca en la esfera de la reciprocidad, busca equilibrarse a través de su articulación al turismo, actividad relacionada con la esfera del mercado. 


conservación de la Amazonía. Entre las áreas protegidas de la Amazonía y los territorios indígenas, cubren el 45 \% del territorio amazónico; 28,1 \% del cual corresponde a territorios indígenas. En la Amazonía existen, 385 pueblos indígenas - con cerca de 1,4 millones de personas, de alguna manera poseen 2244 territorios indígenas (RAISG, 2015). También existen miles de comunidades tradicionales (caboclos, afrodescendientes o campesinos de distinto origen).

El uso diversificado de los recursos naturales que realizan estas poblaciones, la combinación de esferas relacionadas con la reciprocidad y el mercado en sus sistemas económicos, cosmovisiones y sistemas de asentamiento, aún hoy, a pesar de los cambios culturales, ostentan particularidades de tal suerte que las huellas que dejan en los paisajes son distintas a las de otros actores sociales asentados o que intervienen en la región.

De hecho, la comparación de la deforestación entre 2000 y 2013, entre áreas protegidas y territorios indígenas, muestra que en las primeras fue de 1,1\% en tanto que en los segundos fue de $0,8 \%$, menor que en las áreas protegidas. Ambas unidades contrastan con una pérdida de bosque en el conjunto de la Amazonía, en el mismo periodo de tiempo de $3 \%$. Con valores de deforestación acumulados de 2,1\% para las áreas protegidas, $2,3 \%$ para los territorios indígenas y 13,3 \% para el conjunto de la región (RAISG, 2015).

Las áreas protegidas y los territorios indígenas enfrentan renovadas, crecientes y nuevas amenazas relacionadas con proyectos desarrollistas de gran escala y la expansión del "extractivismo". Frente a estas amenazas, los movimientos indígenas de la Amazonía han demostrado suficientemente su compromiso tanto con la conservación de sus propios territorios como, en muchos casos, de las áreas protegidas.

Desde la década de 1990, algunos programas nacionales de WCS que trabajan en la Cuenca Amazónica iniciaron su trabajo con comunidades ribereñas y pueblos indígenas. En el caso de Perú, en la región Tamshiyacu-Tahuayo, en Bolivia en el Paisaje Madidi con los pueblos indígenas Tacana, Lecos de Apolo, Lecos de Larecaja, T'simanes, Mosetenes y Puquina- Colla de la Marka Cololo - Copacabana - Antaquilla, y en el Paisaje Yasuní en Ecuador con comunidades kichwas, las Nacionalidades Waorani y Sápara en la Reserva de la Biósfera Yasuní.

Dos grandes líneas de trabajo destacan a lo largo de los 20 años: el apoyo a la gobernanza territorial y el manejo de los recursos naturales de base comunitaria. Este capítulo se organiza en cinco secciones, la primera refiere a la ruta crítica para la gestión territorial indígena que ha sido identificada a través de los estudios de caso, se define como la secuencia de procesos que resulta de los 20 años de experiencia de WCS y constituye una estrategia privilegiada para el fortalecimiento de la gobernanza y el manejo sostenible de los recursos naturales por las comunidades locales y los pueblos indígenas. Las subsecciones se organizan siguiendo esta ruta crítica.

La segunda sección trata de los hallazgos que, a la luz de las experiencias de los programas de WCS, enriquecen los principales conceptos del marco teórico de referencia. En la tercera sección se presenta una aproximación a los principios y valores que han guiado el trabajo de WCS con los pueblos indígenas y que deben continuar haciéndolo. La cuarta sección puntualiza los riesgos, dificultades y desafíos que, como tendencias, se han identificado a lo largo de la sistematización. Finalmente, en la quinta sección, se presentan las lecciones aprendidas organizadas según los temas tanto de la ruta crítica para la gestión territorial indígena como en relación a los marcos teóricos de referencia, a los valores y principios y a los riesgos, amenazas y desafíos. 


\section{UNA RUTA CRÍTICA PARA LA GESTIÓN TERRITORIAL INDÍGENA}

El fortalecimiento de la gobernanza para la conservación de base comunitaria de los programas de WCS estuvo referido al apoyo a la Gestión Territorial Indígena y el manejo de los recursos naturales tomando en cuenta los sistemas de organización multinivel de las organizaciones indígenas en los casos del Paisaje Madidi en Bolivia y el Paisaje Yasuní en Ecuador, y el manejo de recursos naturales con base en las instituciones de las comunidades ribereñas en el caso de Tamshiyacu - Tahuayo en Perú.

El análisis comparado de las acciones de apoyo de WCS a la gestión territorial indígena en los paisajes Madidi en Bolivia ${ }^{17}$ y Yasuní en Ecuador ${ }^{18}$ nos ha permitido reconstruir un conjunto de lineamientos de acción que, encadenados, constituyen una ruta crítica de acciones que permite alcanzar resultados para la conservación, el empoderamiento de las organizaciones indígenas, el mejoramiento de las condiciones y el bienestar de los pueblos indígenas y comunidades locales. Estos lineamientos son:

- Apoyar los procesos de consolidación de los derechos territoriales.

- Fortalecer las formas orgánicas propias de los pueblos indígenas.

- Apoyar la formulación de Planes de Gestión Territorial Indígena o Planes de Vida en un sentido de "abajo hacia arriba".

- Promover la zonificación de los Territorios Indígenas recogiendo las prácticas de uso actual y potencial de las comunidades.

- Facilitar la autorregulación considerando reglamentos formales, acuerdos comunales u otras formas.

- Promover el manejo de recursos naturales específicos en el marco de la Gestión Territorial.

- Apoyar el control y la vigilancia territorial.

- Desarrollar capacidades para la administración financiera.

- Desarrollar mecanismos de financiamiento sostenible.

- Desarrollar capacidades de monitoreo y sistematización de la gestión territorial y el manejo de los recursos naturales para informar la toma de decisiones por los pueblos indígenas y comunidades locales.

\section{TITULACIÓN Y/O RECONOCIMIENTO LEGAL DE TIERRAS COMUNITARIAS, TERRITORIOS INDÍGENAS O ANCESTRALES}

En relación con la gobernanza, en el marco de legislaciones agrarias particulares, en los tres países WCS ha apoyado la titulación o la regularización de las tierras, sean de 
comunidades campesinas - ribereñas como Tamshiyacu-Tahuayo en Perú, o territorios indígenas como en el Paisaje Madidi en Bolivia, o tierras comunitarias y territorios o reservas ancestrales como en el Paisaje Yasuní en Ecuador.

En el caso del Paisaje Madidi en Bolivia, WCS ha ayudado a diferentes organizaciones indígenas en la titulación de más de 700000 ha como Tierras Comunitarias de Origen. Una motivación común de las comunidades ribereñas y pueblos indígenas o nacionalidades con las que trabaja WCS en los tres países ha sido el reconocimiento de sus derechos a la tierra y a los territorios. El ejercicio de este derecho les ha conducido a reforzar, de propia iniciativa, el control del ingreso de foráneos a sus tierras y territorios.

\section{PLANIFICACIÓN TERRITORIAL}

En los paisajes Madidi y Yasuní en Bolivia y Ecuador respectivamente, el trabajo con pueblos indígenas se ha basado en el apoyo a la elaboración de Planes de Gestión Territorial o de Vida. En ambos casos, los procesos de planificación han partido del nivel comunal para pasar al nivel territorial, esto es particularmente notable en el caso del Paisaje Madidi donde el apoyo a la planificación comunitaria se ha basado en el principio de incluir a todas y cada una de las comunidades que constituyen los territorios indígenas. En el Paisaje Yasuní, este tipo de esfuerzo ha sido sistemático con seis comunidades kichwas que ocupan el área nororiental del Parque Nacional Yasuní, en el caso del territorio Waorani, se ha trabajado con algunas comunidades.

3

Debido a los sistemas de gobernanza de los pueblos indígenas y el dominio de sus territorios, para que los procesos de Gestión Territorial se consoliden y avancen, es necesario que desde la fase de la planificación participen todas y cada una de las comunidades que conforman el territorio. Los procesos de elaboración de los Planes de Gestión Territorial Indígena o de Vida no son procesos de investigación que pueden basarse en muestras estadísticas representativas de las comunidades, sino acuerdos sociales, por ello, es necesario comprender la importancia de que participen todas las comunidades de un territorio indígena. Asimismo, es necesario poner particular atención en promover la participación de sectores frecuentemente excluidos como las personas mayores, las mujeres y la juventud.

De la experiencia de los paisajes Yasuní y Madidi en Ecuador y de Bolivia, se puede identificar 14 pasos operativos para facilitar los procesos de elaboración de los planes comunitarios de manejo territorial: 1 . Acuerdos con las organizaciones matrices para llevar adelante los procesos de planificación. 2. Constitución de equipos técnicos con balance entre profesionales de la ONG y las personas delegadas por la organización indígena. 3. Diseño de la metodología tomando en cuenta técnicas participativas. 4. Convocatoria amplia y adecuada a las comunidades y personas que las componen para participar en los talleres de planificación participativa. 5. Talleres para el acopio de la información en cada comunidad. 6. Procesamiento y análisis de la información (preferiblemente en la misma comunidad). 7. Segunda ronda o segunda fase de los talleres de validación de la información y facilitación de la formulación de los planes comunales. 8. Revisión y corrección de los planes incluyendo las observaciones de los comuneros. 9. Entrega del plan a la comunidad y apoyo para su difusión. 10. Procesamiento de la información de todas las comunidades. 11. Formulación del plan a nivel territorial. 12. Validación y aprobación del plan de gestión territorial o plan de vida por las instancias orgánicas de los pueblos indígenas. 13. Difusión del plan en cada una de las comunidades que constituyen el territorio. 14. Presentación del plan por la comunidad al Ministerio del Ambiente para su aprobación (exclusivamente en el caso de Ecuador, debido a su legislación particular). Tanto en el caso de Bolivia como de Ecuador destacan la incorporación de las personas líderes del nivel territorial junto con los equipos técnicos de WCS para los procesos de planificación, al igual que para los de titulación o demarcación de los territorios indígenas y 
de autorregulación. Esta condición contribuye a fortalecer la gobernanza y las identidades étnico/culturales al incentivar los canales de comunicación entre los líderes indígenas y sus bases comunitarias y entre las comunidades, importante en el contexto de la dispersión de los asentamientos indígenas en la Amazonía.

Principalmente, en los procesos de planificación pero también en los demás procesos que contribuyen a la ruta crítica de la Gestión Territorial, la visión de que las organizaciones se representan en sistemas anidados que van desde los individuos, asociaciones, comunidades y entidades del nivel territorial ha sido de particular utilidad para un sistema coherente de planificación como parte del sistema de gobernanza.

\section{MAPEO, ZONIFICACIÓN Y ORDENAMIENTO DEL USO DE LA TIERRA}

El ordenamiento de las tierras bajo procedimientos participativos tomando en cuenta los diversos tipos de uso de los recursos naturales, actuales y potenciales, de las comunidades y la vocación de los suelos también ha sido común en los tres países. En este punto es compartida la consideración de un gradiente de usos que van desde la designación de tierras de máxima protección relacionadas con las áreas protegidas hacia usos menos y más intensivos. Esta constituye una estrategia que busca tender un puente entre la conservación de las áreas protegidas y el desarrollo sostenible de las poblaciones locales.

En el caso de Bolivia, durante el proceso de la zonificación, fue particularmente útil una herramienta denominada "matriz de compatibilidad de usos". Esta herramienta no solo permite a las comunidades asignar más de un único uso a una determinada zona sino, adicionalmente, determinar aquellos usos que son compatibles tomando en cuenta diferentes grados de condicionamientos relativos al manejo para asegurar la sostenibilidad. Por ejemplo, un área de uso forestal maderable, designada por una comunidad, puede ser compatible con el uso forestal de productos no maderables, designada por otra comunidad, siempre y cuando ambas actividades se realicen con base en planes de manejo. De esta manera, la herramienta ha permitido resolver conflictos de uso entre comunidades, y entre los territorios indígenas y el PNANMI Madidi; simultáneamente, la asignación de diferentes usos a una misma zona asegurando su compatibilidad hace que el ordenamiento sea flexible y adaptable a las necesidades de las comunidades.

Principalmente en el caso del Paisaje Yasuní pero también en el del Paisaje Madidi, los procesos relacionados con el ordenamiento de las tierras en función del acceso y el uso se han caracterizado por la capacitación de personal técnico de las propias organizaciones indígenas y comunidades, incluyendo, en el caso del Paisaje Yasuní, el diseño de un programa de capacitación básica en técnicas del mapeo participativo y en el manejo de sistemas de información geográfica. Esta estrategia ha sido posible gracias al destacable interés de los pueblos indígenas por la información geográfica y ha permitido que se diversifiquen los usos del mapeo a diferentes fines según las necesidades de las organizaciones indígenas y sus comunidades.

De esta manera, las personas capacitadas han podido prestar servicios a sus territorios y comunidades en la delimitación cartográfica y la demarcación, proporcionando información técnica para los procesos de titulación y reconocimiento legal de las tierras y territorios, al monitoreo de los sistemas control y la vigilancia territorial, a la formulación e implementación de planes de manejo de recursos naturales específicos con fines domésticos y de comercialización y a la administración de conflictos. 
Un tercer elemento caracteriza el trabajo en los tres países, se refiere al apoyo para el establecimiento de sistemas de autorregulación para el acceso y uso de los recursos naturales por las propias comunidades y sus entidades territoriales. Particularmente demostrativo en los casos del Paisaje Madidi en Bolivia y la región de Tamshiyacu Tahuayo en Perú, es que la iniciativa de establecer reglas de uso y acceso a los recursos naturales surgió como una urgente necesidad de las comunidades por restringir el acceso y el uso a no residentes, provenientes mayormente de los centros urbanos cercanos o de otras áreas, que ingresaban a los territorios y extraían los recursos ilimitadamente. Las comunidades sintieron la presión al ver reducir los recursos de los cuales dependían para satisfacer sus necesidades.

Mientras que en el Paisaje Madidi en Bolivia se ha facilitado la elaboración de reglamentos formales (escritos y publicados) que definen con claridad a los sujetos de los derechos y deberes, las prácticas permitidas y no permitidas según cada tipo de recursos y según su destino para la subsistencia o para la comercialización y como parte de estos reglamentos se incluye la zonificación, en el Paisaje Yasuní en Ecuador las reglas se refieren solo a las zonas de uso y las prácticas permitidas o no permitidas en cada una de ellas.

En Perú las comunidades de Tamshiyacu - Tahuayo han desarrollado un sistema de acuerdos comunales e intercomunales que se plasman en los libros de actas de cada comunidad. Los acuerdos allí consignados refieren a cuotas de extracción para diferente tipo de recursos naturales e instruyen sobre las prácticas de cómo deben extraerse los recursos sosteniblemente. Estos acuerdos constituyen verdaderos planes de manejo de los recursos naturales que funcionan de una manera bastante autónoma y son de bajo costo.

El funcionamiento de los acuerdos en las comunidades involucradas en la conservación de Tamshiyacu - Tahuayo contrasta con la historia de la legislación estatal relacionada con los recursos naturales renovables, que históricamente ha tendido a ser codificada, sumamente compleja pero con vacíos y superposiciones, demostrando grandes dificultades en su aplicación tanto en las ciudades como en el área rural al tratar de controlar a decenas sino cientos de pequeños extractores ilegales.

Considerando las características de las reglas de acceso a los recursos del bien común que aseguran la sostenibilidad en el uso de los recursos naturales, las demarcaciones territoriales y las zonificaciones contribuyen a la definición de los límites del recurso. Los reglamentos de uso en el caso de Bolivia han incidido en clarificar a los sujetos del derecho, en menor medida los acuerdos comunales de Perú, y en el caso del Ecuador no se ha incidido en este aspecto. En los tres casos las reglas son claras, siendo mucho más detalladas en los casos del Paisaje Madidi (Bolivia) y Tamshiyacu - Tahuayo (Perú) que en el del Paisaje Yasuní (Ecuador). Las posibilidades de cambio de las reglas están más expeditas en el caso de Tamshiyacu - Tahuayo que en los otros dos.

En los tres paisajes se han hecho esfuerzos para que los sistemas de monitoreo nutran las regulaciones con el fin de asegurar un aprovechamiento de recursos naturales sostenible. Sin embargo hay indicios de que la vinculación entre monitoreo y toma de decisiones ha sido más estrecha en el caso de las comunidades de Tamshiyacu - Tahuayo, tanto en relación al uso de recursos naturales para la subsistencia como para la comercialización en pequeña escala. En el Paisaje Madidi ocurre esto mismo para los recursos naturales que se comercializan. En el Paisaje Yasuní, las reglas comunitarias plasmadas en los planes comunitarios y su zonificación aún son de un carácter muy general.

Para las comunidades ribereñas del Área de Conservación Regional Comunal Tamshiyacu Tahuayo (ACRCTT), los acuerdos gozan de extraordinaria legitimidad, las reuniones comunales y sus libros de actas son el espacio y el instrumento privilegiado en el que 
dichos acuerdos se toman y se plasman. La característica más notable de estos acuerdos es que son altamente flexibles y facilitan el ajuste periódico y adaptación para el manejo según el estado de las especies y las necesidades comunales.

Si se consideran las diferencias entre las reglas de naturaleza racional con arreglo a fines que mayormente los mismos pueblos indígenas están adoptando tanto en Madidi como Yasuní, y las reglas de carácter tradicional basadas en la costumbre y la religión que han regido la vida de los pueblos indígenas hasta que por los cambios culturales dejaron de ser efectivas, los acuerdos tal como están funcionando en Tamshiyacu - Tahuayo, constituyen una forma intermedia que probablemente facilitaría la conciliación entre ambas tradiciones jurídicas.

\section{MANEJO DE RECURSOS NATURALES}

También de manera importante, en los tres países se ha apoyado el desarrollo de emprendimientos basados en el manejo de recursos naturales bajo regímenes de acceso común. Basada en las demandas de las comunidades, expresadas en los Planes de Gestión Territorial o Planes de Vida y con un enfoque de cadena productiva y de mercado, WCS en Bolivia ha impulsado 27 asociaciones comunitarias de manejo de recursos naturales entre los tacanas y los lecos de Apolo. Además, en este caso, destaca la diversidad de recursos naturales que contribuyó a manejar en los territorios indígenas: cacao silvestre y cultivado bajo sistemas agroforestales, café, madera, turismo, cacería, pesca, pieles y carne de lagarto, mieles nativas, artesanías, incienso, jatata, huertos, pequeños animales domésticos y ganadería mayor.

En Perú destaca el manejo comunitario de recursos naturales vinculados con la cacería, la pesca y el uso de una diversidad de palmeras, con énfasis en cuotas y contribuciones económicas de los usuarios por el aprovechamiento tanto para el consumo como para la comercialización.

Coincidentemente, en los tres países se ha apoyado iniciativas de turismo comunitario y apoyo a las mujeres en el campo de la producción de artesanías. El estudio detallado del uso de los recursos naturales por las comunidades permitió establecer un conjunto de medidas para hacer posible la conservación basada en el uso de los recursos naturales:

1. Establecer zonificaciones de los territorios o áreas comunales basadas en el uso de los recursos naturales considerando una gradiente en los niveles de uso que va desde zonas de protección estricta, zonas de uso para la subsistencia y zonas de asentamiento y uso intensivo.

2. Mantener o aún reducir los niveles de cosecha de las especies de silvestres cuyo aprovechamiento se encuentra en niveles sostenibles, suspendiendo el aprovechamiento de otras especies que están siendo sobreexplotadas.

3. Mantener los niveles de pesca considerando las acciones de control y manejo establecidas por las comunidades.

4. Introducir prácticas de manejo de palmeras: a) suspender las prácticas de tumba de los árboles, b) suspender la recolección de frutos para asegurar la provisión a la fauna silvestre y la dispersión de semillas en las zonas silvestres, c) promover el cultivo de palmas útiles en las chacras en tierras privadas próximas a los caseríos.

5. Promover un uso más sostenible de la madera a través de la introducción de programas de manejo de los bosques naturales. 
En el caso de Ecuador se intenta el encadenamiento de sectores productivos diferentes como el turismo comunitario con el manejo de las charapas (tortugas de río) (Podocnemis unifilis y Podocnemis expansa), con la producción y venta de artesanías, y con la acuicultura.

El estudio de los sistemas económicos basados en el uso de los recursos naturales de las comunidades ribereñas y pueblos indígenas en los tres casos muestra que estos sistemas económicos están basados en el acceso, uso y comercialización de una importante diversidad de recursos naturales. Esta característica hace que los sistemas económicos sean resilientes a diferentes tipos de crisis económicas, ambientales, relacionadas con el cambio climático, etc. De ahí la importancia de considerarlos en su integralidad cuando se promueve el manejo de recursos específicos u otras medidas de conservación.

Del mismo modo que la diversidad en el acceso y el uso de los recursos es una característica de los sistemas económicos de los hogares ribereños e indígenas, también les es inherente la articulación de las esferas de la "reciprocidad" y el "mercado". El enfoque interpretativo de las "esferas económicas" de la "reciprocidad" y el "mercado" permite analizar las experiencias de manejo de los recursos naturales en los tres países.

En Bolivia, Ecuador y Perú, WCS trabaja para asegurar la conservación de una base de recursos naturales que se relacionan principalmente con el uso doméstico de los hogares ("esfera de la reciprocidad"), asegurando la provisión de proteínas a través de la cacería y la pesca o el acceso sostenible a otro tipo de recursos como los frutos de palmas y otros. Adicionalmente, cada país ha puesto énfasis en una u otra esfera.

En el caso de Bolivia, WCS ha desarrollado esfuerzos por asegurar el manejo sostenible de especies para la subsistencia y otras con orientación a la esfera del mercado como: lagartos, cacao, incienso, turismo, madera, mieles silvestres y otros. En esta orientación de mercado destaca muy claramente el apoyo con un enfoque de cadena productiva. En este campo, sus acciones pueden sistematizarse en la siguiente ruta crítica:

1. Demanda o consulta a las organizaciones y comunidades interesadas.

2. Estudios de la distribución, densidad y estructura de las poblaciones silvestres y su ecología, aspectos socioeconómicos y culturales, y sondeos de mercado.

3. Análisis de los resultados con las comunidades involucradas.

4. Apoyo al proceso de organización de asociaciones comunitarias (bajo diferentes modalidades según el tipo de recurso).

5. Elaboración de los planes de manejo y acompañamiento a las asociaciones para gestionar su aprobación ante las entidades estatales competentes.

6. Asistencia en servicio y capacitación técnica tanto en las labores de cosecha como de poscosecha según el tipo de recurso/producto y de acuerdo a las exigencias del mercado, así como en aspectos administrativos, contables, de comercialización y monitoreo.

7. Identificación de nichos de mercado caracterizados por sus altos precios y responsabilidad social.

8. Diseño, establecimiento y apoyo en la implementación de sistemas de monitoreo.

9. Promoción del intercambio de experiencias entre productores y productoras. 
En el otro extremo, el caso de Perú donde, si bien se han desarrollado esfuerzos para la comercialización de las pieles de pecarí, el manejo, a través de los acuerdos comunales, el sistema de cuotas y el enriquecimiento de los sistemas agroforestales con especies de palmas nativas, inciden fundamentalmente en la esfera de la reciprocidad o del uso doméstico de los hogares, pero en parte también en la esfera del mercado.

Finalmente, Ecuador con el apoyo al turismo comunitario y a la producción de artesanías se orienta más a reducir la presión sobre las poblaciones silvestres buscando alternativas económicas para las comunidades sea compensando recursos utilizados para la subsistencia (por ejemplo, el apoyo a la crianza de animales menores o a la piscicultura) o para la generación de ingresos monetarios.

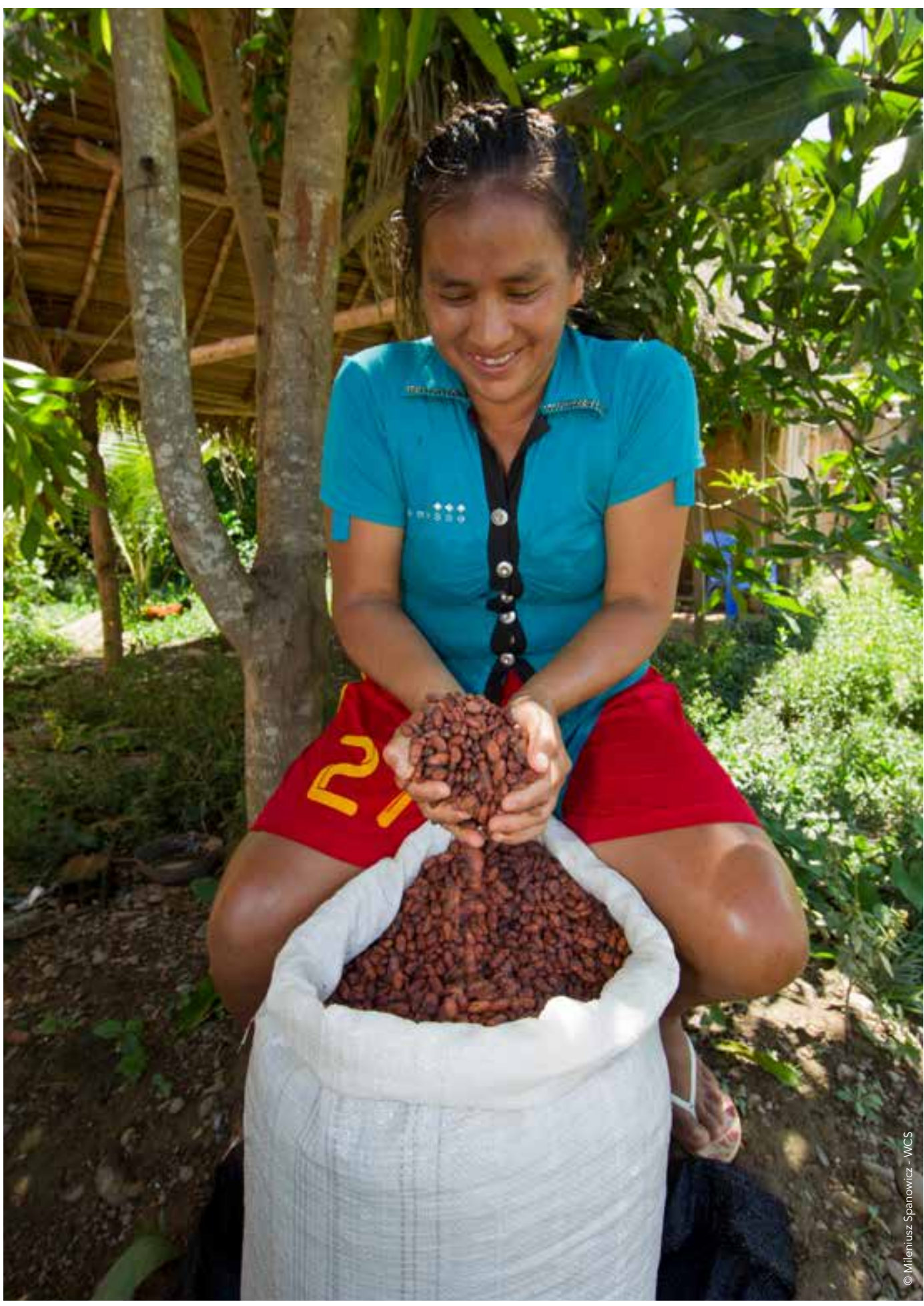




\section{APOYO A LOS SISTEMAS DE CONTROL Y VIGILANCIA DE LOS RECURSOS NATURALES EN ÁREAS COMUNALES, TERRITORIOS INDÍGENAS Y SU RELACIÓN CON LAS ÁREAS NATURALES PROTEGIDAS}

En el caso de Bolivia, tanto en la TCO Tacana como en Lecos de Apolo se han realizado acciones relacionadas con la demarcación, el control y la vigilancia de los territorios indígenas, con la finalidad de controlar las invasiones de tierras y la extracción ilegal de los recursos naturales. Estas acciones al principio fueron reactivas, mediante denuncias de las comunidades o asociaciones productivas. Posteriormente, gracias al proceso de demarcación de los territorios indígenas, al fortalecimiento de capacidades en el manejo de Sistemas de Información Geográfica y cuantificación de los recursos ilegalmente extraídos, y ajustes en las estructuras orgánicas, las acciones de control y vigilancia se tornaron más proactivas, realizadas de oficio a través del patrullaje. En este quehacer, destacan los acuerdos entre las organizaciones indígenas y la Dirección del PNANMI Madidi. A pesar de estos avances, no se ha logrado constituir un sistema de control y protección que asegure las acciones de manera sistemática, constante y de largo plazo.

En Ecuador, destaca el intento por establecer un sistema integrado de control y protección a nivel de la Reserva de la Biósfera Yasuní contando con guardaparques del Parque Nacional Yasuní y guardaparques comunitarios a nivel de comunidades y territorios indígenas. Acompaña a este intento el diseño de un programa de capacitación para ambos tipos de guardaparques. Sin embargo, mientras que el sistema del guardaparques del Parque Nacional Yasuní funciona de alguna manera, no ha sido posible concretar el sistema integrado para el área protegida y las áreas comunales, excepto en aquellas porciones sobrepuestas, donde actúan guardas provenientes de las comunidades que forman parte del sistema de protección del Parque Nacional Yasuní, quedando relativamente desprotegidos los territorios comunales fuera del parque.

En Tamshiyacu - Tahuayo, Perú, el sistema de protección basado en las comunidades funciona con guardas y turnos de los hogares de las comunidades, que realizan patrullajes y el control en puestos (garitas) ubicados en los sitios clave de acceso a la zona. Varios miembros de cada hogar participan en estos turnos, que duran veinticuatro horas en tiempo de ascenso de los ríos y se reducen a ocho horas cuando los ríos se vacían. Además, se cuenta con el apoyo de un puesto de la policía nacional. Con sus dificultades, éste constituye el sistema más exitoso.

En los tres casos, el mayor desafío es el financiamiento sostenible para el funcionamiento de los sistemas de control y vigilancia territorial. Por ejemplo, en el caso de Perú, el funcionamiento del sistema de protección se basa económicamente en la contribución de una parte de los cobros por las cuotas de cacería, en la provisión de alimentos que son asignados o donados en parte por el Gobierno Regional de Loreto y en parte por las organizaciones no gubernamentales que trabajan en la zona, y en contribuciones de las empresas de turismo que operan en la zona; estas contribuciones son sin embargo aún insuficientes.

\section{FORTALECIMIENTO DE CAPACIDADES ADMINISTRATIVAS Y BÚSOUEDA DE FUENTES DE FINANCIAMIENTO SOSTENIBLE}

Tanto en Ecuador como en Bolivia, destacan los esfuerzos por la búsqueda de sostenibilidad financiera para el funcionamiento de la gestión territorial indígena, un aspecto que, a pesar de los esfuerzos realizados aún no se ha logrado concretar. En esta perspectiva, en ambos países también destacan los esfuerzos por construir capacidades administrativas y financieras tanto al nivel de las organizaciones territoriales de los pueblos indígenas como de asociaciones productivas basadas en el manejo de los recursos naturales. 
Bolivia y Ecuador han invertido esfuerzos apoyando para que las comunidades y sus organizaciones puedan obtener recursos financieros de los sistemas nacionales de incentivo por la conservación de los bosques, en el marco de las políticas específicas de los Estados nacionales. Asimismo, en ambos países se ha apoyado de alguna manera para que los territorios indígenas pudieran constituir jurisdicciones que permitiesen a sus organizaciones asumir nuevas responsabilidades y también fondos públicos. Hasta ahora, ninguna de estas estrategias ha logrado consolidarse y el financiamiento sostenible para la gestión territorial indígena constituye aún uno de los mayores desafíos.

En ambos países, el fortalecimiento de las capacidades administrativas ha estado acompañado por la suscripción de sub-acuerdos de financiación, la capacitación y asistencia en servicio, la contratación de personal administrativo y contable idóneo para trabajar con las organizaciones indígenas y el desarrollo de sistemas incluyendo el diseño de manuales administrativos y contables adecuados a las condiciones de los pueblos indígenas, y la promoción de auditorías técnicas y financieras como un hábito entre las organizaciones indígenas. Uno de los retos importantes en este campo es que todos los fondos que manejan las organizaciones indígenas sean administrados bajo un solo sistema administrativo que facilite el control interno y la transparencia. Este aspecto encuentra dificultades cuando cada entidad financiera exige sistemas administrativos separados para cada fuente de financiamiento. Este criterio también es utilizado por las organizaciones en relación a sus ingresos propios.

Una contribución importante del pueblo Tacana y de WCS en Bolivia para la construcción de un modelo organizativo con vocación de transparencia es la combinación de dos elementos fundamentales. El primer elemento es un modelo que articula los diferentes niveles orgánicos de las organizaciones indígenas a través de la distribución de porcentajes de las utilidades netas que generan las asociaciones productivas, definidos de manera diferenciada para las personas individuales que son socias del emprendimiento, el propio emprendimiento, la comunidad o las comunidades que tienen dominio sobre las áreas donde se distribuyen los recursos naturales aprovechados, y la organización matriz representativa del conjunto de las comunidades que constituyen el territorio. El segundo elemento es la separación de las funciones de control y de representación socio-política (comunal y territorial) de aquellas funciones gerenciales exclusivas de las asociaciones productivas.

Acompaña a este sistema la creación de un fondo concursable administrado por CIPTA con el apoyo de WCS para que las comunidades presenten ideas de proyectos de manejo sostenible de los recursos naturales. El funcionamiento de este fondo ha requerido la construcción participativa de un concepto de sostenibilidad y de la identificación de sus principios y criterios, basados en la cultura y la experiencia del pueblo Tacana. Entre otros, este fondo concursable tiene como fin reducir la discrecionalidad en la otorgación de fondos a las comunidades y así preservar la legitimidad y la representatividad del Directorio del CIPTA.

En Perú, en el caso de Tamshiyacu - Tahuayo, las comunidades de la región determinaron que una parte de los cobros recaudados por las cuotas de cacería y del uso de los otros recursos se destinaran al funcionamiento de su sistema de control y protección. Sin embargo, los ingresos recaudados no son suficientes para asegurar su funcionamiento por todo un año. De esta manera, han tenido que recurrir a la donación de alimentos por el Gobierno Regional y las instituciones no gubernamentales que trabajan en la zona. Como resultado, una parte del funcionamiento es sostenible, en parte gracias a la mayor orientación de las comunidades del Tamshiyacu - Tahuayo al mercado y su mayor acceso a ingresos monetarios.

Aunque los costos de control y vigilancia en sistemas comunales organizados por hogares cumpliendo turnos parecieran ser menores que los sistemas basados en guardas 
especializados, en realidad se trata de una transferencia de los costos de la protección a los hogares y la carga en términos de tiempo es pesada para hogares que viven al día. Estos costos requieren ser compensados de alguna manera. Frente a esta problemática, al igual que en los casos de Bolivia y Ecuador, WCS en Perú y las comunidades implementaron estrategias tales como solicitar que el ACRCTT fuera incluida en el presupuesto de gestión del SINANPE, lo que no prosperó, o el cobro de contribuciones a las empresas que tienen albergues turísticos en la zona. Lo que es importante destacar es que en la búsqueda de alternativas financieras para el funcionamiento de sus sistemas de gobernanza, las comunidades, asociaciones productivas y autoridades de los niveles territoriales, toman iniciativas.

En el caso de Tamshiyacu - Tahuayo, el fortalecimiento de las capacidades administrativas parece haberse restringido al diseño e implementación de procedimientos y mecanismos que a su vez coadyuvan en el control de la extracción de los recursos, tal como la extensión de recibos contra el pago de las cuotas de cacería u otros recursos y el registro de los cazadores y recolectores que llevan sus productos para vender a lquitos. En la evaluación de la gobernanza realizada en las comunidades de esta zona, no se registraron muchos reclamos en sentido de que los fondos recaudados estén siendo utilizados para otros fines.

Como se observa, en los tres casos, a pesar de los avances y esfuerzos, uno de los desafíos más importantes continúa siendo el financiamiento sostenible para los procesos de conservación, la gestión territorial y el manejo de los recursos naturales por las comunidades.

\section{LA INVESTIGACIÓN Y EL MONITOREO PARA LA TOMA DE DECISIONES DE LAS COMUNIDADES Y LAS ORGANIZACIONES INDÍGENAS}

Los estudios de caso indagados en esta sistematización muestran que el establecimiento de medidas de conservación en tierras comunales y territorios indígenas se ha basado en alianzas entre las poblaciones locales e investigadores ligados a la conservación. Esta relación no ha sido fácil de construir. En la comunidad científica dedicada a la conservación existe una tensión entre quienes apuestan porque es posible y absolutamente necesario que la población local se haga cargo de la conservación en el largo plazo y quienes desconfían de la posibilidad de que las poblaciones locales se orienten hacia la conservación constituyéndose en actores principales de esta labor.

Los casos aquí indagados demuestran, que es posible que las comunidades locales y pueblos indígenas no solo estén comprometidos con la conservación sino dispuestos a llevarla adelante. Sin embargo, se requieren una serie de condiciones, entre las más importantes: seguridad en relación a los derechos de las comunidades y pueblos indígenas sobre sus tierras y territorios, apoyo técnico de largo plazo en términos de información científica adecuada, oportuna y basada en el reconocimiento y el respeto por los saberes locales, y la asistencia técnica con un enfoque de fortalecimiento de las capacidades locales; así como el reconocimiento y el apoyo del Estado para sus iniciativas de uso sostenible y conservación.

En el caso de Tamshiyacu - Tahuayo, acciones sociales de cuatro sectores confluyeron para el establecimiento de la Reserva y su conservación: 1) las comunidades locales, 2) organismos estatales, 3 ) organizaciones no gubernamentales que realizaban actividades de extensión en la zona y 4) un importante número de investigadores que se encontraban trabajando en la zona. 
o nacionalidades. Para que estos acuerdos sean alcanzados y sostenidos a lo largo del tiempo, se requiere que sean razonables, aceptables para la población local. El mayor desafío desde la ciencia de la conservación es ayudar a establecer esa razonabilidad en términos del equilibrio entre la permanencia de los recursos naturales en el largo plazo y las necesidades de los hogares y las comunidades. Una de las claves para que las negociaciones arriben a acuerdos razonables está en la información científica detallada sobre cada una de las especies de la amplia gama que las comunidades utilizan y sobre las interrelaciones de estas con otras especies o recursos. Como mostró el caso de Tamshiyacu - Tahuayo, mientras se realizaba una prohibición estricta del acceso a los foráneos, se establecían cuotas buscando un balance entre las especies menos reproductivas y más vulnerables con aquellas más reproductivas y menos vulnerables.

La investigación sobre la vida silvestre es una de las mayores fortalezas de WCS en los tres países y ha precedido los procesos de gestión territorial y de manejo de los recursos naturales. Al mismo tiempo, en mayor o menor medida, busca informar a las comunidades y organizaciones indígenas para la toma de decisiones sobre el acceso y el uso de los recursos naturales. El tránsito entre la producción participativa de la información del monitoreo, su análisis y la devolución de los resultados a las comunidades para su uso en la toma de decisiones, demanda atención en términos de las habilidades comunicativas de los investigadores, los procedimientos e instrumentos pedagógicos para lograrlo. Los sistemas de automonitoreo del uso de la vida silvestre enfrentan el desafío de los incentivos y del cansancio de los "monitores comunitarios" que realizan la tarea de registro durante varios años consecutivos.

Aunque WCS desarrolla investigaciones sobre distintos aspectos de la vida silvestre, un conjunto de ellas se caracteriza por la articulación de dos elementos que sustentan el manejo: la investigación sobre las poblaciones de vida silvestre y su ecología, y el uso que de ellas realizan las poblaciones locales, se combinan para lograr una comprensión integral de las necesidades del manejo de la vida silvestre. Del mismo modo, esta lógica de articulación, es observable en el uso del enfoque "fuente" - "sumidero" así como en el descubrimiento de los corredores biológicos entre unidades de gestión diferentes.

Aquí es importante destacar la necesidad de comprender que en vistas de que la conservación sea realizada en el marco del paradigma de "conservación por la gente", los procesos de investigación requieren ser participativos. La formación de "para-biólogos" comunitarios fue un intento de WCS en Ecuador en alianza con entidades académicas que merecería profundizarse, buscando incluso la acreditación de los comuneros (mujeres y hombres) involucrados. En este mismo sentido, en los tres países, WCS ha desarrollado sistemas de automonitoreo de la cacería y la pesca por miembros de las comunidades. La experiencia acumulada en este campo merecería una sistematización específica, la profundización de los intercambios de experiencias entre el personal técnico de WCS que trabaja en el campo, junto a otros de otras instituciones y sobre todo entre comuneros. La producción de materiales didácticos para el registro de las especies constituye otra fortaleza de estos sistemas de automonitoreo. 


\title{
EXPERIENCIAS Y REFLEXIÓN EN TORNO A LOS MARCOS TEÓRICOS Y ÉTICOS PARA EL TRABAJO DE CONSERVACIÓN "POR" LAS POBLACIONES LOCALES
}

\author{
LA CONSTRUCCIÓN DE REDES SOCIALES TIPO "VÍNCULO": EL \\ FORTALECIMIENTO DE LAS ORGANIZACIONES INDÍGENAS, COMUNITARIAS Y \\ DE LAS MUJERES INDÍGENAS
}

Los procesos de titulación de las tierras comunitarias y de los territorios indígenas o ancestrales, la formulación de los planes de gestión territorial o planes de vida, el ordenamiento de las tierras, la autorregulación, la demarcación, el control y vigilancia de los territorios constituyeron estrategias importantes para asegurar el uso sostenible y la conservación en los tres países. Sin embargo, por la forma cómo estas acciones fueron desarrolladas, con un enfoque de "abajo" hacia "arriba", generando espacios de comunicación entre las comunidades y de estas con sus líderes de las organizaciones matrices o de segundo nivel, es posible señalar que los procesos fundamentalmente coadyuvaron a construir o fortalecer redes sociales orgánicas horizontales y verticales de tipo "vínculo" y que estas redes fueron determinantes para asegurar que los instrumentos de gestión territorial, de conservación y manejo sostenible de los recursos naturales no sean solo documentos sino que se constituyan efectivamente en "acción social" o "hechos sociales". A esto contribuyó también el acompañamiento a la implementación de los Planes de Gestión por varios años consecutivos.

El caso de los tacanas y lecos de Apolo en el Paisaje Madidi fue claramente demostrativo del papel de fortalecimiento de las redes horizontales y verticales de tipo "vínculo" en el fortalecimiento de las identidades étnico-culturales indígenas. Este es un proceso mediante el cual, los pueblos indígenas buscan distinguirse de "otros" de su entorno social y en este quehacer han puesto el énfasis en una suerte de vocación hacia la conservación y en el acceso colectivo a la tierra. Dos razones priman en ello: su alta dependencia de los recursos naturales de su entorno y el temor de perder las tierras cuando esta es otorgada individualmente.

Mientras en Bolivia y Ecuador, el fortalecimiento de las relaciones verticales de tipo vínculo se realiza entre las comunidades y las organizaciones matrices representativas de los pueblos indígenas, en el caso de Perú, el Comité de Gestión de la Reserva Tamshiyacu - Tahuayo, basado fundamentalmente en comunidades ribereñas, se ha constituido en una entidad comparable, al representar a las comunidades ante el Estado cumpliendo una función de articulación entre el Estado y las comunidades en relación a los asuntos del uso de los recursos naturales y la conservación. Sin embargo, otras demandas de las comunidades como las relativas a la salud, educación, servicios básicos y otras no parecen haber encontrado canales orgánicos expeditos para su representación y procesamiento. La experiencia de la creación de la ACRCTT puso en evidencia que los espacios de encuentro informal como los transportes públicos, las tiendas y las reuniones en domicilios particulares fueron los escenarios informales en los que se gestó el diálogo y la articulación de una red social capaz de establecer las medidas de conservación y luego demandar al Estado la creación de un área protegida (Reserva Comunal).

Si bien todas las acciones orientadas a fortalecer la gestión territorial y el manejo de recursos naturales contribuyen a la formación de líderes (hombres y mujeres), en los tres casos sistematizados se observan debilidades en la formación de líderes y lideresas, aspecto crítico para la sostenibilidad de los procesos desarrollados en el largo plazo. Particularmente importante es la atención que merecen las personas jóvenes que serán herederas de los territorios y sus recursos naturales. Solo en el caso de Ecuador se elaboró un programa específico de formación de líderes que, sin embargo, por razones financieras no pudo implementarse plenamente. 
En todos los casos aquí documentados, los sistemas organizativos tanto de las comunidades ribereñas como de los pueblos indígenas se han tenido que adecuar, por su propia decisión, para atender los desafíos del manejo sostenible de los recursos naturales y la conservación de sus territorios. En algunos casos creando nuevos cargos en las estructuras orgánicas, en otros casos ampliando las competencias de los cargos tradicionales o creándose nuevas organizaciones al interior de las comunidades. En esta dinámica un riesgo se hace presente: la proliferación de organizaciones o cargos especialmente en las comunidades puede terminar por confundir a sus miembros y debilitar las organizaciones existentes.

El fortalecimiento de las organizaciones de mujeres indígenas, desarrollado tanto por Bolivia como por Ecuador, demuestra que el apoyo a la producción y comercialización de sus artesanías y otras producciones que realizan, redunda en su empoderamiento y que desde esa dimensión económica ellas avanzan en el conocimiento y demandas de sus derechos específicos como mujeres y como integrantes de los pueblos indígenas.

Al mismo tiempo, la sistematización del trabajo en este ámbito muestra la delicadeza de las relaciones entre las organizaciones propias de las mujeres y de aquellas que representan al conjunto de un pueblo indígena o una nacionalidad, dominantemente representadas por hombres. En relación con este aspecto ha sido importante la participación de líderes de estas últimas organizaciones en los eventos de apoyo a las mujeres auspiciados por WCS, logrando mantener, sin embargo, espacios propios y autonomía en las decisiones que atañen a los intereses de las mujeres.
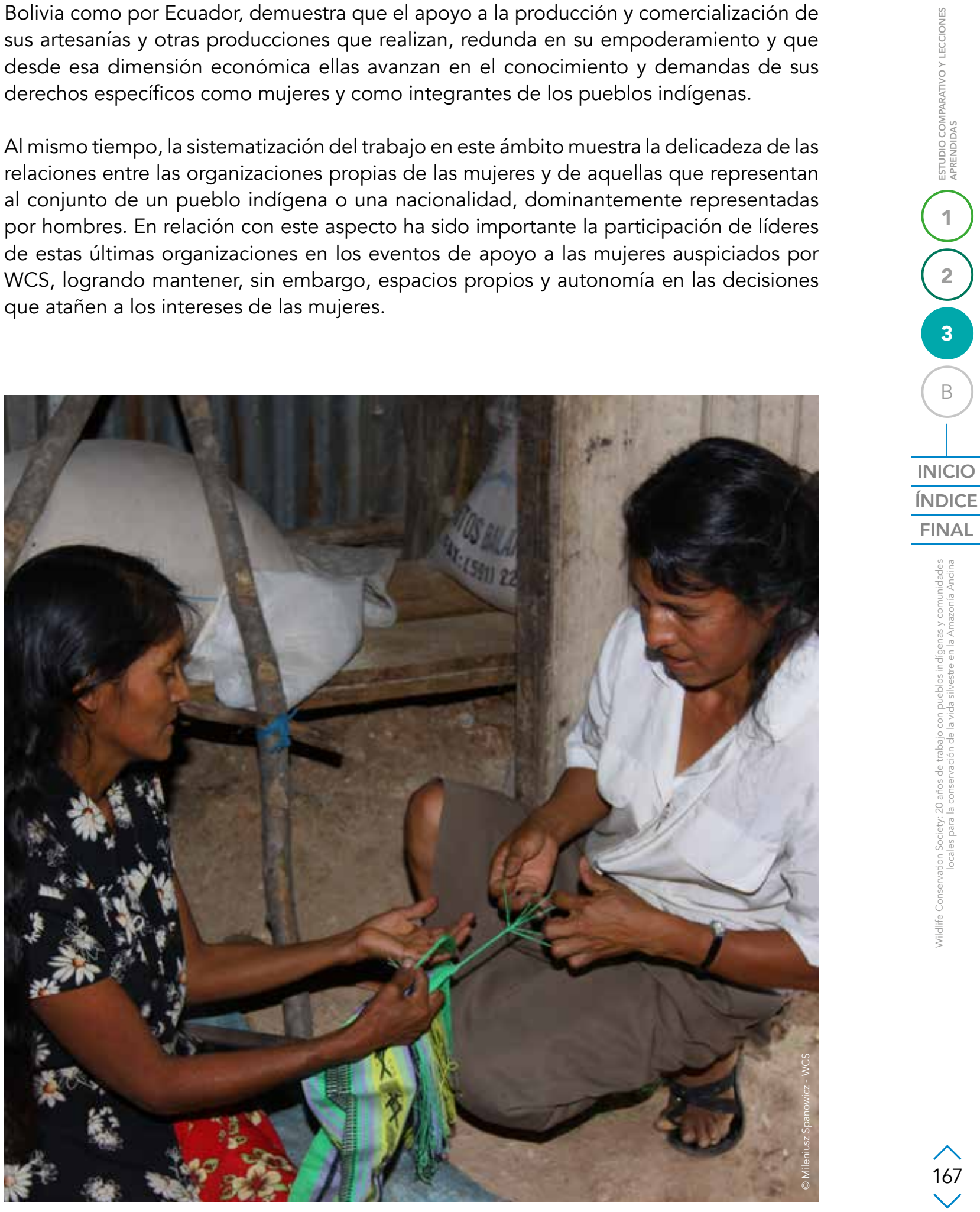


\section{LA CONSTRUCCIÓN DE RELACIONES SOCIALES DE TIPO "PUENTE" ENTRE LAS COMUNIDADES, LOS PUEBLOS INDÍGENAS Y EL ESTADO}

El enfoque de los "Paisajes Vivientes", propio de WCS, entendidos como "paisajes de oportunidad basados en la gobernanza de la biodiversidad y los recursos naturales para la conservación efectiva" tiene como finalidad asegurar la conservación de las "especies paisaje", aquellas que requieren mayores espacios, mayor diversidad de ecosistemas y conectividad entre ellos y así favorecen, además, la permanencia de las demás especies. Este propósito implica la inclusión de espacios mucho más amplios que las áreas protegidas. Esta delimitación de espacios más amplios conlleva el involucramiento de diferentes unidades de gestión: áreas protegidas de diversas categorías, territorios indígenas, áreas comunales campesinas y otras.

Mientras el apoyo a la construcción de procesos sociales basados en los instrumentos de gestión al interior de cada unidad de gestión, y especialmente en relación a los pueblos indígenas, implica el fortalecimiento de articulaciones sociales de tipo vínculo horizontales y verticales (entre grupos humanos semejantes) por ejemplo entre las comunidades, al interior del territorio tacana o leco de Apolo en Bolivia, o kichwa y waorani en Ecuador, o entre las comunidades ribereñas del Tamshiyacu - Tahuayo en Perú, la relación entre ellas y el Estado u otros actores sociales con jurisdicción o titularidad de derechos sobre la tierra en los grandes paisajes, demanda la construcción de otro tipo de relaciones sociales que se caracterizan por ser de tipo "puente" entre actores sociales diferentes, más difíciles de construir, más desafiantes pero imprescindibles para la conservación a nivel de paisajes.

Para el fortalecimiento o la construcción de este tipo de relaciones de "tipo puente", WCS ha desarrollado estrategias y acciones relativamente diferentes en cada país, marcadas también por las particularidades legales, en este caso, relativas a la permisividad en términos de la sobre posición de las áreas protegidas y territorios indígenas. En el caso de Bolivia, WCS desarrolló estrategias en dos niveles: 1) para conectar unidades de gestión en el paisaje a través de la conservación de corredores biológicos entre el PANNMI Madidi y la TCO Tacana I y 2) contribuyendo con la construcción de una propuesta de gestión compartida entre el Estado y las organizaciones indígenas tomando como punto de partida una extensa área sobrepuesta entre el territorio indígena Leco de Apolo y el PNANMI Madidi.

En ambos casos, ayudó el hecho de que WCS en Bolivia apoyó tanto a la Dirección del PNANMI Madidi como a las organizaciones indígenas para que tuvieran instrumentos de gestión relativamente comparables: planes de manejo con sus respectivas zonificaciones. De esta manera, ambas partes podían reunirse y analizar las diferencias y negociar cuando los usos propuestos por uno u otro para una misma zona eran distintos, llegando a buen término en las negociaciones. Además, se tuvo que encarar la problemática de la toma de decisiones para la gestión del área sobrepuesta en el largo plazo, intentando, en el marco de un precepto constitucional, que tanto las instancias competentes del Estado como la organización indígena se reconociesen en un mismo nivel de jerarquía y a partir de ello, se definieran competencias concurrentes, complementarias o exclusivas de cada entidad.

Puede señalarse que lo anterior fue posible debido a que WCS en Bolivia reconoce, entre el conjunto de actores sociales que se relacionan con el "Gran Paisaje Madidi", la relevancia de los Pueblos Indígenas y sus territorios para la conservación, con base en el reconocimiento de sus derechos territoriales preconstituidos $y$, a partir de esto, también el reconocimiento de la importancia del Estado a través del SERNAP en su relación con las áreas protegidas.

En Ecuador, la construcción de relaciones de "tipo puente" entre el Estado y las comunidades tiene un carácter más "vinculante" que deriva del contexto legal, en el cual, el reconocimiento de los derechos territoriales indígenas en las áreas protegidas depende 
del Ministerio del Ambiente. En este marco, WCS en Ecuador ha desarrollado experiencias, por un lado, para que el personal técnico del Ministerio participe en la formulación de los planes de manejo y zonificaciones de las comunidades sobrepuestas por el Parque Nacional Yasuní y, por otro lado, ayudando al Ministerio a promover que las comunidades participen en la actualización del Plan de Manejo del Parque realizada en 2011.

Del mismo modo, contribuyen a la relación de tipo "puente" los esfuerzos por establecer un sistema integrado de control y vigilancia a nivel de la Reserva de la Biósfera Yasuní, contemplando al cuerpo de guardaparques del área protegida así como a los guardaparques comunitarios, y adicionalmente el diseño e implementación de un programa de capacitación para guardaparques donde también han participado los delegados de las comunidades.

En Perú, a fines de los años 1980, fueron las comunidades del Tamshiyacu Tahuayo las que iniciaron las acciones de conservación, en circunstancias que la sobreexplotación de los recursos naturales había llegado a límites en los que estas se vieron en la necesidad de enfrentar el control de los recursos naturales de los cuales dependían para su consumo y generación de ingresos monetarios. Al establecimiento de sistemas de control comunal para evitar el ingreso de extractores provenientes de la ciudad de lquitos y el inicio del proceso de autorregulación le siguió la demanda al Ministerio de Agricultura para que estableciera una Reserva de Conservación Comunal.

A pesar de ello, las comunidades demostraron también desconfianza en los funcionarios estatales. Aquí, la posibilidad de construir una relación de tipo "puente" entre el Estado y las comunidades se logró a través del compromiso estatal de respaldar las acciones de control por las mismas comunidades frente al ingreso al área de no residentes para extraer los recursos naturales y se estableció que los funcionarios estatales recorrieran dos veces al año todas y cada una de las comunidades vinculadas a la ACRCTT. De manera importante, el establecimiento de un Comité de Gestión conformado exclusivamente por las comunidades ribereñas interesadas en la conservación de la Reserva, en ausencia de un sistema de organización formal que vincule a todas las comunidades entre sí, se ha constituido tanto en una instancia de interrelación entre las comunidades y al mismo tiempo de "puente" entre las comunidades y el Estado.

Como señaló Putnam (2003), mientras la construcción de relaciones de tipo "vínculo" entre semejantes ayuda a la solución de los problemas locales, la construcción de relaciones de tipo "puente" es más dificultosa pero contribuye a la construcción de la democracia. En este caso, son estas relaciones las que permiten conectar las unidades de conservación en los "grandes paisajes", pero igualmente, son las relaciones más complejas de construir o de fortalecer. En las relaciones entre el Estado y las comunidades locales o pueblos indígenas, las dificultades derivan de la complejidad del propio Estado, en su heterogeneidad interna y a sus relaciones múltiples con una amplia gama de actores de la sociedad, incluyendo aquellos que tienen intereses encontrados con los derechos indígenas o con la conservación.

La construcción de relaciones de tipo "puente" entre las comunidades locales y pueblos indígenas, y el Estado, precisamente por su dificultad, requiere de largos y continuos periodos de planificación, implementación, seguimiento, evaluación y complementación o adecuación. 


\section{LAS CONSTRUCCIONES TEÓRICAS Y CONCEPTUALES RELATIVAS A LA GOBERNANZA Y AL MANEJO DE LOS RECURSOS NATURALES POR LAS COMUNIDADES LOCALES Y PUEBLOS INDÍGENAS}

Las características diferentes de los grupos humanos con los que se trabaja en cada país y sus condiciones legales particulares, han determinado el desarrollo de marcos conceptuales y estrategias relativamente diferentes. En el caso de Bolivia y Ecuador, el trabajo con pueblos indígenas de la Amazonía, con sistemas de organización multinivel que van desde los hogares, las asociaciones comunitarias para el uso de los recursos naturales, las comunidades y los territorios mancomunados con sus diferentes niveles de representación que llegan a los niveles departamentales o provinciales y nacionales, han determinado que la gestión territorial indígena sea la mejor opción para la conservación en este tipo de unidades de gestión.

Desde un punto de vista teórico y conceptual, este enfoque implica el reconocimiento de los derechos indígenas a sus territorios en tanto propiedades colectivas, aparejado al reconocimiento y respeto a la gobernanza territorial y al derecho de autodeterminación de los pueblos. Esta visión, implica el fortalecimiento de la gobernanza a nivel comunal y permite escalar la conservación, basada en el manejo y el uso de los recursos naturales, hacia espacios muchos más amplios que las solas áreas comunales.

En cuanto al manejo de recursos naturales específicos, WCS en Bolivia responde a las necesidades de autoconsumo de las poblaciones indígenas y simultáneamente ha desarrollado un proceso de conceptualización y práctica basada en el enfoque de cadenas productivas con orientación de mercado. Asimismo, ha desarrollado y aplicado los enfoques de la gestión territorial indígena, de las "esferas económicas": de "la reciprocidad y del mercado" y de la "equidad social y de género". Estos desarrollos conceptuales, le han permitido comprender mejor la distribución de los ingresos económicos a nivel de los hogares, demostrando que la contribución de la conservación a la economía de los hogares es más visible cuando se consideran tanto los ingresos como los costos no monetarios (asimilados a la "esfera de la reciprocidad") y monetarios ("esfera del mercado"). WCS en Bolivia destaca la importancia de observar y monitorear la diversidad de fuentes de ingreso que caracteriza a los sistemas económicos de los pueblos indígenas amazónicos.

En el caso de Perú, desde 1990, las acciones se enfocan más en las áreas comunales, en el contexto de una zonificación del ACRCTT que toma como referencia los usos que realizan las comunidades más allá de sus áreas de asentamiento. WCS en Perú ha contribuido con un enfoque económico de las relaciones entre conservación y población local, basada en la experiencia de Tamshiyacu Tahuayo.

Este enfoque supone la racionalidad económica de la población local en el sentido de que mientras los recursos naturales tengan valor económico para esta, entonces, se encontrará más dispuesta a conservarlos. Sin incentivos económicos, la población local se inclinará más bien por actividades menos sostenibles. Esto significa que si se quiere alcanzar el paradigma de la "conservación por la gente", es imperativo que quienes promovemos la conservación debamos considerar el uso sostenible de los recursos naturales por la población local.

Lo anterior, conlleva el análisis sobre el frágil equilibrio entre las expectativas de desarrollo de las comunidades y las posibilidades de los ecosistemas para sostener el uso y el aprovechamiento. Así como la constatación de que los ingresos extraordinarios de corto plazo conducen al deterioro de los recursos minando las posibilidades de ingresos moderados pero sostenibles en el largo plazo.

Si bien en la actualidad, este enfoque económico está ampliamente difundido a nivel global y se han desarrollado sofisticados modelos que buscan ser cada vez más rigurosos, 
WCS en Perú fue pionero en estos debates teóricos pero sobretodo, se nutre de la experiencia de las comunidades de Tamshiyacu Tahuayo.

En el caso de Tamshiyacu - Tahuayo, se acompaña el enfoque económico con otro menos frecuente pero no menos importante: la reconstrucción de la historia del uso de los recursos naturales para comprender las decisiones de la población local, tomando en cuenta las dinámicas de los mercados locales, nacionales e internacionales así como la dinámica de las políticas estatales que dan cuenta de las oportunidades u obstáculos para el uso sostenible de los recursos naturales y la conservación.

La consideración de los sistemas de acceso ha guiado en mayor o menor medida el análisis sobre la sostenibilidad en el uso de los recursos por las comunidades tradicionales y los pueblos indígenas. Sin embargo, aquí se observan algunas diferencias. Mientras, tempranamente, en Perú se consideró que los sistemas de acceso común favorecían la sobreexplotación de los recursos y de alguna manera se sugería que el cultivo de las palmas de aguaje y de especies maderables en parcelas de propiedad individual garantizaba el uso sostenible de dichas especies, en el caso de Bolivia se buscó demostrar que los sistemas de acceso común podían tener regulaciones y que de hecho las tenían y bien pueden asegurar el uso sostenible de los recursos naturales en sistemas de acceso común o combinado.

\section{LOS PARADIGMAS DE CONSERVACIÓN "PARA", "CON" Y "POR" LAS POBLACIONES LOCALES EN LOS PROGRAMAS DE WCS EN LA CUENCA AMAZÓNICA}

Como fue anotado en el marco de referencia de esta sistematización, cuando se trata de la conservación y su relación con las poblaciones locales, históricamente se observa un movimiento pendular entre los paradigmas que proponen que la conservación de las regiones de alta biodiversidad solo es posible si se prescinde de la población local y el que señala que la conservación efectiva solo es posible si la población local lidera los procesos de conservación. El concepto de "conservación de base comunitaria" se enmarca en la última tendencia señalada.

Complementariamente señalamos que, cuando se trata de conservación de base comunitaria, es posible identificar, analíticamente, tres paradigmas de acción que se han gestado a través de la historia:

El primero, hace referencia a la conservación "para la gente" que tiene dos connotaciones, ya que por un lado, considera a la población local como objeto pasivo, receptora de los beneficios de la conservación, pero al mismo tiempo, reconoce la importancia de los ecosistemas bien conservados para el bienestar de la población.

Un segundo paradigma hace referencia a la conservación "con la gente"; en este, se inscriben por ejemplo, las acciones de consulta, algunos Comités de Gestión (según las atribuciones que les definen las legislaciones nacionales), considera a la población como sujetos de algunas acciones de conservación pero no como decisores o actores fundamentales.

El tercer paradigma hace referencia a la conservación "por la gente", considera a la población local como agente decisivo para la conservación. Supone que la sostenibilidad de la conservación en el largo plazo solo es posible si la población local organizada se hace cargo, establece sus propios mecanismos de gobernanza y estos son reconocidos como legales y legítimos tanto por los Estados como por la institucionalidad privada y la sociedad en general. 
Como se señaló, la distinción de estos "paradigmas" de acción solo es posible a través de un proceso analítico que permite establecer tendencias, pues en la realidad, las acciones que podrían caracterizar a uno $u$ otro paradigma se combinan, se sobreponen o se articulan de una u otra manera. La importancia de clarificarlos, de cara a la práctica de la conservación es porque ayudan a definir estrategias y dar sentido a las acciones en relación a las poblaciones: comunidades locales y pueblos indígenas, en nuestro estudio.

$\mathrm{Si}$, tomando en cuenta la advertencia anterior, utilizamos la tríada de los "paradigmas" mencionados para el análisis de las experiencias que aquí se han sistematizado podría señalarse que los casos de Tamshiyacu - Tahuayo en Perú y de los territorios indígenas tacana y leco de Apolo en Bolivia, tienen una tendencia hacia el paradigma de conservación "por la gente", en cambio, en el caso del Parque Nacional Yasuní en Ecuador se enmarca más en un paradigma de conservación "con la gente". En gran medida, estas tendencias están determinadas por los contextos legales relativos a las áreas naturales protegidas en cada país.

Sin embargo, esta clasificación merece consideraciones adicionales debido a que la sistematización que aquí se presenta se enfoca estrictamente en las estrategias y acciones que los programas de país han desarrollado para su trabajo de conservación con las comunidades locales y pueblos indígenas en espacios claramente delimitados, que incluye las áreas protegidas y los territorios indígenas y tierras de comunidades ribereñas y su relación entre ambas. Cada área presenta características particulares en términos de la sobreposición de las áreas protegidas con los territorios indígenas o las tierras de las comunidades ribereñas. En esta sistematización no se ha incluido, en ninguno de los casos, la amplia gama de acciones que los Programas de País realizan con los Estados y las entidades encargadas de las áreas protegidas, excepto en aquellos aspectos que se relacionan con la población local y que también realizan en otras unidades de gestión de los "paisajes", ni en otras áreas protegidas o regiones de los países donde operan.

\section{UNA APROXIMACIÓN AL TRABAJO DE CONSERVACIÓN CON COMUNIDADES LOCALES Y PUEBLOS INDÍGENAS CON ARREGLO A PRINCIPIOS Y VALORES ${ }^{19}$}

\section{Reconocimiento y apoyo a los pueblos indígenas o nacionalidades con enfoque en sus derechos}

El reconocimiento y la titulación de las tierras, territorios y a la autodeterminación, entre los más importantes, constituyen derechos por los cuales los pueblos indígenas y nacionalidades y las comunidades locales han luchado por mucho tiempo y se encuentran profundamente enraizados en su conciencia. Adicionalmente, como resultado de sus acciones de larga data, son derechos reconocidos tanto en las legislaciones nacionales como en los acuerdos internacionales como el Convenio 169 de la OIT y la Declaración de Naciones Unidas sobre los Pueblos Indígenas suscritos y/o ratificados, donde corresponde, tanto por Bolivia, como por Ecuador y Perú.

Debemos comprender que los derechos a la tenencia de la tierra y los territorios constituyen derechos irrenunciables de los pueblos indígenas y de las comunidades locales, pues de ellos dependen su existencia y desarrollo económico, social y cultural. Al mismo tiempo que el derecho a la autodeterminación se relaciona con la necesidad histórica de los pueblos indígenas por revertir los procesos de conquista y colonización. Es necesario reconocer

19 El contenido de este capítulo, en parte, es el resultado de un taller de WCS en Bolivia realizado en octubre de 2016, con el objetivo de identificar los principios y lineamientos institucionales para el trabajo con pueblos indígenas, a partir del análisis de su experiencia y las lecciones aprendidas durante casi 20 años de trabajo. Los resultados de esta sistematización también contribuyeron a esa reflexión. 
que el derecho a la autodeterminación expresa la necesidad de construir relaciones entre iguales, opuestas a las relaciones de subordinación o dependencia. Atañe a este derecho y obligación el principio del respeto mutuo.

El derecho a la autodeterminación implica el reconocimiento y el respeto a las estructuras orgánicas e instancias que los pueblos indígenas y las comunidades locales, se han dotado, así como el respeto a sus decisiones.

El derecho a la autodeterminación incluye la consulta libre, previa e informada para cualquier acción sea de conservación o de desarrollo. Para WCS, en los tres países, el resultado de la consulta es (y debiera ser) vinculante y obligatoria. Es más, la adscripción al "paradigma" de conservación "por la gente", en los casos estudiados, específicamente comunidades ribereñas y pueblos indígenas o nacionalidades ha implicado el apoyo para que las acciones de conservación se orienten de tal manera que sean lideradas por las comunidades locales y los pueblos indígenas.

La atención al derecho de autodeterminación de los pueblos indígenas y las comunidades implica también asegurar que los procesos que ayudamos a desarrollar sean sostenibles a lo largo del tiempo. Aquí, la sostenibilidad está entendida también como el hecho de que los procesos que hemos trabajado tiendan a mantenerse a lo largo del tiempo sin nuestra colaboración. Esto implica el diseño e implementación de "estrategias y planes de salida" con objetivos, metas, indicadores, acciones y periodos definidos.

\section{La consideración de las comunidades y organizaciones indígenas como "socios" en la conservación de la vida silvestre}

Una aproximación basada en derechos comporta una dimensión ética de evitar el relacionamiento instrumental con las comunidades locales y pueblos indígenas. No usamos a la gente para nuestros fines de conservación, generamos espacios de negociación, concertación, consenso y coordinamos las estrategias y acciones, considerando los intereses propios y particulares de las comunidades locales y pueblos indígenas y nuestros intereses como organismo de conservación. Esta postura implica vigilancia autocrítica constante respecto de un relacionamiento instrumental con los pueblos indígenas y comunidades locales.

El paradigma de conservación "por la gente" local exige reconocerla como sujetos, no como objetos de las acciones de conservación y en esa medida, nos relacionamos como "socios", como "pares iguales" y juntos, promovemos la conservación de la vida silvestre. Esto implica reconocer el rol fundamental que la población local, las comunidades locales y los pueblos indígenas juegan en la conservación. En el caso de WCS en Bolivia, se privilegia el trabajo con los pueblos indígenas, por su demostrada contribución a la conservación.

Es necesario superar la visión ampliamente difundida de considerar a la población local, las comunidades locales y pueblos indígenas como una amenaza para la conservación, esta visión pone obstáculos de partida al tipo de relacionamiento que se busca construir.

\section{Respeto responsable por las decisiones de las comunidades y los pueblos indígenas}

Como se observó de manera más clara en esta sistematización, en el caso de Tamshiyacu - Tahuayo, se reconoce y se respeta la competencia exclusiva de las comunidades para decidir sus reglas de acceso y uso de los recursos naturales consignados en sus acuerdos internos. Este ejemplo puntual refiere al conjunto de otras decisiones que las comunidades 
locales y pueblos indígenas toman en sus tierras y territorios. Sin embargo, con base en esta primicia, en aras de nuestra responsabilidad, cumplimos roles importantes:

1. Promovemos espacios de diálogo, negociación, concertación y consenso con el Estado y otros actores sociales buscando igualar el "campo de juego" y que se establezcan relaciones equitativas.

2. Producimos y comunicamos información de diversos campos de la ciencia (incluido el campo legal) con la finalidad de que las decisiones autónomas se tomen en conocimiento y conciencia de esa información.

3. Buscamos que el acceso a la información se enmarque en los principios de la justicia y la equidad y que esté al alcance de los sectores frecuentemente marginados de la toma decisiones: mujeres, personas adultas mayores y jóvenes, personas con dificultades en la lectura y escritura, quienes viven más alejados de los centros comunales y otros.

A ello contribuye la técnica del análisis participativo de escenarios donde el personal técnico y de investigación ayuda a la construcción de los escenarios con información sólida identificando las consecuencias positivas y negativas de las decisiones en cada escenario, se abstiene de incidir, más allá de esto, en la toma de decisiones de las comunidades locales y pueblos indígenas.

3

\section{Generar y comunicar información científica adecuada y oportuna para la conservación y el manejo sostenible de los recursos naturales por las comunidades locales y pueblos indígenas}

Es parte de la misión de WCS desarrollar conocimiento científico para la conservación. La investigación constituye la base y precede a las acciones de conservación y de comunicación para inspirar a la gente a la conservación. Los Programas de los tres países de esta sistematización tienen importantes fortalezas en este campo.

La conservación "por la gente" requiere investigaciones adecuadas, que articulan tanto el conocimiento sobre las especies de vida silvestre, sus poblaciones y ecología con el conocimiento sobre el uso de estas especies por las comunidades locales y pueblos indígenas, sobre las conexiones ecosistémicas entre unidades de conservación (áreas protegidas y tierras comunales o territorios indígenas) y con un enfoque inter y transdisciplinario donde se conjugan la biología con la economía, la sociología, la antropología e incluso la ciencia política y el derecho. Para trabajar con las comunidades y los pueblos indígenas se requieren equipos interdisciplinarios, pero sobre todo personas con actitud científica de "mente abierta" para el abordaje de la diversidad de problemas que plantea la conservación "por la gente".

Tanto la gestión territorial, pero sobretodo el manejo de los recursos naturales por las comunidades locales y pueblos indígenas son procesos muy dinámicos, requieren flexibilidad y adaptaciones sobre la marcha. Uno de los mayores desafíos es lograr acompañar estos procesos con investigaciones de calidad y de manera oportuna a las exigencias del manejo.

La consideración de las comunidades locales y pueblos indígenas como "socios" incluye los procesos de investigación y demanda el fortalecimiento de sus capacidades para esta tarea, al igual que para otras que exige la conservación. Los procesos participativos de investigación son indispensables para asegurar la apropiación y consideración de sus resultados en la toma de decisiones por las comunidades locales y pueblos indígenas. 
La conservación "por la gente" demanda el desarrollo de habilidades comunicativas y didácticas entre los investigadores.

\section{Valoración de los conocimientos y prácticas de los pueblos indígenas y las comunidades}

Los pueblos indígenas de la Amazonía son herederos de una vasta gama de conocimientos. Han sido capaces de domesticar variedades vegetales, desarrollar tecnologías para el procesamiento de sus recursos e identificar, entre miles de especies, aquellas que son útiles para su vida, así como determinar las condiciones adecuadas para realizar las diversas actividades. Muchos de los conocimientos de las comunidades locales y pueblos indígenas no se encuentran en la verbalización de los mismos sino en las prácticas.

El respeto no debe entenderse en el sentido de asumir un conocimiento como verdad o como elemento aislado, debe entenderse como "episteme"20, es decir, como sistemas de conocimientos, que tienen fundamentos filosóficos y culturales e implican procesos de experimentación, reflexión, práctica y comunicación en sus propios contextos, en desarrollo y transformación continua. Asimismo, es importante considerar que estos conocimientos, al igual que la biodiversidad están amenazados y en riesgo de desaparecer.

En atención a lo anterior, nuestra aproximación a los pueblos indígenas y comunidades locales requiere actitud respetuosa y de valoración de dichos conocimientos y prácticas, a la vez que trabajamos para la conservación y desarrollo de los mismos.

\section{Valorar y proteger la diversidad en el uso de los recursos naturales y fortalecer la resiliencia en un contexto de cambio climático}

Entre las prácticas que involucran los conocimientos ancestrales y adaptados de los pueblos indígenas y comunidades ribereñas se encuentra el uso altamente diversificado de los recursos naturales. Esta diversidad encierra el secreto del bajo impacto de sus actividades sobre los ecosistemas, al mismo tiempo de su resiliencia frente a la diversidad de eventos traumáticos que históricamente han tenido que enfrentar, así como los momentos críticos del ciclo anual o de la vida de las personas y hogares.

Más aún, en la actualidad, frente a escenarios de cambio climático, el uso diversificado de los recursos naturales constituye una base de resiliencia que, sin embargo, requiere ser reforzada apoyando a los pueblos indígenas y comunidades locales a identificar alternativas adicionales de adaptación.

La conservación de la biodiversidad y de sus usos diversos por las poblaciones indígenas es básica para el mantenimiento económico, social y cultural de los pueblos indígenas y las comunidades locales y prefigura un horizonte de desarrollo diferente, sostenible. Por ello, nuestras acciones de apoyo al manejo de los recursos naturales requieren considerar tanto este uso diverso como el hecho de que igualmente importantes son las esferas no monetarias como monetarias en la economía de los hogares indígenas y de las comunidades locales. 


\section{Reconocer y fortalecer los valores y las culturas de los pueblos indígenas}

Los valores y las culturas indígenas de los pueblos indígenas de la Amazonía están íntimamente relacionados con la biodiversidad. La pérdida de estos incide en la pérdida de la biodiversidad y viceversa. Por ello, se hace imperativo el conocimiento, reconocimiento y fortalecimiento de los valores y las culturas indígenas en la Amazonía.

\section{Compromiso, responsabilidad y vocación de excelencia}

La conservación "por la gente" demanda gran dosis de compromiso combinada con responsabilidad y vocación por la excelencia en los procesos de investigación, capacitación y asistencia técnica. Aquí es necesario subrayar que el compromiso no suple la vocación de excelencia y que esta es un gesto de responsabilidad. La conservación y el manejo de los recursos naturales "por la gente" implican riesgos que pueden afectar la salud de los ecosistemas y de las especies así como de las poblaciones locales. La vocación por la excelencia es uno de los medios para mitigar esos riesgos, de ahí su crucial importancia.

\section{Enfoque del trabajo de "abajo hacia arriba"}

Una de las contribuciones de esta sistematización es haber puesto de relevancia la importancia del "capital social" o de la construcción de redes sociales como garantía de sostenibilidad de los procesos de gestión territorial, del manejo de recursos naturales y de la conservación "por la gente". Esta construcción solo es posible a partir de una aproximación de trabajo de "abajo hacia arriba". Las redes sociales así construidas son una suerte de núcleo que puede nutrirse de otras estrategias de acción de "arriba hacia abajo", pero esta última, en el marco del paradigma de conservación "por la gente", no podrá sustituir a la primera en la construcción de las redes sociales.

\section{Asegurar la apropiación de los instrumentos de gestión por las comunidades locales tradicionales y los pueblos indígenas}

El proceso de elaboración de los instrumentos de gestión y la construcción de las "redes sociales" tienen una relación de ida y vuelta. La conciencia de este hecho implica tomar en cuenta la "construcción de las redes sociales" desde el momento que surge la idea de la elaboración de los instrumentos, el diseño de las metodologías, su aplicación y la implementación. De esta manera, se busca que el proceso de elaboración de los instrumentos de gestión contribuya a la "construcción de las redes sociales" y de esta suerte, los instrumentos de gestión se constituyan, más allá que simples documentos, en "acuerdos sociales", "acción o hecho social". Esta búsqueda de legitimidad social de los instrumentos implica la consideración de las particularidades históricas y culturales de cada pueblo indígena o comunidad. Si bien pueden existir metodologías y modelos de acción, estos deben ser observados en un marco de gran flexibilidad, y su rediseño y aplicación exigen creatividad para hacer que los resultados sean únicos y adecuados a las condiciones particulares de cada pueblo indígena o comunidad, de tal suerte que se identifique con ellos.

\section{Compromiso institucional de largo plazo}

Los procesos de conservación y manejo sostenible de los recursos naturales "por" las comunidades se caracterizan por avances y retrocesos, no son lineales ni expeditos, entre dulces y amargos, son de larga duración. Una característica de WCS en cualquiera de los tres países es su compromiso institucional de largo plazo. Esta característica expresa 
su aproximación responsable hacia los procesos que apoya en el fortalecimiento de las capacidades locales.

\section{Perfil institucional en función de las necesidades de los pueblos indígenas y comunidades locales}

El apoyo de las instituciones de conservación que como WCS brindan apoyo a los pueblos indígenas y comunidades locales requiere ampliar su perfil de manera flexible a mucho más que exclusivamente, por ejemplo, la conservación de la vida silvestre. Es evidente que por razones de experticia o de financiamiento, una institución no puede cubrir con su apoyo todas las necesidades de un pueblo indígena o una comunidad tradicional, sin embargo, también es claro que el trabajo de conservación "por" la población local demanda mucho más que lo inmediatamente evidente u obvio. En este quehacer, se hace imprescindible el tejido de alianzas con otras entidades, públicas y privadas, con perfiles institucionales diferentes, para poder apoyar de una manera más integral la gestión territorial indígena e incluso el manejo de recursos naturales específicos.

\section{Construir relaciones de confianza, ejercer y promover la transparencia}

La colaboración para la conservación de la vida silvestre requiere relaciones basadas en la confianza y para ello es clave el ejercicio y la promoción de la transparencia. Ello implica la predisposición a la rendición de cuentas periódica, tanto financieras como de las acciones técnicas, y estar abiertos a la crítica y a los consecuentes cambios y rectificaciones.

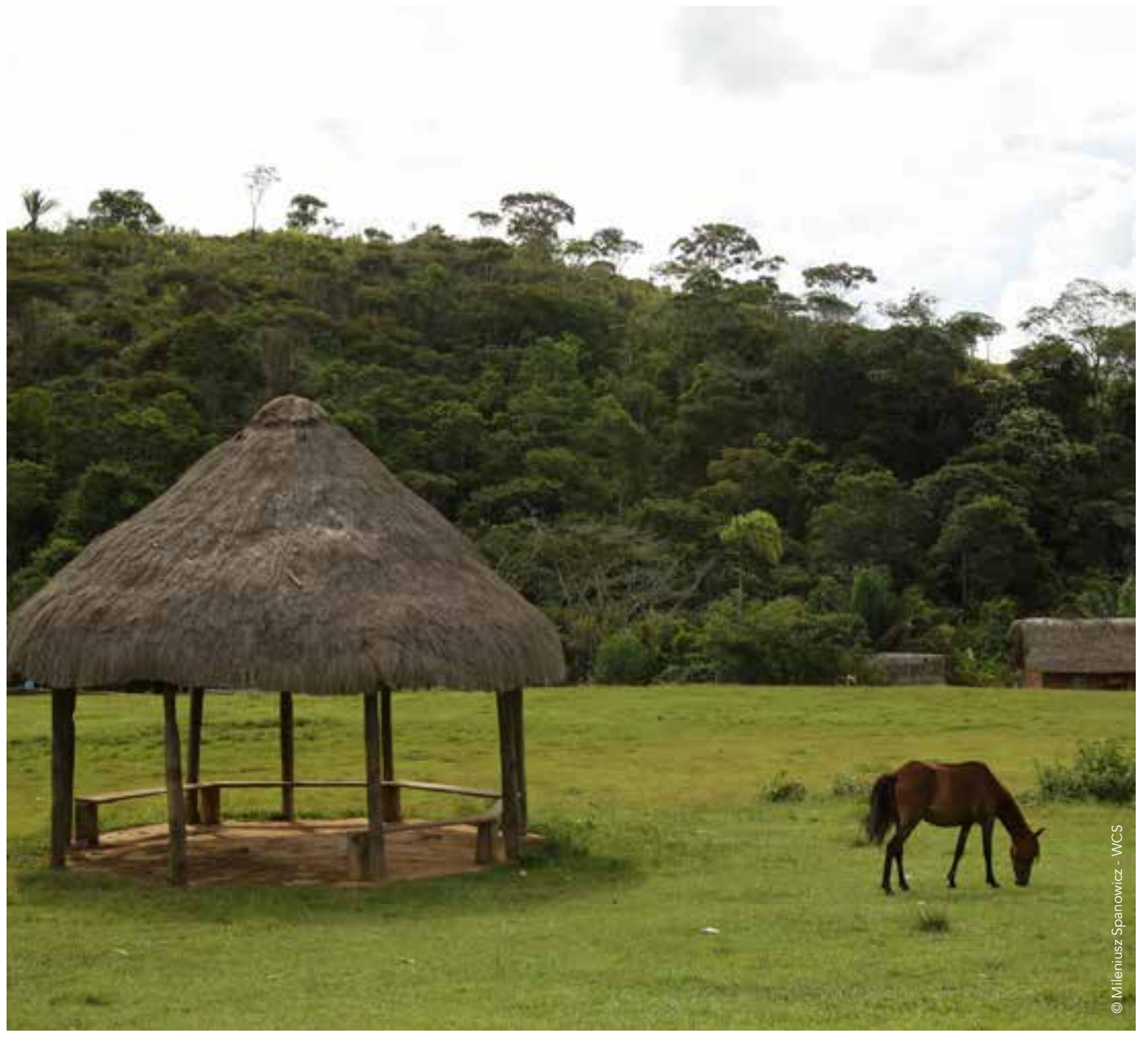




\section{RIESGOS, DIFICULTADES Y DESAFÍOS}

\section{Planificación estratégica y financiamiento de largo plazo}

Mayormente, las entidades de conservación planifican estratégicamente en función de "objetos de conservación": especies, ecosistemas, conectividad, etc. La ausencia de hacer visibles a las comunidades locales y pueblos indígenas en el nivel más alto de la planificación da como resultado acciones aisladas sin encadenamientos estratégicos y se diluyen los impactos. El trabajo para la conservación "por la gente" exige un análisis de la compleja problemática social, económica, cultural y política, el diseño e implementación de planificación estratégica de largo plazo identificando cadenas de resultados e impactos, que den sentido a cada una de las actividades y acciones.

El diseño de rutas críticas para apoyar la Gestión Territorial Indígena y el manejo de recursos naturales que hemos logrado construir en esta sistematización a partir de la implementación de acciones durante los últimos treinta años, busca ayudar en esa planificación estratégica para el trabajo con los pueblos indígenas y las comunidades locales. Sin embargo, deben comprenderse como modelos flexibles que requieren ser adecuados, enriquecidos o transformados en función de las condiciones históricas y características particulares de cada grupo humano.

En el mismo sentido, debe comprenderse que el trabajo con los pueblos indígenas y las comunidades locales es complejo, tanto como cualquier realidad social y los procesos no son lineales, se desarrollan mediante avances y retrocesos, así como cambios permanentes de distinta intensidad. De ello resulta que la planificación estratégica está sujeta a muchos avatares.

Estas condiciones exigen a su vez financiamiento de largo plazo tomando en cuenta la planificación estratégica, con visión de integralidad de los procesos (en lugar de actividades o acciones aisladas) y flexible en el sentido de la dinámica de los procesos.

\section{De la escala y la intensidad de las operaciones}

Como se ha demostrado a través de esta sistematización, en el ámbito de trabajo con los pueblos indígenas y comunidades locales, WCS ha contribuido a desarrollar "capital social" para la conservación. Definido el "capital social" como el desarrollo de relaciones interpersonales, "cara a cara" en varios sentidos: relaciones horizontales y verticales de "tipo vínculo" y de "tipo puente". Necesariamente, este tipo de trabajo se basa en un enfoque de "abajo hacia arriba", con soportes del trabajo de "arriba hacia abajo", pero no a la inversa, además es un trabajo de alta intensidad. Con todas sus dificultades, es más fácil de lograr en pequeña escala. El riesgo aquí es que los equipos técnicos que trabajan con los pueblos indígenas y las comunidades locales se afinquen en esta "zona de confort (relativa)" derivando, como se explicará más adelante, en procesos de "rutinización" de las acciones.

El enfoque de "los paisajes vivientes", entendidos como articulaciones de unidades de gestión y de sistemas de gobernanza, a través del fortalecimiento de las relaciones de "tipo vínculo" y de "tipo puente", contribuye a ampliar la escala geográfica y social de las operaciones para la conservación. Sin embargo, el riesgo de mayores presiones para el "escalamiento" es que se cambie el enfoque de trabajo de "abajo hacia arriba" a uno de "arriba hacia abajo", donde los procesos de fortalecimiento de las redes sociales, que hasta ahora han venido soportando la efectividad de la gestión con resultados favorables para conservación, sean desestructurados. 


\section{De la pérdida de los marcos teóricos y conceptuales enfocados a la conservación "por la gente"}

Como se mencionó al tratar de los marcos interpretativos y se pudo ver en situaciones concretas en los estudios de caso, una tensión persistente en el ámbito de la ciencia de la conservación es la que se refiere en un extremo a las estrategias de conservación "sin la gente local" (expulsando a las poblaciones locales de las áreas de alto valor en biodiversidad) y en el otro el de la conservación "por la gente", que en los casos aquí estudiados, con matices, es a la que, en la práctica se pueden inscribir los programas de WCS.

Aquí se presenta una debilidad y un riesgo en el sentido de que, si bien los Programas a nivel de cada país pudieron iniciar sus acciones ostentando marcos teóricos y conceptuales de alto nivel y claridad, a lo largo de los años y en ausencia de espacios de debate teórico y conceptual estos marcos teóricos y su actualización se diluyen; así, de manera muchas veces inconsciente las acciones viran de un "paradigma" de la conservación a otro sin consideración de sus implicaciones.

\section{De la persistencia a la "rutinización" de las acciones}

Como se vio en esta sistematización, el trabajo de conservación "por la gente" requiere persistente acompañamiento (pero dosificado en función de las estrategias de salida) a través de la asistencia técnica y la capacitación. Sin embargo, existe el riesgo de lo que podríamos denominar la "rutinización" de las acciones, que consiste en repetirlas mecánicamente aplicándolas indistintamente y sin variación a las diferentes unidades de gestión sin considerar sus particularidades. También se expresa en la mantención indefinida de acciones en determinadas comunidades o con determinados grupos de personas al interior de las comunidades, "afines a la conservación", aquí el riesgo de afincamiento en las "zonas de confort", o en la ausencia de innovación y el consiguiente empobrecimiento de la calidad de las acciones y de los procesos.

\section{Debilidades en la formación de liderazgos para la conservación "por la gente"}

El trabajo de la organización de conservación con una visión de "abajo" hacia "arriba", fortaleciendo las relaciones de las comunidades con sus líderes, ha sido determinante para procesos más sostenibles y resilientes, sin embargo, ese proceso requiere la formación de líderes (mujeres y hombres) con visión de defensa y de gestión de los territorios indígenas. Lo anterior, implica ampliar y profundizar los mecanismos de "balance de pesos y contrapesos" en la relación de los líderes con sus bases para asegurar sistemas de gobernanza con vocación de transparencia, representatividad y legitimidad. Importantes esfuerzos de WCS en los programas que aquí se analizan han sido para el fortalecimiento de capacidades mayormente de carácter técnico, pero los procesos demandan más que eso, formación de mujeres y hombres con capacidades de liderazgo. Del mismo modo, asegurar sistemas orgánicos con distribución de funciones que aseguran el balance de los "pesos y contrapesos" requiere que la capacitación se base en programas que identifican a sus grupos meta en los diferentes niveles de la organización.

\section{Desafíos en la incorporación de los valores y la cultura de los pueblos indígenas}

Como se vio a lo largo de esta sistematización, de manera directa o indirecta, los Programas de WCS han contribuido a la conservación y fortalecimiento de los valores y la cultura de los pueblos indígenas y las comunidades locales: el fortalecimiento de las identidades 
étnico - culturales, la conservación de los recursos naturales como base de las prácticas culturales, el apoyo al desarrollo, producción y comercialización de servicios y productos con "marca" cultural, el apoyo al desarrollo de curriculums educativos regionalizados y a la formalización de alfabetos de algunos idiomas indígenas.

Del mismo modo, es de destacar la incorporación de conceptos propios del desarrollo sostenible o del vivir bien en algunos de los planes de vida o de gestión territorial como los del pueblo leco y tacana en el Paisaje Madidi. Sin embargo, dos debilidades destacan aquí, en primer lugar, que esta incorporación no es generalizada en los diferentes Programas que trabajan con los pueblos indígenas y en segundo lugar, aún en aquellos donde se han incorporado las definiciones existen dificultades en la operacionalización de los planes en concordancia con las definiciones culturales. Esta última debilidad deriva en parte de la dinámica de los cambios culturales entre los pueblos indígenas pero también de la insuficiente insistencia o motivación para la profundización de su análisis e implicaciones en términos de su transversalidad y definición de lineamientos y acciones.

\section{Debilidad en la incorporación del enfoque de equidad de género}

En los últimos años, los Programas de WCS han avanzado significativamente en la inclusión del enfoque de equidad de género buscando incidir tanto en las relaciones entre su personal cuanto en las acciones con sus socios institucionales a través de políticas y planes institucionales para la equidad de género. Sin embargo, como se deduce de esta sistematización, esto no siempre ha sido así y aún queda un largo camino por recorrer. Aquí, el argumento del financiamiento parece ser una limitante sin embargo, en la consideración de que los recursos financieros siempre son insuficientes, puede deducirse también de que se trata de un problema de prioridades.

\section{Financiamiento sostenible para la gestión territorial y el manejo de los recursos naturales "por la gente"}

Como se anotó, en todos los casos, se han identificado y desarrollado estrategias para lograr financiamiento sostenible para la gestión territorial indígena y el manejo de los recursos naturales, bien que en relación a este último, por su propia dinámica, las iniciativas tienden a autosostenerse financieramente en muchos casos y aún se ha buscado que contribuyan al funcionamiento de los procesos de gestión territorial indígena y a los sistemas de control y vigilancia de las comunidades ribereñas. Sin embargo, pese a los esfuerzos e intentos diversos por asegurar mecanismos de financiamiento sostenible, éste aspecto constituye aún uno de los mayores desafíos. Su importancia además de económica está relacionada con la dimensión política en el sentido de la autonomía y la autodeterminación de los pueblos indígenas y las comunidades.

\section{La incorporación formal de los instrumentos de gestión indígena a los planes de desarrollo gubernamental}

Los Programas de WCS han invertido esfuerzos y en algunos casos muy exitosos en el sentido de lograr la compatibilización de los planes de gestión territorial o de vida con los planes de manejo de las áreas naturales protegidas. Además, estos procesos han servido para la construcción de relaciones sociales de "tipo puente" entre los pueblos indígenas y comunidades locales con el Estado.

Sin embargo, más dificultosa ha sido la incorporación de los planes de gestión territorial o de vida en los planes de desarrollo de otras instancias estatales municipales, departamentales o provinciales y nacionales. Un intento importante, en este sentido ha 
sido la experiencia de los lecos de Apolo. La importancia de este desafío radica no solo en la incorporación de las propuestas contenidas en los planes de vida o de gestión territorial sino en su transversalización al conjunto de la planificación estatal buscando evitar o al menos mitigar los impactos de las acciones de desarrollo que se definen en estos planes.

\section{Las grandes amenazas que se ciernen sobre las áreas protegidas, territorios indígenas y tierras comunitarias}

En la actualidad y hacia el futuro, todo lo avanzado en términos de conservación "por" los pueblos indígenas y comunidades locales se enfrenta a desafíos mayores y renovadas amenazas relacionadas con proyectos de infraestructura a gran escala y el remozamiento del "extractivismo" en los países que constituyen la Cuenca Amazónica. Del mismo modo, el cambio climático enfrenta a las poblaciones indígenas y comunidades tradicionales a nuevos escenarios.

Frente a ellos, el énfasis aún mayor en el fortalecimiento de las "redes sociales" y las identidades indígenas constituyen mecanismos de resiliencia. Sin embargo, se hace necesario incluir en los instrumentos de gestión y en los sistemas de monitoreo mecanismos que ayuden a los pueblos indígenas y las comunidades tradicionales a enfrentarlos. La identificación de ámbitos específicos en la planificación, con la consiguiente identificación participativa de estrategias específicas, la transversalización de gestión del riesgo así como la identificación de indicadores de impacto tanto ambientales como socioeconómicos y culturales acompañada de procesos de capacitación para el monitoreo de las grandes amenazas, son algunos elementos que los Programas de WCS en la Amazonía están empezando a desarrollar. 


\section{LECCIONES APRENDIDAS:}

\section{Respecto de la Gestión Territorial Indígena en general}

- La Gestión Territorial Indígena se construye sobre la base de procesos de fortalecimiento organizativo basados en las identidades indígenas.

- La implementación de los instrumentos de gestión territorial indígena requiere liderazgos comunales respetuosos, firmes y capaces.

- Uno de los mayores desafíos es la apropiación y la legitimidad de los instrumentos de gestión territorial. Estos desafíos deben ser previstos y encarados en cada fase: del diseño metodológico, la formulación e implementación.

- La Gestión Territorial Indígena demanda apoyo integral en aspectos tales como: a) la titulación de los territorios, b) la planificación, c) el ordenamiento territorial y la autorregulación para el acceso y uso de los recursos naturales, d) el manejo sostenible de los recursos naturales, e) el acompañamiento a la gestión de las organizaciones para resolver las demandas comunales de servicios básicos, educación, salud y recuperación de prácticas culturales y saberes ancestrales, f) el monitoreo, evaluación y la sistematización de las experiencias, g) la difusión y el intercambio entre pueblos indígenas, sus líderes y entre comunidades.

- La planificación es un componente de la gestión territorial indígena para la conservación, no constituye la gestión territorial en sí. Esta implica la implementación de los planes en relación a sus diferentes ámbitos y fundamentalmente el manejo de los recursos naturales para asegurar los medios de vida sostenibles para los pueblos indígenas y las comunidades locales tradicionales.

- La implementación de los planes de vida o de gestión territorial indígena por las organizaciones indígenas requiere del acompañamiento técnico y financiero por varios años.

- El apoyo a los procesos de la Gestión Territorial Indígena requiere flexibilidad tanto de la organización de conservación como de sus donantes.

\section{Los derechos al territorio y a la tierra por los pueblos indígenas y comunidades tradicionales}

- Una motivación común de las comunidades locales y pueblos indígenas o nacionalidades con las que trabaja WCS en los tres países ha sido el reconocimiento de sus derechos a la tierra y sus territorios.

- El ejercicio de este derecho, les ha conducido a reforzar de propia iniciativa, el control del ingreso de foráneos a sus tierras y territorios.

- Acciones de conservación "por" las comunidades ribereñas y pueblos indígenas implican tomar en cuenta la importancia que para ellos revisten la titulación y la seguridad jurídica sobre sus territorios y tierras comunitarias. 


\section{La planificación territorial}

- La conformación por equipos técnicos mixtos, integrados por profesionales y personas elegidas por las organizaciones indígenas, contribuye a la legitimidad, asegura el intercambio de conocimientos y la implementación de los PGTI o Planes de vida.

- Los Planes de Gestión Territorial o Planes de Vida, al expresar acuerdos sociales, requieren ser construidos tomando en cuenta todas y cada una de las comunidades que constituyen un territorio indígena. Es necesario poner particular atención en promover la participación de sectores frecuentemente excluidos como las personas mayores, las mujeres y la juventud.

- Diseñar las metodologías para la capacitación y asistencia técnica considerando el carácter concreto del pensamiento de las poblaciones locales y tomando en cuenta que la mejor forma de expresión de este tipo de pensamiento es el dibujo.

- La implementación de los planes de vida o de gestión territorial indígena por las organizaciones indígenas requiere del acompañamiento técnico y financiero por varios años.

\section{Mapeo, zonificación y ordenamiento del uso de las tierras}

- La consideración de gradientes de uso de los recursos naturales en el ordenamiento de las tierras a nivel de paisajes y de las unidades de gestión permite relacionar la conservación de las áreas protegidas con las necesidades de desarrollo sostenible de las comunidades locales.

- Las zonificaciones u ordenamientos de los territorios deben considerarse como parte integrante de los planes de Gestión Territorial o Planes de Vida, pues estos procesos permiten orientar dónde, de manera sostenible y atendiendo a la vocación de los suelos, deben realizarse las acciones contenidas en el plan.

- Las metodologías del mapeo participativo desde el nivel comunal hasta el nivel territorial requieren ser participativas. Esto implica realizar adecuaciones tecnológicas y acercar a los técnicos de SIG a la población local, al mismo tiempo, se requiere fortalecer las capacidades técnicas de miembros de las organizaciones indígenas y comunidades para el mapeo participativo y el uso de los instrumentos y sistemas de información geográfica.

- En los procesos de zonificación a nivel territorial, un desafío importante es la administración de conflictos entre comunidades por la designación de usos a espacios compartidos entre ellas, se requieren herramientas metodológicas participativas que faciliten la administración de los conflictos. Una herramienta metodológica que ha demostrado ser de gran ayuda es la "matriz de compatibilidad de usos" diseñada por WCS en Bolivia. Además, esta herramienta permite otorgar flexibilidad a las zonas de uso al establecer las condiciones para que los usos diferentes sean compatibles o establecer claramente cuáles usos definitivamente no son compatibles. 


\section{De los procesos de autorregulación}

- Los reglamentos formales o acuerdos comunales en libros de actas requieren contemplar:

a. Los límites claros de los RRNN a través de las zonificaciones y el establecimiento de jurisdicciones comunales,

b. claridad en los criterios que definen a los sujetos de los derechos de acceso,

c. flexibilidad para que las normas de acceso y uso puedan ser ajustadas a lo largo del tiempo,

d. las reglas o cuotas de uso deben responder a la capacidad de carga de los ecosistemas,

e. $\quad$ las normas de uso deben ser claras y de fácil aplicación (McKean \& Ostrom, 1994).

En los procesos de autorregulación estudiados, mayormente de la experiencia de Tamshiyacu Tahuayo y de los tacanas y lecos de Bolivia, destacan los siguientes elementos:

a. El "detonante" de la regulación fueron las restricciones que las comunidades locales decidieron imponer a los "foráneos", no residentes.

b. La regulación comenzó en relación a uno de los recursos más sensibles para las comunidades locales: la pesca que proporciona recursos tanto para el consumo como para la venta.

c. El impulso generado por el éxito de las acciones anteriores se tradujo en que los mismos habitantes empezaran a dialogar sobre sus propios usos hasta llegar a consensos primero entre comuneros de una comunidad y luego entre comunidades.

d. La forma de la regulación basada en acuerdos plasmados en los libros de actas de cada comunidad es destacable por varias razones: a) la forma se enraíza con una práctica organizativa de estas comunidades, el resultado no es "enajenable" y permite que el proceso se mantenga bajo su control, b) coadyuva a la legitimidad del contenido de los acuerdos y c) da flexibilidad para su adecuación y responde a las necesidades de adaptabilidad que requiere el manejo de los recursos naturales.

e. Los reglamentos más formales incluyen la definición más clara de los criterios para la constitución de los sujetos de los derechos y deberes.

f. El contenido de los acuerdos y reglamentos formales recoge los conocimientos de las comunidades: tradicionales y adquiridos a través del intercambio con investigadores.

g. El sistema de cuotas que se establece en los acuerdos fue adoptado exitosamente, particularmente por las comunidades ribereñas de Tamshiyacu - Tahuayo.

h. El sistema de cobros en dinero por las cuotas destinadas a la comercialización probablemente se adecúe a comunidades como las de Tamshiyacu - Tahuayo que tienen mayor orientación al mercado. 
i. El destino de los cobros o multas por sanciones para fines de interés comunal así como la inclusión en los acuerdos de excepciones para casos de enfermedad, extrema necesidad y la identificación de momentos críticos del año para la economía de los hogares, es un factor que coadyuva a la legitimidad de los acuerdos.

j. Una condición importante es que la decisión sobre el contenido de los acuerdos o reglamentos formales constituye una atribución exclusiva de las comunidades y esta condición es reconocida y respetada por otros actores como el Estado, organizaciones técnicas de apoyo, investigadores, etc.

k. El proceso de autorregulación y particularmente de aplicación de las sanciones, en el caso de Tamshiyacu - Tahuayo ha sido acompañado de cerca y respaldado por la Policía Nacional. Esto implica que los acuerdos, además de tener significativos niveles de legitimidad, están respaldados por la autoridad del orden público.

I. Una gran debilidad en el proceso de Tamshiyacu - Tahuayo es la escasa participación de las mujeres.

\section{Sistemas de control y vigilancia territorial}

Sistemas de control y vigilancia de los territorios indígenas requieren:

- Iniciativa y organización de las comunidades y sus hogares.

- Respaldo estatal a las iniciativas comunales.

- Fortalecimiento de capacidades.

- Alianzas estratégicas con los Sistemas Nacionales de las Áreas Protegidas.

- Financiamiento sostenible que contemple fuentes internas de las propias comunales (en trabajo y en especie) y otras fuentes externas entre ellas de los Estados.

\section{Fortalecimiento de capacidades administrativas y fuentes de financiamiento sostenible}

- Desde el principio se requiere diseñar participativamente y concertar sistemas que aseguren la articulación de los diferentes niveles orgánicos, basados en la distribución de los beneficios, la rendición de cuentas recíprocas entre los diferentes niveles y la separación de funciones generando pesos y contrapesos para asegurar sistemas con vocación de transparencia.

- El fortalecimiento de capacidades administrativas se ha basado en los siguientes elementos:

a. Suscripción de sub-acuerdos de financiación entre WCS y las organizaciones indígenas.

b. Diseño participativo de sistemas administrativos adecuados a las necesidades y condiciones de las organizaciones indígenas. 
c. Capacitación y asistencia en servicio a nivel de organizaciones indígenas, autoridades comunales y asociaciones productivas.

d. Producción y difusión de materiales de capacitación y manuales adecuados.

e. Contratación de personal administrativo y contable idóneo por las organizaciones indígenas.

f. Promoción y financiación de auditorías técnicas y financieras del manejo de las organizaciones indígenas como una práctica habitual.

- A pesar de los esfuerzos realizados para concretar financiamiento sostenible para la Gestión Territorial Indígena, a través de apoyar a las comunidades locales y pueblos indígenas para que sean considerados en los mecanismos nacionales de incentivos para la conservación de los bosques o su inclusión como circunscripciones territoriales o autonomías indígenas como parte de los sistemas descentralizados del Estado, ninguno de estos mecanismos ha funcionado sosteniblemente.

\section{Investigación y monitoreo}

- La efectividad de la conservación de base comunitaria se funda en acuerdos legítimos y aceptables. El mayor desafío desde la ciencia de la conservación es ayudar a establecer esa razonabilidad en términos del equilibrio entre la permanencia de las poblaciones silvestres en el largo plazo y las necesidades de los hogares y las comunidades.

- Una de las claves para que las negociaciones arriben a acuerdos razonables está en la información científica detallada sobre cada una de las especies de la amplia gama que las comunidades utilizan y sobre las interrelaciones de estas con otras especies o recursos.

- La investigación participativa contribuye al intercambio de conocimientos, facilita la apropiación de los resultados y su uso en la toma de decisiones por las comunidades.

- La comunicación y difusión periódica de los resultados del monitoreo a las comunidades es una tarea ineludible para favorecer la adecuada toma de decisiones sobre el uso de los recursos naturales y su conservación.

- El enfoque de "los paisajes vivientes" de WCS implica articular unidades espaciales de gestión diferentes. La investigación para determinar "áreas fuente" y "áreas sumidero" y sobre todo corredores biológicos entre dichas áreas constituye un insumo básico para informar políticas y las acciones de gestión y conservación tanto de las entidades estatales encargadas de la gestión de las áreas naturales protegidas como de las organizaciones indígenas para la gestión de sus territorios.

- Para la Gestión Territorial Indígena, el manejo y la conservación de las especies a nivel de "paisajes" se requiere que la investigación aborde tanto el estado de las poblaciones silvestres y su ecología cuanto el uso de estas por la población local. Esta información debidamente comunicada a las organizaciones y comunidades permite que la toma de decisiones y los acuerdos de acceso y uso de los recursos naturales contribuyan a la conservación por la población local. requiere de una diversidad de temas de investigación, pero además es necesario 
que los equipos e investigadores tengan una visión inter y transdisciplinaria de los procesos de investigación.

- La comunidad científica no es homogénea: así como hay quienes respaldan el papel protagónico de las comunidades locales hay quienes piensan que poner el énfasis en restringir el acceso y el uso por las comunidades locales es mejor para la conservación. En los casos estudiados, la definición de esta tensión a favor de las comunidades locales ha demostrado ser la mejor opción.

- Es necesario contribuir a la formación de jóvenes investigadores que apuesten por el trabajo con las comunidades locales. Las escuelas de campo constituyen espacios de interrelación y aprendizaje sobre cómo trabajar con las comunidades locales y pueblos indígenas.

\section{Construcción de redes sociales de "tipo vínculo": fortalecimiento de las organizaciones indígenas y comunitarias}

- Es necesario no perder de vista que la constitución de los instrumentos de gestión en "hechos sociales" o "acciones sociales", requiere de la construcción y el fortalecimiento de las redes sociales tanto horizontales de tipo "vínculo" como de tipo "puente".

- Al mismo tiempo, para que los instrumentos de gestión coadyuven a fortalecer las redes sociales de tipo "vínculo" es necesario: a) diseñarlos con un enfoque de trabajo de "abajo - arriba", b) generando espacios de comunicación entre las comunidades y de estas con sus líderes de los niveles comunales y territoriales.

- A su vez, la vinculación metodológica de los instrumentos de gestión con las redes sociales de tipo vínculo es clave para asegurar que los instrumentos de gestión no sean solo documentos sino que se constituyan efectivamente en "acción social" o "hechos sociales".

- Los instrumentos de gestión territorial son fundamentales pero tanto o más importantes son las redes sociales que se construyen durante su elaboración e implementación.

- El fortalecimiento de las redes sociales horizontales y verticales de tipo vínculo entre los pueblos indígenas para la Gestión Territorial contribuye de manera determinante al fortalecimiento de las identidades indígenas.

- Mientras en Bolivia y Ecuador, el fortalecimiento de las relaciones verticales de tipo vínculo se realiza entre las comunidades y las organizaciones matrices representativas de los pueblos indígenas, en el caso de Perú, el Comité de Gestión de la Reserva Tamshiyacu - Tahuayo, basado fundamentalmente en las comunidades locales, se ha constituido en una entidad comparable, al representar a las comunidades ante el Estado cumpliendo una función de articulación entre el Estado y estas para tratar los asuntos de la conservación de sus tierras y recursos naturales.

- El fortalecimiento de las organizaciones de mujeres indígenas, desarrollado tanto por Bolivia como por Ecuador, demuestra que el apoyo a la producción y comercialización de sus artesanías y otras producciones que realizan, redunda en su empoderamiento y que desde esa dimensión económica ellas avanzan en el conocimiento y demandas de sus derechos específicos como mujeres y como integrantes de los pueblos indígenas. 


\section{Construcción de redes sociales de "tipo puente" entre los pueblos indígenas o las comunidades locales y el Estado}

- Como señaló Putnam (2003), mientras la construcción de relaciones de tipo "vínculo" entre semejantes ayuda a la solución de los problemas locales, la construcción de relaciones de tipo "puente" es más dificultosa pero contribuye a la construcción de la democracia. En este caso, son estas relaciones las que permiten conectar las unidades de conservación en los "grandes paisajes", pero igualmente, son las relaciones más complejas de construir o de fortalecer y requieren de largos y continuos periodos de trabajo.

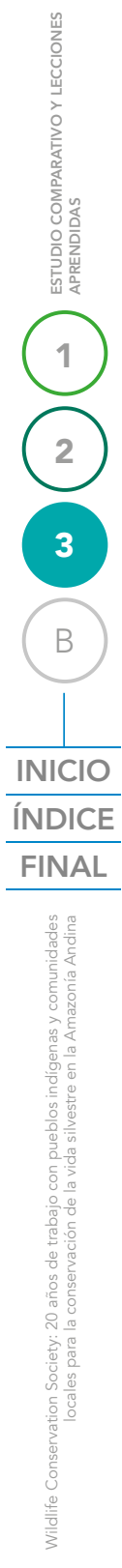

- Requiere que ambos actores cuenten con instrumentos de gestión comparables. La posesión de los instrumentos de gestión por cada una de las partes implicadas, las organizaciones indígenas y el Estado, contribuye a un escenario de confianza.

- Se consideren los planes de manejo de las áreas naturales protegidas como acuerdos sociales.

- Se faciliten los espacios de diálogo, canales de comunicación, negociación y concertación en un campo de juego que asegure relaciones simétricas entre ambos actores.

- Se identifiquen competencias exclusivas y concurrentes.

- Trabajar simultáneamente a diferentes niveles de las estructuras organizativas de los pueblos indígenas y del Estado.

- Los arreglos institucionales para la gestión compartida de territorios indígenas y áreas naturales protegidas sobrepuestas demanda construcciones conceptuales, visión de sistemas, pensamiento abstracto y concreto, así como la promoción de ejercicios técnicos de compatibilización de los instrumentos de gestión de las diferentes unidades.

- En el caso de Bolivia, WCS desarrolló estrategias en dos niveles: 1) para conectar unidades de gestión en el paisaje a través de la conservación de corredores biológicos entre el PANNMI Madidi y la TCO Tacana I y 2) contribuyendo con la construcción de una propuesta de gestión compartida entre el Estado y las organizaciones indígenas tomando como punto de partida una extensa área sobrepuesta entre el territorio indígena Leco de Apolo y el PNANMI Madidi.

- En un contexto legal específico donde el reconocimiento de los derechos territoriales indígenas en zonas sobrepuestas por las áreas naturales protegidas dependen de la entidad encargada de estas áreas como en el caso de Ecuador, WCS ha auspiciado la participación de los funcionarios en la formulación de los instrumentos de gestión de las comunidades y al mismo tiempo de las comunidades en la formulación de los instrumentos de gestión del área protegida. Asimismo, ha diseñado e implementado un programa de formación de guardaparques que incluye a funcionarios estatales y delegados de las comunidades.

- En Perú, el Comité de Gestión de Tamshiyacu - Tahuayo cumple el papel de "puente" entre las comunidades ribereñas y el Estado. El apoyo a su funcionamiento contribuye a fortalecer este tipo de relación social. 


\section{Manejo de recursos naturales específicos por las comunidades locales}

La promoción del manejo de los recursos naturales por comunidades locales y pueblos indígenas en la Amazonía debe considerar:

- La diversidad de usos y de actividades que realizan.

- La diversidad de sus actividades es la base de su resiliencia y la causa de que la huella que dejan en el paisaje sea diferente a la de otros grupos sociales.

- La articulación de las esferas no monetaria (reciprocidad) y monetaria (del mercado) y la importancia de mantener el equilibrio entre ambas.

- El enfoque de cadena productiva y de valor en relación al manejo de los RRNN permite que el apoyo institucional sea más efectivo.

- La articulación entre emprendimientos diferentes puede generar "círculos virtuosos" que favorece al desarrollo de todos y cada uno de ellos.

- Con un enfoque de cadena productiva y de mercado, WCS en Bolivia ha impulsado 27 iniciativas comunales de manejo de recursos naturales en la TCO Tacana I y Lecos de Apolo. Entre ellas destacan las de aprovechamiento de las pieles y carne de lagarto, de manejo y aprovechamiento de cacao silvestre y bajo sistemas agroforestales, de incienso, mieles nativas, café, artesanías, jatata, aprovechamiento forestal maderable, y turismo. Con un enfoque de apoyo al autoconsumo, apoyó al manejo de la caza, la pesca, los huertos, el manejo de animales domésticos menores y la ganadería.

- En Perú destaca el manejo comunitario de recursos naturales vinculados con la cacería, la pesca y el uso de una diversidad de palmeras, con énfasis en cuotas y contribuciones económicas de los usuarios por el aprovechamiento tanto para el consumo como para la comercialización.

- En el caso de Ecuador, se intenta el encadenamiento de sectores productivos diferentes como el turismo comunitario con el manejo de las charapas (tortugas de río) con la producción y venta de artesanías y con la acuicultura.

\section{Conservación "para", "con" y "por" las poblaciones locales en los programas de WCS en la Cuenca Amazónica}

Como fue anotado en el marco de referencia de esta sistematización, al tratar de la conservación y su relación con las poblaciones locales, históricamente se observa un movimiento pendular entre los paradigmas que proponen que la conservación de las regiones de alta biodiversidad solo es posible si se prescinde de la población local y el que señala que la conservación solo es posible si la población local lidera la conservación.

Complementariamente señalamos que, cuando se trata de conservación de base comunitaria, es posible identificar, analíticamente, tres paradigmas de acción:

Conservación "para la gente" que tiene dos connotaciones: considera a la población local como objeto pasivo, receptora de los beneficios de la conservación, pero reconoce la importancia de los ecosistemas bien conservados para su bienestar.

Conservación "con la gente"; considera a la población como sujetos de algunas acciones de la conservación pero no como decisores o sujetos fundamentales. 
El tercer paradigma hace referencia a la conservación "por la gente", considera a la población local como agente decisivo para la conservación.

Como se señaló, la distinción de estos "paradigmas" de acción solo es posible a través de un proceso analítico. $\mathrm{Si}$, tomando en cuenta la advertencia anterior y utilizamos la tríada de los "paradigmas" para el análisis de las experiencias que se han sistematizado podría señalarse que los casos de Tamshiyacu - Tahuayo en Perú y de los territorios indígenas tacana y leco de Apolo en Bolivia, tienen una tendencia hacia el paradigma de conservación "por la gente", en tanto que en el caso del Parque Nacional Yasuní en Ecuador se enmarca más en un paradigma de conservación "con la gente". En gran medida, estas tendencias están determinadas por los contextos legales relativos a las áreas naturales protegidas en cada país.

El tránsito de unos paradigmas de áreas protegidas "para la gente" o "con la gente" hacia uno de más alto nivel de conservación "por la gente" demanda:

- Enfoque en sus derechos. - Consideración de las comunidades locales y organizaciones indígenas como
"socios" en la conservación de la vida silvestre.

- Respeto responsable por las decisiones de las comunidades locales y los pueblos indígenas.

- Generar y comunicar información científica adecuada y oportuna.

- Valorar los conocimientos y prácticas de los pueblos indígenas y las comunidades locales.

- Valorar y proteger la diversidad en el uso de los recursos naturales.

- Fortalecer la resiliencia en un contexto de cambio climático.

- Reconocer y fortalecer los valores y las culturas de los pueblos indígenas.

- Compromiso, responsabilidad y vocación de excelencia.

- Enfoque de trabajo de "abajo hacia arriba".

- Asegurar la apropiación de los instrumentos de gestión por las comunidades locales y los pueblos indígenas.

- Compromiso institucional de largo plazo.

- Perfil institucional en función de las necesidades de los pueblos indígenas y comunidades locales.

- Construir relaciones de confianza, ejercer y promover la transparencia.

- Apertura y habilidad para establecer y mantener alianzas interinstitucionales como soporte al uso sostenible y la conservación por la población local. 


\section{En relación con los riesgos, dificultades y desafíos}

- En el ámbito de la planificación institucional de las entidades de conservación, el trabajo para la conservación "por la gente" exige identificar objetivos de acción relacionados con los Pueblos Indígenas y las comunidades locales en el más alto nivel de la planificación, el análisis de la compleja problemática social, económica, cultural y política, el diseño e implementación de estrategias de largo plazo identificando cadenas de resultados e impactos, que den sentido a cada una de las actividades y acciones.

- Los modelos de acción para la gestión territorial indígena y el manejo de recursos naturales por las comunidades locales, que hemos logrado identificar a través de esta sistematización, buscan ayudar a la planificación institucional pero deben comprenderse como modelos flexibles que requieren ser ajustados según el contexto de cada pueblo indígena o comunidad tradicional.

- La construcción de "capital social" en sus versiones de "redes horizontales o verticales de tipo vínculo" o de "redes sociales de tipo puente" se define como la construcción de redes "cara a cara". Necesariamente, este tipo de trabajo se basa en un enfoque de "abajo hacia arriba", con soportes del trabajo de "arriba hacia abajo", pero no a la inversa, además es un trabajo de alta intensidad. Dos tipos de riesgo se producen: a) el que se refiere al "acomodamiento" del personal técnico en una "zona de confort" que impide el "escalamiento" de las acciones a un número mayor de comunidades y unidades de gestión b) mayores presiones para el "escalamiento" pueden traducirse en un cambio del enfoque de trabajo de "abajo hacia arriba" a uno de "arriba hacia abajo", desestructurando las redes que ya han sido construidas.

- El enfoque de los "paisajes vivientes", entendidos como articulación de unidades de gestión exige la ampliación de la escala geográfica a través de la "construcción de relaciones de tipo puente", esto demanda tiempo.

- Las tensiones entre los "paradigmas" de conservación "sin la gente local" en un extremo y "por la gente local" en el otro, exigen la actualización constante de los debates teóricos y conceptuales para evitar que la claridad en el enfoque de conservación "por la gente" se diluya y termine cediendo a un enfoque de conservación "sin la gente local".

- El riesgo de la "rutinización" de las acciones en el trabajo con las comunidades y la población local al interior de los equipos técnicos que apoyan la conservación debe combatirse a través de abrir y mantener los espacios de debate teórico, conceptual y sobre las estrategias de intervención, así como de aquellos destinados a la creatividad y simultáneamente, promover el diseño de estrategias de salida con buena base de información, objetivos, metas y periodos tentativos, aun considerando que los procesos de conservación "por la gente" son de largo aliento.

- La sostenibilidad de los procesos de gestión territorial indígena y manejo de los recursos naturales por las comunidades locales con una orientación de conservación requiere el diseño e implementación de procesos orientados a la formación de líderes, abriendo los canales de comunicación intergeneracionales.

- El riesgo de ausencia de transparencia en el manejo tanto de los territorios, como de sus recursos naturales y financieros, requiere preverse a través del establecimiento de "pesos y contrapesos" entre los diferentes niveles orgánicos: separación de funciones, distribución de beneficios y rendición de cuentas. A su vez, ello demanda 
procesos de fortalecimiento de capacidades a los diferentes niveles orgánicos según sus competencias en el sistema de funciones separadas.

- El apoyo efectivo a la revaloración de las culturas de los pueblos indígenas pasa por acciones relacionadas con este quehacer pero fundamentalmente por la transversalización de los principios y valores propios de cada cultura en las definiciones de los planes de gestión territorial o planes de vida y en su operacionalización en todos los ámbitos o programas de la gestión.

- Asegurar el enfoque de equidad de género implica identificar e implementar acciones afirmativas para reducir las brechas de inequidad entre hombres y mujeres, transversalizar el enfoque en el conjunto de las acciones de apoyo a la gestión territorial indígena y el manejo de los recursos por las comunidades así como asignar a este ámbito recursos financieros asumiendo su carácter prioritario.

- El cambio climático y las grandes amenazas relacionadas con proyectos de infraestructura a gran escala y el remozamiento del "extractivismo" demandan aún mayor énfasis en el fortalecimiento de las "redes sociales", las identidades indígenas y el uso y acceso diversificado a los recursos naturales así como la identificación de ámbitos específicos en la planificación, la identificación participativa de estrategias, la transversalización de la gestión del riesgo, la identificación de indicadores de impacto tanto ambientales como socioeconómicos y culturales y el desarrollo de procesos de capacitación para el monitoreo. 


\section{BIBLIOGRAFÍA Y REFERENCIAS DOCUMENTALES}

GOREL y PROCREL. (2010). Plan Maestro del Área de Conservación Regional Comunal Tamshiyacu Tahuayo 2011 - 2015. Iquitos: Gobierno Regional de Loreto y Programa de Conservación, Gestión y Uso Sostenible de la Diversidad Biológica de Loreto .

AMWAE. (2015). Análisis de la cadena productiva de las artesanías de chambira y evaluación de las fortalezas y debilidades de la Asociación de Mujeres Waorani de la Amazonia Ecuatoriana. El Puyo: AMWAE - NAWE - WCS.

Asociación de Artesanas Manos Amazónicas. (2015). Diagnóstico de fortalezas y debilidades de la gobernanza.

Balée, W., \& Erickson, C. (2006). Time and complexity in historical ecology. New York: Columbian University Press.

Bennet, N. J. (2016). Using perceptions as evidence to improve conservation and environmental management. Conservation Biology, doi: 10.1111/cobi.12681.

Berkes, F. (1986). Common Property Resources and Hunting Territories. Anthropologic No $28,145-162$.

Berkes, F., \& et.al. (1989). Las Ventajas de los Recursos Comunitarios. Nature, 111 - 123.

Berkes, F., Folke, C., \& Colding, J. (2000). Linking Social and Ecological System: Management Practices and Social Mechanisms for Building Resilience. Cambridge UK: Cambridge University Press.

Bodmer, R. (1993). Manejo de Fauna Silvestre con las Comunidades Locales: El caso de la Reserva Comunal Tamshiyacu Tahuayo. Community Based Conservation Workshop. Airlie, Virginia: Liz Claiborne, Art Ortenberg Fundation.

Bodmer, R., Penn, J., Puertas, P., Moya, L., \& Fang, T. (1995). Uniendo conservación y habitantes locales a través del uso sostenible de los recursos naturales: manejo comunal en la Amazonia peruana. WWF Wild Species.

Bodmer, R., Valverde, Z., Puertas, P., Pérez, P., Escobedo, A., Rios, C., \& Antúnez, M. (2006). Reporte Anual 2006. Manejo de la fauna silvestre en la Reserva Comunal Tamshiyacu - Tahuayo: Sistematización de experiencias y lecciones aprendidas. Iquitos: Proyecto: Conservación de la Vida Silvestre en la Amazonia Peruana de Loreto. 
Brian, C. (2004). Parks in Transition: Biodiversity, rural development and the bottom line. London: Earthscan.

Bruner, A., Gullison, R., Rice, E., \& Da Fonseca, G. (2001). Effectiveness of Parks in Protecting Tropical Biodiversity. Science, 291(125), 125 - 128. doi:10.1126/science.291.5501.125

Camacho-Benavides, C., Porter-Bolland, L., Ruiz-Mallén, I., \& McCandless, S. (2013). Introduction: Biocultural Biodiversity and the Participation of Local Communities in National and Global Conservation. En L. Porter-Bolland, \& et. al., Community Action for Conservation: Mexican Experiences. (págs. 1 - 10). New York: Springer Science+Business Media.

Castillo, O., Barahona, Z., Mendía, D., Noss, A., Hesse, A., Burbano, A., \& Comités de Gestión. (2007). Sistemas de Gestión Integrada y Gobernanza en áreas protegidas de Bolivia, Ecuador y Perú: Desde la visión de sus Comités de Gestión. Santa Cruz: WCS Fundación Tinker.

Central de Pueblos Indígenas de La Paz. (2008). Plan Estratégico Institucional 2008 - 2012. La Paz.

Central de Pueblos Indígenas de La Paz. (2009). Propuesta de Cogestión del Parque Nacional y Área Natural de Manejo Integrado Madidi. La Paz - Bolivia: CPILAP y WCS.

Chirif, A. (2012). La Historia del Tahuayo contada por sus Moradores. Lima: Wildlife Conservation Society.

Chirif, A. (2015). Querido Perico. Pedro García Hierro, defensor de los derechos de los pueblos indígenas. Lima: IWGIA.

CIDOB. (2008). Estrategia de la Confederación de Pueblos Indígenas de Bolivia para la Gestión Compartida del Sistema Nacional de Áreas Protegidas. Santa Cruz - Bolivia: CIDOB.

CIDOB. (2008). Programa de Gestión Territorial Indígena. Santa Cruz.

Cincotta, R., Wisnewski, J., \& Engelman, R. (27 de Abril de 2000). Human Population in the Biodiversity Hotspots. Nature, 404, 990 - 991. Obtenido de www.nature.com

CIPLA. (2002). Zonificación preliminar de la TCO Lecos de Apolo. Proyecto de Apoyo a la Administración del Parque Nacional y Área de Manejo Integrado Madidi.

CIPLA. (2009). Plan de Vida del Pueblo Leco de Apolo. La Paz: Inédito.

CIPLA. (2010). Plan de Vida del Pueblo Leco de Apolo - Resumen Ejecutivo. La Paz Bolivia: CIPLA y WCS.

CIPLA. (Diciembre de 2011). Reglamento de Uso, Acceso, Manejo y Aprovechamiento de los Recursos Naturales en el Territorio Indígena Originario Campesino (TIOC) Lecos de Apolo.

CIPLA. (16 de Abril de 2011). Resolución No. 01/2011. Asamblea Consultiva Ordinaria del Pueblo Leco de Apolo. Apolo.

CIPLA. (19 - 20 de Septiembre de 2013). Reglamento Interno Central Indígena del Pueblo Leco de Apolo. 
CIPLA. (Noviembre de 2014). Reglamento para el Manejo Sustentable y Conservación de los Componentes (Recursos Naturales) del Territorio de la TCO Lecos de Apolo.

CIPTA - CIMTA. (2014). Plan de Gestión Territorial Indígena del Pueblo Tacana. Kema Ejudes'a Jakuastas'iati S'aida Enime 2015 - 2025. Tumupasa: CIPTA - CIMTA - WCS.

CIPTA - WCS. (2002). Estrategia de Desarrollo Sostenible de la TCO - Tacana con Base en el Manejo de los Recursos Naturales (2001 - 2005). La Paz: Talleres Gráficos Hisbol SRL.

CIPTA - WCS. (2012). Base de datos sobre participación en eventos 2000 - 2012.

CIPTA - WCS. (2013). Memoria del Encuentro de Emprendimientos Productivos de la TCO Tacana 9 al 10 de Octubre de 2012. Tumupasa.

CIPTA. (2008). Reglamento de Acceso, Uso y Aprovechamiento de los Recursos Naturales Renovables del Territorio Indígena Takana. La Paz: CIPTA.

CIPTA y WCS. (2002). Memoria: Taller para el análisis e intercambio de ideas sobre la gestión territorial y el manejo de los recursos naturales de la TCO Tacana. Tumupasha: (Inédito).

CIPTA y WCS. (2009). Plan de Ordenamiento Predial. Territorio Indigena Tacana. TCO Tacana 1. La Paz.

COICA - OXFAM AMERICA. (1996). Amazonía: Economía indígena y mercado. Quito.

Comité de Gestión del ACRCTT, Wildlife Conservation Society, Instituto DICE de la Universidad de Kent. (2005). Expediente Técnico Propuesto para el Reconocimiento y la Inclusión de la Reserva Comunal Tamshiyacu Tahuayo en el Sistema Nacional de Áreas Protegidas por el Estado. Iquitos.

Comunidad Campesina El Chino. (Actualizado el 18 de enero de 2015). Acuerdos comunales internos de la comunidad.

Comunidad Diamante/7 de Julio. (Actualizado el 4 de enero de 2015). Acuerdos comunales internos de la comunidad.

Comunidad Jerusalén. (2015). Evaluación de las fortalezas y debilidades de la comunidad de Jerusalén - Rio Tahuayo y Plan comunal. Wildlife Conservation Society.

Comunidad San Pedro. (Actualizado el 19 de enero de 2015). Acuerdos comunales internos de la comunidad.

Congreso de la República del Perú. (16 de Julio de 2000). Ley No. 27308. Diario Oficial El Peruano, págs. 190283 - 190289.

Convenio de cooperación interinstitucional WCS - ECOLEX. (2014). Talleres sobre derechos NAWE, AMWAE, FICCKAE y NASE. Informe Final. Quito: WCS - ECOLEX.

Coomes, O. T. (1991). Rainforest Extraction, Agroforestry and Biodiversity Loss: An Environmental History from the Northeastern Peruvian Amazon. XVI International Congress of the Latin American Association, (pág. 28). Washington.

Cueva, R., Utreras, V., \& Muñoz, I. (2010). Manejo comunitario de tortugas charapas en comunidades kichwa y waorani del Parque Nacional Yasuní. Quito: Wildlife Conservation Society. 
D'Acuña, C. (1865). Novo Descobrimento do Grande Rio das Amazonas [1641]. Revista trimestral do Instituto Geographico e Ethnographico do Brasil, 163 - 265.

Denevan, W. (1980 b). La Población Aborígen de la Amazonia en 1492. Amazonia Peruana. Vol III. No. 5, 3-41.

Denevan, W. (1980). La Población Aborígen de la Amazonia en 1492. Amazonia Peruana. Vol III. No. 5, 3-41.

Equator Initiative. (10 de Diciembre de 2016). Equator Prize 2014. Obtenido de http:// www.equatorinitiative.org/index.php?option $=$ com_content\&view $=$ article\&id $=818 \&$ lte mid=1031\&lang=en\#asociación-de-de-mujeres-waorani-de-la-amazonia-ecuatoriana--ecuador

Estado Plurinacional de Bolivia. (2009). Nueva Constitución Política del Estado Promulgada el 7 de febrero de 2009. La Paz: La Razón.

Firth, R. (. (1974). Temas de antropología económica (Primera edición en castellano ed.). México: Fondo de Cultura Económica.

Flores, F., Antúnez, M., Padilla, G., Silva, M., \& Lehm, Z. (2016). Evaluación de fortalezas y debilidades de la gobernanza en la región del Área de Conservación Regional Comunal Tamshiyacu Tahuayo. Iquitos: Wildlife Conservation Society.

Frankenberg, R. (1974). Antropología económica. Opinión de un antropólogo. En R. Firth, Temas de Anropología Económica (págs. 54 - 94). México: Fondo de Cultura Económica.

Gómez, H., Espinoza, F., \& Wallace, R. (2002). Corredores de hábitat entre el PN \& ANMI Madidi y la TCO Tacana. Documento técnico. WCS.

Hardin, G. (1968). The Tragedy of the Commons. Science 162, 1243-1248.

Hissink, K.; Hahn, A. ([1952-1954] 2000). Los Tacana. Datos sobre la historia de su civilización. La Paz - Bolivia: Vol. 16. Editor Jürgen Riester.

Hutton, J., Adams, W., \& Murombedzi, J. (2005). Back to the Barriers? Changing Narratives in Biodiversity Conservation. Forum for Develpment Studies(2), 341 - 370.

Hyden, G., \& Court, J. (2002). Governance and Development. World Governance Survey. Discussion Paper 1. United Nations University.

Ima Omene, N. (2012). Saberes Waorani y Parque Nacional Yasuní: lantas, salud y bienestar en la Amaznia del Ecuador. Quito: Iniciativa Yasuní ITT, Ministerio Coordinador de Patrimonio, Ministerio del Ambiente, Programa de las Naciones Unidas para el Desarrollo (PNUD) y Fondo para el Medio Ambiente Mundial (FMAM).

INEI. (13 de Octubre de 2016). Estado de la población peruana 2014. Obtenido de https:// www.inei.gob.pe/media/MenuRecursivo/publicaciones_digitales/Est/Lib1157/libro.pdf

Isasi-Catalá, E., Torres-Oyarce, L., Bardales-Alvites, C., Muñoz, L., Flores-Ponce, F., OdicioIglesias, M., \& Maffei, L. (2017). Resultados del Programa de Monitoreo de Cacería del ACRCTT: TO. Documento de trabajo. Lima: WCS - Perú.

Kowler, L. F., Gonzales Tovar, J., Ravikumar, A., \& Larson, A. M. (Marzo de 2015). La legitimidad de las estructuras de gobernanza multinivel para la distribución de beneficios: REDD + y otras opciones de bajas emisiones en Perú. Brief(116). 
Kwaw S., A., Ferraro, P., Pfaff, A., Sanchez-Azofeifa, G., \& Robalino, J. (21 de October de 2008). Measuring the effectiviness of protected area networks in reducing deforestation. PNAS, 105(42). Recuperado el 8 de Abril de 2016

Lehm, Z. (2002). Avizorando los retos para los pueblos indígenas de América Latina en el nuevo milenio. Economía indígena y mercados en la Amazonia Andina: avances, limitaciones y retos. En P. Oliart, \& R. Smith, Pueblos indígenas de América Latina: Retos para el nuevo milenio (pág. Presentación Multimedia). Lima: Fundación Ford - Oxfam América.

Lehm, Z. (2010). Los Takanas: El acceso a la tierra y a los recursos naturales (1950 - 2003). Boletín Americanista. Año LXI. No. 60, 115 - 139.

Lehm, Z. (2012). Los Takanas: Representaciones de los sistemas de organización sociopolítica (1986 - 2010). En D. Villar, \& I. Combes, Las tierras bajas de Bolivia: Miradas históricaas y antropológicas (págs. 177 - 200). Santa Cruz: Colección de Ciencias Sociales de El Pais No. 29.

Lehm, Z. (2015). La Gestión Territorial Indígena y los tacanas del Norte de La Paz. En L. Córdoba, \& I. Combès, En el Corazón de América del Sur Vol. 1 (págs. 43-78). Santa Cruz: Museo de Historia. Universidad Autónoma Gabriel René Moreno.

Lehm, Z. (2016 a). Sistematización de la zonificación de la TCO Tacana I. La Paz: Wildlife Conservation Society (WCS) y Consejo Indígena del Pueblo Tacana (CIPTA).

Lehm, Z. (2016 b). Sistematización de la Reglamentación del Acceso y Uso de los Recursos Naturales en la TCO Tacana I. La Paz: Wildlife Conservation Society (WCS) y Consejo Indígena del Pueblo Tacana (CIPTA).

Lehm, Z. (2016 c). Sistematización de la Demarcación, Control y Vigilancia de la TCO Tacana I. La Paz, Bolivia: Wildlife Conservation Society (WCS) y Consejo Indígena del Pueblo Tacana (CIPTA).

Lehm, Z. (2016 d). Historia del gobierno de la Región Tacana. La Paz - Bolivia: Wildlife Conservation Society (WCS) y Consejo Indígena del Pueblo Tacana (CIPTA).

Lehm, Z., Lara, K., \& Solares, T. (2017). Ingresos económicos en hogares de la TCO Tacana I. La Paz - Bolivia: Wildlife Conservation Society.

Lehm, Z., Salas, H., Salinas, E., Gómez, I., \& Lara, K. (2002). Diagnóstico de Actores Sociales del PNANMI Madidi. La Paz: Dirección del PNANMI Madidi y CARE Madidi.

Levillier, R. (1976). El Paititi, el Dorado y las Amazonas. Buenos Aires: Emecé.

Maffi, L., \& Woodly, E. (2010). Biocultural Diversity Conservation. A Global Sourcebook. London: Earthscan.

Manfredo, M. J. (2008). Who Cares About Wildlife?: Social Science Concepts for Exploring Human - Wildlife Relationships and Conservation Issues. New York: Springer Science + Businees Media, LLC.

Mason, D., Baudoin, M., Kammerbauer, H., Calvo, L., Lehm, Z., \& Heinrich, F. (2004). Integrating Local People and Institutions into Protected Area Management: Lessons Learned from Bolivia. 
McKean, M., \& Ostrom, E. (1994). Bosques en régimen de propiedad común: ¿sólo un vestigio del pasado? Estados Unidos: Departamento de Ciencias Políticas de la Duke University y Taller de toería política y análisis de las políticas de la Indiana University.

McKean, M., \& Ostrom, E. (1994). Bosques en régimen de propiedad común: ¿sólo un vestigio del pasado? Estados Unidos: Departamento de Ciencias Políticas de la Duke University y Taller de teoría política y análisis de las políticas de la Indiana University.

Messerschmidt, D. A. (1993). Common forest Resource management. Rome: Food and Agriculture Organization of the United Nations.

Ministerio del Ambiente. (14 de Diciembre de 2016). ¿Quienes somos? . Obtenido de Programa de Protección de Bosques: http://sociobosque.ambiente.gob.ec/node/755

Muiba Núñez, C., Loayza Cossio, O., Durán Laura, A., \& Gonzales Buitrago, L. (2011). Territorios Compartidos. Construyendo un modelo de gestión territorial entre el Parque Madidi y el Pueblo Leco de Apolo . La Paz: PIEB - DANIDA.

Oats, J. (2000). Myth and Reality in the Rainforest: How Conservation Strategies are Failing in West Africa. Berkeley: Press of California Presss.

Ortiz Cruz, L. E. (2014). Plan de Manejo para Astrocaryumchambira en comunidades de base de la Asociación de Mujeres Waorani de la Amazonia Ecuatoriana (AMWAE). El Puyo: WCS.

Padoch, C. (1990). Importancia económica y comercialización de los productos del bosque y de las purmas en la región de lquitos. En W. Denevan, \& C. Padoch, Agroforesteria tradicional en la Amazonia Peruana (págs. 161-195). Lima: Centro de Investigación y Promoción Amazónica / The New York Botanical Garden.

Painter, L., Siles, T., Reinaga, A., \& Wallace, R. (2013). Escenarios de deforestación en el Gran Paisaje Madidi - Tambopata. La Paz. Bolivia: Consejo Indígena del Pueblo Tacana y Wildlife Conservation Society.

Penn, J. (2006). The Use and Conservation of Non Timber Forest Resources in the Reserva Comunal Tamshiyacu - Tahuayo of Perú: Management Considerations for the 2007 Pilot Project and Beyond. Draft I. Prepared for WCS - Perú.

Penn, J., \& Alvarez, J. (1990). Comunidad campesina protege sus cochas. Kanatari, 3 - 10.

PIEB. (1 de Junio de 2011). El Pueblo Indígena Leco aprueba novedosa forma de gestión compartida. Obtenido de Periódico Digital PIEB: http://www.pieb.com.bo/sipieb_ imprimir.php?idn $=5793$

Platt, T. (1982). Estado boliviano y ayllu andino. Tierra y tributo en el Norte de Potosí. Lima: Instituto de Estudios Peruanos.

Porter-Bolland, L., Ellis, E., Guariguata, M., Ruiz-Mallen, I., Negrete-Yankelevich, S., \& Reyes-Garcia, V. (2011). Community managed forests and forest protected areas: An assessment. Forest Ecology and Management, 1 - 12. Obtenido de www.elsevier.com/ locate/foreco

Programa Derechos, Cambio Climático y Bosques. CEPLAES. (2015). Bosques, Derechos de las Mujeres y Cambio Climático. Quito: CEPLAES.

Putnam, R. D. (2000). Bowling Alone. The Collapse and Revival of American Community. 
New York: Simon and Schuster.

Putnam, R. D., \& Feldstein, L. M. (2003). Better Together. Restoring the American Community. New York: Simon \& Shuster Paperbacks.

RAISG. (2015). Amazonia 2015. Áreas Protegidas. Territorios Indígenas. Deforestación $2000-2013$.

República del Ecuador. (2008). Constitución del Ecuador. Quito: Asamblea Constituyente.

República del Ecuador. (2016). Ley orgánica de tierras rurales y territorios ancestrales. Quito: Registro oficial - Asamblea Nacional.

Ribeiro, D. (1977). Fronteras Indígenas de la Civilización. México: Siglo XXI Editores.

Robarchek, C., \& Robarchek, C. (2008). Waorani: The Contexts of Vilence and War. Mason: $\mathrm{OH}$ : Cengage Learning.

Rojas Almeida, C. (2014). Plan de Negocios del Yaku Kawsay. Quito: WCS - Gordon \& Betty Moore Foundation.

SERFOR. (2015). Ley Forestal y de Fauna Silvestre No. 29763 y sus reglamentos. Bosques productivos para la vida. Lima : WWF.

SERNAP/Madidi y CIPLA. (25 de Noviembre de 2009). Acta de Compatibilización de la Zonificación de la TCO Lecos de Apolo con la Zonificación del PN y ANMI Madidi y de inicio de la concertación de una estrategia de protección conjunta de las áreas de sobreposición.

Smith, R. C. (1984). A Search of Unity Within Diversity: Peasant Unions, Ethnic Federations, and Indianis Movements in the Andean Republics. En T. M. Donald, Native Peoples and Economic Development (págs. 5 - 38). Cambridge: Cultural Survival.

Terbogh, J. (1999). Requiem for Nature. Washington DC: Island Press/Shearwater Books .

The Field Museum. (2003). Rapid Biological Inventories: 11, Perú - Yavarí. Chicago: The Field Museum.

Torres Carrillo, A. (2014). Viejos y nuevos sentidos de comunidad en la educación popular. Comunidades(81), 4-9.

UICN. (2014). Annual Report. Obtenido de https://portals.iucn.org/library/efiles/ documents/2015-020.pdf

UNESCO/MAB. (2013). Formulario de Propuesta para el reconocimiento de la Reserva de la Biósfera Yasuní.

Uphoff, N. (1986). Local Institutional Development: An Analytical Sourcebook with Cases. West Hartford: Kumarian Press.

Uphoff, N. (2003). Local Institutions and Participation for Sustainable Development. Gatekeeper(31), 1 - 14.

Vasquez, R., \& Gentry, A. (1989). Use and Misuse of Forest-harvested Fruits in the lquitos Area. Conservation Biology, 4, 350 - 361. 
VBRFMA; SERNAP y CIDOB. (26 de Octubre de 2007). Convenio marco de cooperación y coordinación entre el Viceministerio de Biodiversidad, Recursos Forestales y Medio Ambiente (VBRFMA), Servicio Nacional de Áreas Protegidas (SERNAP) y la Confederación de Pueblos Indígenas de Bolivia (CIDOB) . Santa Cruz.

Wallace, R. (2008). Mapping and Meassuring Conservation Oportunity . Wildlife Conservation Society.

Wall

ace, R., Gómez, H., \& Coppolillo, P. (2001). Criterios de selección de especies paisaje en el noreste de los Andes de Bolivia. La Paz: Wildlife Conservation Society - Programa de los paisajes vivientes.

Wasserstrom, R. (2016). Waorani Warfare on the Ecuadorian Frontier 1885 - 2013. The Journal of Latinamerican and Caribbean Anthropology , 1-20.

WCS - Ecuador. (2014). Restauración de tallas en balsa del Centro de Interpretación Yaku Kawsay, comunidad Kichwa Nueva Providencia, Rio Napo. Quito: WCS - Gordon \& Betty Moore Foundation.

WCS - Ecuador. (2015). Manejo participativo para la conservación de tortugas charapas en

la región noroccidental del Parque Nacional Yasuní, de la Amazonia Ecuatoriana. Informe de avance presentado al Ministerio del Ambiente - Orellana. Quito.

WCS - Ecuador. (2016). Propuesta del programa de apadrinamiento de tortugas charapas (Podocnemis unifilis) con operadoras turísticas en el Noroccidente del Parque Nacional Yasuní. Quito.

WCS - Programa Ecuador. (2011). Gestión Integrada de Territorios Indígenas.

WCS. (2002). Memoria del taller inicial para compatibilizar la Estrategia de Desarrollo Sostenible con Base en el Manejo de los Recursos Naturales de la TCO Tacana y el Plan de Manejo del PNANMI Madidi. Tumupasa: Inédito.

WCS. (2017). Amazon Measures Database.

Weber, M. (1977). Economía y sociedad. Esbozo de sociología comprensiva (Tercera reimpresión de la segunda edición en español de la cuarta en alemán 1964 ed., Vol. I). Mexico: Fondo de Cultura Económica.

Wentzel, S. (1989). Tacana and Highland Migrant Land Use, Living Conditions and Local Organizations in the Bolivian Amazon. University of Florida: A Dissertation presented to the Graduate School of The University of Florida in Partial Fulfillment of the Requierements for the Degree of Doctor of Philosophy.

Western, D., Wright, M. R., \& Strum, S. C. (1994). Natural Connections. Washington D.C.: Island Press.

Wildlife Conservation Society - Programa Ecuador. (2014). Informe. Actualización del Plan de Uso y Manejo Territorial de seis comunidades Kichwa: Pompeya, Rio Indillama, Nueva Providencia, Añangu, Sani Isla y San Roque, asentadas en la zona noroccidental del Parque Nacional Yasuní. Quito: Con el apoyo de Gordon and Betty Moore Fundation.

Wildlife Conservation Society, Programa Ecuador y Ministerio del Ambiente del Ecuador, Parque Nacional Yasuní. (2015). Actualización del Plan de Uso y Manejo Territorial de seis comunidades Kichwa: Pompeya, Rio Indillama, Nueva Providencia, Añangu, Sani Isla y San 
Roque, asentadas en la zona Noroccidental del Parque Yasuní . Quito: Con el apoyo de la Fundación Gordon y Betty Moore.

Wilkie, D., \& Cowles, P. (2014). Directrices para evaluar las fortalezas y debilidades de la gobernanza de recursos naturales en paisajes terrestres y marinos. USAID. 


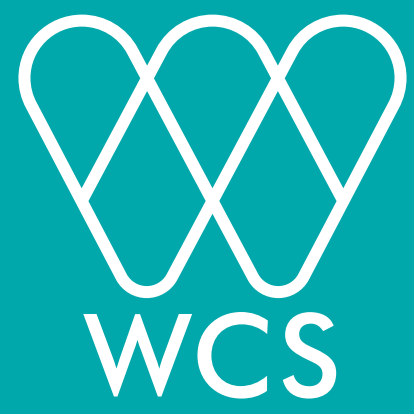

Con el apoyo de:

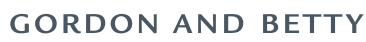
MOORE 